\title{
Computed tomography in gynaecological malignancies
}

Citation for published version (APA):

van Engelshoven, J. M. A. (1983). Computed tomography in gynaecological malignancies. [Doctoral Thesis, Maastricht University]. Rijksuniversiteit Limburg. https://doi.org/10.26481/dis.19830318je

Document status and date:

Published: 01/01/1983

DOI:

10.26481/dis.19830318je

Document Version:

Publisher's PDF, also known as Version of record

\section{Please check the document version of this publication:}

- A submitted manuscript is the version of the article upon submission and before peer-review. There can be important differences between the submitted version and the official published version of record.

People interested in the research are advised to contact the author for the final version of the publication, or visit the DOI to the publisher's website.

- The final author version and the galley proof are versions of the publication after peer review.

- The final published version features the final layout of the paper including the volume, issue and page numbers.

Link to publication

\footnotetext{
General rights rights.

- You may freely distribute the URL identifying the publication in the public portal. please follow below link for the End User Agreement:

www.umlib.nl/taverne-license

Take down policy

If you believe that this document breaches copyright please contact us at:

repository@maastrichtuniversity.nl

providing details and we will investigate your claim.
}

Copyright and moral rights for the publications made accessible in the public portal are retained by the authors and/or other copyright owners and it is a condition of accessing publications that users recognise and abide by the legal requirements associated with these

- Users may download and print one copy of any publication from the public portal for the purpose of private study or research.

- You may not further distribute the material or use it for any profit-making activity or commercial gain

If the publication is distributed under the terms of Article $25 \mathrm{fa}$ of the Dutch Copyright Act, indicated by the "Taverne" license above, 


\section{Computed tomography in gynaecological malignancies.}

Proefschrift

ter verkrijging van de graad van doctor in de geneeskunde aan de Rijksuniversiteit Limburg te Maastricht, op gezag van de Rector Magnificus Prof. Dr. H.C. Hemker, volgens besluit van het College van Dekanen in het openbaar te verdedigen in de aula van de universiteit op vrijdag 18 maart 1983, des middags te vier uur

door

Josephus Maria Antonius van Engelshoven

geboren te Maastricht 
Promotores: Prof.Dr. J de Haan, Prof.Dr. J.H.J. Ruys,

Referenten: Prof.Dr. J. Janssens, Prof.Dr. J. Drukker,
Rijksuniversiteit Limburg, Maastricht

Rijksuniversiteit, Utrecht

Rijksuniversiteit, Groningen

Rijksuniversiteit Limburg, Maastricht

(C)

No part of this hook my be reptoduced in any torm, by print, photoprint, microfilm or any other means without when permissom from the pulolisher.

Nicts uit deze uigave mag worden wervel voudigd en/of openbaar genaakt door middel vandruk. Fotocopie. microhtmof op welke andere wijze ook zonder voor foande schriftolijke toestemming van de uitgewer.

\section{CIP-gegevens}

Engolshowen. Josephus Maria Avolomis wan

Compuled romography in gynaccological malignancies/Josephus Maria Anomius wan Engelshoven. *

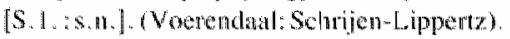

Proetscibritt Matatrich. - Met simenwatting in het Nederlands. - Met lit. opg.

ISBN $90-9000440-8 \mathrm{geb}$.

SISO 605.5 UDC 618.

Trefw : gynacologie: computertomografietoepassing. 
to my father 



\section{Contents}

\section{Chapter I}

\section{Introduction}

1.1 . introduction

1.2. outline of study

\section{Chapter II}

\section{Technical aspects of computed tomography}

2.1. introduction 5

2.2. CT technology, basic principles 5

2.3. image quality 9

2.4. Philips Tomoscan 30009

2.5. CT scan protocol 11

2.5.1. patient preparation 11

2.5.2. CT scan procedure 11

\section{Chapter III}

Normal cross-sectional anatomy of the female pelvis

3.0. introduction 13

3.1. pelvic wall 13

3.1.1. skeleton 13

3.1.2. muscles 15

3.1.3. abdominal wall 16

3.2. pelvic floor 16

3.3. abdominal pelvic cavity 18

3.4. extra-peritoneall space 19

3.4.1. great vessels $\quad 19$

3.4.2. nerves 19

3.4.3. lymph nodes 20

3.5. the female genital tract 23

3.5.1. normal cross-sectional anatomy, a retrospective study 23
A. introduction

B. method and material $\quad 23$

$\begin{array}{ll}\text { C. results } & 24\end{array}$

D. discussion $\quad 27$

3.5.2. uterus and related tissue 27

3.5.3. uterine adnexa 30 
3.6. bladder 31

3.7. rectum $\quad 32$

3.8. vagina 32

\section{Chapter IV}

\section{Cervical cancer}

4.1. introduction 35

4.2. F.I.G.O. classification of cervical cancer 35

4.3. review of literature concerning the use of special diagnostic procedures in staging cervical cancer $\quad 37$

$\begin{array}{ll}\text { 4.3.1. introduction } & 37\end{array}$

4.3.2. intravenous urography (I.V.U.) 38

4.3.3. cystoscopy 38

4.3.4. barium enema and proctoscopy $\quad 39$

4.3.5. lymphangiography 39

4.3.6. liver imaging procedures $\quad 39$

4.3.7. chest X-ray 39

4.3.8. computed tomography 40

4.4. a study of CT features in untreated patients with cervical cancer $\quad 41$

4.4.1. introduction 41

4.4.2. method and material 42

4.4.2.1. retrospective study $\quad 42$

4.4.2.2. prospective study 42

4.4.3. results 44

4.4.3.1. measurements 45

4.4.3.2. correlation of CT and clinical staging 46

4.4.3.3. parametrium infiltration: $\mathrm{CT}$, clinical and surgical findings 47

4.4.3.4. lymph node pathology: CT, clinical and surgical findings 49

4.4.3.5. CT compared to I.V.U., cystoscopy, proctoscopy and barium enema 50

4.4.3.6. liver lesions and suprarenal masses $\quad 50$

4.4.4. discussion 50

4.5. recurrent cervical cancer 58

4.5.1. introduction 58

4.5.2. diagnoses of recurrent cervial cancer $\quad 59$

4.5.3. CT in evaluation of recurrent cervical cancer - literature review 59

4.6. study of CT features in treated cervical cancer 60

4.6.1. introduction 60

4.6.2. method and material 61

4.6.3. results 62

4.6.4. discussion 66

$\begin{array}{lll}4.7 . & \text { conclusions } & 71\end{array}$ 


\section{Chapter V}

\section{Endometrial cancer}

5.1. introduction 75

5.2. Spread of endometrial cancer 76

5.3. radiological imaging techniques in staging $\begin{array}{ll}\text { endometrial cancer } & 77\end{array}$

5.4. study of CT features in untreated patients $\begin{array}{ll}\text { with endometrial cancer } & 78\end{array}$

5.4.1. introduction 78

5.4.2. method and material 78

$\begin{array}{ll}5.4 .3 \text {. results } & 79\end{array}$

5.4.4. discussion $\quad 82$

5.5. CT in recurrent endometrial malignancy $\quad 85$

5.5.1. introduction $\quad 85$

5.5.2. method and material $\quad 85$

5.5.3. results $\quad 86$

5.5.4. discussion 86

5.6. conclusion $\quad 86$

\section{Chapter VI}

Gestational trophoblastic disease

6.1. introduction 89

6.2. method and material 90

6.3. Tesults 90

6.4. discussion 95

6.5. conclusion 96

\section{Chapter VII}

\section{Ovarian cancer}

7.1. introduction 99

7.2. the spread of ovariancancer 99

7.3. F.I.G.O. classification of ovarian cancer 101

7.4. imaging techniques in the diagnosis and staging of ovarian cancer, review of literature. 102

7.4.1. plain radiography 102

$\begin{array}{ll}7.4 .2 . & \text { urography } \\ 7.4 .3 . & 102\end{array}$

7.4.3. barium studies $\quad 102$

$\begin{array}{ll}\text { 7.4.4. lymphography } & 103\end{array}$

7.4.5. ultrasound $\quad 103$

7.4.6. computed tomography 104 
7.5. computed tomography in ovarian cancer - a clinical study 105

$\begin{array}{ll}\text { 7.5.1. introduction } & 105\end{array}$

7.5.2. outline of the study 105

7.5.3. CT in the diagnosis of ovarian cancer 106

7.5.3.1. method and material 106

$\begin{array}{ll}7.5 .3 .2 . \text { results } & 107\end{array}$

7.5.3.3. discussion 110

7.5.4. CT in staging ovarian cancer, a correlation study $\begin{array}{ll}\text { between CT and surgical findings } & 117\end{array}$

$\begin{array}{ll}\text { 7.5.4.1. method and material } & 117\end{array}$

$\begin{array}{ll}7.5 .4 .2 \text {. results } & 121\end{array}$

$\begin{array}{ll}7.5 .4 .3 . & \text { discussion } \\ & 125\end{array}$

7.5.5. CT in treatment monitoring of patients with ovarian cancer $\quad 130$

7.5.5.1. method and material 131

$\begin{array}{ll}7.5 .5 .2 . \text { results } & 132\end{array}$

$\begin{array}{ll}\text { 7.5.5.3. discussion } & 136\end{array}$

7.6. conclusions

\section{Chapter VIII}

Summary and conclusions 141

Samenvatting $\quad 1.45$

Appendices 149

Acknowledgement $\quad 153$

Curriculum vitae $\quad 155$ 


\section{Chapter I}

\section{Introduction}

\subsection{Introduction}

Computed tomography (CT) of the brain is now well established in the field of neuroradiology, and, although the role of body CT is less certain, there is general agreement that its major role is in the field of oncology. Provided the diseased process produces form or density changes, CT makes it possible to visualize its entire extent very accurately, so that primary tumour, infiltration of surrounding structures and distant metastases in lymph nodes, liver and bone can all be seen in the sane examination. Such a diagnostic ideal may in practice be much easier to achieve in some kinds of cancer than in others, and the use of CT for a particular disease process may be limited in a particular hospital by the availability of other imaging techniques and appropriate radiological expertise. Close cooperation between radiologist and clinician is essential if the information provided by imaging techniques is to be usefully applied in problems of cancer management, since radiologists in isolation are often limited by a lack of understanding of the clinical behaviour of a particular tumour, while clinicians in isolation may be poorly informed about not only the new imaging techniques but also the dramatic technical improvements throughout the radiological field in the past ten years, and may therefore have limited understanding of the appropriate applications and limitations of such techniques. Early CT scanners had a scan time of 4 minutes which is inappropriate for body imaging, but today's third and fourth generation scanners are technically capable of producing high resolution images of abdomen and chest, unimpaired by peristaltic and respiratory movements. Conclusions about the applications and limitations of $\mathrm{CT}$ based on studies using 20 seconds second generation scamers may no longer be appropriate to third and fourth generation scanners.

The value of $\mathrm{CT}$ in the diagnosis and staging of lymphoma and testicular tumours is well established in the literature (Best and Blackledge 1981, Lee et al. 1979) and its use, though with varying success, in staging renal, rectal or lung cancer is also well described (Weyman et al. 1980, Dixon et al. 1981, Wouters et al. 1982), but its role in the diagnosis and staging of gynaecological malignancies is less well known and such studies as are available have been made predominantly with second generation scanners.

This comprehensive study was therefore undertaken firstly to describe the CT features of the different gynaecological malignancies, secondly to test the reliability of CT diagnostic: signs already described in literature and thirdly to assess the indications, potentials and limitations in this field of CT in its present state of development.

\subsection{Outline of study}

The material for study consists of 403 CT scans of the pelvis and abdomen in 301 patients. The basis of the study itself is a correlation between CT findings on the one hand and 
surgical, pathological and/or clinical findings on the other. Patients of five different hospitals are represented and the physical examinations, operations and histo-pathological examinations were performed by the referring gynaecologist and his pathologist. The CT examinations, on the other hand, were performed in only two different hospitals, using the same type of scamer and a standard protocol. All scans of patients with cervical or ovarian cancer were reviewed by two radiologists to test the hitherto accepted pathological criteria. In the absence of pathological criteria in endometrial cancer and gestational throphoblastic tumours, these scans were reviewed by the author in an attempt to define such criteria. Chapter II gives a brief description of CT technology, including basic principles and factors affecting image quality, and summarizes the features of the particular scanner used for this study. A description is then given of the scan protocol, in relation to patient preparation and scan procedure, used throughout this study.

Computed tomography has in general been used to study only pathological processes, but there is a lack of CT criteria of normality against which pathological changes can be judged. Chapter III therefore begins with an anatomical description of the normal female pelvis, then presents a CT study of the pelvis in 42 patients, defined for the purpose of this study as "gynaecologically normal" on the basis of absence of clinical symptoms of genital tract disease.

Cervical cancer presents considerable problems in terms of initial assessment of stage of disease, particularly in relation to the presence or absence of parametrial and lymph node involvement. Since accurate initial assessment has vital therapeutic implications it is important to know whether CT can add greater precision to such assessment. Chapter IV begins with a comparative review of the techniques currently used in staging cervical cancer, then presents a correlative study in untreated patients with cervical cancer to ascertain the value of CT in initial staging. The chapter concludes with a further study to evaluate CT in the diagnosis of recurrent cervical cancer.

Because of a virtually complete absence of established $\mathrm{CT}$ criteria for endometrial cancer, the study described in chapter $V$ is devoted principally to a careful study of CT features in the uterus and surrounding tissues in an attempt to identify signs which can be regarded as pathognomonic for endometrial cancer. Some discussion is also included of features which may be indicative of possible spread of the discase. The chapter concludes with a small study to test the abillity of CT to diagnose recurrent disease.

Chapter VI comprises a short study of the CT features in gestational trophoblastic tumours, and correlates $\mathrm{CT}^{*}$, ultrasonography and angiograplyy with the progress of disease as monitored by beta HCG levels.

Ovarian cancer presents particular problems in diagnosis, even though it is so frequently far extended at the time of presentation, so the first study in chapter VII is an examination of the CT features in patients with any clinical suspicion of ovarian cancer in an attempt to specify the CT picture of this disease. Then follows a study correlating $C T$ with surgical findings in patients with established ovarian cancer, both treated and before treatment, to determine the accuracy of CT in staging the disease. The final part of the chapter attempts to define the value of $\mathrm{CT}$ as a method of treatment monitoring in ovarian cancer. 


\section{References chapter I}

BEST, $J$ and BLACKLEDGE, G.: Do we need CT for the management of lymphomas;

in: Computerised Axial Tomography in Oncology, pp 59-68 Eds:

Husband, J.E. and Hobday, P.A., Churchill Livingstone, 1981.

DIXON, A.K., KELSEY, I., MORSON, B.C., NICHOLLS, R.J. and MASON, A.Y.: Pre-operative computed tomography of carcinoma of the rectum.

Br. J. Radiol. 54:655-659, 1981.

LEE, J.K.T, MCCLENNAN, B.L., STANLEY, R.J., SAGEL, S.S : Computed tomography in the staging of testicular neoplasms.

Radiology, 130: 387 - 390, 1979

WEYMAN, P.J., MCCLENNAN, B.L., STANLEY, R.R., LEVITT, R.G., SAGEL, S.S.:

Comparison of computed tomography and angiography in the evaluation of renal cell carcinoma.

Radiology。 137: $417-424,1980$.

WOUTERS, E.F.M., OEI, T.K., VAN ENGELSHOVEN, J.M.A., LEMMENS, H.A.J. and

GREVE, L.H.: Evaluation of the contribution of computed tomography to the staging of non-oat-cell primary bronchogenic carcinoma.

Fortschr. Röntgenstr. 137: 5: 640 - 543, 1982. 


\section{Chapter II}

\section{Technical aspects of computed tomography}

\subsection{Introduction}

In conventional radiography, a divergent $X$-ray beam produces a projection or shadow of everything standing between $X$-ray source and film, and the resultant image represents many overlapping organs and tissues. Although air, bone and soft tissue are easily distinguishable, the minor differences in X-ray attenuation by normal and diseased soft tissue cannot be seen, even when the organs are not overlapping. To overcome these two major shortcomings, namely superposition and lack of contrast resolution, many additional techniques have been introduced with variable success. The lack of contrast resolution can partly be solved by the use of a contrast medium (as in I.V.U., angiography or barium enema). But with such techniques, only the contrast outline is displayed and not the tissue itself. The problem of superposition may be partly solved by conventional tomography, in which $\mathrm{X}$-ray tube and film are moved simultaneously in opposite directions, keeping the desired layer in focus, while blurring all over-and underlying structures. In practice, there is always some blurring in the desired plane, and it is impossible to blurr out all unwanted structures which themselwes diminish the image quality. These limitations are overcome by $\mathrm{CT}$, which produces a cross-sectional image with excellent contrast resolution and without superposition. The resultant image is a two dimensional cross-sectional display of the linear X-ray attenuation coefficients. By contrast, ultrasound gives a two dimensional cross-sectional display of the accoustic properties of tissue.

\subsection{CT Technology, basic principles}

Attenuation of an X-ray beam depends on the effective atomic density (atoms/volume) and atomic number of the tissue, and the photon energy of the $X$-ray beam. $X$-ray interaction with matter by the photo-electric and compton effects are mostly responsible for $X$-ray attenuation. Photo-electric absorption occurs mainly in material of high atomic number (e.g. bone, contrast material) and minimally in material with low atomic number (c.g. soft tissue). The compton effect, however, occurs mainly in soft tissue (low atomic number) and tissue density differences result in differences in compton interactions (Phelps ct al., 1975, Seeram, 1982).

A CT scanner can measure the X-ray attenuation coefficient $(\mu)$ of very small volume elements (voxels) of tissue, and can reconstruct all these measurements to form a two dimensional cross-sectional image in proportion to the scanned object. Nowadays (1983), 4 generations of clinically useful CT scanners have been identified and their differences are well described in literature (Seeram, 1982). In a third generation CT scanner, as used in this study, the intensity (I) of a highly collimated fan X-ray beam is measured by an array of some hundred detectors after traversing the body (fig. 2.1.). The intensities (I) measured by each detector are compared with the initial intensity (1o) to give corresponding figures for attenuation of the $\mathrm{X}$-ray beam by the traversed tissue. By rapidly 


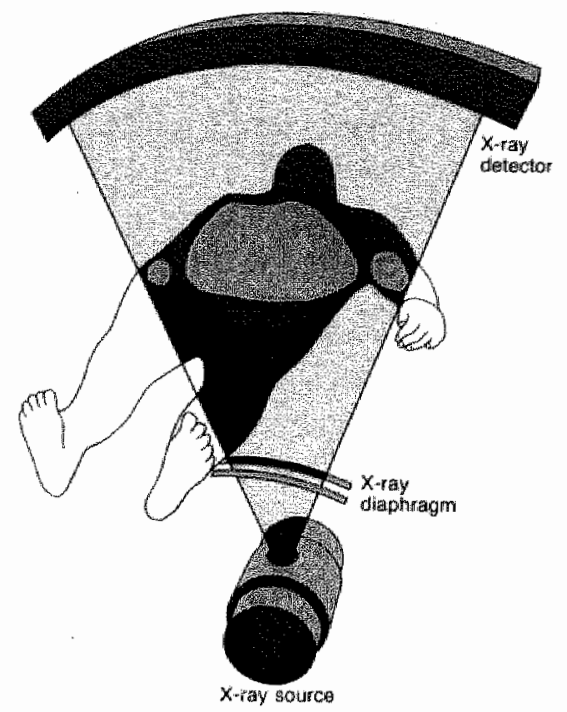

fig. 2.1.

Principle of third generation CT scanning: wide angle X-ray beam traverses the body after which its intensity (1) is measured by an array of detectors. (Courtesy of $\mathrm{N}$. V. Philips glowilampenfabriekem, Medical Systoms Division).

repeating this measure procedure while rotating the $\mathrm{X}$-ray tube and detector array together around the patient, a whole set of measurements in many directions is obtained (fig. 2.2.).

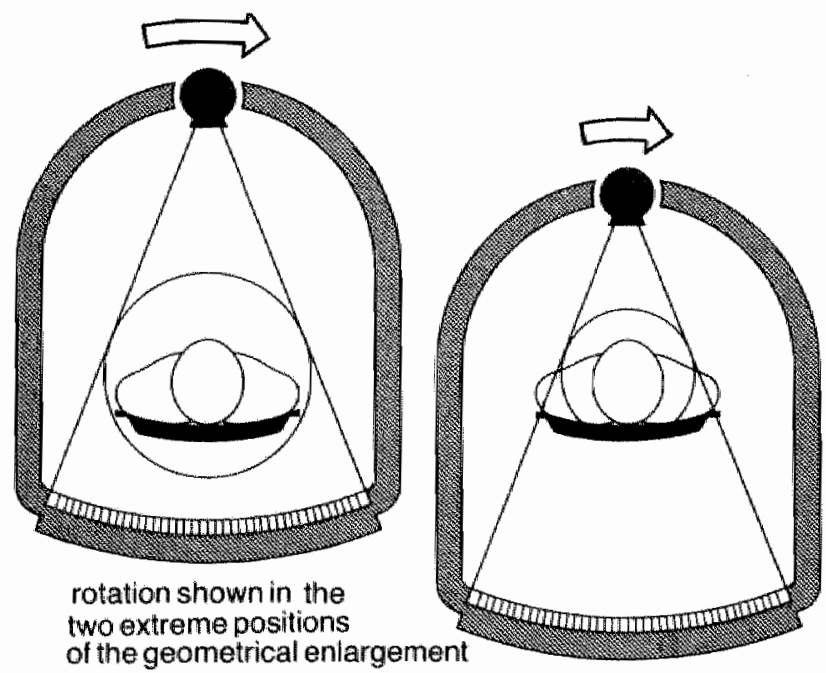

fig. 2.2 .

The measure procedure is repeated many times while rotating the $X$-ray source and detectors around the patient. (Courtesy of N.V. Philips gloeilampenfabrieken, Medical Systems Division).

With a computer using different correction and reconstruction algorithms, the linear attenuation coefficients of a system-dependent number of volume elements can be alculated, and these data can be displayed on a video-display system in different shades of 
grey. The attenuation values as measured by $\mathrm{CT}$ are expressed as a $\mathrm{CT}$ number relative to the attenuation value of water $\left(\mu_{w}\right)$ in Hounsfield Units (HU) by means of the formula:

$$
\text { CT number }=\frac{\mu_{W}-\mu_{w} \text { at } 73 \mathrm{KeV}}{\mu_{W} \text { at } 73 \mathrm{KeV}} \times 1000 \text { Hounsfield Units (HU) }
$$

The resultant scale varies from - $1000 \mathrm{HU}$ for air and $0 \mathrm{HU}$ for water, while bone is in the region of 250 to over $1000 \mathrm{HU}$ (fig . 2.3.). All image data can be stored on tape or floppy disc for subsequent retrieval and display.

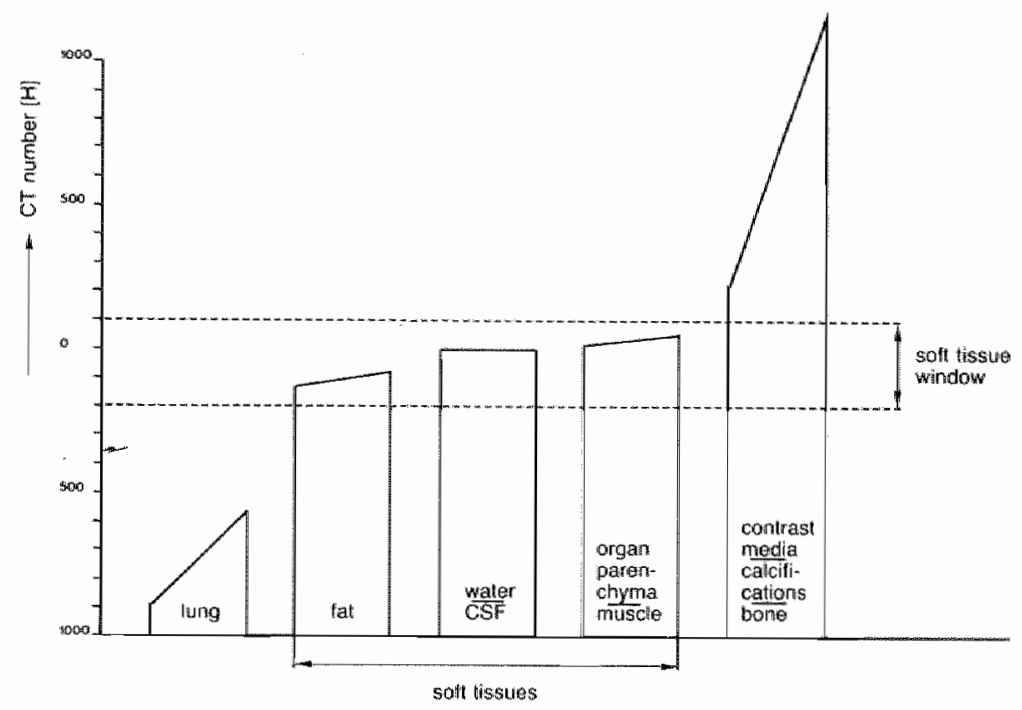

fig. 2.3 .

Altenuation coefficients of different tissues in Hounsfield Units (Courtesy of N.V. Philips gloeilampenfabrieken, Medical Systems Division).

Because it is impossible for the human observer to distinguish more than 50 to 100 shades of grey, the so called window manipulation technique is used (fig. 2.4.). Selective contrast enhancement is achieved by applying the entire grey scale ( 64 shades), to a selected range of CT number (window width) at a selected CT number level (window level). Normally, CT numbers above and below this range are displayed as white and black respectively. The image on TV monitor consists of many small squares, each representing one woxel in the CT slice and with its CT number displayed in grey scale. The displayed square is called a pixel, and its size is determined by the size of the display matrix (fig. 2.5.). The CT number of a voxel represents the mean density of all structures within that voxel. It follows that a structure which only partially occupies a voxel is subject to "partial volume averaging" (fig. 2.5.). This may be responsible for false positive or false negative results. For example, a small liver cyst of $5 \mathrm{~mm}$ in diameter will never be displayed with water density if a slice thickness of $9 \mathrm{~mm}$ is used, because its density will be averaged with the remaining $4 \mathrm{~mm}$ of liver clensity. However, a cyst of $1 \mathrm{~cm}$ in diameter may lie only partially in the slice, and its density will again average with the density of the surrounding liver tissue. 


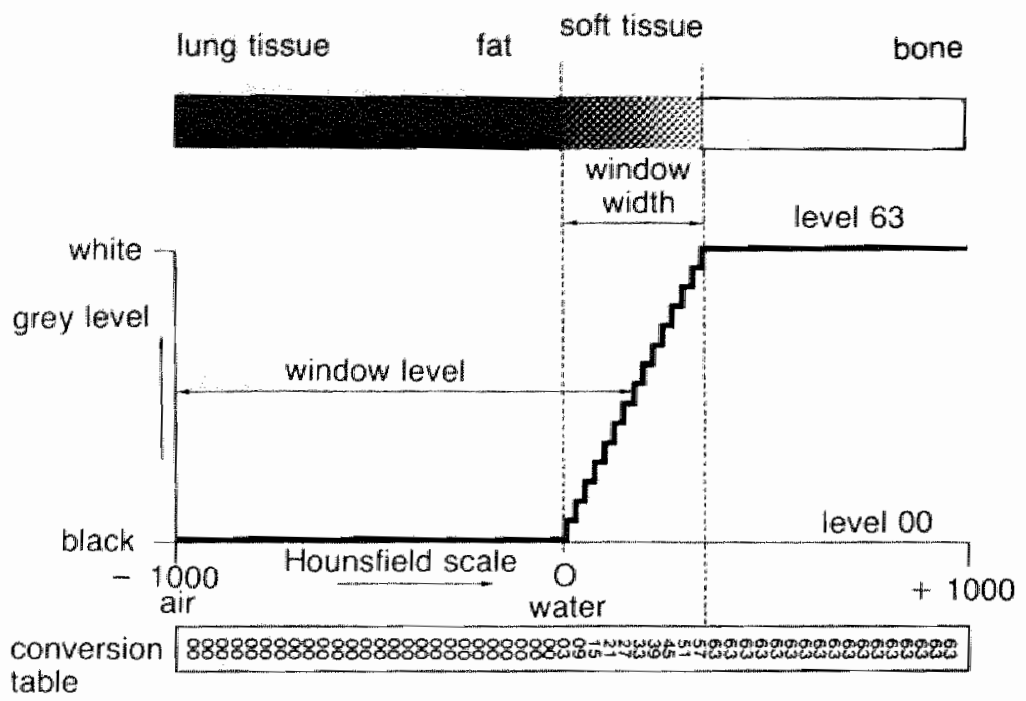

fig. 2.4 .

Principle of the window manipulation technique (Courtesy of N.V. Phillps glocilampenfabrieken, Medical Systems Division).

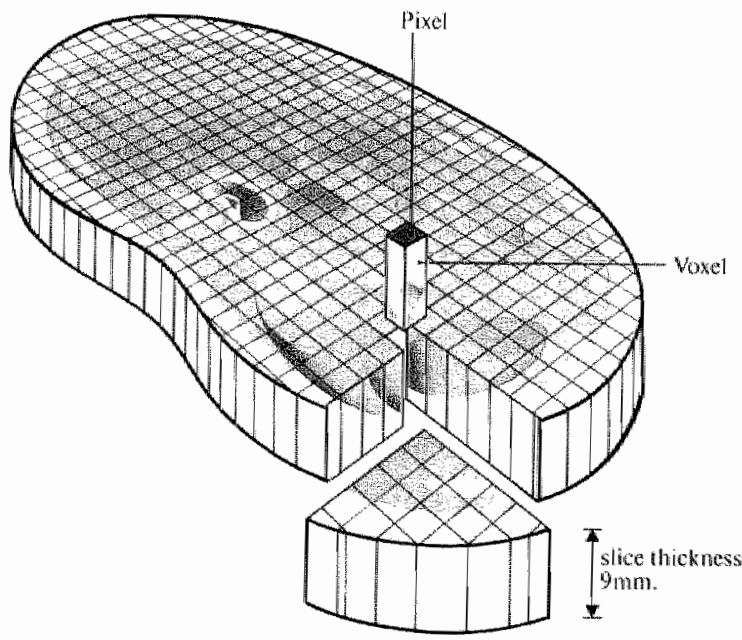

lig. 2.5 .

Relationship between pixels and voxels, the voxel being the volnme of tissue for which an individuat attenuation value is computed. The density of the voxel will be the average density of all the structures occupying the voxel (partal volume averaging). 
2.3. Image quality.

The minimum detectable lesion size depends on the density difference between lesion and surrounding normal tissue, so that a $2 \mathrm{~mm}$ soft tissue lesion (density $50 \mathrm{HU}$ ) differs widely from surrounding lung parenchyma (air density -1000 HU) and can therefore be detected, whereas a larger mass lesion within the liver with only slight density difference from normal liver tissue may not be detectable. Urographic contrast agents, by increasing density differences, may make such lesions detectable. A distinction must therefore be made between spatial and contrast resolution. The latter is an expression of the sensitivity of $\mathrm{CT}$ in detecting attenuation value differences, whereas the former determines the funeness of detail which can be seen. These two types of resolution are distinct, but interrelated, and additionally, influenced by the radiation dose. A detailed discussion of this problem is beyond the scope of this study, but some discussion is necessary if the practical limitations of $\mathrm{CT}$ are to be understood. The CT numbers of an image of uniform material should theoretically be equal, but in practice show minor variation from pixel to pixel, a phenomenon which is known as noise and is dependent on a number of factors, such as number of detected photons, matrix size, slice thickness, algorithms, electronic noise, scattered radiation and target size (Seeram, 1982). Resolution, noise and dose are closely related. Contrast resolution is limited by the noise, and therefore often specified in terms of the standard deviation of the noise (Zonneveld, 1980). In general, the higher the dose applied, the lower will be the noise and the better the contrast resolution. Contrast resolution in CT is always much better than in conventional radiography and contrast differences of less than $0.5 \%$ can be measured, but compared to conventional radiography CT is limited in its spatial resolution, which is mainly dependent on detector size, focal spot size, slice width and matrix size. Spatial resolution can be improved by reducing the detector size, but this in turn increases the noise and decreases the contrast resolution for a given radiation dose. It is not possible to specify resolution and patient dose for computed tomography in general, because both depend on mot only the type of machine but also on the particular machine settings chosen for a specific clinical indication. In order to limit the maximum patient dose, a compromise usually has to be made between maximal contrast resolution (e.g. brain scanning) or maximal spatial resolution (c.g. car scanning). Slice width, slice interval, scan time and degree of geometric enlargement are all variables influencing resolution and dose.

In addition to the factors already discussed, image quality is also dependent on patient positioning and patient-dependent factors. Adequate intra-abdominal fat planes are necessary to delineate intra-abdominal structures, and their absence in the very lean or cachetic patient produces images with poor natural contrast. The presence of high density structures such as metallic clips, barium or hip prosthesis, may cause such serious artifacts as to make CT scanning a pointless procedure.

\subsection{Philips Tomoscan 300}

The Tomoscan 300 as used in this study is a third generation CT scanner with a scan time of 4.8 seconds in which $600 \mathrm{X}$-ray pulses of $2 \mathrm{msec}$ are generated resulting in an cxposure time of $1.2 \mathrm{sec} /$ single scan. The slice thick mess is $3,6,9$ or $12 \mathrm{~mm}$. The available tube settings are within a $100-120 \mathrm{KV}$ p range and a $100-500 \mathrm{~mA}$ range. The patient aperture is $56 \mathrm{~cm}$ and 
the maximum gantry tilt is $20^{\circ}$ in a cranial or caudal direction. An array of 288 Xenon high pressure detectors is focussed towards the focal spot. The field of view (FOV) varies from $16 \mathrm{~cm}$ to $48 \mathrm{~cm}$. The distance between $X$-ray tube and axis of rotation can be changed while the X-ray tube detector distance remains fixed, utilizing the maximum rumber of detectors for the object size (fig. 2.2.). By means of geometric enlargement, the intrinsic spatial resolution is improved. Pixel size in the $40 \mathrm{~cm}$ FOV is $1.56 \times 1.56 \mathrm{~mm}$ on a fixed $256 \times 256$ matrix. The pixel sizes in the $32 \mathrm{~cm}$ and $24 \mathrm{~cm}$ FOV are $1.25 \times 1.25 \mathrm{~mm}$ and $0.93 \times 0.93 \mathrm{~mm}$ respectively. Since these pixel sizes may limit the spatial resolution in the displayed image, reconstructive zoom can be used. This technique permits the reconstruction of a subject of the original measurements on the full $256 \times 256$ matrix. The smaller field of view (with smaller pixel sizes) thus obtained will no longer limit the potential spatial resolution of the scanner.

Contrast resollution, spatial resolution and skin dose for these three different fields of view, with a slice width of $9 \mathrm{~mm}$ and a scan time of 4.8 seconds are listed in table 2.1 .

Table 2.1.

Contrast resolution, spatial resolution and skin dose for three fields of view (FOV) of the Tomoscan 300. Contrast resolution is measured for circular objects with a difference of 15 HU with surrounding (water) (Courtesy of N.V. Philips gloeilampen fabrieken, Medical Systems Division).

\begin{tabular}{|c|c|c|c|c|}
\hline FOV $(\mathrm{cm})$ & 40 & 32 & 16 & phantom \\
\hline$k V p$ & 120 & 120 & 120 & not applicable \\
\hline mAs & 300 & 216 & 216 & not applicable \\
\hline Skin dose (mGy) & 20 & 25 & 25 & $32 \mathrm{~cm}$ plexiglass \\
\hline Spatial resolution $(\mathrm{mm})$ & 2.0 & 1.5 & 1.25 & $\begin{array}{l}20 \mathrm{~cm} \text { water }+10 \mathrm{~cm} \\
\text { plexiglass (body ring) }\end{array}$ \\
\hline Contrast resolution ( $\mathrm{mm}$ ) & 9 & 6 & 6 & $\begin{array}{l}20 \mathrm{~cm} \text { water }+10 \mathrm{~cm} \\
\text { plexiglass (body ring) }\end{array}$ \\
\hline Noise (HU) & 10 & 8 & 8 & $\begin{array}{l}20 \mathrm{~cm} \text { water }+10 \mathrm{~cm} \\
\text { plexiglass (body ring) }\end{array}$ \\
\hline
\end{tabular}

After bolus injection of contrast media, it is sometimes necessary to obtain sequential CT scans as quickly as possible. This can be done by a batch scanning technique (Rapid Sequence Scanning, R.S.S.). With this technique, sequential scans are made at a speed ordered by the radiologist, but limited by the $\mathrm{X}$-ray tube beat loading. The whole sequence is completed prior to reconstruction.

The Tomoscan 300 has the ability to produce a projection radiograph (scanogram) by keeping the $\mathrm{X}$-ray detector system in a fixed position while moving the patient to be seanned through the gantry opening. On this scanogram, the exact location of a slice to be made can be indicated by a light-pen, after which the patient can be brought to the indicated slice position under computer control. 


\section{CT Scan protocol}

\section{..5.1. Patient preparation}

Since bowel loops have attenuation values similar to muscle, lymph nodes and vascular structures, they may mimic a soft tissue mass, particularly in patients with poorly developed fat planes. Bowel opacification with contrast medium is therefore necessary to prevent false positive results (Kreel, 1981; Ruys, 1979; van Waes and Ruys, 1979). In this study, a $4 \%$ solution of Telebrix 38 (Laboratoire Guerbet) was used for small and large bowel opacification. It is tasteless and can also be mixed with juice. The day before the CT examination, $200 \mathrm{cc}$ of this solution is given with each meal, the patient is then required to fast 4 hours prior to the CT examination, and a further $400 \mathrm{cc}$ is given $1-2$ hours prior to examination.

Before examination, the patient inserts a vaginal tampon to outline the vagina and identify the cervix. The air trapped between the fibres serves as a negative contrast medium.

\subsubsection{C'T scan procedure}

The examination is performed in supine position. A scanogram is made, and with the lightpen, the first slice is located through the dome of the diaphragm. The whole abdomen is then scanned from diaphragm to perineum with a field of view of $32 \mathrm{~cm}$, using $9 \mathrm{~mm}$ slices at $13,5 \mathrm{~mm}$ intervals from diaphragm to iliac crest, and then continuous $9 \mathrm{~mm}$ slices down to the perineum, using a reconstructive zoom to $24 \mathrm{~cm}$. The advantage of scanning in a caudal direction is that the bladder is nearly always full by the time the pelvis is scanned. The FOV is always adjusted in such a way that the whole abdominal cavity is imaged. After this routine procedure, the radiologist in charge of the examination reviews all the slices, and if necessary rescans regions of interest after a bolus contrast injection of an urographic contrast medium ( $80 \mathrm{cc}$ Telebrix 38), or after an enema of $500 \mathrm{cc}$ Telebrix 38 $4 \%$ solution. All spatial and density measurements are made with the SAVC (Stand Alone and Viewing Console). 


\section{References chapter II}

KREEL, 1.: Contrast media for computerized tomography of the gastrointestinal tract.

in: Contrast Enhancement in body Computerized Tomography. pp 28 - 33:

Fuchs, W.A., George Thieme Verlag Stutigant-New York. 1981.

PHELPS, M E., GADO, M.H., HOFFMAN, E J,: Correlation of the effective atomic number and electron density with attenuation coefficients measured with polychromatic X-rays.

Radiology 117: $585-588,1975$.

RUYS, J.H.J.: A simple procedure for patient preparation in abdominal CT.

A in. J. Roentgenol. 133:551-552, 1979.

SEERAM, E.: Principles of computed tomography

in: Secram, E. Computed tomography technology. pp $33-53$.

W.B. Saunders Company, Philadelphia, 1982.

SEERAM, E.: CT image quality

in: Sceram E. Computed tomography technology. pp. 123 - 138,

W. B. Saunders Company, Philadelphía, 1982.

VAN WAES, P.F.G.M. and RUYS, J.H.J.: Some aspects of patient preparation for abdominal CT scans.

Medicamundi 24: (2) 38, 1979 .

ZONNEVELD. F.W.: Principles of computed tomography.

in: Zonneveld, W.F., Computed Tomography, pp $9-27$.

Publisher: Philips Medical Systems, 1980 


\section{Chapter III}

\section{Normal cross-sectional anatomy of the female pelvis}

3.0. Introduction

A comprehensive account of the cross-sectional anatomy of the female pelvis is beyond the scope of this thesis, and the following descriptive outline is given simply to aid understanding of the pathological processes demonstrable by CT. The description is primarily derived from a study of the literature and standard textbooks of anatomy (Gardner et al., 1975, Grant, 1978, Lyons, 1978), but, because there is a lack of detailed description in the literature about the cross-sectional CT anatomy of the female genital tract, which is the specific subject of this thesis, the anatomical account has been supplemented by a retrospective study of pelvic CT scans in 42 women with no clinical evidence of gynaecological cancer. As an aid to understanding, this description is given according to the conventional anatomical subdivisions, but it must be emphasized that such subdivisions do not exist in anatomical reality, and in particular, the connective tissue skeleton shouid be regarded as a continuum (De Blok, 1982).

\subsection{Pelvic wall}

The pelvis comprises a pelvic wall enclosing the pelvic contents, and is bounded above by a plane through the arcuate lines, and below by the urogenital diaphragm and a plane through the sciatic rami. The space formed by the upper plane and the iliac wings bilaterally belongs to the abdominal cavity. Without computerized reconstruction techniques it is impossible to make one CT cut through the plane of the upper pelvic aperture, because the angle of this plane to the examination table is too acute. Furthermore, the lower pelvic aperture is in two planes, and cannot therefore be displayed by a single CT cut.

The pelvic wall can be considered in three layers."

1. An outer layer consisting of skin, subcutaneous fat, fasciae and muscles outside the skeleton.

2. A middle layer consisting of skeleton and fibrous tissue, particularly the obturator membrane.

3. An inner layer consisting of muscles and fasciae attached to the interior of the skeleton.

In a CT scan, muscles and skeleton are always clearly visible, whereas fasciae and ligaments are often difficult to identify.

\subsubsection{Skeleton}

The configuration of the bony pelvis in a CT cut is determined by the degree of spinal curvature, because, regardless of the angle between the pelvis and the examination table, 
the most frequently used scan plane is one perpendicular to the examination table. Allowing for such variations in configuration, a modern high resolution CT scan provides a transwerse section without superimposition, and displays very fine detail particularly in the bones, because of the relatively large contrast differences. Cortex, medulla and surrounding soft tissues are almost always well delineated.

\section{Sacrum}

The sacrum is a wedge-shaped bone, formed by the fusion of five primordial vertebral homologues. When seen in transverse section, the sacrum appears trapezoid cranially and more triangular caudally. The sacral canal appears triangular in outline cranially, but caudally it is flattened antero-posteriorly. It communicates, through the intervertebral foramina, with both the ventral and dorsal sacral foramina which appear, in transverse section, as gaps in the pelvic and dorsal surfaces of the sacrum. Since all the major nerves exit anteriorly the ventral foramina are larger than the dorsal foramina which carry only minor cutaneous nerves. Anatomically, the sacral canal contains the dural sac, the filum of the dura mater, the lower part of the cauda equina and the filum terminale, but these are indistinguishable in a routine CT cut. The epidural space may be very large and contains much fatty tissue wherein root sheaths, veins and the spinal ligament can be seen. The sacro-iliac joints, with typical subchondral sclerotic margins, and the retro-auricular space are always easily seen. The retro-auricular space is wider, has less sclerotic borders and runs more horizontally than the more vertically orientated synoviall joint space. (Lawson et al., 1982).

\section{The hip bone}

The hip bone is formed by the fusion of the ilium, ischium and pubis in and around the acetabulum, and the further fusion of the pubis and ischium around the obturator foramen. In the majority of patients the upper part of the iliac crest can be identified in the same CT cut as the fourth lumbar vertebra. The ilium consists of a body and a wing, the latter being sometimes very thin and an interruption simulating a fracture may be seen. In cadaver studies a hole in the centre of the iliac fossa is often found. The dorsal part of the ilium, lateral to the retro-auricular space is always clearly seen in a CT scan, in contrast to a conventional radiograph. Serial scanning in a cranio-caudal direction reveals an increasing gap between sacrum and ilium, part of which represents the sciatic foramina. These foranina are often difficult to delineate in cross-section, because the ligamentous margins are scarcely visible in CT. The sacro-tuberous ligament appears as a small dot of soft tissue density in a transverse CT section, being almost perpendicular to the scan plane, and forms the dorsomedial margin of the greater and lesser foramina. The piriformis muscle runs through the greater foramen and bends slightly around this ligament, a feature which is nearly always seen in CT (fig. 3.5c.) and enables the sacro-tuberous ligament to be localized even if the

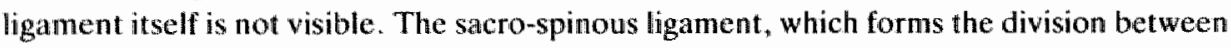
the greater and lesser sciatic foramina, runs parallel to the scan plane, and together with the tiny coccygeus muscle is visible as a thin strand from sacrum to ischial spine (fig. 3.5a.). The sciatic nerve and pudendal vessels and nerves cross the greater sciatic foramen in front of the piriformis, but gnly the sciatic nerve is large enough to be seen at this level. 
The pudendal nerves and vessels in addition to the muscle and tendon of the obturator internus, then pass through the lesser sciatic foramen, but are only visible in the pudendal canal (fig. 3.1c). The hip joints are very clearly seen at approximately the same crosssectional level as the ischial spines (fig. 3.4d). Cuts more caudally reveal the obturator foramen, the body and rami of the ischium and the superior and inferior rami of the pubis.

\section{Lumbar spine}

In cross-section a lumbar vertebral body appears kidney-shaped with the convexity ventrally. The medulla and cortex are clearly distinguishable. The medulla appearing a little granular. and small lines of low density may be visible dorsally in the vertebral body, representing the canal of the basivertebral vein (Hahn's canal). Branches of this canal may also be occasionally visible and can be mistaken for a fracture. Small areas of increased density in the medulla are commonly seen and usually represent bony islands. The transverse processes point dorsolaterally and are smaller than the thoracic ones, the pedicles and laminae are thick and short, and the spinous processes, being in a horizontal plane, are frequently seen in the same CT cut as the bodies. The intervertebral facet joints run obliquely in a dorsolateral direction and are best seen at the same level as the intervertebral disc. The articular processes of the upper lumbar vertebrae appear medially and of the lower laterally. Although in general, the more cranial the vertebra, the smaller the body and the pedicle. the larger the mamillary process, it is still difficult to determine the actual vertebra crosssectioned without the aid of the scanogram. The fifth lumbar vertebra is exceptional, because its transverse process is much bigger and broadly anchored to the body.

Additionally, the inferior articular processes of L5 are widely separated and, together with the upper joint surfaces of the sacrum, form joints situated almost in the frontal plane, although these are frequently asymmetrical.

The vertebral foramen shows considerable variations being round or oval cranially and more triangular caudally. The spinal ganglion is situated cranially in the intervertebral foramen where it is sometimes visible in CT, but more caudally, the ganglion is situated wholly within the spinal canal, and instead, the rami of the spinal nerves may be seen in the intervertebral foramen. The strong, in cross-section, C-shaped ligamentum flavum is wisible in the spinal canal and is dorsally related to the larger interspinous ligament.

\subsubsection{Muscles}

The muscles of the pelvis are easily defined, especially in patients with good fat planes. The muscles of the outer layer of the pelvic wall are the glutei and adductors, whereas those of the inner llayer are the obturator internus and the piriformis (fig. 3.4 and 3.5) both of which are always clearly visible and form important landmarks in the pelvis. The obturator internus arises from the inner aspect of the pubis, ischium and obturator membrane, and its tendon leaves the pelvis through the lesser sciatic foramen, turns sharply ventrally and is inserted onto the medial part of the greater trochanter. The piriformis arises from the ventral surface of the lateral mass of the sacrum, leaves the pelvis through the greater foramen and is also inserted onto the greater trochanter. In a CT scan however, these two insertions cannot be distinguished nor can they be differentiated from the other deep dorsal hip muscles in this region. The illopsoas does not run through the pelvis, but is a 
very important landmark in $\mathrm{Cr}$, because its immediate medial relations are large vessels and lymph nodes. "The muscle is in fact compound, consusting of the broad flat iliacus and the psoas major. The ifiacus arises from the iliac fossa and inserts laterally into the tendon of the psoas. The origin of psoas major extends from the lateral aspects of the lower dorsal spine to the lower lumbar spine, increasing in bulk as it runs caudally and forming, together with the iliacus, one bundle, which passes below the inguinal ligament into the upper leg, and is finally inserted onto the lesser trochanter. Psoas minor is a small muscle, present in only $60 \%$ of individuals, lying immediately anterior to psoas major, and may sometimes be distinguished on CT scan. The psoas muscles are enveloped by aftascial sheath extending from the lower thorax to the proximal part of the femur, and its close relationship to many retroperitoneal structures such as kidneys, pancreas, lymph nodes, spine, vessels and nerves, is frequently responsible for the spread of disease into and through it (Donovan et al., 1981$)$.

\subsubsection{Abdominal wall}

Although the abdominal wall is outside the boundaries of the pelvis, its normal anatomy requires some discussion, since abnormalities within it, may simulate or indicate pathology related to gynaccological cancer. The anterior abdominal wall consists of skin, subcutaneous tissue and muscle layers. Below the umbilicus, the subcutaneous tissue is divided into two layers, namely a superficial fatty layer and a deep fibrous layer which is continuous with the deep fibrous layer in the perineum and the fascia lata of the thigh. Although these two layers are normally very closely related, the deep fibrous layer may sometimes be visible as a soft tissue line parallel to the abdominal wall in CT scans of very fat subjects (Fisch and Brodey, 1981). Furthermore, the superficial epigastric vessels are frequently seen in the subcutaneous fatty layer. The muscles of the muscular layer can be divided into an anterolateral group (external oblique, internal oblique and transwersus abdominis) and a midline group (rectus abdominis, and pyramidalis). Deliniation of the individual muscles in a CT scan depends on the presence of sufficient fat in the intermuscular connective tissue. Medially, the muscles of the anterolateral group become tendinous and fuse to form the rectus sheath, the exact structure of which depends on the anatomic level examined. Above the umbilicus, the rectus sheath invests the rectus abdominis on both sides, but some distance below the umbilicus, it passes predominantly anterior to the rectus abdominis and fuses with the contralateral sheath in the linea alba. At this lower levell, the dorsal wall of the rectus sheath is only a thin membrane, the transversalis fascia, which is the inner surface of the whole muscular layer, and is separated from the parietal peritoneum by only a small quantity of fatty tissue. Immediately posterior to the anterior parietal peritoneum and within the peritoneal cavity is the greater omentum, a fold of the peritoneum hanging down from the stomach, in front of the transverse colon, to which it is attached, but in normal cases invisible on CT.

\subsection{Pelvic floor.}

The pelvic floor is composed of the levator ani and the urogenital diaphragm. Levator ani is a compound funnel shaped muscle, of which one part arises from the dorsal aspect of the 

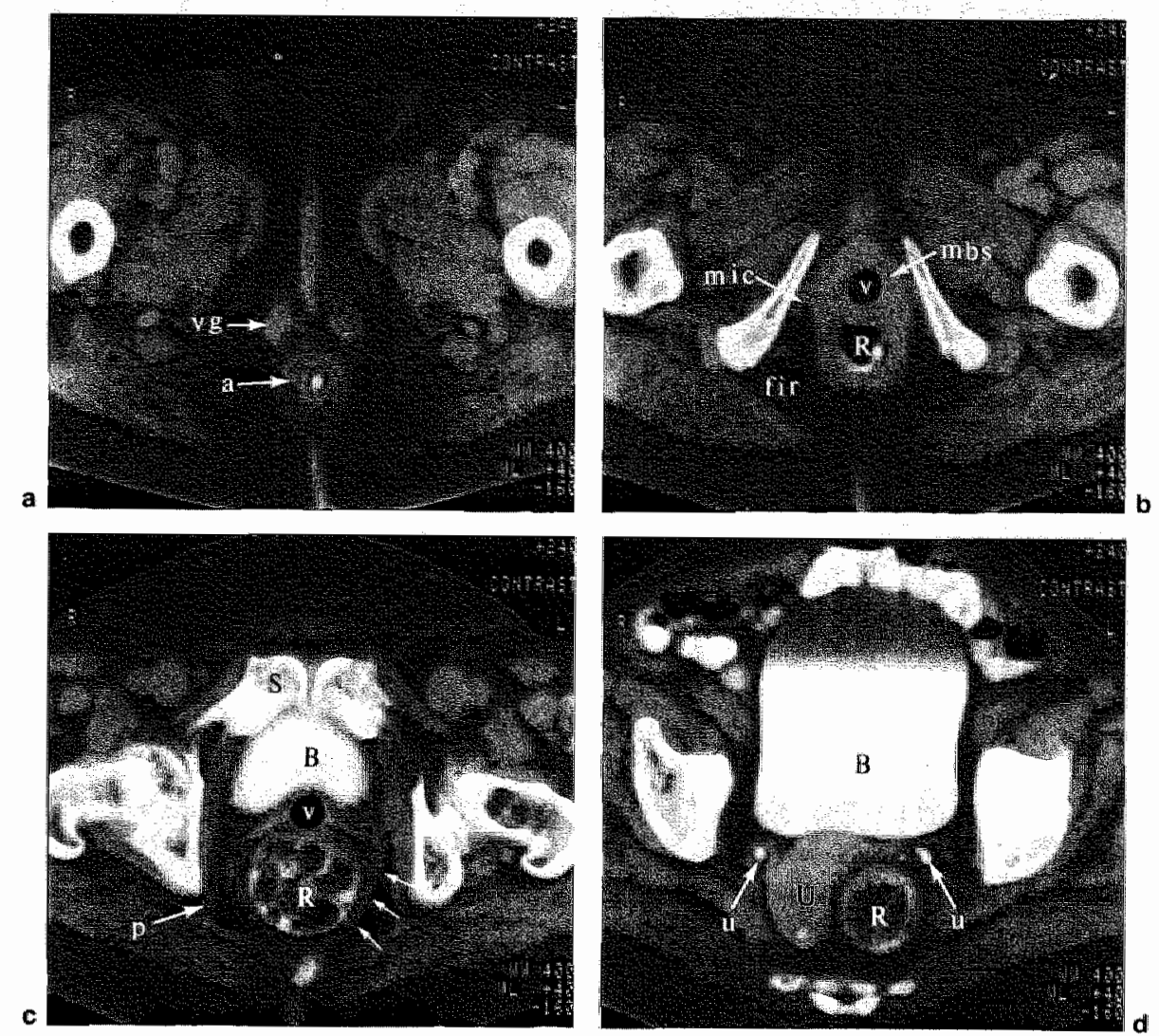

fig. 3.1.

Normal anatomy of pelvis and perineum. The uterus (U) is in retroflexion. $B=$ bladder, $R=$ rectum, $v=$ vagina with tampon, $u=$ ureter, $p=$ pudendal canal, $a=$ anus with canula, fir $=$ ischio-rectal fossa, mbs = bulbo-spongiosus muscle, mic $=$ ischio-cavernosus muscle, $\mathrm{S}=$ symphysis, small arrows = levator ani, $\mathrm{vg}=$ vestibular gland.

pubis, close to the symphysis, and is inserted into the coccyx. Another part alrises from a tendinous arch in the obturator fascia and runs dorsally to the coccyx and the anococeygeal ligament (fig. 3.1c.). Dorsocranially, the levator ani is strengthened by the coccygeal muscle, and ventrally behind the symphysis, there is a narrow gap (levator hiatus) (fig. 3.4b.), through which vagina and urethra pass. Finally, both sides of levator ani are covered by fascia. The muscle and its fascial layers may be very thin or even membranous, and, in common with the related parietal peritoneum, are generally insufficiently perpendicular to the scan plane to be easily visualized in CT. When thickened, or in the presence of ascites, the more perpendicular parts of the peritoneum may be visible (fig. 3.8b.). For these reasons, it is frequently impossible in CT to localize a mass lesion in relation to these structures. Blood and lymph vessels, lymph nodes, nerves and ureters are located between peritoneum and the upper fascia of the levator ani.

The urogenital diaphragm consists of two muscles stretched transversely between the inferior rami of the pubis and the ischii, namely the sphincter urethrae anteriorly and the deep transversus perinei posteriorly. The latter forms the dorsal margin of the urogenital 

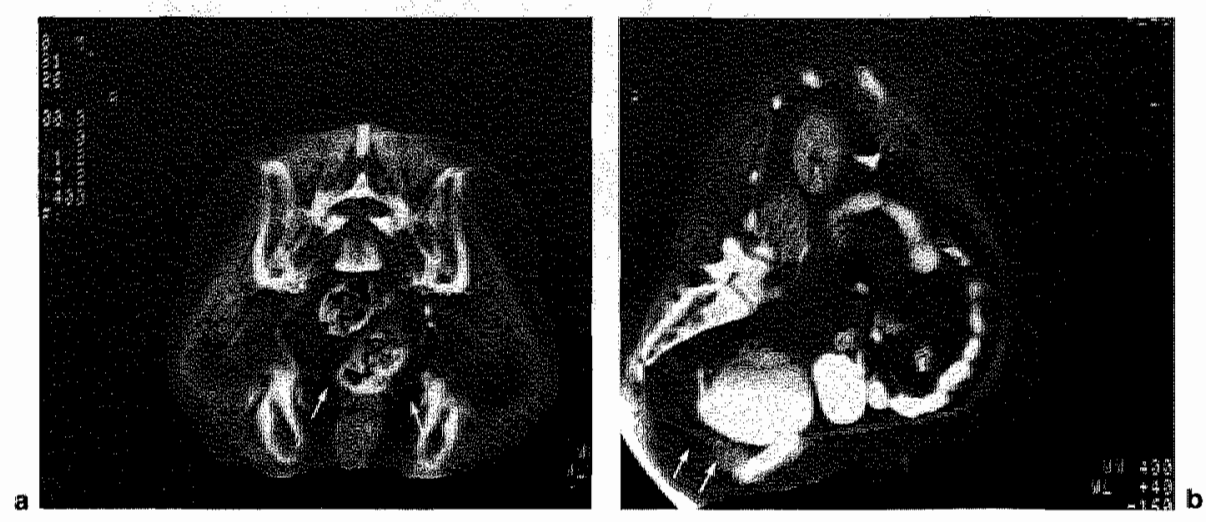

Ilig. 3.2 .

Coronal (a) and sagital (b) CT scans of the female pelvis and abdomen, Arrows denote the levator ani muscle (fig. a) and urogenital diaphragm (fig. b) (Courtesy of Dr. M. Feldberg and Prof. Dr. P. van Waes, Academisch Ziekenhuis Utrecht).

diaphragm with the perineal body in the centre. Caudally (superficially) lie the ischiocavernosus and bulbo-spongiosus muscles together with the superficial transversus perinei. The greater vestibular glands lie next to the vaginal orifice and, like the bulb of the vestibule, are covered by the bulbo-spongiosus muscle (fig. 3.1a.). These structures cannot be individually distinguished on CT. Furthermore, the urogenital diaphragm being thin and parallel to the scan plane, is not normally visible in cross-sectional CT, but, in common with levator ani, may be clearly defined in sagittal and coronal scans (fig. 3.2. Tisnado et all., 1981). Caudally to the levator ani, lies the ischio-rectal fossa with a ventral recess extending cranial to the urogenital diaphragm to the pubic symphysis, and bordered by the fascia of this muscle and of the obturator internus and by the sphincter ani. The fossa contains fatty tissue and dorso-laterally the pudendal canal, containing pudendal artery, wein and nerve, is visible against the obturator internus (fig. 3.1c.).

\subsection{Abdominal-pelvic cavity}

The peritoneal cavity, in healthy women contains only a small quantity of peritoneal fluid, and post ovulation, a small quantity of blood. Abnormally, particularly in malignant disease, it may contain ascites and tumour seedlings. All other structures are extra peritoneal, although many pedunculate into the abdominal pelvic cavity.

In CT, many structures have similar density and, if not distinguishable by their relative position, size and internal structures, require to be labeled with contrast to prevent misinterpretations. The space between bowel loops may be very large and has fat density $(-50$ to -150 Hounsfield Units). Within it small thin strands of higher density represent blood wessels and lymph nodes (fig. 3.3.). The omentum majus is indistinguishable from general intra abdominal fat except when tumour-infiltrated. The structures of importance in CT can now be described in greater detail. 


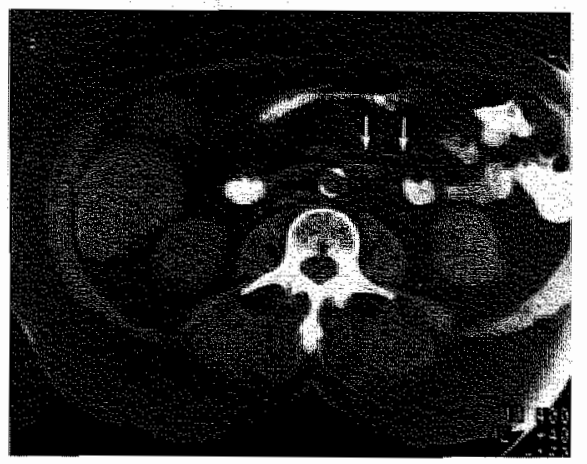

fig. 3.3.

Abdominal cavity: note the small thin strands of higher density (small arrows), surrouded by fatty tissue, representing normal blood wessels in the mesentery.

\subsection{Extra peritoneal space}

\subsubsection{Great vessels}

At the level of the fourth lumbar vertebra, the aorta divides into the common iliac arteries. The inferior vena cava is formed by the common iliac veins, just caudal to this bifurcation and dorsal to the right common iliac artery. At the upper level of the sacro-iliac joint, the common iliac arteries divide into external and internal iliac arteries. The external vessels run caudally on the medial border of the psoas major and leave the abdominal cavity through the lacuna vasorum. The vein lies slightly medial and dorsal to the artery (fig. 3.7). The internal iliac artery (hypogastric artery) runs dorso-caudally and has various branches, visible but not identifiable on $\mathrm{CT}$, as their origin and calibre varies from woman to woman. Each artery has one or two escorting veins. Behind these vessels lies the sacral plexus, appearing as highly variable small densities, each less than $1.5 \mathrm{~cm}$ in diameter, in front of the pirifornis and with almost invariable asymmetry (fig. 3.7). Some of these vessels leave the pelvis through the greater sciatic foramen (inferior and superior gluteal artery and internal pudendal artery), while the others run more caudally and ventrally. The obturator artery, veins and nerve are sometimes seen as small structures within the obturator canal, but are not otherwise visible.

The pudendal canal (Alcock's canal), containing the internal pudendal artery, vein and nerve, is nearly always visible just medial to the obturator internus (fig. 3.1c.).

All the organs in the pelvis are surrounded by a plexus of thin walled veins without valves, which communicate freely with each other and give branches to the internal iliac vein. These may be visible as small densities in the parametria (fig. 3.6.).

\subsubsection{Nerves}

With the exception of parts of the sciatic and femoral nerves, nerves are practically al ways invisible in abdominal CT. However, as nerve involvement may be the first indication of tumour spread, it is very important to know the course of the large nerves, so that the area of likely neurological involvement may be specifically scanned. The spinal nerves are 

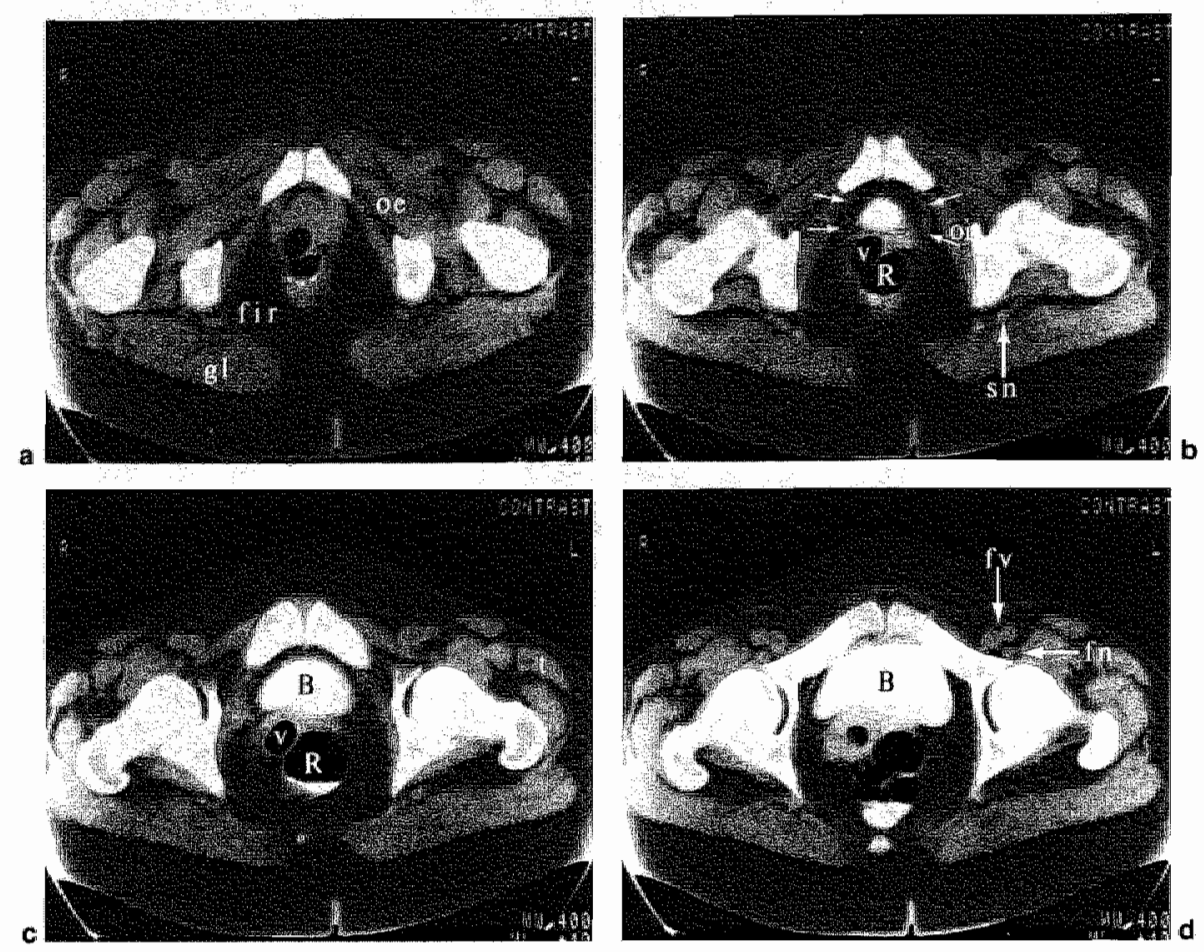

fig. 3.4.

visible in the interwertebral foramina and behind the psoas, then, as they penetrate psoas muscle, the lines of penetration are sometimes visible as areas of decreased (fat) density (Donovan et al. "1981). Small soft tissue densities are often wisible adjacent to the spine, behind psoas, aorta and vena cava, and may represent parts of the sympathetic trunk and its ganglia, normal small lymph nodes or more probably small veins. The spinal nerves then form the lumbosacral plexus, which in turn gives rise to two large nerves:

1. The femoral nerve is formed by the spinal nerves of L2 to L4 running caudo-laterally behind and through psoas, then between iliacus and psoas, and, passing under the inguinal ligament lateral to the great vessels, enters the upper leg, at which level it is sometimes visible in $\mathrm{CT}$ (fig. 3.4d.).

2. The sciatic nerve is formed by the sacral plexus. The spinal nerves of L4 to $S 2$ leave the pelvic sacral foramina, run laterally on the sacrum and converge into one bundle, forming the sciatic nerve, which then runs along the lower rim of the piriformis, to the greater sciatic foramen and then dorsally out of the pelvis. In transverse section, the sciatic nerve is visible just caudal to the ischial spine and ventral to the gluteus maximus (fig. 3.4.6).

\subsubsection{Lymph nodes}

The lymphatic drainage of the abdominal and pelvic organs follows the blood vessels towards the para-aortic region and then to the thoracic duct. Many nodes are scattered 

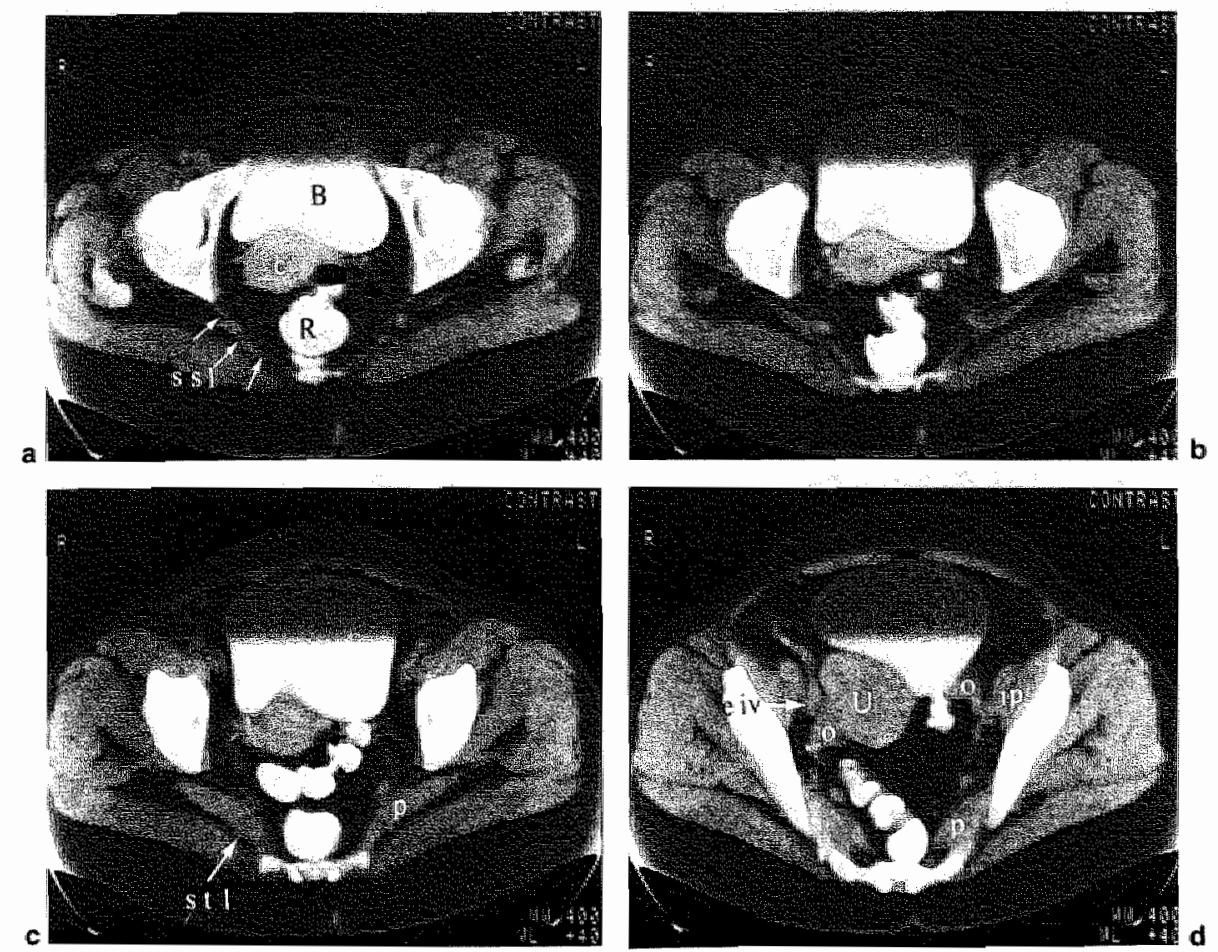

fig. 3.5 .

fig. 3.4. and 3.5.

Normal CT anatomy of the female pelvis. Eight consecutive scans. Bladder (B) and rectum (R) contain contrast medium. $\mathrm{c}=$ cervix, $\mathrm{U}=$ uterine body, $\mathrm{o}=$ ovary, $\mathrm{v}=$ vagina, $\mathrm{t}=$ femoral vessets, $\mathrm{f} n=$ femoral nerve, $\mathrm{sn}=$ sciatic nerve, eiv = external hiac vessels, fir $=$ ischio rectal fossa, $s t 1=$ sacro-tuberous ligament, ssl = sacro-spinous ligament, arrows (fig. 3.4b) = levator ani, oi = obturator internus, oe = obturator externus, $\mathrm{gl}=$ gluteal muscle, $\mathrm{t}=$ tensor fascia lata, $\mathrm{p}=$ piriformis, ip $=$ iliopsoas.

along these blood vessels and they vary in size, number and postition. In the pelvis three groups of nodes can be distinguished (Jackson, 1969):

1. The external iliac nodes, around the external iliac vessels, are arranged in three chains :

a. a lateral chain, lateral or anterolateral to the external iliac artery.

b. a middle chain, ventral or medial to the external iliac artery (obturator nodes).

c. a medial chain, dorsal to the external iliac artery.

2. The internal iliac nodes, around the internal iliac vessels, lie medial to these vessels and form one chain.

3. The common iliac nodes, around the common iliac vessels, are arranged in three chains:

a. a lateral chain, lateral to these vessels.

b. a medial chain, ventral to the vertebrae in the bifurcation of the aorta.

c. a dorsal chain wentral to the sacral promontory.

There are three para-aortic chains, one on the left side of the aorta, one between aorta and vena cava and one on the right side of the vena cava, with many nodes anterior and posterior to these vessels. However the whole system shows considerable variability and there are numerous communications between all the chains. 
The middle chain of the externall iliac nodes, known as the obturator nodes, deserves special mention because they are the most frequently inwolved nodes in cervical cancer. They are located in the obturator fossa, which is bordered by the external iliac vein ventrally, the illium laterally and the internal iliac artery dorsally. The obturator nerve is also situated in this fossa, but never seen on CT.

Although CT can demonstrate normal lymph nodes, it does not display their internal architecture, in contrast to lymphography, and the cross- sectional size of the node is the only criterium of normality. It is widely accepted that nodes less than $1 \mathrm{~cm}$ in diameter on CT can be considered normal and those larger than $2 \mathrm{~cm}$ as abnormal (Korobkin, 1981). Between these limits, opinion varies, most authors considering nodes larger than $1.5 \mathrm{~cm}$ to be abnormal (Redman et al., 1977, Hodson et al., 1979). However, Callen et all. (1977) stress that normal retrocrural nodes (nodes between vertebra and diaphragmatic crura) rarely exceed the diameter of $6 \mathrm{~mm}$, while Walsh et al. (1980) believe that for normal pelvic nodes, the upper limit should be $2 \mathrm{~cm}$. It seems likely that normal limits depend on the location of the node, and it is well known from lymphographic studies that pelvic nodes are often larger than para-aortic nodes. Kolbenstved (1975) stated that only $37 \%$ of patients with enlarged nodes on lymphography proved to have metastases but, in contrast, Patriquin (1967) found no normal nodes larger than $2 \mathrm{~cm}$, and Hendriksen (1949) states that enlarged nodles may be histologically normal, while very small nodes may contain metastatic deposits. Even if the upper limit of normality is defined as $1.5 \mathrm{~cm}$ to $2 \mathrm{~cm}$, nodes of this size may not be identified, particularly in the pelvis, where the anatomical structures are not always so clcarly defined. Many authors (Walsh et al., 1980, Levitt et al., 1978, Hodson et al., 1979, Korobkin, 1981) stress that asymmetry of the soft tissue structures around the pelvic vessels is an important indication of lymph node abnormalities. However in our experience such asymmetry is seen frequentlly, and this sign must therefore be interpreted with caution. There are three main causes of false-positive interpretation of enlarged pelvic lymph nodes: Firstly, non-opacified bowel loops misinterpreted as cnlarged nodes, secondly, normal ovaries interpreted as enlarged nodes (fig. 3.9a.) (especially in patients with poor fat planes) and thirdly, dilated collateral blood vessels simulating large nodes, when there is obstruction of a large vein. Rescanning the doubtful area after further contrast orally or by enema to delineate bowel, after micturation to relocate the ovaries, or after intravenous bolus contrast injection to enhance the vessels will help to prevent such misinterpretations. In the para-aortic region, misinterpretation of enlarged lymph nodes may be caused not only by poor bowel opacification, but also by a subacute retroperitoneal haematoma, a left sided inferior vena cava or prominent left gonadal wein, a diaphragmatic crus (particularly the right) near its caudal attachment to the vertebral body and by retroperitoneal fibrosis (Korobkin, 1981, Jasinski et 1., 1981, Brun et al., 1981). Such problems are rare. The nomal aorta is sharply demarcated from the surrounding fatty tissue, which contains few if any wery small tissue densities. Disappearance of the normal aortic contour, particularly in the dorsolateral area, indicates para-aortic pathology, most commonly enlarged nodes (Harell et al., 1977). More advanced stages of lymph node enlargement may completely obliterate the para-aortic fatty tissue and displace the aorta anteriorly, producing the characteristic "floating aorta sign" (Zelch and Haaga, 1979, fig. 4.6b.c.). However enlarged nodes may also be visible with the normal aortic contour. 


\subsection{The female genital tract}

\subsubsection{Normal cross-sectional anatomy - a retrospective study}

\section{A. Introduction}

Uterine size is age-dependent being very small at birth and growing in width and bulk following the menarche. The postmenopausal uterus is usually atrophic and sometimes difficult to identify with ultrasound (Miller et al., 1977). The size and shape of the uterus in cross-section is determined by the angle of its axis to the scan plane, which in turn is governed by the degree of ante- or retroversion of the uterus as a whole and ante- or retroflexion of the corpus relative to the cervix. Both may be influenced by a full rectum or bladder and the particular combination of an empty bladder and markedly anteflexed uterus, may cause cervix and fundus to appear in one single CT cut as two different structures ${ }_{\text {, }}$ simulating an additional mass anterior to the cervix. Filling the bladder corrects the anteflexion and the additional mass disappears. For these reasons, the AP diameter of the corpus is difficult to define and reasonable accuracy can only be achieved in the presence of a full bladder. Slight lateral deviation of the uterine axis is also common, and may change the position and form on CT. The cervix is less variable in position, and in general more perpendicular to the scan plane. In order to establish the normal cross-sectional anatomy of the female genital tract, 42 pelvic CT scans were reviewed with particular reference to measurements of size and density and pattern of contrast enhancement of the uterus.

\section{B. Method and material}

42. CT scans of the female pelvis, originally made for a variety of clinical indications on women with no clinical evidence of genital tract cancer, were reviewed. The clinical indications are tabulated in table 3.1. All scans were primarily interpreted as normal and a follow-lip of at least 6 months in 31 patients, a laparotomy in 10 patients, and an autopsy in

Table. 3.1

Indications for the 42 pelvic CT scans which are used to study the normal CT anatomy of the female genital tract.

Lymphoma, staging examination

10 patients

Lymphoma? (definite diagnosis: normal) 5

Ischialgia 6

Palpable pelvic mass $\quad 2$

Abnormal X-ray examination $\quad 4$

Vague abdominal complaints 5

Trombosis of lower extremity 5

Abscess? 1

Protein losing enteropathy 1

Neurofibromatosis 1

Unknown 2

Total 42 
one patient who died 6 months later, revealed no signs of pelvic cancer. Ten patients had a laparotomy within 4 weeks of $\mathrm{CT}$ scan as a staging procedure for lymphoma, and no genital tract abnormalities were found. In all cases the CT slice thickness was $9 \mathrm{~mm}$, scanned consecutively to the pelvis in 23 cases, and with a half-slice $(4.5 \mathrm{~mm})$ interval through the pelvis in the remaining 19. Seventeen cases had only a plain (non-contrasted) scan while 14 had, in addition, a scan after intravenous bolus injection of contrast medium ( $80 \mathrm{~m}$ telebrix $38,30.4 \mathrm{grams}$ iodine). The injection lasted 20 seconds on average followed immediately by a first scan at the level of the cervix, followed at 55 second intervals by consecutive 9 mm CT sections proceeding cranially. In II patients, the pelwis was scanned only after contrast injection ( 30.4 grams of jodine) given about $15-30$ minutes previously for another reason. Diagram 3.1 shows the distribution of patients with the different scan techniques for each decade age group.

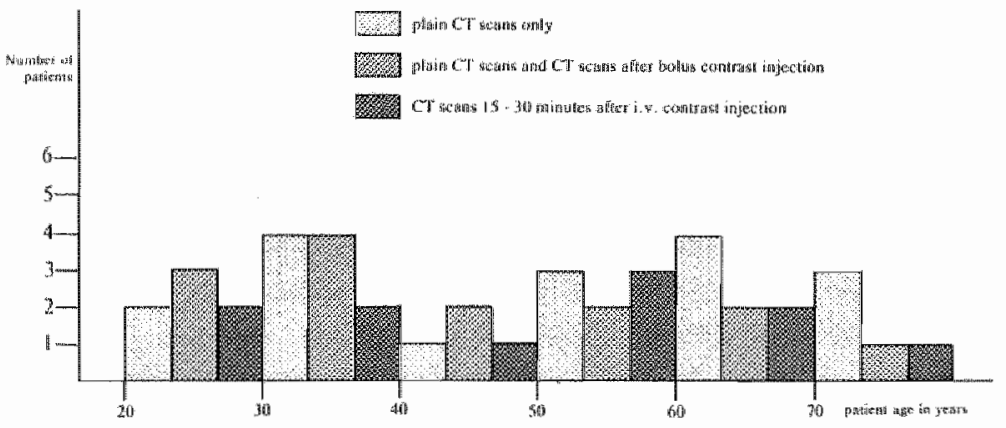

Dielgram 3.1.

Age distribution of 42 patients related to the scan technique, forming the material of the normal anatomy study.

Using the SAVC (Stand Alone and Viewing Console) of the CT scanner, AP and lateral diameter in $\mathrm{mm}$, and density in Hounsfield Units of the uterus were measured. For density measurements, a region of interest of at least 61 pixels was used, unless it exceeded the size of the structure (e.g. vessels), in which case the region of interest was made as large as possible. In post bolus contrast scans, density measurements of uterus, gluteal muscles and femoral or iliac artery and vein were made for each slice and plotted against time. The lateral cervix borders were assessed and classified as smooth, irregular or with linear soft tissue extensions into the parametria. The parametria were classified in one of two ways : 1. Fatty tissue with some small soft tissue densities only. 2. Fatty tisue with many linear soft tissue strands (fig. 3.6.). The transwerse diameter of the uterus and the relative positions of the ovaries, if visible, were recorded.

\section{Results}

Tables 3.2 and 3.3 and graph 3.1 summarize the results. CT artefacts prevented cervical density measurement in 2 patients. Small calcifications were visible in the uterine corpus in 4 patients and in the cervix in 1. In general, the uterine outline appeared circular or oval, but in 17, it was a little lobulated. "The cervix appeared flat or oval and exceptionally round. In 3 premenopausal women CT cuts at a level of the cervix or just above demonstrated a soft tissue mass extension reaching to the pelvic wall (fig. 3.7). Excluding the post bolus contrast films, a small central lucency was visible in the cervix in 7 patients, and in the corpus in 4 . Of these 4,3 were plain scans, and one was 30 minutes post cont rast (without a plain scan). In the 3 plain scans, with a lucency in the corpus, the density differences 


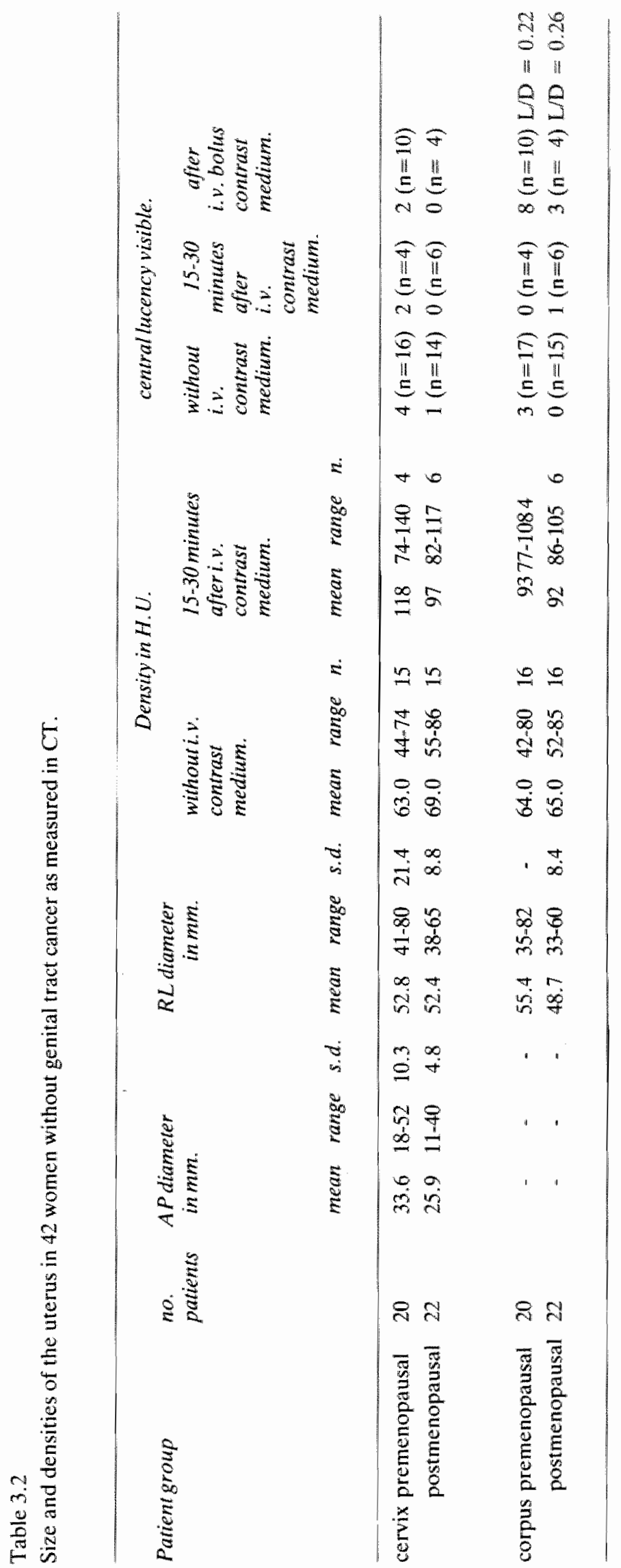


Table 3.3.

Assessment of the cervix borders and parametria in 41 women without genital tract cancer.

\begin{tabular}{|c|c|c|c|c|c|}
\hline \multirow[t]{2}{*}{ Patientgroup } & \multicolumn{3}{|c|}{ lateralcervix-borders } & \multicolumn{2}{|c|}{$\begin{array}{l}\text { parametria with many linear soft } \\
\text { tissue strands. }\end{array}$} \\
\hline & smoolh & $\begin{array}{l}\text { irre- } \\
\text { gular }\end{array}$ & $\begin{array}{l}\text { linear } \\
\text { soft tissue } \\
\text { extensions }\end{array}$ & no & yes \\
\hline $\begin{array}{l}\text { premenopausal } \\
(\mathrm{n}=19)\end{array}$ & 14 & 20 & 4 & 19 & 19 \\
\hline $\begin{array}{l}\text { postmenopausal } \\
(\mathrm{n}=22)\end{array}$ & 34 & 6 & 4 & 37 & 7 \\
\hline
\end{tabular}

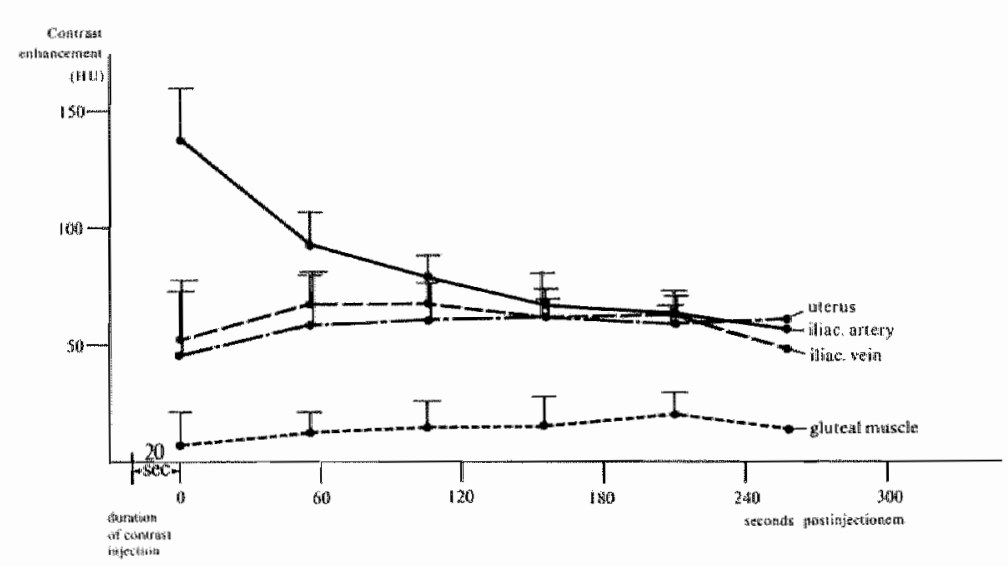

graph. 3.1

Average contrast enhancement of uterus, gluteal muscle, iliac artery and vein after bolus contrast injection ( 30.4 grams of iodine).

between central lucency and surrounding tissue were 11,12 and $23 \mathrm{HU}$. The central lucencies in the cervix were barely visible and the description inhomogeneous would be better. Of the 14 patients receiving bolus contrast injection, 11 had central lucency in the corpus averaging $13.6 \mathrm{~mm}$ in diameter on post bolus contrast films, with a maximum density difference compared to surrounding tissue of between 6 and 97 Hounsfield Units. All patients with a lucency in cervix or corpus on the pre contrast scans had a clearly visible lucency if the scan was repeated after bolus contrast injection. In 3 cases, a ring of central contrast enhancement was briefly visible in the cervix in the film immediately after bolus injection ("arterial phase", fig. 3.6d.).

Of the 14 patients receiving bolus contrast injection, the pattern of bolus contrast enhancement of the uterus was studied in the 10 pattients meeting the following criteria :

1. Density greater than 1.50 Hounsfield Units in the iliac artery at time 0 .

2. Density difference between iliac artery and vein of least 50 Hounsfield Units at time 0.

3. A minimum of three post contrast slices through the uterus. 
In the 10 selected cases, at time 0 , the mean ilac artery density was 183,9 . HU and the mean arteriovenous difference was $81 \mathrm{HU}$. One patient had 3 uterine slices, 4 patients had 4,2 patients 5 , and the remainder 6,7 and 8 slices respectively. Graph 3.1 plots the average contrast enhancement against time for these 10 patients.

\section{Discussion}

Ideally, criteria of normality should be based on a study of normal healthy subjects, but with $\mathrm{CT}$ this cannot be considered ethically justified. The validity of this study is therefore based on the assumption that the absence of clinical evidence of genital tract cancer implies normality of the genital organs, regardless of the underlying disease for which CT was indicated. The cross-sectional size of cervix and uterine corpus showed great variability, as. indicated in table 3.2, and, although sharp demarcation of cervix from bladder and rectum permitted relatively precise measurements of the AP diameter of cervix in all cases, the lateral diameter was much less easily defined, because of frequent irregularities of the lateral cervix borders. Such irregularities, with linear strands of soft tissue density in the parametria, were present in many patients, particularly in the premenopausal group, and will be discussed further in 3.5.2. In chapter $V$ the CT dimensions of corpus and cervix were compared with the dimensions of fresh surgical specimens (table 5.6), indicating an enormous discrepancy between measurements at the level of the cervix and a relatively good correlation at the level of the corpus. It may be that the vaginal vault is also measured with the cervix in CT.

Although contrast enhancement of organs and pathological structures in general by both bollus injection and infusion techniques are well established in the literature (Fuchs, 1981), little research has been specifically devoted to the uterus and gynaecological tumours. However, Hamlin and Burgener (1981) state that differentiation of uterine malignancy from normal myometrium is often possible after infusion of $300 \mathrm{ml}$ diatrizoate $30 \%$, with scanning ideally at the end of the infusion, because contrast accumulation in the myometrium, though extensive, is delayed and is washed out very slowly. In another paper (Burgener and Tamlin 1981), they suggest that contrast enhancement of an organ is related to the amount of smooth muscle it contains and to the amount of iodine administered. The features of a delayed uptake and a long wash-out period are supported by the results of our study (compare uterine densities without i.v. contrast and 15-30 minutes after i.v. contrast. table 3.2). The time of maximal contrast enhancement and therefore the best scanning time would appear to be between one and five or more minutes after injection. A uterine density enhancement of at least 100 Hounsfield Units after rapid contrast infusion is quoted by Burgener and Hamlin (1981) but was never achieved in our material, although we used almost the same amount of iodine (30.4 grams 1). Burgener and Hamlin (1981) conclude from a review of 89 pelvic CT scans that "intravenous contrast enhancement should be routinely performed in the demonstration and staging of all pelvic tumours" and "because concealment of tumour after contrast administration does not occur in pelvic organs, a pre contrast scan is not necessary".

\subsubsection{Uterus and related tissue}

The following description is based not only on the literature but also on additional information gained from the foregoing retrospective study. 

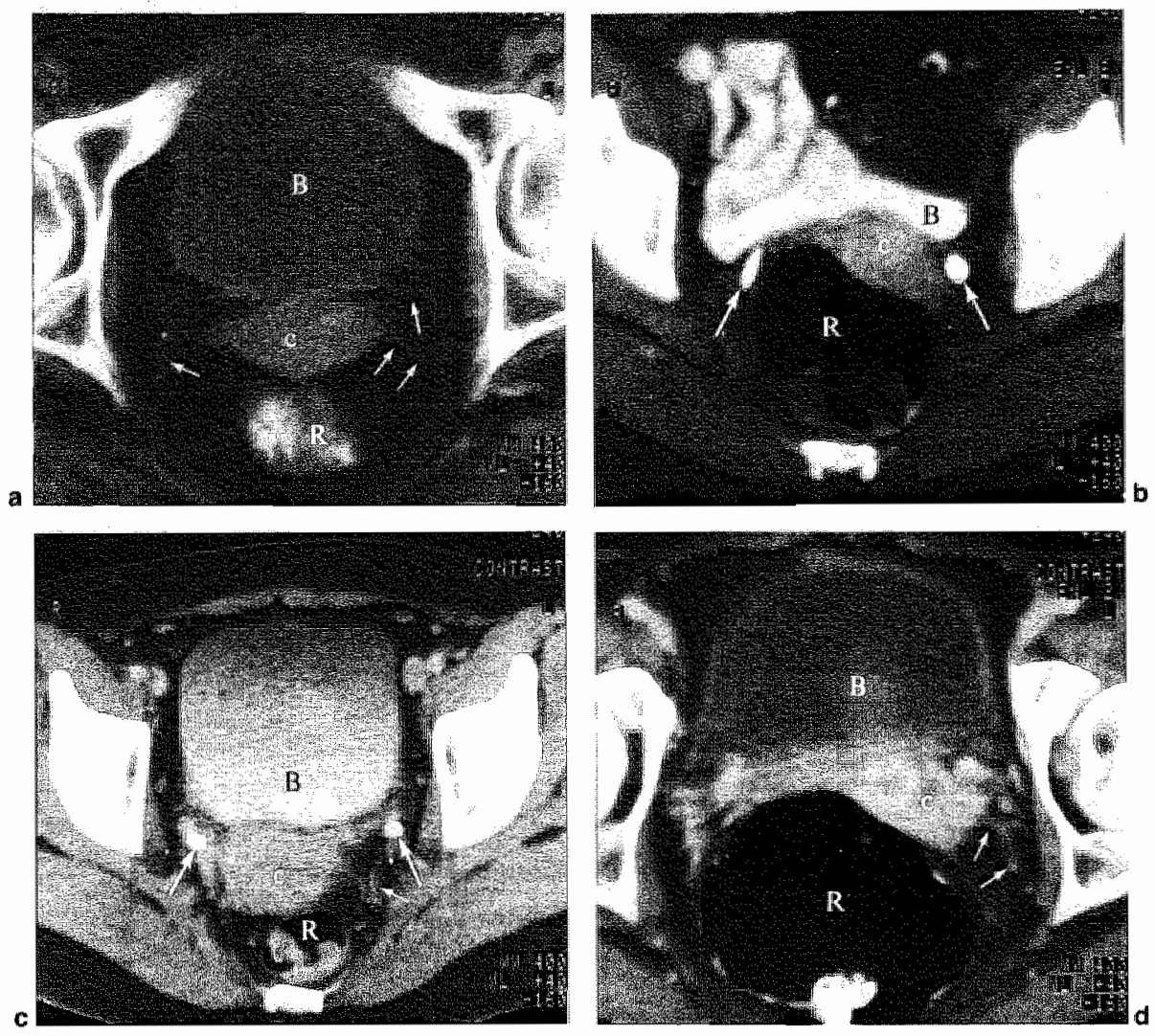

fig. 3.6.

Different scans of a nomal corvix.

all. Phatin scan: normal oval cervix (c) with smooth lateral borders and only some strands of soft tissu* density in the pentenetria (small arrows).

b. Post contust scan: normal oval cervix (c) with smooth lateraborders and some soft tissue densities in the pantimetria. Note the oomt assted ureters (large arrows).

c. Post contrust soan: latge, round, irrigular bordered cervix (c) with strand of soft tissue density in the parametria (small arrows) and contrasted areters (barge arrows).

d. Post contrast scan: flat or oval ecrvix (c) with a contral ring of contrast enhancement and many linctil soft tisswe extensions into the paramerra (small arrows). The contrast enhaneenent of these soft tissue lines indicates their vascular component ( $\mathrm{R}=$ rectum, $\mathrm{B}=$ bladder).

The uterus can be anatomically divided into three parts, but transition from one part to the next cannot be distinguished on $\mathrm{CT}$.

1. The fundus or uppermost part of the uterus, together with the Fallopian tubes on each side is often seen in a partial volume effect with bowel loops.

2. The corpus or body of the uterus is separated from the bladder and rectum by the uterovesical and utero-rectal (pouch of Douglas) pouches respectively.

3. The cervix is the least mobile part of the uterus and can be divided anatomically into supravaginal and vaginal portions. It is visible as a flat or oval mass and can only be distinguished from the vagina with a contrast marker in the vagina. The use of a tampon, as in this study, is simple, but not very accurate, since it is not always in the very top of the 
vagina. Other methods of cervix identification in $\mathrm{CT}$ include instillation of positive contrast medium into the vagina, marking the posterior fornix, or application of an opacified cap. However, the fact that the ureters turn medially at the level of the cervix enables the cervix to be correctly located in many patients who are scanned following intravenous contrast medium. Although the uterine cavity is usually invisible on CT (Steinbrich and Friedman, 1981 ), in 3 of the 32 women studied, a region of lower density on pre contrast scans was visible in the centre of the corpus. All these patients were aged less than 50 years, and, as in ultrasonography, this effect may be temporally related to the menstrual cycle. However, in 11 of the 14 women described in 3.5.1. a central lucency was seen following bolus contrast injection. None of the total 42 women had a curettage prior to CT scan.

The uterus is tightly enclosed by peritoneum, which is reflected from the posterior aspect of the bladder onto the isthmus of the uterus and then passes upwards on the vesical surface of the corpus, forming the utero-vesical pouch, though this is often invisible on CT. After passing over the fundus, the peritoneum continues downwards over the corpus "cervix and upper part of the vagina, from which it is then reflected onto the anterior aspect of the rectum, forming the utero-rectal pouch. On each side of the uterine body, the two leaves of peritoneum join to form the broad ligament, which encloses between its two layers some connective tissue and smooth muscle, known as the parametrium close to the uterus and uterine tube. The parametrium is not abundant but increases in amount below and laterally and within it dots or thin lines of soft tissue density are frequently visible in CT (fig. 3.6). These lines may start in the cervix and enclose the ureters and sometimes run as far as the pelvic sidewall. After running laterally, they frequently turn more ventro-dorsally and run to the sacrum. Such lines may represent vasculature in the fibrous tissue skeleton described by De Blok (1982). He studied the anatomy of the fibrous connective tissue of the female pelvic region by blunt dissection, histological serial thick section techniques and transparent analytical glass-plate reconstruction techniques and described a skeleton of connective tissue involving adipose tissue, muscles, vessels, lymphatic structures and viscera in an organized way. The utero-sacral ligaments were found to be parts of the entire connective tissue skeleton and not isolated dense bands of collagen fibres. The pelvic viscera were connected to the walls of their own space via radially orientated systems of connective tissue septa containing supplying arteries and veins. These septa were very thin and it

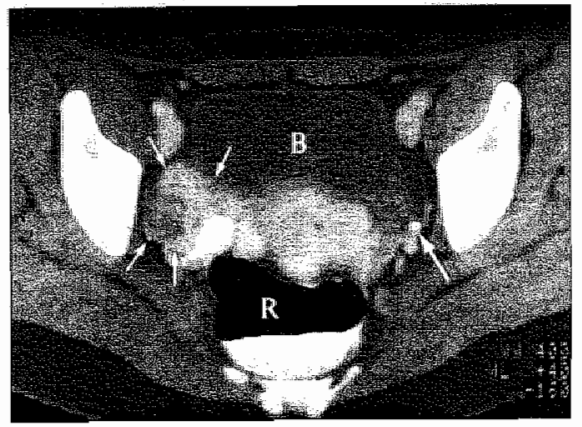

fig. 3.7 .

Post contrast sean just above the level of the cervix: Note the soff tissue mass extension on the right (small arrows) and the contrasted ureter on the left (large arrow). This patient had a staging laparotomy because of lymphoma and no abnormalities were found in the pelvis $(B=$ bladder, $R=$ rectum). 

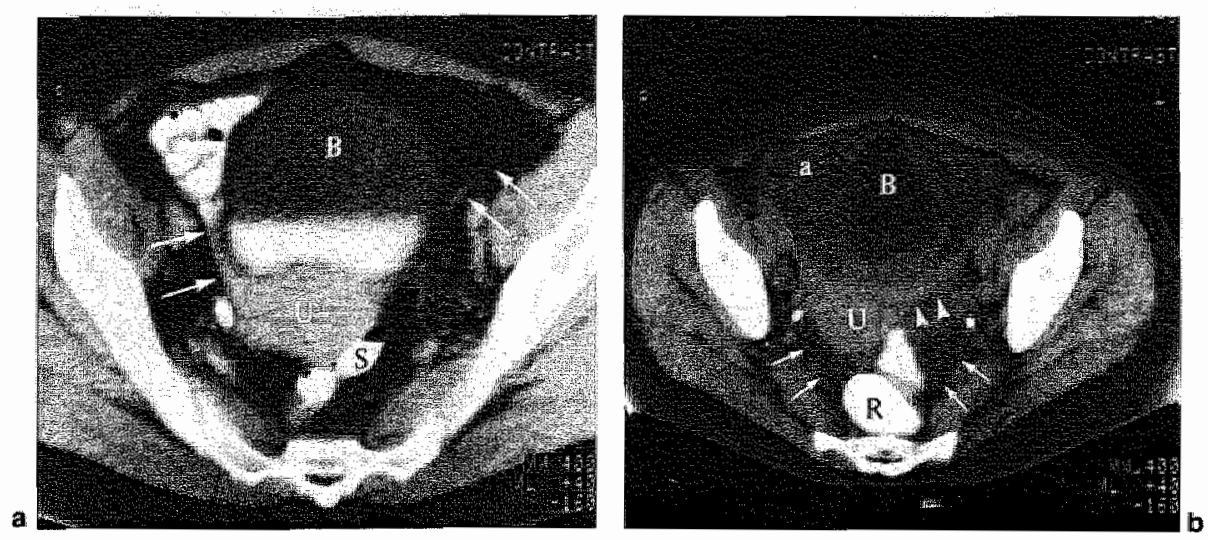

fig. 3.8 .

Peritoneum and ligaments: al scan through the uterus just below the fundus demonstrates two lines of soft tissue density (arrows) running ventrally which may represent the round ligaments.

b. Scan through the uterine body of a patient with ascites (a). The smal arrows indicate the peritoneum and the arrowheads the broad ligament. ( $U=$ uterus, $B=$ bladder $R=$ rectum, $S=$ sigmoid)

would seem unlikely that they would be visible in CT, although it is remarkable that thin lines in the parametria orientated in the same manner as described by De Blok (1982) are often seen in CT. Furthermore, enhancement of these lines after i.v. bolus contrast injection may be visible, indicating a vascular component (fig. 3.6d.). These septa probably allso contain the lymphatics and would therefore be one of the first locations of tumour spread. However, linear soft tissue strands of cervix into the parametria are often visible in "normal" women and must not be mistaken for early tumour spread. We have therefore tabulated the presence or absence of soft tissue strands in the parametrium and described the cervical borders in patients with no evidence of genital tract cancer (table 3.3). The results clearly indicate that irregular lateral cervical borders, with or without linear soft tissue extensions into the parkmetrium, are visible in the majority of women below the age of 50 years and in many women over 50 years, and are the refore not a sign of tumour spread, as put forward in literature (Walsh and Goplerud, 1981, Langer et al., 1981, Haertel, 1980). The broad ligament also encloses the Fallopian tube, ovarian and round ligaments, uterine artery and vein, utero-vaginal nerve plexus and part of the ureter. It is often visible in CT, particularly in the presence of ascites (fig. 3.8). The round ligament is a cord of fibrous tissue attached to the uterus, just below and in front of the insertion of the Fallopian tube, running ventrolaterally forming a relief in the anterior layer of the broad ligament, then running through the inguinal canal and finally disappearing in the subcutaneous tissue of labium majus.

\subsubsection{Uterine adnexa}

Normal uterine adnexa (ovaries, tubes and ligaments) can be visualized in CT but are often not identifiable as such between bowel loops. In the 42 pelvic CT scans of women with no gynaecological malignancy, the adnexa could be recognized in $57 \%$ of the premenopausal group and $13 \%$ of the postmenopausal group, representing $34.5 \%$ overall. 29 ovaries were visualized ( 22 being solid and 7 cystic), their average diameter being $28 \mathrm{~mm}$ in the premenopausal group and $19 \mathrm{~mm}$ in the postmenopausal group. Cystic ovaries were only 

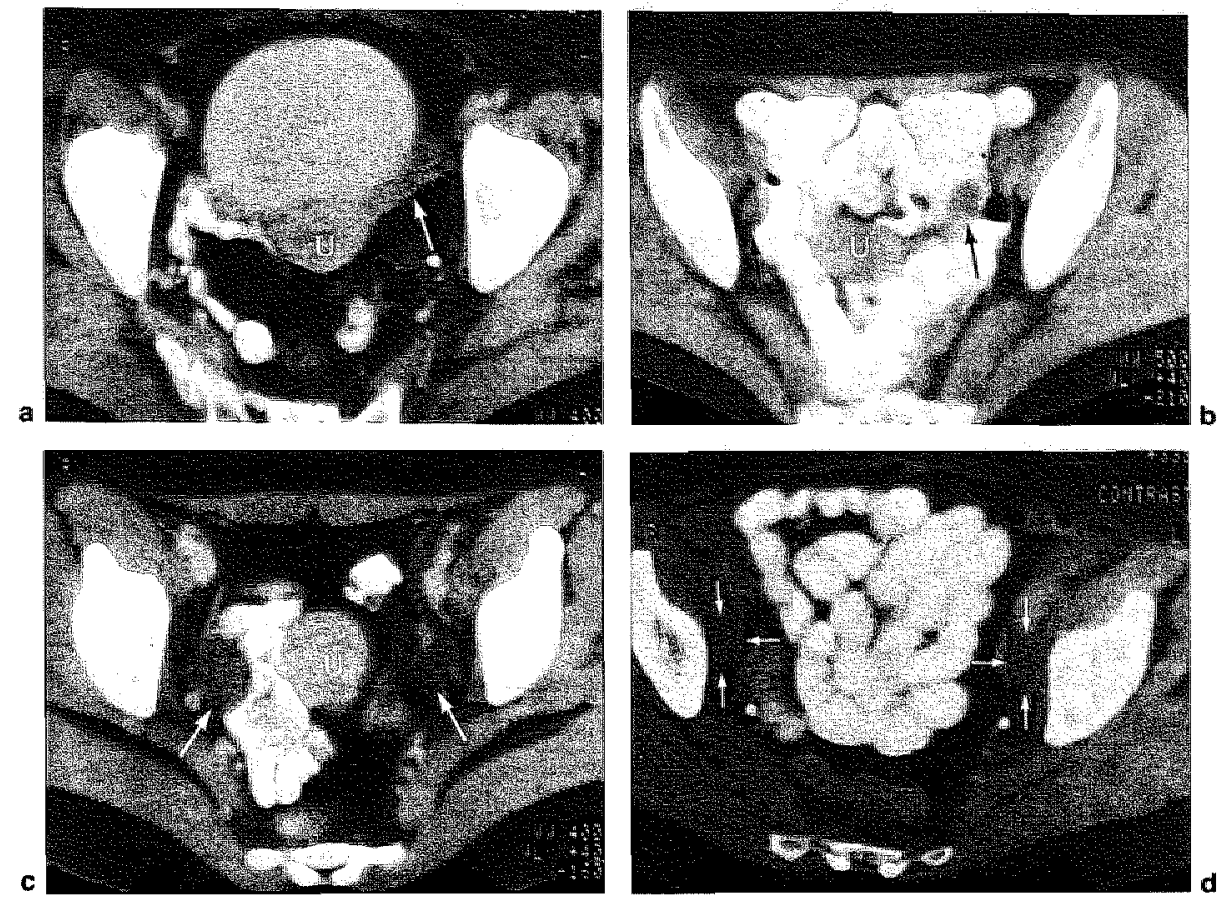

fig. 3.9.

a and $\mathbf{b}$ : normal ovaries (large arrows), $\mathbf{c}$ : small ovarian cysts (large arrows), d: enlarged pelwic lymph nodes (small arrows) in the obturator fossa. (U = uterus)

seen in the premenopausal group. Their location in the peritoneal cavity showed considerable variation. They were usually identifiable just medial to the ureter and thus against the parietal peritoneum (fig. $3.9 \mathrm{a}$ and $\mathrm{c}$.) with an area of fat density (representing the extraperitoneal space) visible between the ovary and bony pelvic wall. However, small masses, probably representing the ovaries, were frequently visible alongside the uterus and not separated from it by a fat line (fig. 3.9b.) and in one case a cystic structure of $30 \mathrm{~mm}$ diameter was visible in the pouch of Douglas. Particularly in the obturator fossa, ovaries and enlarged lymph nodes can be easily confused (fig. $3.9 \mathrm{~d}_{\text {. }}$ ), but in this area, the ovary is medial and a node lateral to the ureter and a fat line is normally visible between owary and bone. In no case was an ovary visible directly against the iliac bone, though this may be possible in women with very poor fat planes.

\subsection{Bladder}

Bladder appearance in CT depends on its degree of filling. A urine-filled bladder is necessary to elevate bowel loops out of the pelvis and deflex the uterus, thus eliminating artificial images caused by non-opacified bowel loops and partial volume effects between bowel, uterus and bladder. Examination of the bladder wall is difficult if the bladder is filled with high density contrast, and impossible if the bladder is empty, its superior surface being very close to or even compressed by the body of the uterus, and, lying parallel to the scan 
plane, indistinguishable from it in CT because of partial volume effects. With a filled bladder, the wall is sharply delineated between low density urine and surrounding fatty tissue, and is normally $1-3 \mathrm{~mm}$ thick, though is frequently thickened after radiotherapy and chenotherapy. The ureter crosses the bifurcation of the common iliac artery ventrally and passes downwards on the lateral pelvic wall, where it is closely related to the peritoneum and to the medial border of the ovary, but is never identifiable without i.v. contrast unless it is dilated. In the lower part of the pelvis, it passes posterior and inferior to the uterine artery, and, after reaching a point about $2 \mathrm{~cm}$ lateral to the cervix turns antero-medially to the bladder and runs slightly upwards, lateral to the vagina and into the bladder.

\subsection{Rectum}

The rectum is situated in the subperitoneal space, beginning at the mid-point of the sacrum. It is partly covered by peritoneum ventrally and usually surrounded by fatty tissue, which is always visible between rectum and sacrum. Soft tissue density in this space is almost always pathological. At the level of the cervix, thin strands around the rectum from cervix to sacrum are visible, probably representing the connective tissue septa described by de Blok (1982). Some centimeter caudally, a thin line of soft tissue density around the rectum is visible, representing the caudal part of levator ani, separated from the rectum by a thin fat plane. The external sphincter receives important support from levator ani and blends with it. Vagina and rectum are sometimes separated by a very thin fat plane, but are usually so close together that no interface is seen.

3.8. Vagina

The vagina appexs in C $T$ as a flat or oval mass of soft tissue density between rectum and bladder, alt hough the interfaces with these structures are frequently invisible. Its upper dorsal part, however, is covered by peritoneum and small bowel loops may be seen in the pouch of Douglas. Caudally, it runs through the levator thatus and the levator muscle is sometimes visible. A tampon is frequently inserted in the vagina to aid localization of the cervix and appears as a central air density.

\section{References chapter III}

DE BLOK, S.: Spatial architecture of musculowfibrous tissuc in the female pelvic region.

Thesis: Amsterdam, 1982.

BRUN, B., LAURSEN, K, SORENSEN, I.N., LORENTZEN, J.E. and KRISTENSEN, J.K.. CT in retroperitoneal fibrosis.

Am. I. Roentgenol. 137: 535-538, 1981 .

BURGENER, F.A and HAMLIN, D.J.: Imtravenous contrastenhancement in computed tomography of pelvis malignancies.

Fortschr. Röntgenstr. 134 (6), 656-661, 1981.

CALLEN, P.W. KOROBKIN, M., ISHERWOOD, 1.: Computed tomographic evaluation of the retrocrural prevertebral space.

Am. J. Roentgenol 129: $907-910,1977$. 
DONOVAN, P.H.J., ZERHOUNI, E.A., SIEGELMAN. S.S.: CT of the psoas compartment of the retroperitoneum.

Sem. in Roentgenol. 16: 241 - 250, 1981.

FISCH, A.E., BRODEY, Ph.A.: Computed tomography of the anterior abdominal wall: Normal anatomy and pathology.

J. of Comput. Assist. Tomogr. 5: 728 - 733, $198 \mathrm{y}$.

FUCHS, W. A.: Contrast Enhancement in Body COMPUTERISED Tomography, 11 th Internationat Symposium, Bern.

Georg Thieme Verlag, Stuttgart-New York, 1981 .

GARDNER, E., GRAY, D.J., ORAHILLY, R.: Anatomy, a regional study of human structure. W.B. Saunders Company. Philadelphia, 1975.

GRANT, J.C.B.: An atlas of anatomy.

The Williams \& Wilkins Co. Baltimore, 1978.

HAERTEL, M.: Zur Computertomographie gynäkologiseher Karzinome.

Fotschr. Röntgenstr. 132:652-657, 1980.

HARELL, G.S. BREIMAN, R.S., GLATSTEIN, E.J., MARSHALL. W.R., CASTELLINO,

R.A.: Computed tomography of the abdomen in the malignant lymphomas.

Rad. clin. of Nrth America 15, 391 - 400, 1977.

HENDRIKSEN, E.: The lympiratic spread of carcinoma of the cervix and of the body of the uterus. Am. J. Obstet. Gynecol. 58: $924-942,1949$.

HODSON, N.J., HUSBAND, J.E., MACDONALD, J.S.: The role of computed tomography in the staging of bladder cancer.

Clin. radiol. 30: $389-395,1979$.

JACKSON, R.J.A.: Topography of the Hiopelwic lymph nodes.

Am. J. Obstet. Gynecol. 8:1118-11:23, 1969.

JASINKSKI, R.W, YANG, Ch.F., RUBIN, J.M.: Vena cava anomalies simulating adenopathy on computed tomography.

J. of Comp. Tomogr. 5: $921-924,1981$.

KOLBENSTVEDT, A.: Lymphography in the diagnosis of metastases fron carcinoma of the uterine cervix stages I and II.

Acta Radiologica Diagnosis, $16: 81-97,1975$.

KOROBKIN, M.: Computed tomography of the retrope ritoneal vascalature and lymph nodes.

Semin. in Roentgenol. 16:25»-267, 1981 .

LANGER, M., LANGER R, SCHUMACHER, K.A., MAIER, W.: Darstellbarkeit und

Differenzierungsmöglichkeit benigner und maligner gynäkologischer Tumoren im axialen Computertomogram.

Geburtshilfe Fratuenheilk. 41:551-555, 1981.

LAWSON, Th.L., FOLEY, W.D., CARRERA, G.F., BERLAND, L.L.: The sascroiliac joints:

Anatomic, plain roentgenographic, and computed tomographic analysis.

J. Comp. Assist. Tomogr. 6:307 - 314. 1982.

LEVITT, R.G., SAGEL, S.S., STANLEY, R.J. et al.: Computed tomography of the pelvis.

Semin. Roentgenol. 13: 193-200, 1978.

LYONS, E.A.: A colour atlas of sectional anatomy: Chest, abdomen and pelvis.

The C.V. Mosby Company, St. Louis, 1978.

MILLER, E.I., THOMAS, R.H., LINES, P.: The atrophic postmenopausal uterus.

J. Chim. Ultrasound $5: 261 \cdot 263,1977$.

PATRIOUIN, H.B.: The lymph node-normal and neoplastic: a radiological - pathological correlation.

J. Can. Assoc. Radiol. 18: $452-458,1967$. 
REDMAN, H.C., GLATSTEIN, E., CASTELLINO, R.A., FEDERAL, W.A.; Computed tomography as an adjunct in staging of Hodgkin's disease and non Hodgk in's lymphomas.

Radiology, $124: 381-385,1977$.

STEINBRICH, W., FRIEDMAN, G.: CT derOrgane des kleinen Becken-normale und pathologische Anatomie, Indicationen, Ergebnisse.

Fortschr, Röntgenstr. 134, 2: 115-122, 1981 .

TISNADO, J, AMENDOLA, M.A., WALSH, J.W., JORDAN, R.L., TURNER, M.A., KREMPA. $J .:$ Computed tomography of the perineum.

Am. J. Roentgenol. 136: 475-481, 1981 .

WALSH, J.W., AMENDOLA, M.A., KONERDING, K.F., TISNADO, J, HAZRA, T.A.:

Computed tomographic detection of pelvic and inguinat lymph-node metastases from primary and recurrent pelvic malignant discase.

Radiology 137: 157 - 166, 1980.

WALSH, J.W., GOPLERUND, D.R.; Prospective comparison between clinical and CT staging in primary cerwical carcinoma.

Am. J. Rocntgenol. 137: 997 - 1003, 1981.

ZELCH, M.G., HAAGA, J.R.: Clinical comparison of computed tomography and lymphangiography for detection of retroperitoneal lymphadenopathy.

Rad. Clin. of Nith America 17: 157 - 158, 1979. 


\section{Chapter IV}

\section{Cervical cancer}

\subsection{Introduction}

The prognosis of cervical cancer is determined by the stage of the disease at the time of diagnosis, as evidenced by 5 year survival rates of $87 \%$ for stage $1 \mathrm{~b}, 70 \%$ for stage $11 \mathrm{a}, 61 \%$ for stage IIb, 49\% for stage III and $16 \%$ for stage IV (Timmer 1982). Accurate staging of the disease is important not only for the choice of treatment and for accurate prognosis, but also to facilitate comparison of different treatment methods. For this reason in 1929 the Radiologic subcommission of the cancer commission of the League of Nations Health Organization recommended a classification of cervical cancer based on anatomical borders. This classification has been frequently revised and in 1970 in New York the cancer committee of the F.I.G.O. (Fédération International de Gynécologie et d' Obstétrique) determined the presently accepted classification (F.T.G.O. 1971).

Table 4.1.

Definitions of the different clincal stages in carcinoma of the cervix (F.I.G.O., 1971)

\section{Non invasive carcinoma:}

stage 0: $\quad$ carcinoma in situ, intra epithelial carcinoma

\section{Invasive carcinoma:}

stage I: carcinoma strictly confined to the cervix

a: the cancer cannot be diagnosed by clinical examination

b: $\quad$ all other cases of stage 1 .

stage II: the carcinoma extends beyond the cervix but has not extended on to the pelvic wall

al: the cancer involves the upper two third of the vagina only, withoul parametrium infiltration

b: there is parametrium inwolvement

stage III: the cancer has extended on to the pelvic wall. On rectal examination there is mo caneer-free space between the tumour and the pelvic wall.

The tumour involves the lower third of the vagina.

a: no extension on to the pelvic wall

b: $\quad$ extension on to the pelvic wall

stage IV: the carcinoma has extended beyond the true pelvis or has involved the mucosa of the bladder or rectum.

\subsection{F.I.G.O. Classification of cervical cancer}

The report accepted by the general assembly of F.I.G.O. in New York (1970) states: "In order to obtain a correct and uniform classification and staging, the cancer committee considers it important that exclusively such examinations should be used which can be carried out in any hospital by the physicians and surgeons." According this, the classification is based on clinical examination, colposcopy, endocervical curettage, X-ray examination of 
lungs and skeleton and urography (F.I.G.O. 1971), and therefore the results of more sophisticated techniques like lymphography, arteriography and CT cannot influence the F.I.G.O. classification staging (table 4.1). However, F.I.G.O. staging of cervical cancer is largely dependent on physical examination, lacks objectivity and reproducibility and is dependent on the experience of the examiner. To ewaluate the role of experience, Friedman and Taylor (1965) reviewed the hospital records of 127 cases in which pre-operative staging had been recorded by a resident and then by a gynaecologist, and in more than half of the cases the stage was changed (51.2\%), 31.5\% staged down (less advanced disease) and $19.7 \%$ staged up (more advanced disease). Heyman et al. (1953) carried out an experiment in which two experienced doctors independently examined and staged 161 patients with cervical cancer, and demonstrated a staging difference in 18 cases $(11.2 \%)$.

Because clinical assessment is subject to examiner variability, and takes no account of distant metastases in lymph nodes, liver etc., many authors subsequently record a "surgical staging". Averette et al (1972) compared surgical and clinical staging in 70 patients. In 27 $(38.6 \%)$, the surgical findings were inconsistent with the clinical staging, 21 (30\%) having more advanced disease, of whom 19 were "regraded" to stage IV by the finding of lymph node metastases (9) and/or bladder or bowel invasion (12) (table 4.2). Van Nagell et al. (1971) compared clinical and surgical staging in 125 patients and found similar differences. the most frequent error being misinterpretation of parametrium involvement. Although both authors regard the surgical finding of metastatic lymph nodes as indicating a clinical staging error, this is not strictly correct, since by definition, F.I.G.O. staging cannot detect the majority of metastatic lymph nodes. Similar comparisons in the assessment of lymph node metastases have been made by several other authors (table 4.3). The morbidity and mortality associated with surgical staging, and in particular para-aortic lymph node biopsy and dissection, preclude its use for routine staging. and therefore several non-invasive procedures are used to assist in staging carcinoma of the cervix.

Table 4.2.

Correlation between clinical and surgical staging in 70 patients with cervical cancer (Averette et all., 1972).

\begin{tabular}{|c|c|c|c|c|c|c|}
\hline \multicolumn{7}{|c|}{ Clintcal staging } \\
\hline surgicalsraging & $I$ & $M A$ & $M B$ & III & $r$ & Total \\
\hline I & 32 & 1 & & & & 33 \\
\hline $11 \mathrm{~A}$ & 3 & 5 & 1 & & & 9 \\
\hline IIB & 1 & & 4 & 2 & & 7 \\
\hline III & & & & 0 & & 0 \\
\hline IV & 4 & 3 & 4 & 8 & 2 & 21 \\
\hline Total & 40 & 9 & 9 & 10 & 2 & 70 \\
\hline
\end{tabular}


Table 4.3

Lymph node metastases in patients with cervical cancer found during surgical staging with lymph node dissection (several authors).

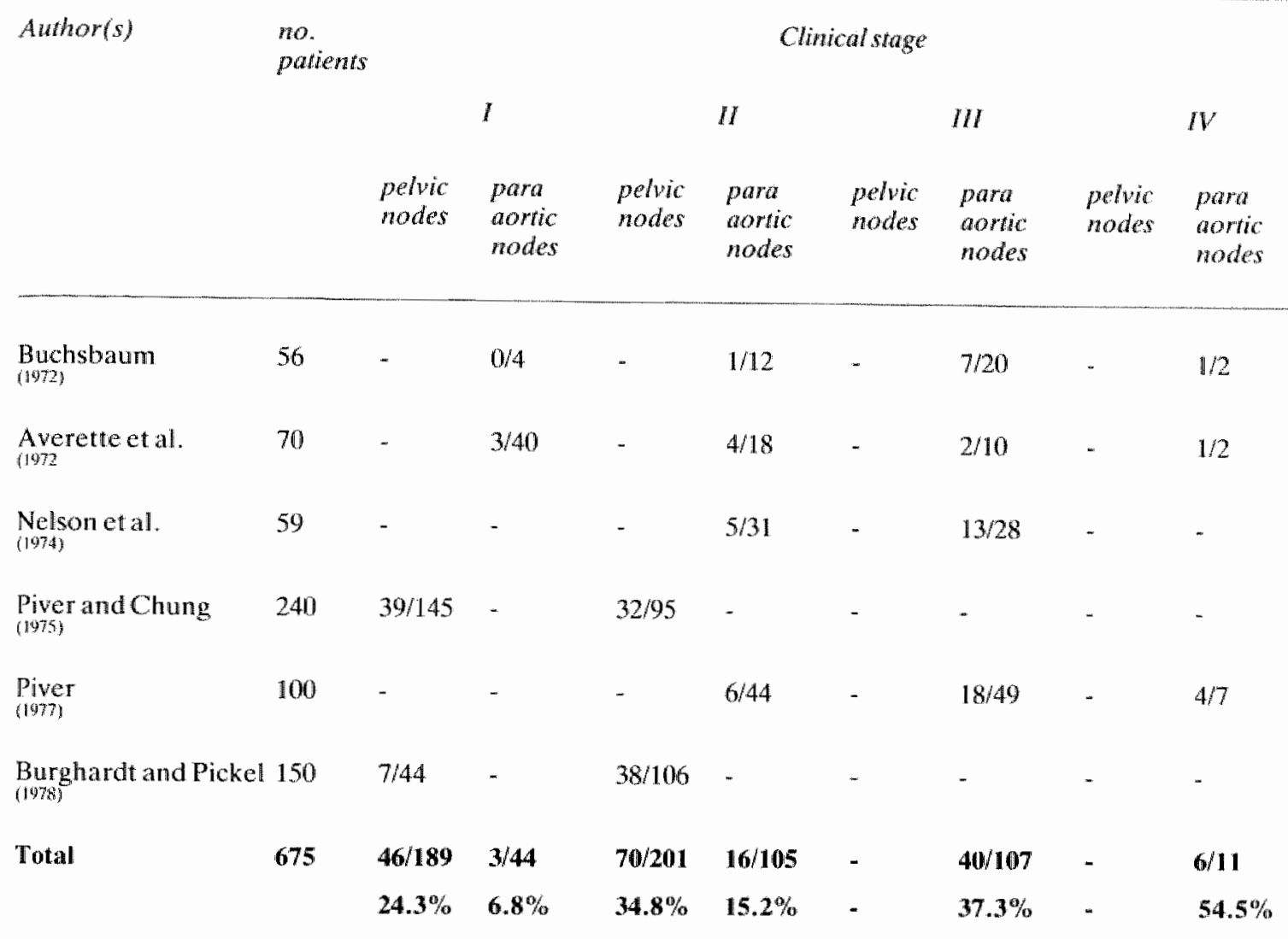

\subsection{Review of literature concerning the use of special diagnostic procedures in staging cervical cancer.}

\subsubsection{Introduction}

Because spread of this disease is principally to the parametrium or by direct invasion of adjacent organs, intravenous urography, cystoscopy, barium enema and proctoscopy are frequently used as staging procedures. The incidence of abnormalities detected by these procedures is directly related to the extent of local disease found at clinical staging. When distant metastases occur, they do so early and usually by the lymphogenic route (table 4.3), and many authors therefore advocate lymphangiography. Although bloodborn metastases are comparatively rare, a base-line chest $X$-ray is frequently performed, and some authors have considered the use of liver imaging procedures. 


\subsubsection{Intravenous Urography (I.V.U.)}

Urography is frequently used in staging, and is a mandatory part of the F.I.G.O.

classification. Tumour may cause pressure and invasion of ureters and bladder, either directly or wia involved lymph nodes. The possible resultant I. V.U. abmormalities are unior bilateral partial or complete ureteric obstruction, with or without displacement, and distortion of bladder outline. Many authors record the relative incidence of such abnormalities in the different clinical stages based on physical examination only (table 4.4.). Bosch et al. (1973) state that, in pre-treatment assessment, mild unilateral hydronephrosis is not of serious significance, whereas moderate or severe hydronephrosis, or renal failure, are ominous prognostic findings. The significance of $\mathbb{1}$. V.U. abnormalities is reflected in the official F.I.G.O. report (F.I.G.O. 1971), which states: " the presence of hydronephrosis or non-functioning kidney, due to stenosis of the ureter by the cancer. permits the allotment of a case to stage III, even if, according to the other findings, the catse should be alloted to an earlier stage".

Table 4.4.

Abnormal I.V.U. in patients with cervical cancer related to the clinical stage (several authors)

\begin{tabular}{lcccc}
\hline Awhors & \multicolumn{5}{c}{ Chinical Stage } \\
& $I$ & $I I$ & $I I I$ & $I V$ \\
\hline Waggoner and Spratt(1969) & $8 / 129$ & $20 / 256$ & $83 / 374$ & $99 / 136$ \\
Van Nagell et al. (1975) & $4 / 181$ & $12 / 199$ & $40 / 124$ & $30 / 79$ \\
Griffin et al. (1976) & $0 / 111$ & $2 / 167$ & $26 / 46$ & $3 / 4$ \\
Szabó (1981) & $0 / 151$ & $4 / 126$ & $11 / 71$ & $3 / 7$ \\
Total & $12 / 572$ & $12 / 748$ & $165 / 615$ & $135 / 276$ \\
& $(2.1 \%)$ & $(5.1 \%)$ & $(26.8 \%)$ & $(48.9 \%)$
\end{tabular}

\subsubsection{Cystoscopy}

Cystoscopic abnormalities in cervical cancer are rare, and usually restricted to clinical stages III and IV (Griffin et al, 1976. Szabó 1981, Van Nagell et al. 1975, Shingleton et al 1971). Szabo (1981) therefore considers cystoscopy indicated only in clinical stages III and IV, while Griffin at al. (1976) also include stage IIB because they consider the distinction between stage IIIB and more advanced disease to be very difficult. Regarding cystoscopic abnormalities actually found, F.I.G.O. (1971) considers bullous oedema as such to be insufficient reason to allot a case to stage IV. 


\subsubsection{Barium enema and proctoscopy}

Barium enema abnormalities are rare in cervical cancer. Szabo (1981) found none in 350 new cases, and Griffin et al. (1976) found 7 in 209 new cases, but all 7 also had positive proctoscopy. Barium enema therefore had nothing to add to proctoscopy and both authors conclude that it should be abandoned as a routine staging procedure

\subsubsection{Lymphangiography}

The value of lymphangiography in staging cervical cancer is the subject of much discussion. Piver and Barlow (1973) found a correlation of $95.8 \%$ between lymphangiography and para-aortic lymphadenectomy or aortic node biopsy in 26 untreated patients, whereas Brown et al. (1979) reported a correlation figure of only $57 \%$ in 21 patients. Lagasse et al. (1979) compared lymphangiography with para-aortic and pelvic lymphadenectomy in 95 patients and found a correlation of $67 \%$. Recently Szabo (1981) correlated lymphangiographic and surgical findings (Wertheim-Meigs procedure) in 91 patients with stage I or IIA cervical cancer, and, although the accuracy of lymphangiography was $73 \%$, he had $71 \%$ false-positives and $16 \%$ false-negatives. Kolbenstvedt (1975) stated that the choice of treatment in stages I and II should not be altered on the basis of lymphangiography alone. Lagasse et al. (1979) and Brown et al. (1979) shared this opinion not only for stages I and II, but for stage III also.

\subsubsection{Liver imaging procedures}

Bloodstream spread of cervical cancer is rarely evident at the time of diagnosis. Surgical staging in stage IT, III and IV cancer yielded an incidence of liver metastases ranging from 4 to 6\% (Piver and Barlow 1974, Buchsbaum 1972, Guthrie et al. 1974). Szabó (1981) reviewed radionuclide liverscans in 340 new cases of cervical cancer (all stages) and found focal liver defects in only 4 patients, three of which were simple cysts. The fourth was histologically proven metastases in a patient who already had abnormal liver function tests and he concluded that radionuclide liver scan is not indicated in new cases of cervical cancer with normal liver function tests. It is generally accepted in the literature that radionuclide liver scans do not yield a useful differentiation between metastases, cysts, haemangiomata or other focal abnormalitics. Furthermore, anatomical variation, cirrhosis, and compression of the liver by adjacent organs may all cause false positive radionuclide scans (van Engelshoven 1981). Since most of these problems can be resolved by ultrasonography or $\mathrm{CT}$, these techniques are increasingly used as screening procedures for liver metastases.

\subsubsection{Chest X-ray}

Many hospitals perform a routine chest $X$-ray to provide a pre treatment baseline, although the yield of lung metastases in cervical cancer is likely to be no more than $2 \%$ (Parker and Friedman 1966, Griffin et al. 1976). 


\subsubsection{Computed tomography}

Since the introduction of body CT, many authors have emphasized its importance in demonstrating the extent of disease in cases of cervical cancer. Based on experience with $C T$ in 455 patients with female genttal tract cancer, Breit and Rohde (1979) state that CT is indicated in all cases of cervical cancer to objectify and complete the clinical findings. In a review of 27 patients with benign and malignant uterine tumours, Langer ef al. (1981) consider tumour infiltration of the parametrium to be easily recognizable on CT, and to be reliable evidence of malignancy. They therefore recommend, together with Haertel (1980), the routine use of CT in the after-treatment program of cervical cancer, while mentioning the problems of differentiation between fibrosis and tumour recurrence.

Table 4.5 .

C. criteria in staging cervical cancer and the CT findings in 75 patients with cervical cancer (Walsh and Goplerud, 1981)

FIGOstage CTriteria CT-findings

I and IIA Tumour confined to the cervix

IIB

IIIB extension to pelvic side wall or hydronephrosis

IVA bladder or rectal involvement

IVB

inguinal lymph node metastases. introperitoneal metastases slight cervix enlargement

( $3 \mathrm{~cm}$ in anteroposterior diameter) smooth lateral cervix margins and normal parametrial fat.

disrupted irregular lateral cervix borders with parametrial soft mass extension separated from the pelvic side wall. Anteroposterior diameter of cervix $3-6 \mathrm{~cm}$.

hydroncphrosis or tumour extension to pelvic sidewall, or by direct tumour growth in the obturator internus or piriformis or by linear soft tissue strands extending to these muscles.

nodular indentations along the posterior bladder wall or intraluminal tumour mass or focal loss of the posterior perivesical fat plane surrounding the anterior surface of the rectum

lymph node metastases, adnexal masses 
All these studies, however, are retrospective and the CT criteria of pathology are not precisely defined. Walsh and Goplerud (1981) prospectively correlated CT staging with clinical findings in 75 untreated patients, and with surgical findings in 25 of these, who were operated on. Their CT staging criteria and actual CT findings are tabulated in table 4.5. CT stage was identical to clinical stage in $65 \%$, more advanced in $19 \%$ and less extensive in $16 \%$. In the surgical group, there was exact correlation in $64 \%$ (16 patients), and of the 9 errors, 8 were CT stage IIB, 4 of which showed no evidence of parametrial invasion on pathological examination of radical hysterectomy specimens. In three CT stage IIB patients , surgery showed tumour extension to pelvic side wall. CT correctly identified 11 of the 12 more advanced lesions (IIIB and IV). They concluded that CT was not sufficiently accuratte to differentiate IB and early IIB lesions, and thus alter treatment decisions. Kilcheskiet al (1981) prospectively compared surgical and CT staging in 17 new cases of cervical cancer. and found total agreement in 15 , the two errors being CT stage IIB, but surgical stage IVB on the basis of metastases in lymph nodes $1.5 \mathrm{~cm}$ or less in diameter. They fail to define their CT staging criteria accurately, but conclude, nevertheless, that, after the initial clinical examination, CT should be used to evaluate the pelvis and retroperitioneum in all patients with more than micro-invasive cervical disease, and that intravenous urography and barium enema need not be used as routine screening procedures, since $\mathrm{CT}$ is equally or more effective in detecting bladder or rectal involvement.

Lee et al. (1978) studied CT detection of lymph node metastases by comparing CT and surgical findings in 26 patients with pelvic malignancies, and found an overall accuracy of $73 \%$ and false-negative rate of $40 \%$ and no false-positives. In all false-negative cases, the metastatic nodes were not enlarged. Fourteen of the 26 patients also had lymphangiography as part of the staging procedure and this yielded a false negative rate of $37 \%$ with a false positive rate of $40 \%$. However, they stressed that in the unequivocally abnormal cases, CT is superior to lymphangiography in demonstrating the true extent of tumour involvement, because the abnormality as shown in lymphangiography is often only the "tip of the iceberg". CT was also superior in demonstrating abnormal nodes in the retrocrural space, renal hilus, splenic hilus, porta hepatis and mesenteric areas, where contrast material from lymphangiography does not usually reach. Walsh et al (1980) compared CT findings with pelvic lymph node histology in 35 cases of malignant genito-urinary disease, and found an overall accuracy for $\mathrm{CT}$ of $77 \%$ with a false negative ratte of $15 \%$ and a false positive rate of $33 \%$, and concluded that $\mathrm{CT}$ was a valuable non-invasive screening technique for pelvic node metastases. Walsh and Goplerud (1981) made a similar study in 19 patients with untreated cervical cancer, and found a CT accuracy rate of $74 \%$ with $30 \%$ false negatives and $22 \%$ false positives. It should be noted that in both these studies, the lymph node histology was selective and consequently the accuracy rates quoted may be over-optimistic.

\subsection{A study of CT features in untreated patients with cervical cancer}

\subsubsection{Introduction}

The role of CT scanning in staging untreated patients with invasive cervical cancer is uncertain and three basic questions remain unanswered:

1. Can CT provide objective information about parametrial infiltration ? 
2. Can CT provide objective ewidence and indicate the incidence of metastatic lymph node involvement in untreated cervical cancer?

3. Is CT indicated as a routine procedure in staging untreated patients with cervical cancer?

In an attempt to answer these questions, this study compares $C T$ findings with surgical and/ or clinical findings in 56 consecutive patients with histologically proven invasive cervical cancer. The study was commenced as a retrospective detailed review of hospital records, but the number of patients was too small to draw any definite conclusions, so a prospective study became essential.

\subsubsection{Method and material}

\subsubsection{Retrospective study}

Fifteen consecutive CT scans performed as an initial staging procedure in untreated patients were reviewed by two radiologists without knowledge of the clinical staging. Using the assessment method described in chapter 3.5.1., details of the cervix, its borders and the parametria were recorded. Soft tissue masses in the region of the pelvic neurovascular bundles and the para-aortic nodes were recorded as enlarged lymph nodes if they had a diameter of mote than $1.5 \mathrm{~cm}$. Non-cystic focal liver lesions, suprarenal masses, peritoneal and omental soft tissue masses and skeletal lesions were recorded as possible metastases. The extent of disease was then expressed in CT staging using 2 modifications in the criteria of Walsh and Goplerud (1981) (tabel 4.5). The modifications are that "irregular cervix borders" are omited from CT stage IIB criteria and the single criterion for stage IVB is "presence of distant metastases". The reason for these modifications is the frequent finding of irregular cervical borders in women without genital tract cancer as described in the anatomy study of chapter III. The new CT criterion for stage IVB is a logical interpretation of the F.I.G.O. stage IVB criterion that "the carcinoma has extended beyond the true pelvis".

The hospital records of all the patients were then reviewed in detail, with particular reference to the findings of physical examination under anaesthesia concerning the sife and the extent of parametrial infiltration, and the results of I.V.U. and cystoscopy. In one case, the clinical staging examination had been performed without anaesthesia. Surgical findings in three patients were available and recorded. Tables 4.6 and 4.7 summarize the different clinical staging in these patients, and the operations performed.

Histologically, 13 patients had squamous cell carcinoma, one had adenosquamous cell carcinoma and one adeno carcinoma. Three patients were scanned from perineum to diaphragm, and in the remaining twelve only the pelvis was scanned. In 10 patients, consecutive CT cuts were made throughout the pelvis, and in the remaining five, cuts were made at $4.5 \mathrm{~mm}$ intervals. Intravenous contrast was not used in any of these patients.

\subsubsection{Prospective study}

By agreement with the gynaccologists of five different hospitals, all new patients with invasive cervical cancer were referred to the de Wever Ziekenhuis, Heerlen or the St. Annadal Ziekenhuis, Maastricht for CT scan of pelvis and abdomen as described in chapter II. A total of 41 patients were thus examined, and form the material of this study. One paticnt received no intravenous contrast medium, six patients had a bolus injection 
immediately prior to rapid sequence scanning (RSS) through the liver, 18 had multiple bolus injections to outline vessels and ureters or bladder and 16 had a bolus injection ( 30.4 grams iodine) immediately prior to rapid sequence scanning through the uterus. $\mathrm{All} \mathrm{CT}$ scans were reviewed by two radiologists as described in 4.4.2.1. without knowledge of the clinical staging.

Table 4.6

Clinical stages (F.I.G.O.) in 56 consecutive patients with untreated invasive cervical cancer who are subject of this study (combined retro and prospective studies).

\begin{tabular}{lccc}
\hline Stage & $\begin{array}{l}\text { Retrospective } \\
\text { study }\end{array}$ & $\begin{array}{l}\text { Prospective } \\
\text { study }\end{array}$ & $\begin{array}{l}\text { Total no. } \\
\text { patients }\end{array}$ \\
\hline I & 4 & 17 & 21 \\
IIA & 2 & 5 & 7 \\
B & 5 & 7 & 12 \\
IIIA & - & 1 & 1 \\
B & 3 & 6 & 9 \\
IVA & 1 & - & 1 \\
Nodefinite & & & \\
clinical stage & & 5 & 5 \\
Total & $\mathbf{1 5}$ & $\mathbf{4 1}$ & $\mathbf{5 6}$ \\
\hline
\end{tabular}

Table 4.7.

Different types of operation performed in 26 patients with invasive cervical cancer (retrospective and propective study)

\begin{tabular}{lccc}
\hline Operation & $\begin{array}{l}\text { Retrospective } \\
\text { study }\end{array}$ & $\begin{array}{l}\text { Prospective } \\
\text { study }\end{array}$ & Total \\
\hline AVRUEL & 2 & 11 & 13 \\
AVRUEL (abandoned) & 1 & 5 & 6 \\
Wertheim-Meigs & 2 & 2 \\
Vaginal hysterectomy and Schauta proc. & 2 & 2 \\
Abdominal hysterectomy & & 1 & 1 \\
Diagnostic laparotomy & 3 & 2 & 2 \\
Total & $\mathbf{2 3}$ & $\mathbf{2 6}$ \\
\hline
\end{tabular}

\section{Notes:}

1. AVRUEL = Abdominal Vaginal Radical Uterus Extirpation and Lymphadenectomy.

2. 2 of the abandoned AVRUEL operations were begun for inconclusive clinical staging, but stopped on the finding of parametrial involvement. The remaining 4 were stopped because off positive lymph nodes on frozen section. 
Routine clinicall staging procedure included physical examination (under anaesthesia in 33 cases), chest X-ray, IV.U. (39 patients), cystoscopy (37 patients), barium enema (16 patients) and proctoscopy (17 patients). Physical examination was performed by the referring gynaecologist, usually prior to CT scan, and the findings were recorded on a special form. (appendix I). In six cases, CT scan was performed within the week preceding physical examination, and in the remainder within the 25 days following examination (average 6.7 days). It was agreed that all therapeutic decisions should be made without referrence to CT scan findings, and except when contra-indicated, operation should be performed for all clinical stage I or IIA. Although individual gynaecologists were allowed freedom of choice in the type of surgical procedure, an agreement was made that all would record basic surgical and histological findings on a special form (appendix II). Subsequent detailed histopathological reports were also available for review. Tables 4.6 and 4.7 record the dinical stages found and the operations performed. In two patients no clinical staging procedure was performed, and in 3 the results were inconclusive. In one patient, the clinical staging form recorded stage IIB in the presence of an obstructed ureter on I.V.U. As this was an error by definition, the author restaged this patient form IIB to IIIB. Histologically, 35 patients had squamous cell carcinona, 5 had adeno carcinoma and one had adenosquamous cell carcinoma.

\subsubsection{Results}

Throughout this section, the use of brackets differentiates the results of the retrospective study from those of the prospective study. In all tables where brackets are not used the results refer to the combined study.

Table 4.8

Measurements of the cervix related to age and cllinical stage in 47 patients with cervical cancer (3 patients were cxcluded because of a technically suboptimal pelvic CT Scan, on one patient no floppy disc was available to do measurements and on 5 patients no clinical stage was avallinble.

\begin{tabular}{|c|c|c|c|c|c|c|c|c|}
\hline \multirow[t]{2}{*}{ Age } & \multirow{2}{*}{$\begin{array}{l}\text { clinical } \\
\text { stage }\end{array}$} & \multirow{2}{*}{$\begin{array}{l}\text { no. } \\
\text { pariens }\end{array}$} & \multicolumn{3}{|c|}{ AP diameter in nnm. } & \multicolumn{3}{|c|}{ RL diameter in mon. } \\
\hline & & & mean & range & s.d. & mean & range & s.d. \\
\hline \multirow[t]{4}{*}{ premenopausal } & $1+11 \mathrm{~A}$ & 8 & 42.2 & $35-51$ & 9.6 & 64.2 & $45-86$ & 14.9 \\
\hline & IIB & 2 & 40.0 & 40 & - & 66.5 & $53-80$ & - \\
\hline & IIIB & 3 & 52.3 & $48-58$ & - & 77.7 & $56-94$ & $\sim$ \\
\hline & IVA & 1 & 40.0 & - & - & 50.0 & - & - \\
\hline \multirow[t]{4}{*}{ postmenopausal } & $I+I I A$ & 17 & 34.3 & $24-60$ & 7.8 & 58.8 & $34-87$ & 10.8 \\
\hline & $\mathrm{IIB}$ & 11 & 39.7 & $27-68$ & 11.6 & 54.1 & $42-60$ & 7.9 \\
\hline & III.A & i. & 24.0 & - & - & 39.0 & $-\infty$ & \\
\hline & $111 \mathrm{~B}$ & 4 & 54.2 & $38-60$ & 28.0 & 67.8 & $43-80$ & 14.0 \\
\hline
\end{tabular}


Table 4.9

Cervical density features in patients with cervical cancer (brackets indicate retrospective study).

Clinicalstage
I+IIA IIB IIIA IIIB IV $\quad \begin{aligned} & \text { nodefinite } \\ & \text { clinicalstage }\end{aligned}$

CT findings

no.

patients

Total

Central air density

$41+(15) 9+(0) \quad 6+(0)$

$4+(0)-4+(0)$

$23+(0)$

Scans without

i.v. contrast medium

(plain scan)

- cervix homogeneons

- cervix inhomogeneous

$18+(13)$

Scans $15-30$ minutes

after $i . v$. contrast

medium

$24+(0)$

- cervix homogeneous

- cervix inhomogeveous

Scans immediately after

bolus contrast

injection (RSS)

- cervix homogeneous

- cervix inhomogeneous

$16+(0)$

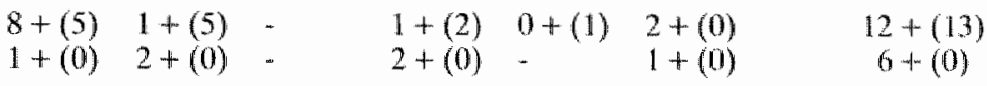

\begin{tabular}{|c|c|c|c|c|c|c|c|}
\hline \multicolumn{8}{|l|}{$24+(0)$} \\
\hline & $5+(0)$ & $2+(0)$ & . & - & - & - & $7+(0)$ \\
\hline & $7+(0)$ & $3+(0)$ & $1+(0)$ & $4+(0)$ & 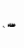 & $2+(0)$ & $17+(0)$ \\
\hline \multicolumn{8}{|l|}{$16+(0)$} \\
\hline & $2+(0)$ & $1+(0)$ & - & - & $\mathrm{m}$ & - & $3+(0)$ \\
\hline & $6+(0)$ & $2+(0)$ & - & $2+(0)$ & - & $3+(0)$ & $13+(\theta)$ \\
\hline
\end{tabular}

\subsubsection{Measurements}

Table 4.8. relates objective measurements of AP and right - left diameter of the cervix to the clinical disease stage (c.f. table 3.2.). Table 4.9. correlates cervical density features in plain and contrasted scans with the clinical stage in cervical cancer patients. On plain scan. 6 patients had a slightly inhomogeneous cervix, and following bolus contrast injection "this became much more obvious and was surrounded by a rim of more contrasted tisste (fig.

4.3.). In addition, several patients witly a homogeneous cervix on plain scan showed inhomogeneous features following contrast injection (fig. 4.1d-e.). In sone of these cusces in the lower stages of disease, contrast revealed a central lucency, sometimes only visible with optimal window width and window level settings, but in the higher stages of disease, the lucent area was larger and more irregular, with a density difference between centre and rim of 30 to 40 Hounsfield Units. The seven patients, groups 1 and IIA, with homogeneous contrast enhancement were all operated, and 6 had a small infiltrating cervical cancer of less than $5 \mathrm{~mm}$ in diameter. The one exception was a patient with clinical stage IB and $\mathrm{Cr}$ stage IVB on account of possible liver metastases and a large pelvic mass. At operation. however, the uterus was found to be fixed in retroflexion, appearing on contrast CT as a large homogeneous mass. A retrospective inspection of the contrast CT scan did in fact show a lucent inhomogeneous area representing the cerwix. The liver lesions prove to be haemangiomas. Ten of the 13 patients, F.I.G.O. stage I and IIA, with an inhomogencouss contrast accumulation in the cervix were operated, and in 2 , the operation was abandoned because of parametrial involvement, while in the remaining 8 the cervix was histologically 
extensively infiltrated (fig. 4.1c). Moreover all five patients without a definite clinical stage had a laparotomy and four had surgically proven parametrium involvement (fig. 4.4) and in the fifth the uterus was remowed and the cervix was deeply infiltrated histologically. In no case where plain and contrasted scans could be compared did a lesion, visible on plain scan, disappear after contrast.

\subsubsection{Correlation of $\mathrm{C} T$ and clinical staging}

The criteria for CT staging used in this study are shown in table 4.5 and are as used by Walsh and Goplerud (table 4.5) with the important modifications as mentioned in paragraph 4.4.2.1. Clinical staging in this present study is based on the F.I.G.O. criteria. Table 4.10 summarizes the resullts of the first observer. Two of the 28 patients with clinical stage I and IIA were upstaged to CT stage IIB on the basis of parametrial extension and 6 to CT stage IVB, 4 for suspected lymph node enlargement, 1 for suspected liver metastases and the sixth for both lymph node enlargement and bladder wall involvement. Three clinical stage IIB patients and 1 clinical stage IIIA had completely normal CT scans, in spite of histologically proven cervical cancer, and were therefore downstaged to CT stage $\mathbb{I}$ and IIA. Three clinical stage IIB patients were upstaged to CT stage IVB, because of lymph node enlargement. Of the nine patients with clinical stage IIIB, one was upstaged to $C T$ stage IVA, for bladder wall unvolvement and 6 to CT stage IVB for lymph node enlargement, 1 also showing signs of liver metastases. The one patient with clinical stage IVA on the basis of bladder wall infiltration at cystoscopy was downstaged to CT stage IIB. In total, CT and clinical stages differed in 23 patients (47\%), $18(37 \%)$ being upstaged and $5(10 \%)$ being downstaged by CT.

In order to detect interobserver variability and to exclude bias all CT scans were reviewed by a second observer. Table 4.11 compares the results of observer I and II.

To study each of these areas of discrepancy in greater detail specific CT, clinical and surgical comparisons were made.

Table 4.10

Correlation between CT and clinical staging in 56 consecutive untreated patients with cervical cancer (observer I) (patients of the retrospective study between brackets).

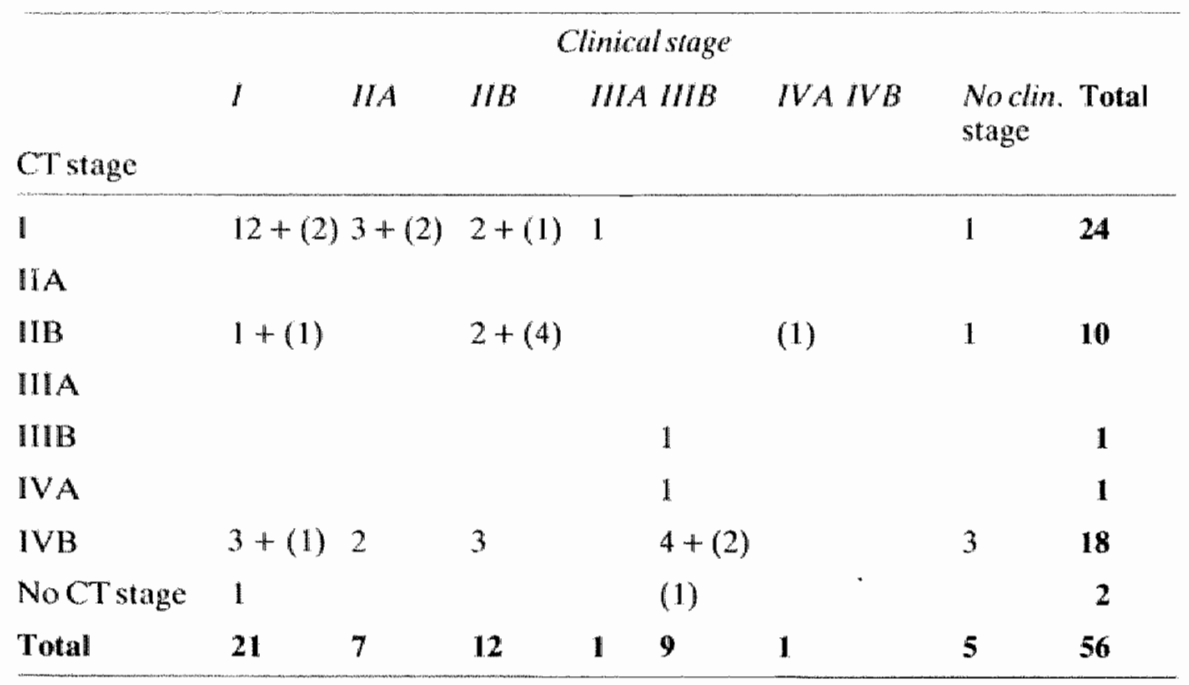


Table 4.11

Comparison between CT interpretations by two observers of $56 \mathrm{CT}$ scans of patients with cervical cancer.

\begin{tabular}{|c|c|c|c|c|c|c|c|}
\hline \multirow[b]{2}{*}{$\begin{array}{l}\text { CT stage } \\
\text { observer I }\end{array}$} & \multicolumn{7}{|c|}{ CT-siage observer II } \\
\hline & $I-I L A$ & $J B$ & $M I B$ & WA & $I V B$ & $\begin{array}{l}\text { NoCT } \\
\text { stage }\end{array}$ & Total \\
\hline$I+I I A$ & 11 & 12 & & & 1 & & 24 \\
\hline II $\mathrm{B}$ & & 8 & 1 & & 1 & & 10 \\
\hline III $\mathbb{B}$ & & & 1 & & & & $\mathbb{1}$ \\
\hline IV A & & & & 1 & & & 1 \\
\hline IV B & & 2 & & & 16 & & 18 \\
\hline NoCTstage & & & & & & 2 & 2 \\
\hline Total & 11 & 22 & 2 & 1 & 18 & 2 & 56 \\
\hline
\end{tabular}

Table 4.12

Correlation between CT (two observers) and clinical interpretation of parametrium infiltration in 48 untreated patients with cervical cancer.

(Prospective study 35 patients, retrospective study 13 patients).

Clinical interpretarion

Noparametrium Parametrium

CTinerpretation

infiltration infiltration

Noparametrium

- observer $1 \quad 39+(11) \quad 8+(6)$

infiltration

$\begin{array}{llr}\text { - observer II } & 30+(6) & 5+(5) \\ \text { - observer I } & 13+(2) & 10+(7)\end{array}$

Parametrium

infiltration

- observer II $22+(7) \quad 13+(8)$

\subsubsection{Parametrial infiltration: CT, clinical and surgical findings}

An examination of the left and right parametria in 48 untreated patients with cervical cancer permitted a total of $96 \mathrm{CT}$-clinical comparisons in the interpretation of parametrial infiltration (table 4.12). 8 Patients had to be excluded, 5 because clinical staging was inconclusive or not done and three patients had a technically unsatisfactory CT. The re was agreement between clinical and CT findings in $69 \%$ (observer I) and $59 \%$ (observer II) of 
the parametria exarmined. The disagrements, however, were sometimes dramatic, 4 patrametria interpreted clinically as invaded to the pelvic wall appearing normal on $C T$ (both observers) and 6 appearing invaded to the pelvic wall on CT (both observers) appearing clinically normal.

Comparison of CT and surgical interpretation of the left and right parametria of 24 patients cnabled an assessment of 48 parametria to be made. This group consisted of 19 patients operated for clinical stage I or IIA carcinoma of the cervix, 2 for carcinoma in situ and 3 because physical examination was inconclusive. The correlation is shown in table 4.13 . There was complete agreement between surgical and CT findings in $75 \%$ (observer 1) and $67 \%$ (observer II) respectively.

\section{Tabie 4.13}

Correlation between $\mathrm{CT}$ interpretation (two observers) and surgical findings concerning parametrium infiltration in 24 untreated patients with cervical carcinoma. (Prospective study 22 patients, retrospective study 2 patients).

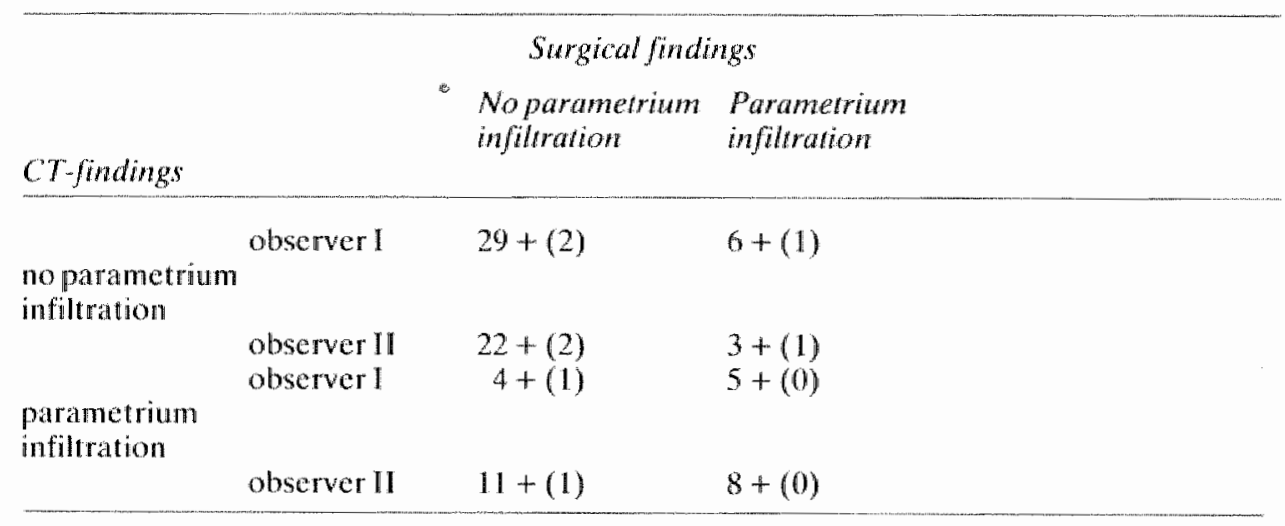

Table 4.14

C demonstration of lymph node enlargement (two observers) related to clinical stage in 56 consecutive untreated patients with cervical cancer (retrospective study 15 patients, prospective study $4 \|$ patients). One patient (stage I B) had enlarged obturator and para-aortic nodes.

\begin{tabular}{lllll}
$\begin{array}{l}\text { No. } \\
\text { patients }\end{array}$ & Stage & $\begin{array}{l}\text { Externaliliac } \\
\text { nodes } \\
\text { (obmutar) }\end{array}$ & $\begin{array}{l}\text { Para-doricor } \\
\text { commoniliac } \\
\text { nodes }\end{array}$ & Percentage \\
\hline 28 & H-IIA & $5+(1)$ & 2 & $25 \%$ \\
12 & IIB & 1 & 1 & $16.6 \%$ \\
1 & IIIA & - & - & - \\
9 & IIIB & $4+(2)$ & - & $66 \%$ \\
1 & IV & - & - & - \\
5 & noclin. stage & 3 & & \\
\hline
\end{tabular}




\subsubsection{Lymph node pathology - CT and surgical findlings}

In 19 of the 56 patients the CT scan showed abnormalities suggesting lymph node enlargement with a disagreement between both observers in 4 patients concerning pelvic node abnormalities. Table 4.14 shows the distribution and site of all these findings (both observers together) according to dinical stage. Only one patient in stage I - IIA had enlarged nodes on both sides. To determine the accuracy of CT in detecting lymph node metastases in new patients with cervical cancer, CT and surgical findings were compared in 15 patients who had a complete pelvic lymphadenectomy (AVRUEL or Wertheim-Meigs), in 4 patients who had an abandoned AVRUEL procedure and in one patient who had a pelvic node bilopsy during abdominal hysterectony. In all these patients, except one, both observers agreed about the presence or absence of lymph node enlargement. No information about pelvic lymph nodes was obtained in the other 6 operations. The results are given in table 4.15 and show an overall correlation of $75 \%$. The CT false-positive finding was a pelvic node $1.7 \mathrm{~cm}$ in diameter not found during surgery, and of the 4 CT false-negatives, only one node exceeded two cm diameter in cross-section.

Table 4.15

Correllation between CT (two observers) and histological examination concerning the presence of metastatic pelvic lymph nodes in patients with cervical cancer who had a completed pelvic lymph node dissection (15) or a pelvic lymph node biopsy (5)

\begin{tabular}{lcc} 
CTfindings & $\begin{array}{c}\text { Histological findings: } \\
\text { negative pelvic } \\
\text { lymph nodes }\end{array}$ & $\begin{array}{c}\text { positive pelvic } \\
\text { iymph nodes }\end{array}$ \\
\hline $\begin{array}{l}\text { negative pelvic } \\
\text { lymph nodes }\end{array}$ & $12+(0)$ & $2+(2)$ \\
$\begin{array}{l}\text { positive pelvic } \\
\text { ymph nodes }\end{array}$ & $0+(1)$ & $3+(0)$
\end{tabular}

Tabie 4.16

The incidence of tumour related abnormalities demonstrated by different diagnostic procedures in 56 untreated patients with cervical cancer.

(1.5 retrospective, 41 prospective) .

\begin{tabular}{lll} 
& \multicolumn{2}{l}{ Tumour related abnomalities } \\
& Present & Absent \\
& No. Pts & No. Pts. \\
\hline Chest X-ray & 0 & $41+(15)$ \\
I.V.U. & 3 & $36+(15)$ \\
Cystoscopy & $3+(1)$ & $34+(14)$ \\
Bariumenema & $0+(1)$ & $16+(10)$ \\
Proctoscopy & $0+(1)$ & $17+(10)$
\end{tabular}




\subsubsection{CT compared to I.V.U., cystoscopy, proctoscopy and barium enema}

Table 4.16 shows the incidence of tumour related abnormalities demonstrated by other special investigations in untreated patients with cervical cancer. The three I.V.U. abnormalities were unilateral distal ureteric obstruction, two in clinically staged IIIB patients, who were upstaged to IIIB and the third already staged as IIIB. In all three, CT demonstrated the obstruction cause as a soft tissue mass. CT indicated no ureteric obstruction in any of the other patients. Four cystoscopic abnormalities were found, but only one case was upstaged, because no biopsy was taken in the other three. In this patient, barium enema and prostoscopy revealed abnormalities probably caused by extraluminal compression, and laparotomy demonstrated mesosigmoid metastases not visible on CT. In two of the other three, the parametria were clinically invaded to the pelvic wall. The remaining paticnt also had a IIIB lesion due to an obstructed ureter. In only one of the four cases did CT confirm bladder wall invasion, but in another case, clinically IB . CT demonstrated clear thickening and irregularity of the dorsal bladder wall, indicative of tumour invasion (fig. 3.6a.), but this was not confirmed by cystoscopy, although the patient died four months later with extensive metastatic disease. There were no tumour related abnormalitics on barium enema or proctoscopy other than the one case mentioned earlier.

\subsubsection{Liver lesions and suprarenal masses}

In 44 patients, the liver and suprarenals were included in the CT. Liver abnormalities were found in 5 cases, easily interpreted as liver cysts in two, but solid and suspiciously metastatic in the other threc. In one patient an operation (AVRUEL) demonstrated a liver haemangioma. The other two were clinical stage IIIB and therefore not operated. In 4 patients $C T$ demonstrated a unilateral suprarenal mass, $1-2 \mathrm{~cm}$ diameter. Two had a clinical IIB lesion, one with bilateral ovarian cysts and the other with very extensive pelvic disease on $\mathrm{CT}$. Of the other two patients, one had histologically proven lymph node metastases and the other liver metastases.

There was no disagreement between the two observers about the interpretation of the liver and suprarenalls.

\subsubsection{Discussion}

The discrepancy between clinical and surgical staging of cervical cancer is well documented in the literature (table 4.2). The principal areas of disagreement concern the interpretation of parametrial infiltration, and the presence of distant metastases. The fact that F.I.G.O. staging lacks techniques capable of diagnosing distant metastases would appear to be a major reason for failure to detect more advanced disease. In the attempt to find suitable techniques, CT is finding increasing favour with many workers, and this study attempts to evaluate the possible role of $\mathrm{CT}$ in elucidating the two main areas of disagreement.

A preliminary discussion of the $\mathrm{CT}$ features of the cervical tumour itself is worthwhile, because it is well known that, quite apart from other factors, prognosis is related to the pelvic tumour bulk at the time of diagnosis. The objective nature of CT scanning lends itself to measurement as a method of establishing tumour bulk. A study already described in chapter III uses such measurements to establish average normal values for the cervix in women with no genital tract disease, and is used as the baseline for a similar study described in this chapter in patients with cervical cancer. In chapter $V$ however, table 5.6 demonstrates 

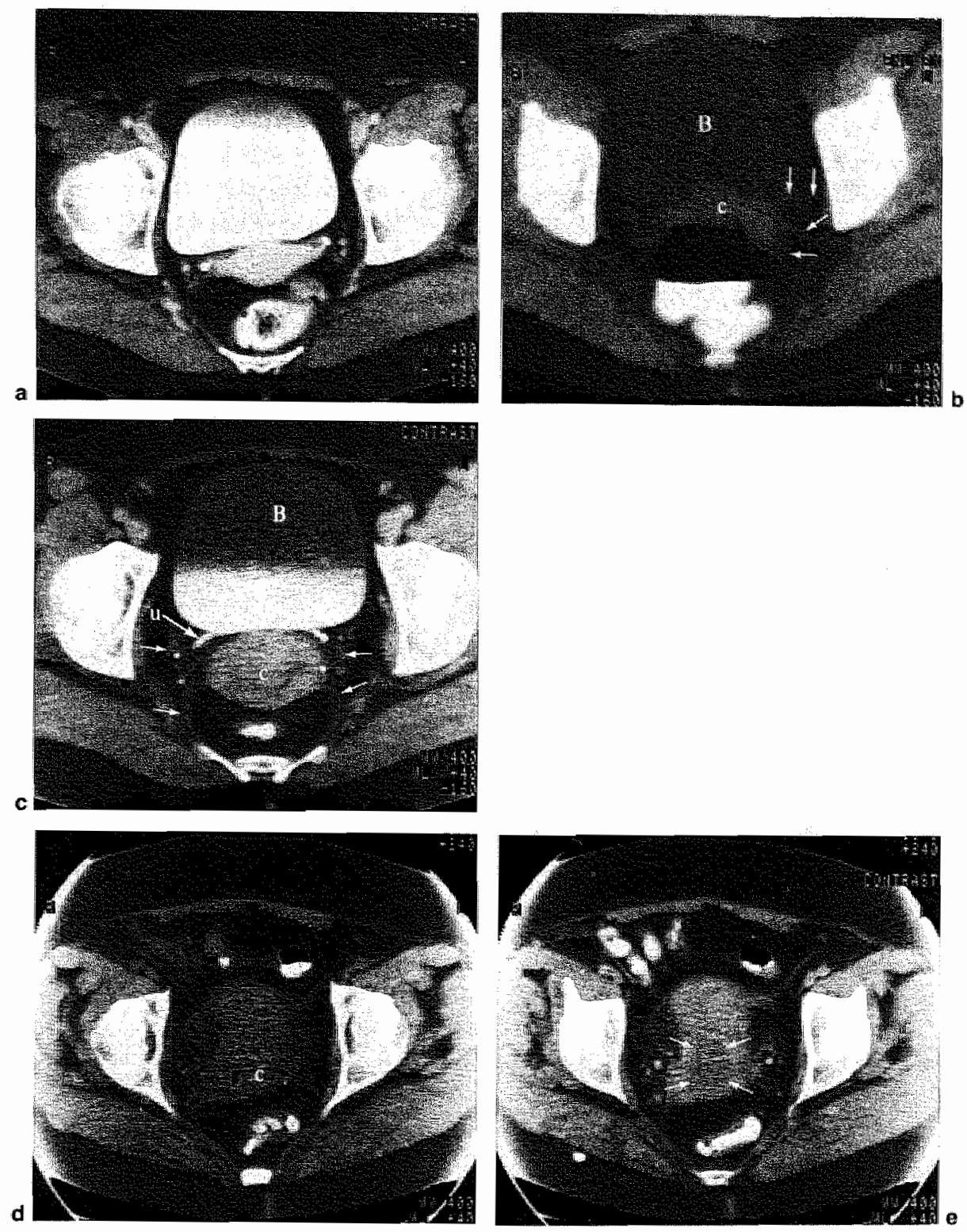

fig. 4.1.

Four patients with cervical cancer, clinical Ib (F.I.G.O.) a. Post contrast scan: normal CT scan willy homogeneous cervix. Operation and histology revealed a minmal lesion (cervical infiltration $2 \mathrm{~mm}$ ) and no spread outside the uterus. b. Pre contrast scan: irregularly bordered cervix, especially on the left. with linear soft tissue extensions (arrows) and a homogeneous density. Operation revealed parametrium infiltration on the right and a normal feft parametrium. c. Post contrast scan: large inhomogeous cervix, sharply bordered with soft tissue densities in the parametrium (arrows). Operation revealed no parametrium involvement but histologic examination demonstrated an extensively infiltrated cervix. d/e. Pre and post contrast scan: the pre contrast scan reveals al homogeous cervix and in the post contrast scan is a central region of slighty lower density (arrows) visible, possibly representing the tumour (no operation). $(\mathrm{B}=\mathrm{Bladder}, \mathrm{u}=$ ureter, $\mathrm{c}=$ cervix) 
a poor correlation between CT and surgical specimen dimensions of the cervix. Although the lateral cervical borders and thus the right - left diameter of the cervix are also determined by the surgeon, the discrepancy indicates that the borders are difficult to define and that CT measurement of the cervix may also inlcude surrounding structures (vaginal vault). Average diameters of the cervix in cervical cancer are greater than in nomal subjects, and the more so with increasing clinical stage, but the wide overlap (large standard deviation), particularly in the premenopausal patient group, indicates that absolute measurements have little or no significance in the diagnosis and staging of cervical cancer. Comparisons of cervicall cancer stage 1 and IIA with the normal cervix revealed statistically significant differences in the premenopausal patient group for the AP diameter $(0.02, P \times 0.05$, Student $t$ test $)$ and not for the transverse diameter $(\mathrm{P} \times 0.1$, Student $t$ test $)$. In the postmenopausal patient group there were more significant differences (AP diameter $P$. 0.001 and transverse diameter $0.05 \times P<0.1$, Student $t$ test $)$. Walsh and Goplerud (1981) made similar measurements and quote averages broadly in line with these figures.
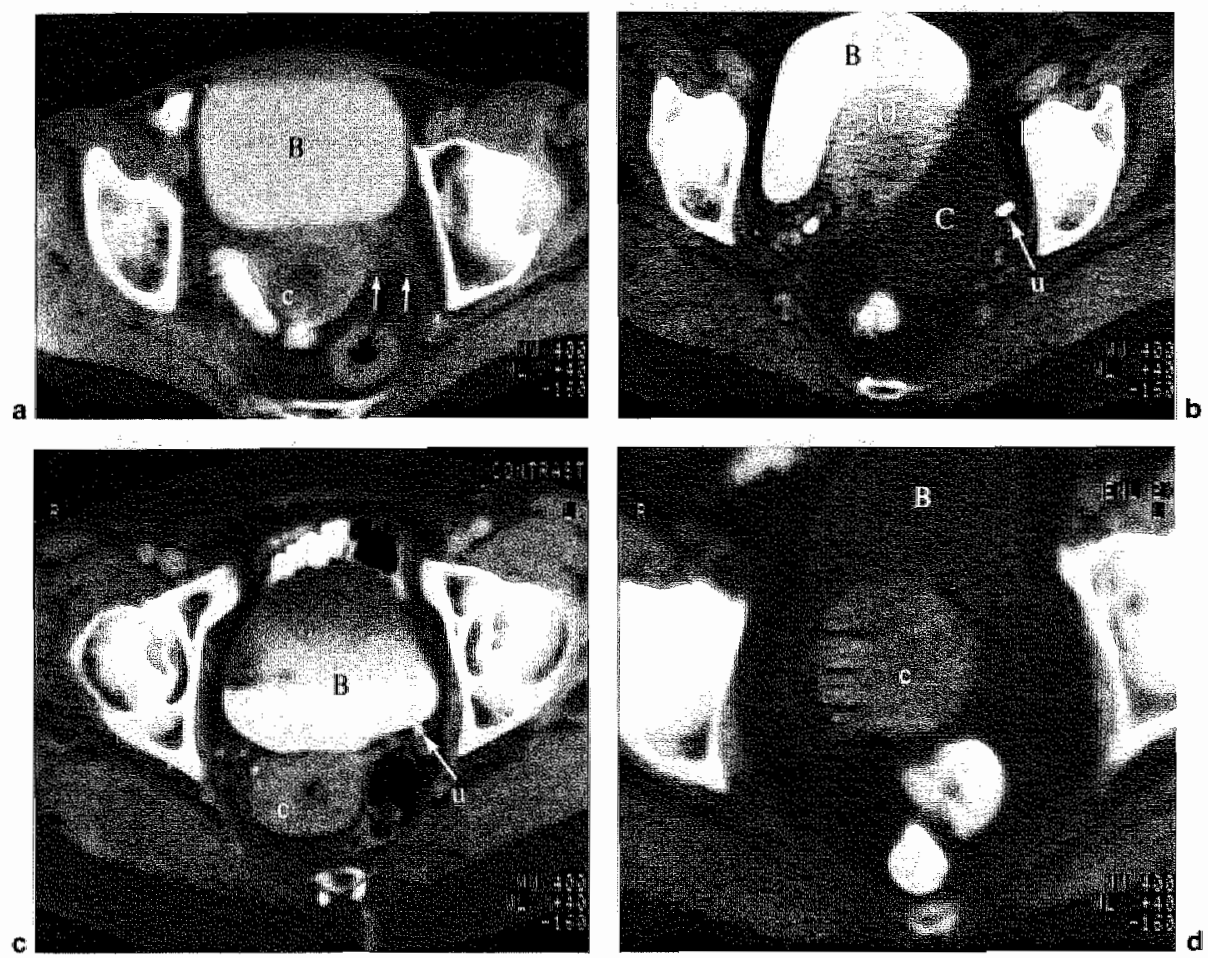

fig. 4.2 .

Fout patients with cervical cancer, clinical stage IIb (F.I.G.O.). a. Post contrast scan: CT demonstrates parametriun mass extension on the left (arrows). but plysical examination tuder anaesthesia (e.u.a.) revealed a normal parametrium on the left and parametrium infiltration on the right. b. Post contrast scan: CT shows a left side ovarian cyst but e.u. a. revealed parametrium infiltration on the left and a normal right parametrium. c. Post contrast scan: $\mathrm{CT}$ de monstrates a sharply demarcated large cervix. e. U. a. revealed parametrium infilt ration on the right and a normal left parametrium. d. Pre contrast. scan: CT demonstrates a large round cervix but e. u. a. revealed parametrium tumour infiltration on both sides just mot reaching the pelwic wall $(B=$ bladder, $U=$ uterus, $\mathrm{c}=$ cervix. $\mathrm{C}=\mathrm{cyst}$. $u=$ ureter). 
Although not objectively measurable, because of frequent inhomogeneity, a lucency in the cervix, in pre- or postcontrast scans was a clearly identifiable $\mathrm{CT}$ feature in cervical cancer. In general, the normal cervix, or one containing a very small tumour, appears homogeneous on pre and post contrast CT scans, while the characteristic of the large anfiltrating cervical tumour is an inhomogeneous lucent zone of variable size in the cervix on both pre and post contrast scans, with the additional post contrast feature of an irregular densely contrasted rim. Intermediate sized tumours greater than $1 \mathrm{~cm}$. diameter generally appear homogeneous precontrast, while revealing a central lucent zone on post contrast scan (fig. $4.1 \mathrm{~d}$. and e.). It is important to note, however, that the limits of lucency do not necessarily indicate the limits of the tumour, since a clearly circumscribed lucent zone on CT may prove surgically to represent an infiltrating carcinoma involving the parametria. In this study inhomogeneous lucency of the cervix was sometimes accompanied by a central lucent zone in the uterine corpus (fig. 4.5 b.), usually seen on post contrast scan. The literature confirms this finding, and some have interpreted it as representing endometrial extension of the cervical tumour, on the basis of fractional endometrial curettage (Walsh and Goplerud 1981). In the present study however, three of the ten cases showing this feature were operated ( 2 adeno- and one squamous cell carcinoma) and histology of the uterus revealed no endometrial extension, and it seems possible that the feature represents haematometra after curettage. As described in chapter $V$, endometrial cancer is also characterized by central lucency in the corpus, but with a more sharply demarcated and regular transition, and a less density difference on plain CT scans. Twenty-three cases of cervical cancer had a central cervical lucency of air density (fig. $4.1 \mathrm{~d}$. and $4.2 \mathrm{c}$.), possibly representing the cervical canall following fractional dilatation and curettage, but significantly never seen in patients with endometrial cancer following curettage. A possible explanation is that a tumour infiltrated cervical canal has lost its elasticity and remains patent following dilatation. In two such patients, there was a small area of very low density immediately adjacent to the open cervical canal and in both this could be correlated with a cervical biopsy taken some days prior to the CT scan. In three other patients, the air density was large and irregular and could represent a necrotic centre to the tumour (fig. 4.3).

Although there may be specific CT features for the presence of cervical cancer, this study reveals such a poor correlation of $\mathrm{CT}$ with clinical (table 4.12.) and surgical (table 4.13.) findings with regard to the the presence of parametrial involvement that it is virtually impossible on the basis on CT findings to make any differentiation between IB and IIB lesions (fig. 4.1b.). Moreover the enormous interobserver variability demonstrates the lack of objectivity in the $\mathrm{CT}$ interpretation of the parametria. The irregular cervical borders and linear soft tissue extensions described by other authors (Walsh and Goplerud 1981, Langer et al., 1981) were so frequently seen in the normal control study described in chapter IIII that such features cannot form the basis of CT staging of tumour infiltration. The only $\mathrm{CT}$ sign considered to be indicative of parametrial extension is soft tissue mass extension (fig. 4.3 - 4.5). The poor correlation of such CT signs with both clinical and surgical findings must, however, be interpreted in the context of the absence of histological proof of parametrial infiltration. Because the parametrium was surgically presumed to be tumour involved when palpation at operation suggested this. Biopsy for histological confirmation would be unethical because this might carry unwarranted risk for the patient. Nevertheless. the accuracy of CT in differentiating IB from IIB lesions would appear to be too low to be permitted to alter treatment decisions. Mention has already been made of the very marked 

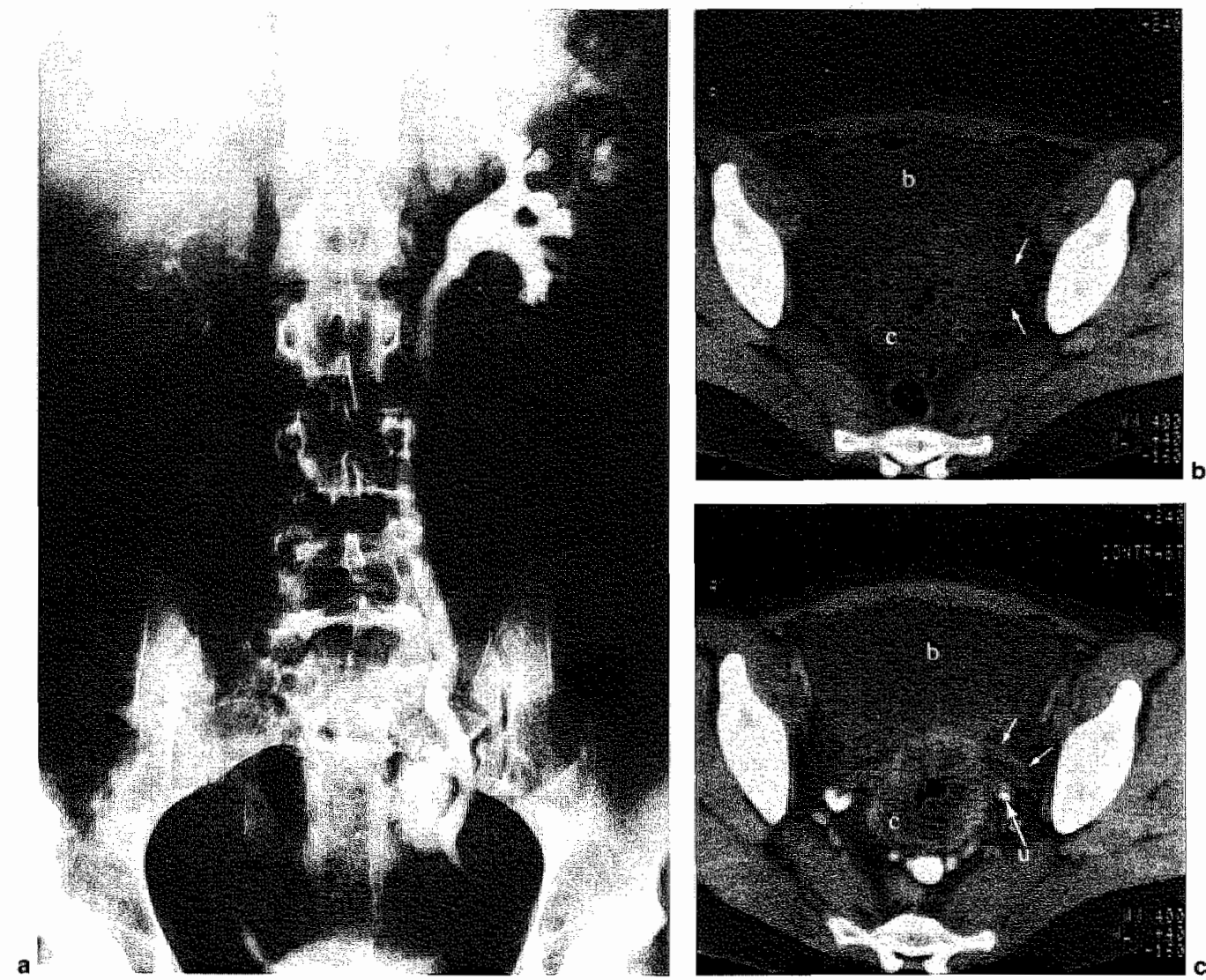

fig. 4,3 .

I.V.U. (a), pre (b) and post (c) contrast scans of a patient with cervical cuncer stage IIIb because of parametrium rumour infiltration on the left not reaching the pelvic wall but with a left distal ureteric obstruction (the right side was normal at e.u.a.). Note the soft wissue mass extension on the left (small arrows) with compression of the ureter, the central air densily and the rim of contrast enhancement (u $=$ uneter, $c=$ cerwix, $b=$ bladder).

differences between clinical and CT findings in estimating the extent of parametrial involvement.

CT found evidence of pelvic or para-aortic lymph node involvement in $25 \%, 16.6 \%$ and $66 \%$ of patients with clinical stage I and IIA, IIB and IIIB lesions respectively, with an interobserver variability of only $7 \%$. These results are not markedly different from those in table 4.3. However, a comparison with surgical results in 20 patients (table 4.15) shows a poor correlation, with many false negatives. Nevertheless, CT evidence suggestive of large nodes should be taken seriously, but no treatment alteration should be made without histological or cytological confirmation, a procedure easily performed by needle biopsy under CT control (fig. 4.10f.). Histological or cytological confirmation is also indicated in the presence of $\mathrm{CT}$ evidence of solid liver lesions.

Finally, CT displayed a considerable advantage over I.V.U. in the three cases of ureteric obstruction in this study, by demonstrating soft tissue mass as the cause of the obstruction (fig. 4.3), but it is inferior to cystoscopy in demonstrating bladder wall involvement. 

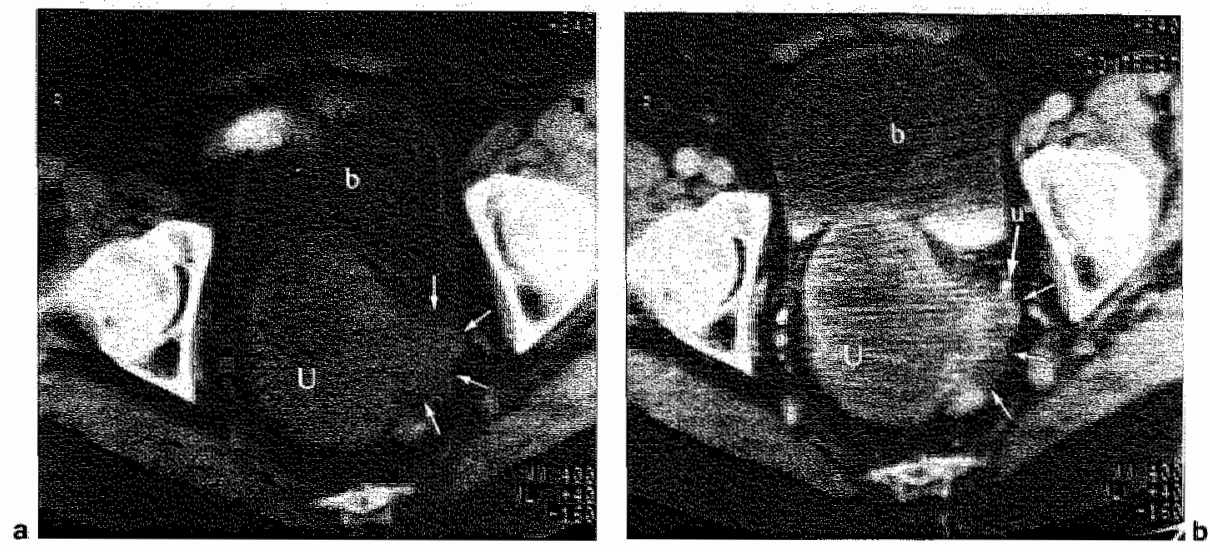

Fig. 4.4 .

Pre (a) and post (b) contrast scans of a patient with squamous cell carcimoma of the cervix with inconclusive clinical stage. Laparotomy revealed a large tumour-infiltrated uterus in retrollexion and parametrium infiltration on the left. CT showed arge uterus (U) with peripherat contrast onhancement and a soft tissue mass extension on the left ( $\mathrm{small}$ arrows) $(\mathrm{b}=\mathrm{blaclder}, \mathrm{u}=$ ureter).

The choice of therapy in cervical cancer is at present based on clinical staging and this study raises the question if whether CT staging would form a more appropriate basis for such therapeutic decisions. A theoretical comparison of the two staging methods reveals important differences, namely that $\mathrm{CT}$ provides objective, reproducable, visible information including the presence of possible distant metastases, while clinical assessment (involving at least 10 different gynaecologists in this study) is essentially subjective, yields palpable information and is unable to detect distant metastases. It is perhaps not surprising that in this study, CT staging differed from clinical staging in about $50 \%$ of cases (table 4.10.), nearly always indicating a higher CT stage, the main areas of disagreement being in the interpretation of parametrial infiltration and the presence of lymph node metastases. Such alterations in clinical stage would theoretically have resulted in $25 \%$ of patients receiving a different treatment, 8 receiving radiotherapy instead of surgery and 4 surgery instead radiotherapy. Of these, two would have received extended field radiation for para-aortic lymph nodes and 3 received chemotherapy for liver metastases. Treatment change between IB and IIB lesions depends on parametrial assessment, and the foregoing discussion about the huge interobserver variability in the assessment of parametrium involvement and the poor surgical correlation, clearly shows that $\mathrm{CT}$ is not yet sulficiently accurate to warrant such a change in policy.

Likewise, treatment change based on the CT findings of lymph nodes is in general not justified, except when a possible lymph node mass is sufficiently large to permit fine needle biopsy under CT control (fig. 4.10f.), and there is histological evidence of metastatic disease. However, future treatment decisions, particularly in the clinical stage IIB to IV group may depend upon an accurate assessment of tumour bulk, and in this respect, CT would appear to provide more accurate and objective information. In such situations, particularly if there is a marked discrepancy between CT and clinical findings, surgical confirmation of the extent of the disease may be justified. Two case examples serve to illustrate the extent of such discrepancies: 

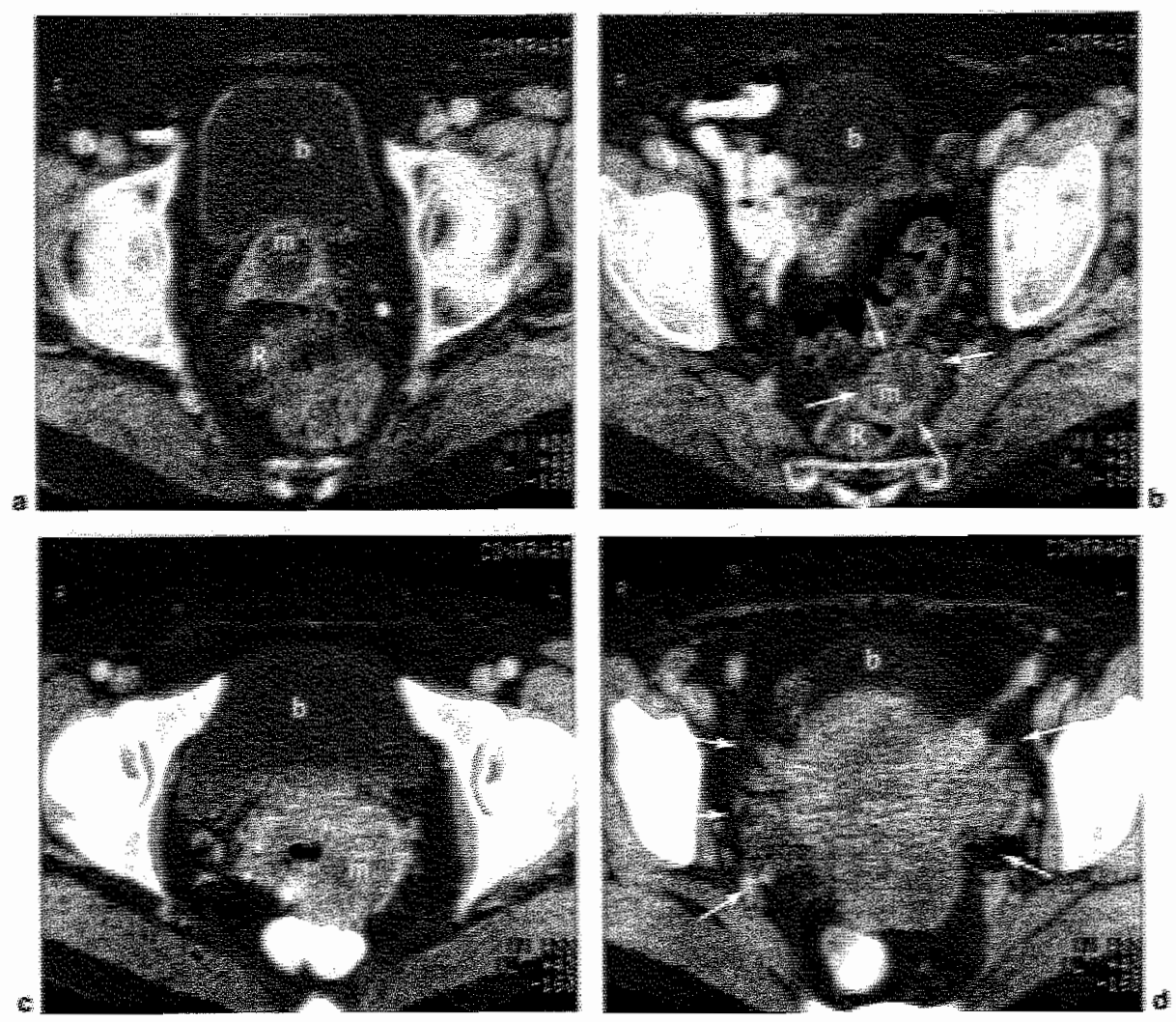

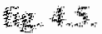

W

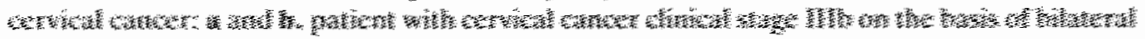

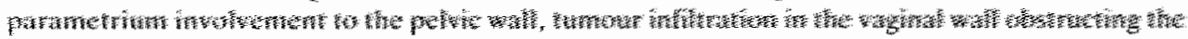

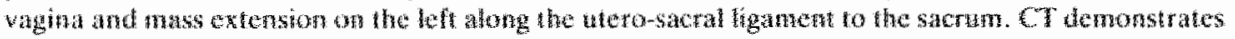

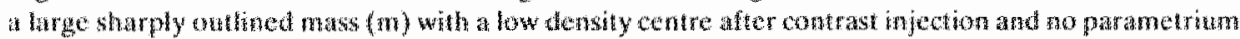

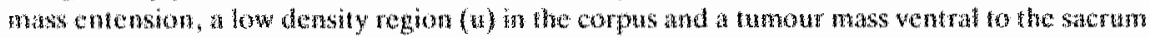

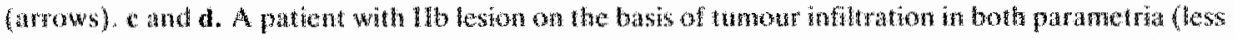

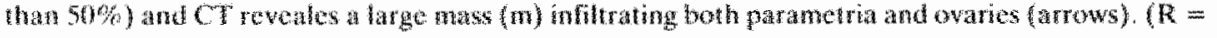
ractum, $b=1$ isuder

\section{Case A.}

A 68 year old woman with squamous cell carcinoma of the cerwix, stage IB, had a barrelshaped tumour and large uterus on pelvic examination, but no signs of parametria involvenemt. Chest X-ray. I.V.U. and cystoscopy were all nomal. CT scan however, benonstrated an anomous inhomogeneous mass whth soft tissue mass extensions almost to the pelvic sidewall, bladder identations suggestive of bladder involvement and many large pelvic and para-artic nodes. These findings inacated a CT stage IVB. She was treated with radiotherapy and died three months water with extensive metastatic disease (ing. 4.6). Case $B$.

A 72 year old woman with adenosquamous cen catcinoma of the cervix was classified as sage IID becatse of twmour involvement of both parametrat alnost to the pelwic wall on the left side and hall way on the right. 


\subsection{Recurrent cervical cancer}

\subsubsection{Introduction}

The prognosis of recurrent cervical cancer is bad, $85 \%$ of patients with untreated recurrence being dead whin a year and 95\% within two years (Brunschwig and Daniel, 1957). The main cause of death is uraemia secondary to ureteric obstruction. Even with treatment, five year survival is very low (Munnell and Bonney 1961, Calame 1969, Timmer 1982). The type of treatment is determined by the extent of the recurrence and although surgery is preferable because many patients had full initiall radiotherapy, the majority of patients already has non-resectable tumours when recurrence is diagnosed (Calame 1969, Brunschwig 1967). Careful follow-up is therefore essential to detect recurrence as early as possible.

If the cancer recurs, it usually does so within two years of primary treatment. In a review of of 2200 cases by Paunier et all. (1967), two-third of the patients dying of tumour recurrence was dead within two years of primary treatment. In the studies by Calame (1969) and by Timmer (1982) respectively $81 \%$ of 191 patients and $91 \%$ of 80 patients with recurrent cervical cancer were diagnosed within two years of primary treatment.

The site of recurrence is variable and can be categorized as follows (Calame, 1969, Munnell and Boney, 1961):

A. Central pelvic recurrence; disease limited to the cervix and/or vaginal vault.

B. Deep pelwic recurrence; recurrent cancer in the parametrium and uterosacral ligaments and in the iliac, hypogastric or obturator lymph nodes.

C. Bladder and/or rectall involvement often combined with $A$ or $B$.

D. Peripheral pelvic recurrence; , recurrent disease in the inguinal lymph nodes, pelvic brim nodes, pelvic bones or lumbosacral vertebrae.

E. Distant metastases, with pelvic recurrence.

F. Distant metastases without pelvic recurrence.

In the material of Paunier et al. (1967), all cases initially treated by radiation only, 47\% of recurrences were restricted to the pelvis, $35 \%$ of the patients had pelvic recurrences and distant metastases and only $18 \%$ had distant metastases at the time of death. Calame (1969) reported that over $50 \%$ of recurrences involved areas which were in the field of operative resection or had received the heaviest dose of radiotherapy, and distant metastases were found in $18 \%$. Munnell and Bonney (1961) quoted similar figures for 143 stage I and II cases. Timmer (1982) reportted that $30 \%$ of recurrences in cases initially treated with combined surgery and radiation were in the field of treatment and this was $54 \%$ in cases having radiotherapy alone.

The incidence of lymph node involvement at careful autopsy of patients treated for cervical cancer is very high and in a report of 15 cases Henriksen (1949) found involvement of hypogastric and aortic nodes in $60 \%$ and $33 \%$ of cases respectively and bloodstream metastases in $53 \%$. In an autopsy review of 202 cases of treated cervical cancer, Henriksen (1949) found liver metastases, lung metastases and lumbar spine metastases in $16.4 \%, 14 \%$ and $9.2 \%$ respectively. Fisher (1980) found 1.5 cases of lumbar spine involvement in 339 patients with cervical cancer. 


\subsubsection{Diagnosis of recurrent cervical cancer}

The five year survival of treated recurrent cervical cancer is only $3 \%$ and a minority of patients has a central recurrence only at the time of diagnosis (Munnell and Bonney, 1961, Calame, 1969). Early diagnosis is vital to any hope of cure, and, in the frequent absence of symptoms, adequate follow-up by pelvic examination, colposcopy and cytology is essential. If symptoms are present, pain, particularly if radiating to thigh or leg, is the primary indicator of recurrence (Callame, 1969, Bergsjö and Kolstad, 1963, Nelson et al, 1972). Pelvic examination following radiotherapy is very difficult since a palpable mass may be caused by radiation fibrosis, simulating recurrent disease and errors in the estimation of the disease extent by physical examination are in the range of $20 \%$ (Walsh et al., 1981). Over a 15 year period, Heyman and Kottmeier observed 80 patients with "tumours" on the pelvic wall and in the parametrium after radiotherapy, which they diagnosed clinically as obvious recurrences but which disappeared without treatment (Brunschwig and Daniel, 1957).

An obstructed ureter on I.V.U. may also be the first sign of recurrent disease because of the close relationship between ureter, cervix and the most frequently involved lymph node groups, and many authors recommend a routine I.V.U. every $6-12$ months for 2.5 or even 5 years after primary therapy (Shingleton et al., 1969, Munnell and Bonney, 1961). However, ureteric obstruction is no proof of recurrent cancer since it may also be caused by operation and radiation. In literature the incidence of ureteric obstruction by radiation is between $0.26 \%$ and $1.4 \%$, by operation between $1.7 \%$ and $4 \%$ and by a combination of surgery and radiation between $3.8 \%$ and $5.3 \%$ (Shingleton et al, 1969, Burns et al., 1960, Kottmeier, 1964, Welch et al. 1961, Green et al, 1962, Decker and Smith, 1968). The need for cytological or histological confirmation of cancer is clear. The mere diagnosis of recurrence gives no indication of its extent (Munnell and Bonney, 1961), and one of the great advantages of CT may be its ability to demonstrate the gross extent of the disease.

\subsubsection{CT in evaluation of recurrent cervical cancer - literature review}

Many authors have stressed the advantages of CT in demonstrating the extent of disease, particularly in patients with pelvic malignancy. Langer et al. (1981) advise a routine CT examination 6 and 18 months after operation, to ensure early diagnosis of recurrence. The 6 month examination would be necessary for subsequent differentiation of fibrosis from recurrent disease. Haertel (1980) stresses the importance of CT in the early recognition of recurrence and the objective evaluation of treatment. Walsh et al. (1981) report the results of $C T$ in diagnosing recurrent cervical cancer in 36 previously treated patients. In $27(82 \%)$ CT diagnosis of recurrence was confirmed by biopsy, in 2 , the CT diagnosis was parametrial tumour, but biopsy revealed chronic parametritis in one and radiation necrosis in the other. In two, the CT scan was negative for abdominal or pelvic tumour but physical examination and biopsy confirmed tumour in perineal nodules in one and in the vagina in the other. CT also detected metastases in unsuspected and clinically inaccessible areas in the pelvis and retroperitoneum. They conclude that CT assessment of the extent of recurrence together with subsequent percutaneous biopsy provide an alternative to laparotomy in establishing a tissue diagnosis. The main disadvantage of CT in their study was its inability to distinguish radiation fibrosis from recurrent tumour and its difficulty in 
diagnosing tumour invasion of bladder and rectum. In a report about the role of $C T$ in the pre-operative screening of carcinoma of the cervix Kilcheski et al. (1981) conclude that CT could be used as a screening imaging technique in the evaluation of patients with either intial or recurrent cervical cancer for possible surgery. They also had problems in differentiating radiation fibrosis from recurrent disease and in diagnosing rectal invasion. They advise CT as the primary examination for evaluation for recurrent cancer.

\subsection{Study of CT features in treated cervical cancer}

\subsubsection{Introduction}

This study attempts to define CT features of post operative or post radiation pelvic fibrosis and recurrent disease. CT scans of two patient groups were reviewed independently by two radiologists with no knowledge of the current clinical findings.

1. Patients with clinical symptoms of recurrent disease.

2. Patients in follow-up for treated cervical cancer, but without clinical symptoms of recurrence.

CT findings were compared with the definite diagnosis.

\section{Table 4.17}

Total number of patients and CT seans related to the indication for scanning (clinically suspected recurrent disease or routine follow-up).

\begin{tabular}{|c|c|c|c|c|}
\hline \multirow[b]{2}{*}{$\begin{array}{l}\text { No. } \\
\text { patients }\end{array}$} & \multicolumn{2}{|c|}{ Retrospective siudy } & \multicolumn{2}{|c|}{ Prospective suady } \\
\hline & $\begin{array}{l}\text { cinical suspected } \\
\text { recumenu disease }\end{array}$ & $\begin{array}{l}\text { routine } \\
\text { Follow-up }\end{array}$ & $\begin{array}{l}\text { clinical suspecked } \\
\text { recurrent disease }\end{array}$ & $\begin{array}{l}\text { routine } \\
\text { Follow-up }\end{array}$ \\
\hline 8 & $y$ & - & - & - \\
\hline 4 & 4 & - & 1 & 3 \\
\hline 13 & - & - & 13 & - \\
\hline 2 & * & - & 4 & - \\
\hline 1 & - & - & 1 & 2 \\
\hline 3 & - & - & 3 & 3 \\
\hline 12 & - & - & - & 12 \\
\hline 5 & $=$ & - & - & 10 \\
\hline Tot. 48 & 13 CT scans & - & 22 C T scans & $30 \mathrm{CT}$ seans \\
\hline
\end{tabular}

\subsubsection{Method and material}

Sixty-five consecutive CT scans were performed on 48 patients treated for cervical cancer: 13 on 12 patients form the retrospective study and 52 on 40 patients form the prospective study, 4 patients being in both the retrospective and prospective studies (table 4.17 ). All 
scans in the retrospective study were made from 1.1.80-1.2." 81 for "suspected recurrent disease". The 52 scans of the prospective study were the result of an agreement with the gynaecologists of five different hospitals to perform a CT scan as a routine follow-up procedure 6, 12 and/or 24 months after primary treatment and whenever there was clinical suspicion of recurrent disease.

Four patients had two scans for suspected recurrent disease, three at an interval of three months (the first scan being reported as normal) and one at an interval of one year (the second scan being for a second recurrence after treatment of the first). Six patients had two scans, one as a routine follow-up and one for suspected recurrent disease (in three cases the routine scan was the first). Five patients had two routine scans at least 6 months apart, and one had three scans, one as routine follow-up, a second for suspected recurrent disease and a third as routine follow-up. Tables $4-18$ and $4-19$ correlate the type of previous treatment and stage of disease with the time after primary diagnosis and the indication for $\mathrm{CT}$ scan. The reasons for suspecting recurrent disease are shown in table $4-20$.

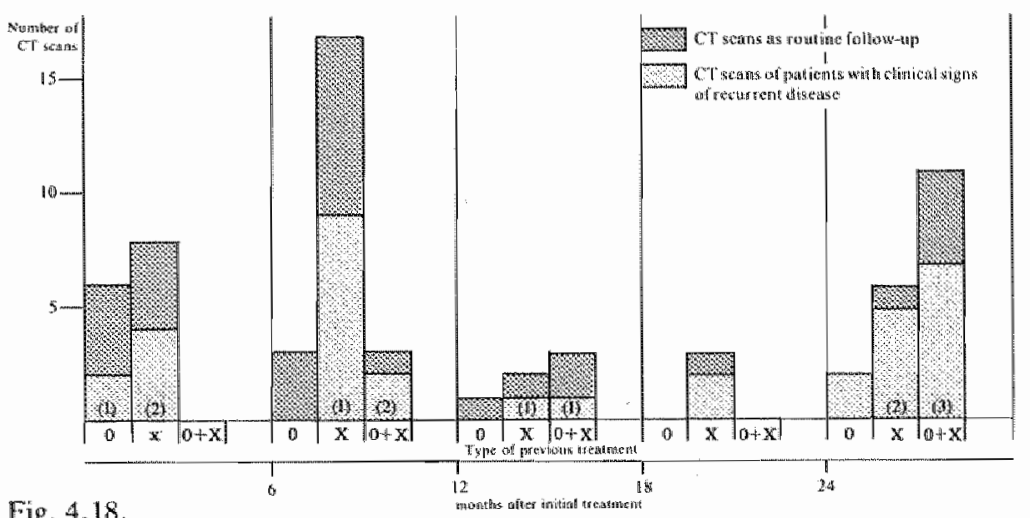

$65 \mathrm{CT}$ scans (48 patients) forming the material of paragraph 4.6., divided into: CT scan indication, type of previous treatment, time after this treatment and prospective and retrospective cases (numbers between brackets are cases of the retrospective study).

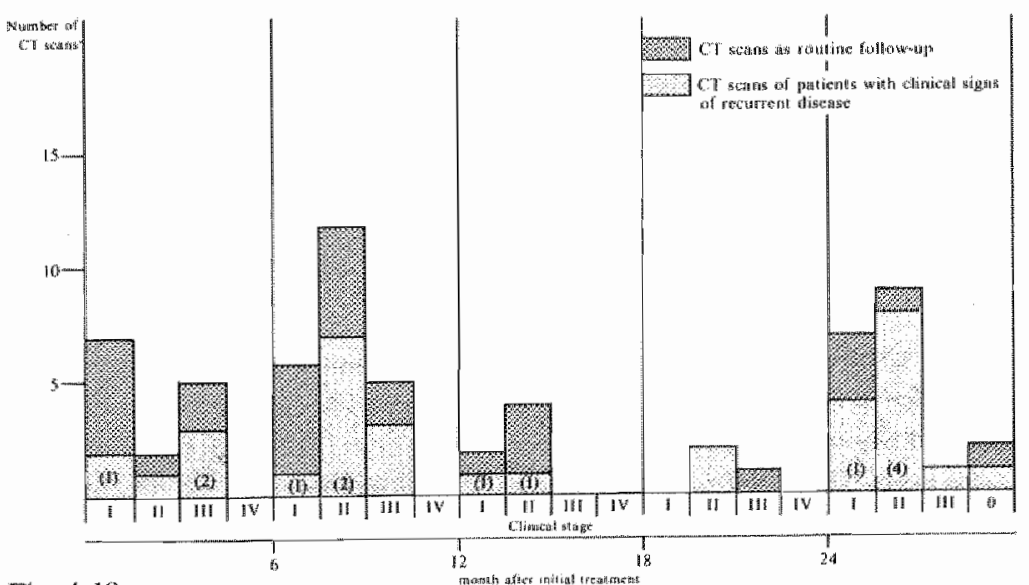

Fig. 4.19.

65 CT scans (48 patients) forming the material of paragraph 4.6 , divided into: CI scan indication, clinical stage, time after initial treatment and prospective and retrospective cases. 

All scans of the prospective study were performed with the technique described in chapter II. Intravenous contrast medium was used particularly to elucidate possible abnormalities on the precontrast scan. With the exception of two cases where only a region of interest was examined, the same technique was used for the retrospective group.
All CT scans were reviewed in random order by two radiologists with no knowledge of the current clinical history except the primary diagnosis, and were cllassified as "suspected recurrence " or " normal ". Any abnormality which could not be confidently regarded as benign was classified as suspected recurrence. The location of abnormalities was noted. In the final classification, the opinion of only one radiologist was sufficient to place a scan in the suspected recurrence category.
Interobserver variability will be discussed later.

Table 4.20

Reason for suspecting recurrence, thus indication for CT scan related to the CT interpretation and the definite diagnosis (brackets indicate retrospective studly).

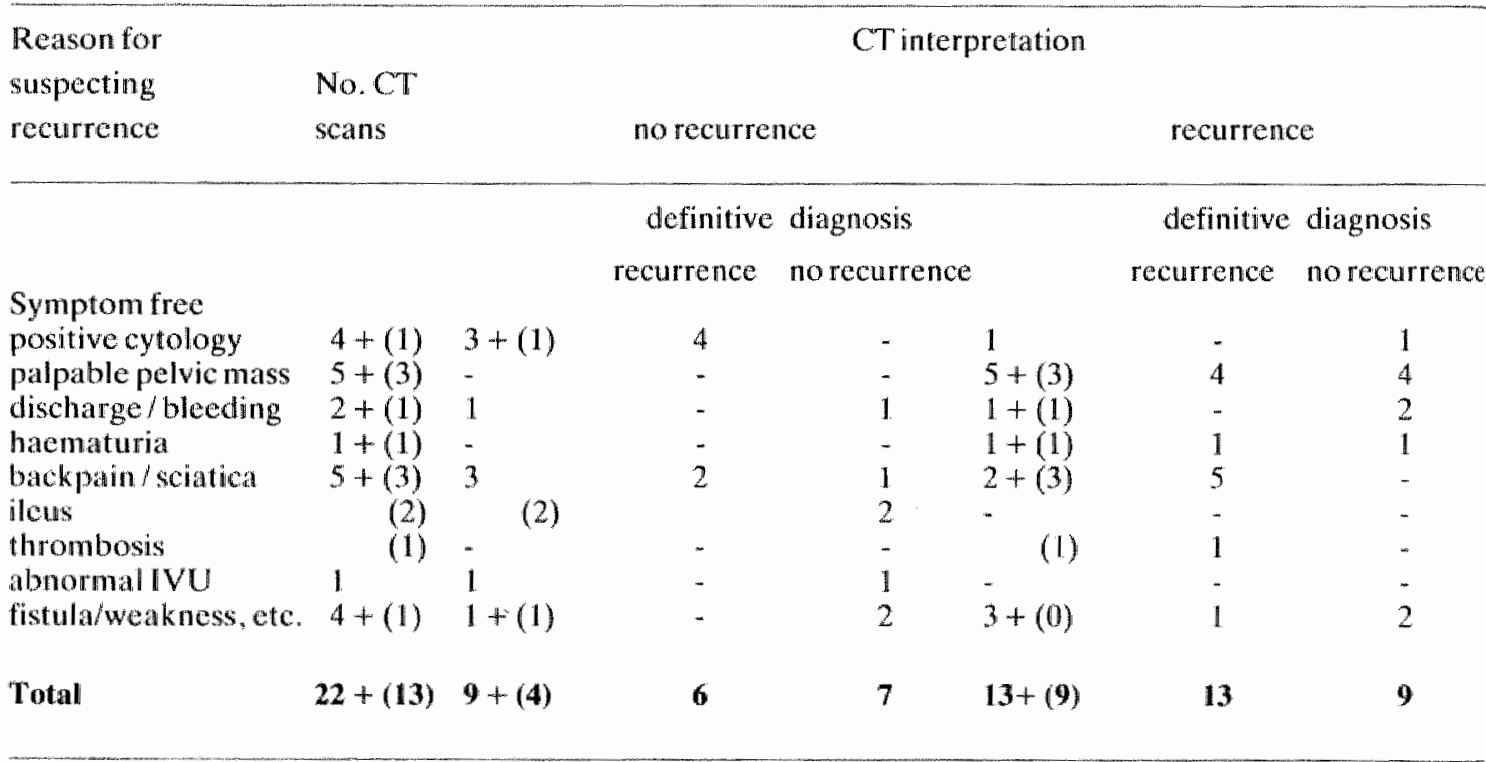

\subsubsection{Results}

Table 4-21 compares the scan interpretation with the surgical or clinical diagnosis and table 4-22 with the indication for $\mathrm{CT}$. There was disagreement between the two observers about the presence of recurrent disease in 6 cases ( 5 patients). These cases are quoted as CT. recurrence but in 5 the surgical or clinical diagnosis was "no recurrence ".

The surgical or clinical diagnosis " no recurrence" was always confirmed by a disease free period of at least 6 months (average 13 months). The methods of confirmation of the CT diagnosis " recurrent disease " are listed in table 4-23. 
Table 4.21

Correlation between CT scan interpretation and definite diagnosis in 65 CT scans of patients treated for cervical cancer (brackets indicate the retrospective study).

\begin{tabular}{|c|c|c|c|}
\hline CT diagnosis & $\begin{array}{l}\text { Surgicallo } \\
\text { norecur- } \\
\text { rence }\end{array}$ & $\begin{array}{l}\text { incaldiag } \\
\text { recur- } \\
\text { rence }\end{array}$ & toral \\
\hline no recurrence & $26+(3)$ & $7+(1)$ & $33+(4)$ \\
\hline recurrence & $13+(1)$ & $6+(8)$ & $19+(9)$ \\
\hline total & $39+(4)$ & $13+(9)$ & $52+(13)$ \\
\hline
\end{tabular}

Table 4.22

Correlation between $\mathrm{CT}$ scan interpretation and the indication for scanning in 65 patients treated for cervical cancer (brackets indicate the retrospective study).

No. of CT scans made for No. of CT Scans made for suspected recurrence. routine follow-up.

CT diagnosis

$\begin{array}{lrr}\text { no recurrence } & 9+(4) & 24+(0) \\ \text { recurrence } & 13+(9) & 6+(0)\end{array}$

Table 4.23

Method of confirmation of the CT diagnosis "recurrent cervical cancer" in 17 patients (22 CT scans) with recurrent disease.

\section{CT-scans Patients.}

Surgery (AVRUEL) and disease free period of

$1+$ year

42

Colpectomy and disease free period of $1+$ year

Biopsy and follow-up of 9 months

11

Biopsy and follow-up (dead within 3 months)

$1+1$

Follow-up only (dead within 6 months)

32

Follow-up and autopsy

$12 \quad 10$

1


Of the 8 CT false negatives, 5 scans represent 3 patients with surgically confirmed central recurrence only, another represents a patient with no clinical extensiom of a central recurrence over a 9 month period, and the last 2 were patients who had a clear clinical (and CT) pelvic recurrence three months later.

In all $14 \mathrm{CT}$ true-positives, abnormal features were clearly visible to both observers, although there were minor disagreements about locations. Table 4.24 gives the anatomical distribution of these abnormalities. In 3 scans, the abnormalities were limited to the pelvis, in 6 to the upper abdomen and in 4 were present in both regions, while in 1 patient only the mid abdominall region was scanned.

Of the 14 CT false positives, two had a large mass on the external iliac vessels, one solid with irregular contrast enhancement (fig. 4.10c.) and the other predominantly cystic with a thick irregular border (fig. 4.10b.). These scans were made 3 and 6 months respectively after an AVRUEL procedure and the corresponding clinical diagnoses were an inflammatory mass and an infected lymphocele. Both masses disappeared (after antibiotic therapy) and the patients were symptom free $6^{+}$months after the $\mathrm{CT}$ scan. A third patient, with a large complex pelvic mass, bladder wall thickening and a history of multiple pelvic operations proved to have an ovarian cyst, an abscess and an inflammatory mass but no recurrent malignancy. One of the observers interpreted this scan as "probable ovarian pathology" but no recurrent cervical disease. In the other eleven scans ( 9 patients) linear or irregular strands of soft tissue density, arranged symmetrically or asymmetrically were visible in the pelvis (fig. 4.11). Three( 2 patients) were interpreted as normal by one observer, and in 4 , a hypodense cystic region about $1-3 \mathrm{~cm}$ in diameter was visible in the pouch of Douglas (fig. 4.12).

Of the 30 scans made as routine follow-up (table 4.22$) 3$ patients had proven recurrence within three months, but in only one was this predicted by CT. However 5 scans of this group demonstrated abnormalities simulating recurrent disease, not present in reality, and probably representing radiation fibrosis.

Twenty-two scans (22 patients) made for suspected recurrence were interpreted as such, but 9 ( 9 patients) were false positives because the abnormalities seen were not caused by recurrent tumour. The probable causes were radiation fibrosis in 4 cases (fig. $4.1 \mathrm{lc}$.) a combination of post operative and radiation fibrosis in 2 (fig. $4.11 . \mathrm{a}, \mathrm{b}, \mathrm{d}$ ) a lymphocele in 1 , an inflammatory mass in 1 , and an inflammatory mass with abscess in the last. "This last patient died of post operative complications three months later, but all the others were symptom free 6 months after CT scan.

There was some interobserver interpretative variation. Six scans ( 5 patients) were classified by one observer as normal and by the other as tumour recurrence. In 5 (4 patients), the abnormalities were seen in the pelvis but the clinical diagnosis in all was "no recurrence". In one patient a density of $15 \mathrm{~mm}$ in diameter was visible behind the vena cava and interpreted as an enlarged lymphnode by one observer and as normal by the other. This patient had a very extensive tumour recurrence 3 months later and died after 4.5 months.

In one case interpreted by both observers as "tumour recurrence", there was incomplete agreement about its extent "A soft tissue mass between rectum and cervix, not distinct from either, was interpreted as recurrence with rectal invasion by one observer and as poor bowel opacification by the other. Clinical pelvic examination also revealed a mass but a 6 
months symptom free follow-up makes recurrent tumour unlikely.

Abnormalities unrelated to lumour were found in 14 patients (18 CT scans) and are listed in table $4-25$.

Table 4.25

Abnormalities unrelated to tumour found in 65 follow-up CT scans of 48 patients treated for cervical cancer.

\begin{tabular}{|c|c|c|}
\hline gallbladder disease & 3 CT scans (3 patients) & $\begin{array}{l}1 \text { stones } \\
1 \text { calcified bladder } \\
1 \text { bladde rwall thickening }\end{array}$ \\
\hline liver disease & $5 \mathrm{CT}$ scans ( 4 patients) & liver cysts \\
\hline pancreatic disease & $2 C T$ scans (1 patient) & pseudocyst \\
\hline renal disease & 4 CT scans (4 patients) & $\begin{array}{l}1 \text { stone + small kidney } \\
1 \text { small kidney } \\
2 \text { renal cyst }\end{array}$ \\
\hline $\begin{array}{l}\text { lymph node disease } \\
\text { uterine disease }\end{array}$ & $\begin{array}{l}5 \mathrm{CT} \text { scans ( } 4 \text { patients) } \\
2 \mathrm{CT} \text { scans (2 patients) }\end{array}$ & $\begin{array}{l}\text { lymphocele } \\
\text { fibroids }\end{array}$ \\
\hline
\end{tabular}

\subsubsection{Discussion}

The problems of diagnosing the presence and extent of recurrent cervical cancer are well documented in literature (Munnell and Bonney, 1961). Because surgery is the treatment of choice, many patients are subjected to laparotomy but the majority already has unresectable tumours. Curative surgery is only possible when the recurrence is limited to the uterus or upper vagina (central recurrence) or (rarely) locally spread to the parametria. Radiotherapy is only possible for recurrences in regions not previously irradiated.
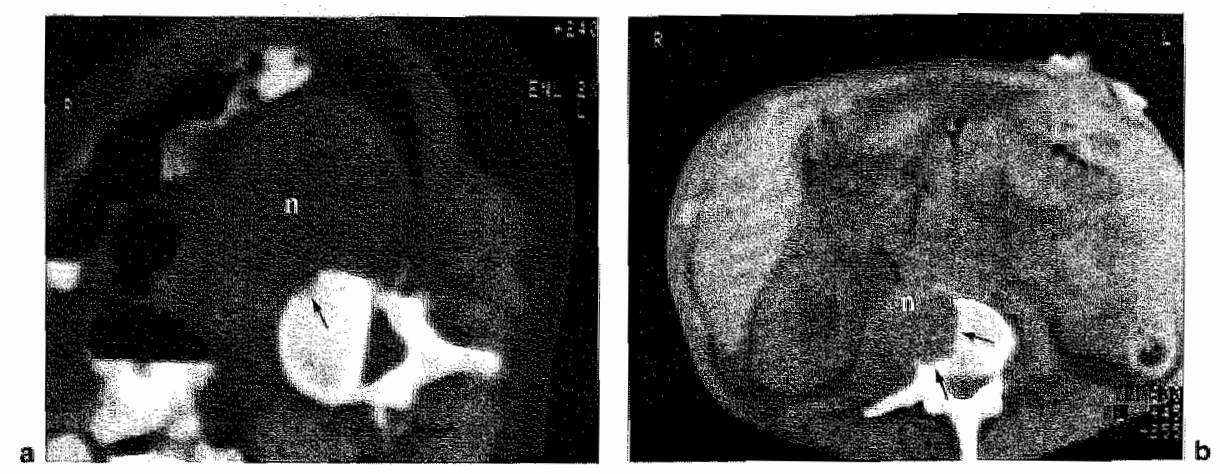

fig. 4.9 .

Recurrent cervical cancer with enlarged retroperitoneal nodes (n) infiltrat ing the vertebra (arrows) 

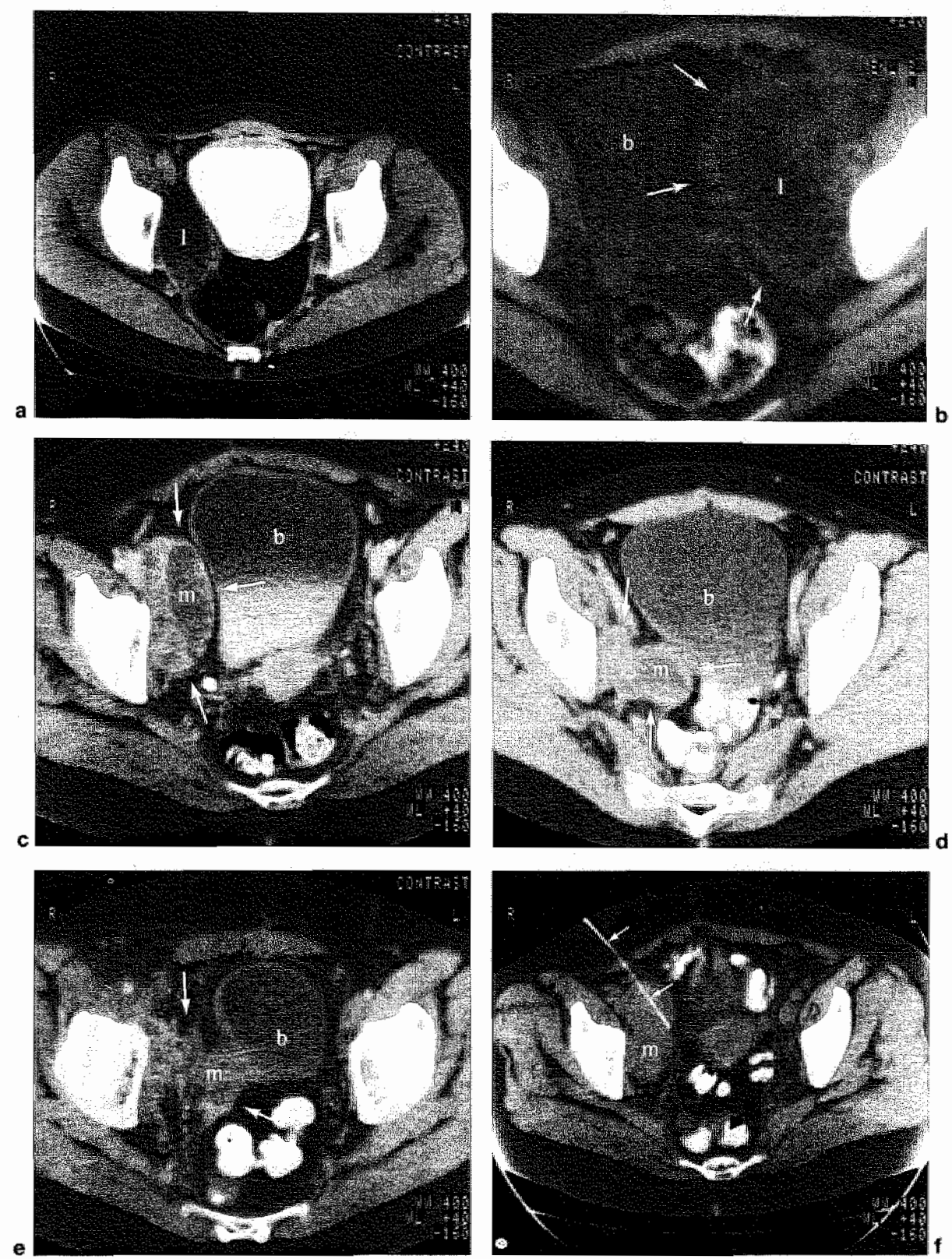

fitig. 4.10.

Five types of pelvic sidewall masses in patients with, or treated for cervical cancer: a. sharply demarcated hypodense mass (1): lymphocele in a symptom free patient. b. hypodense mass (1) with thiek irregular rim: infected lymphocele in a patient with a palpable pelvie mass and fever three months after AVRUEL. operation, treated with antibiotics only. co, solid sidewall mass (m) irregularly enhanced after bolus contrast injection: patient with carcinoma in situ of the cervix and enlarged metastatic lymph nodes with central necrosis. d. pelvic sidewall mass ( $m$ ) wioh contrast enhanced rim: recurrent cancer one year after Wertheim-Meigs operation for Ib cervical cancer. e. irregular mass (m) with bladderwall thickening: inflammatory lesion treated with antibiotics only. f. CT guided biopsy of a pelvie side wall mass $(\mathrm{m})$. The needle (arrows) is in the tumour. $(\mathrm{b}=$ bladder) 
Table 4-21 indicates a $\mathrm{CT}$ accuracy of $66 \%$ in detecting recurrent cervical cancer (sensitivity $=64 \%$, specificity $=67 \%$, F.P.R. $=33 \%$, F.N.R $=36 \%$, appendix IV). There was a high number of false-negatives (8) but 2 were routine follow-ups on symptom free patients, and at least 6 were patients with a central recurrence only and the seventh was a patient with a clinically doubtful pelvic mass that proved to be a recurrence 3 months later. All these CT scans were still interpreted as normal in retrospect, but the eighth scan was clearly abnormal in retrospect (fig. $4.8 \mathrm{a}$.). A normal CT scan does not therefore exclude a central recurrence, which is to be expected because many of these patients have very limited disease only detectable histologically. Consequently a patient with central recurrence and normal pelvic and abdominal CT scan is a candidate for curative surgery because the disease is most probably limited to uterus or upper vagina. No more than 2 of the false negative scans were false-negative for pelwic or abdominal tumour spread.

Fourteen CT scans were false-positive (F.P.R. $=33 \%$ ), of which 5 were interpreted as normal by one of the observers. In all but one, the CT abnormalities were located in the pelvis. In 3, a large pelvic mass proved to be a benign, probably inflammatory, lesion or infected lymphocele (fig. $4.10 \mathrm{~b}$ and e). In the other 11 (9 patients) the CT abnomalities were not histologically proven but may represent radiation changes. All these patients had full pelvic radiotheratpy $4-60$ months previously and 5 also had one or more pelvic operations. In 6 scans ( 5 patients) irregular solid structures were visible in the pelvis, 4 symmetrical ( 3 patuents) and 2 very asymmetrical. Three of these had had surgery, and 2 of them, with a history of multiple pelvic operations 4 and 5 years previously had the most marked abnormalities (fig. 4.11.a-d).

In 4 cases ( 3 patients) cystic masses were visible in the pelvis, symmetrically located behind the uterus and in two cases draped around the rectum, but no histological information was available as to their nature. Laparoscopy was performed in 1 patient for suspected ovarian pathology (fig. $4.12 \mathrm{c}$ ), but was nomal. All these cases were scanned before and after bolus contrast and there was excellent bowel opacification so that non contrasted bowel loops are a very unlikely explanation. All were scanned several times (pre-treatment and at least twice post treatment) and the cystic abnormality appeared gradually in the post treatment period, so may represent abnormallities caused by radiation in the field of maximum dose such as oedema or necrosis. Many authors stress that radiation fibrosis may simulate recurrent disease and some advise baseline CT after primary treatment to identify these fibrotic changes (Walsh ell al., 1981; Kilcheski et al., 1981; Haertel, 1981; Langer et al. 1981). Walsh et al. (1981) state that radiation fibrosis abnormalities are seen only in the parametrium, while recurrent disease is usually located at multiple sites in the pelvis and/or retroperitoneum. Conventional radiological signs of radiation fibrosis are well described in the literature (Libshitz, 1979) but the CT features are not. Doubleday and Bernardino (1980) describe enlargement of the presacral space to more than $1 \mathrm{~cm}$ after radiothcrapy due to an increase of fat and fibrous tissue. They stressed that symmetrical increase of perirectal strands of soft tissue density may be caused by fibrous tissue and not by recurrent cancer. The present study confirms this opinion, and shows in 2 patients that even soft tissue masses may be caused by fibrosis (fig. 4.11).

Recurrent malignancy in the pelvis on the other hand was always asymmetrical and the majority of patients also had distant masses. The density and mode of contrast enhancement of the masses gave no definite indication as to their nature. Enlarged metastatic pelvic lymph nodes may be solid or have a central hypodense region with or without irregular 

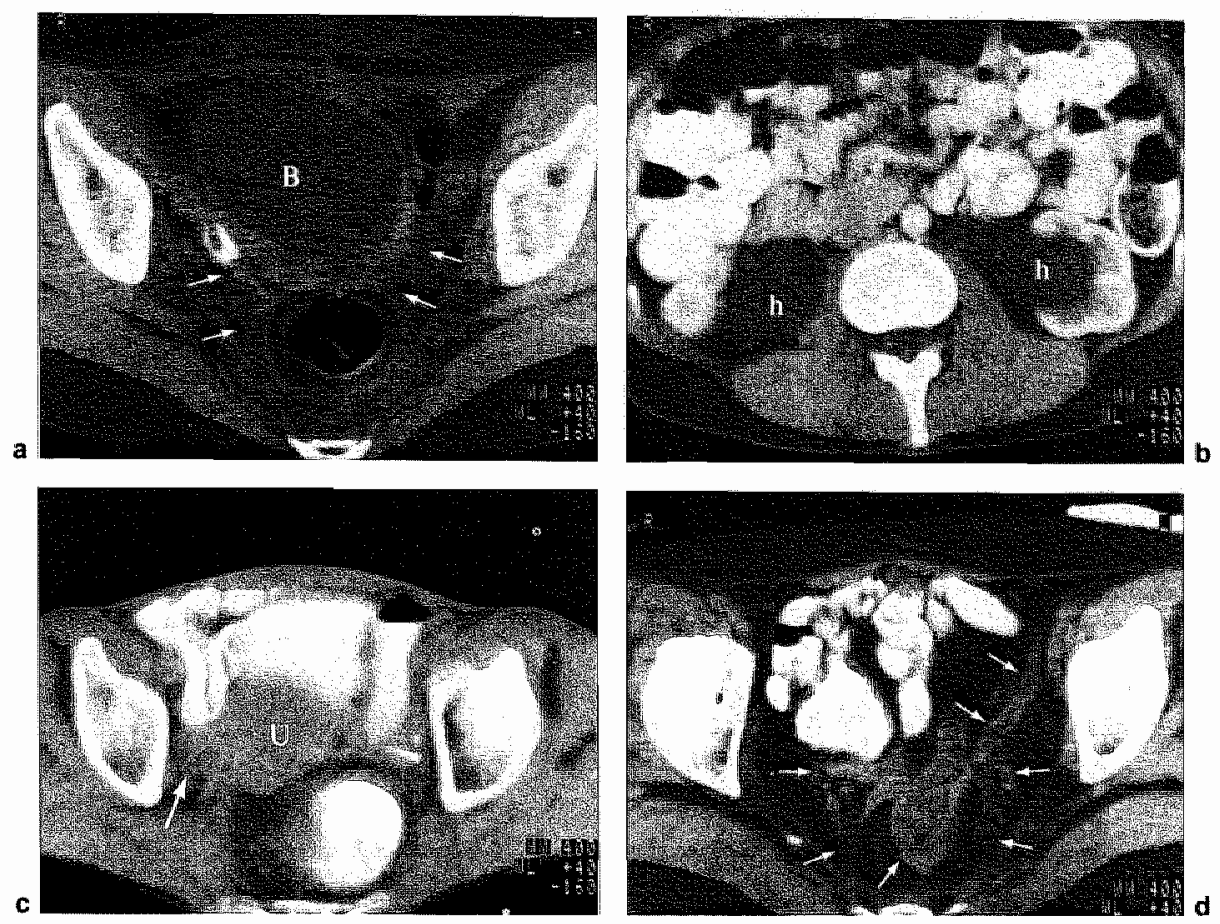

fig. 4.11

Post therapy pelwic fibrosis: a and b: Severe form of pelvic fibrosis (arrows) with hydronephrosis (hi) five year after radiotherapy and surgery for cerwical cancer. Note the symmetrical solt tissue densities in the pelvis. c. Pelvic fibrosis after radiotherapy only. Note the soft tisste mass (arrows) on the right side of the uterus (U) with strands of soft tissue to the salum. d. Severe form of fibrosis (arrows) after radiotherapy and pelvic exenteration for cervical cancer.

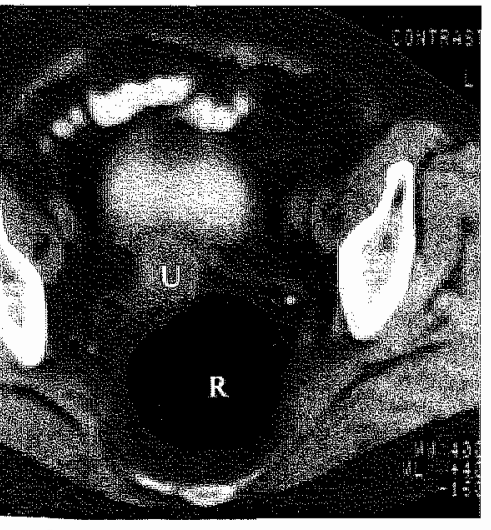

a

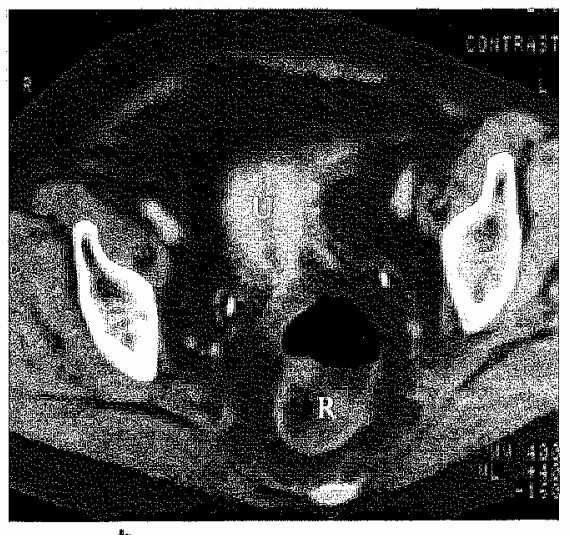

b

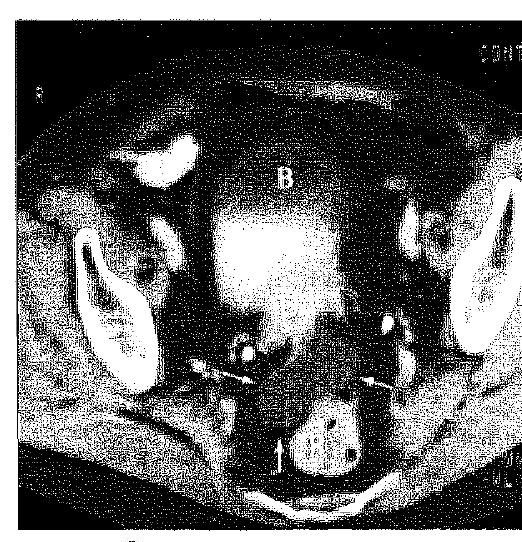

c

fig. 4.12 .

Cervical cancer clinical stage IIIA: CT scan before (a) and 6 (b) and 12 (c) months after radiotherspy; no clinical signs of recurrence. Note the hypodense mass in the pouch of Douglas (arrows) presumed to be an ovarian mass. However, laparoscopy demonstrated no abnormalities on the ovaries and there was a disease free follow up of 12 months ( $\mathrm{U}=$ uterus, $\mathrm{B}=$ bladder, $\mathrm{R}=$ rectum). 
contrast enhancement (fig. 4.10). A colid mass may also be caused by fibrosis or an inflammatory lesion, and a cystic mass by an ovarian tumour, abscess or lymphocele. A Jymphocele after partial or complete lymphadenectomy is a frequent easily identifiable feature, seen as a sharply demarcated cystic mass with thin regular wall located alongside the vessels. When infected, the appearance is more irregular with solid structures and indistinguishable from recurrent tumour or necrotic lymph nodes.

All recurrences outside uterus or vaginal wall were correctly identified by both observers. Although there is no surgical evidence of the extent of disease, $C$ T provides strong evidence of multifocal spread in 9 of the 14 patients, and the majority had tumour spread outside the pelvis (table 4-24). In 6 of the 14 cases, all abnormalities would have been missed, had only the pelvis been scanned. Lymph node enlargement, often conbined with ureteric obstruction and skeletal involvement, was the most frequent CT finding (fig. 4.9). In the four cases of skeletal involvement, the lumbar spine was always affected, presumably due to local tumour infiltration from contiguous metastatic lymph nodes rather than hacmatogenous tumour spread. It is well known in the literature that retroperitoneal lymph node metastases can invade adjacent vertebrae, and this is the most frequent type of skeletal involvement in cervical cancer (Rubin and Prabhasawat, 1961; Fisher et al., 1975 , Fisher, 1980). Conventional radiograplay and tomography rarely detect the early stages of this destructive process along a lateral aspect of the lumbar vertebral bodies, but the crosssectional image provided by CT is diagnostically superior, provided appropriate window settings are used for bone and paravertebral soft tissue. Partial wolume averaging may cause false-positive images particularly in severe kypho-scoliosis and spondylosis. Only one of the three cases of bladder invasion was biopsy proven, but the diagnosis was clinically very likely in the two other cases, and both died within 8 weeks of CT with at climically large pelvic recurrence. The CT features are irregular bladder wall thickening, with a soft tissue mass in the perivesical region (fig. 4.8). However this phenomenon was also seen in 3 other cases ( 2 inflammatory pelvic lesion, fig. $4.10 \mathrm{e}$. and 1 radiation reaction) and is therefore not specific. Bladder wall thickening (alone or combined with bowel wall thickeaing) is often seen shortly after radiotherapy.

Only one of the 30 routine follow-up CT scans (24 patients) correctly demonstrated recurrence but there were also 5 false-positive scans, presumably caused by radiation reaction. Langer et al. (1981) and Haertel (1980) both argue for a baseline study to avoid such problems, but in at least three patients with definite radiation librosis, $\mathrm{CT}$ scans betore radiotherapy and 6,12 and 18 months after radiotherapy indicate that pelvic CT abnormalitics change with time, so that a baseline study would be less helpful. This is not surprising, since although the acute complications of radiotherapy result from damage to the active proliferative system (epithelium of the skin, mucosa of bladder and bowel), the late complications result from fibrosis in the non-proliferative tissues which may increase for many years before eventually stabilizing, and it is therefore questionable if a baseline study would prevent false positive interpretation.

Table 4-20 relates the indication for CT to CT results and clinical or surgical diagnosis and shows that $C T$ is a very useful diagnostic procedure in exciuding recurrent cancer as cause of symptoms. With the exception of central recurrences in patients with positive cytology only, all recurrences were demonstrated by CT. There were false-positive findings like radiation fibrosis or inflammatory lesions, but these were always limited to the pelvis. CT 
is therefore a very useful method of diagnosing recurrent cancer spread in the pelvis or upper abdomen, but CT abnormalities should be proven cytologically or histologically, especially in the pelvis.

Backpain, particularly when radiating to the thigh or leg, is a very ominous symptom in patients with treated cervical cancer, being often caused by metastatic disease in the lumbosacral region, but identifying these metastases may be very difficult without CT. Many patients undergo a lot of investigations (including plain radiography, conventional tomography, myelography and IVU) for retroperitoneal mass lesions, bone involvement or a prolapsed intervertebral disc, but often without positive results. This study has not systematically compared the results of these conventional diagnostic procedures with CT, but in 9 patients, CT showed uni- or bilateral hydronephrosis that could have been diagnosed with IVU and/or ultrasound. Of the four cases of skeletal involvement, only one was visible on plain films.

Because CT accurately demonstrates the whole extent of recurrent cervical cancer, it should be the examination of first choice in all patients with symptoms suggestive of recurrence.

\subsection{Conclusions.}

1. CT scanning is not indicated as routine staging procedure in patients with cervical cancer. It may be helpful in patients with clinical stage II B-IV clisease to map the bulk tumour in the pelvis.

2. CT is the first examination of choice in patients with symptoms of cervical cancer recurrence.

3. CT abnormalities are not specific enough to prove recurrent cancer but need histological confirmation.

\section{References chapter IV}

AVERETTE, H.E., DUDAN, R.C., FORD, J.H. jr.: Exptoratory celiotomy for surgical staging of cervical cancer.

Am. J. Obstet. Gynaecol. 113: 1090-1096, 1972.

BERGS, J.P. and KOLSTAD, P.: Pain as a prognostic symptom in cancer of the cervix.

Acta Obstet. Gyneacol. Scand. 42, suppl 6:32-34, 1963.

BOSCH, A., FRLAS, Z. and DE VALDA, G.C.: Prognostic significance of uteretal obstruction in carcinoma of the cervix uteri.

BREIT, A. and ROHDE, U.: Computertomographic in der Gynäcologie.

Med. Klin. 74: 1881 - 1893, 1979.

BROWN, R.C., BUCHSBAUM, H.J., "TEWFIK, H.H. and PLATZ: Accuracy of lymphangiography in the diagnosis of paraaortic lymph node metastases from carcinoma of the cervix.

Obstet. Gynecol. 54: $571-575,1979$.

BRUNSCHWIG, A.: Surgical treatment of carcinoma of the cervix, recurrent after irractiation or combination of irradiation and surgery.

Am. J. Roentgenol. 99: 365-370, 1967. 
BRUNSCHWIG, A and DANIEL, W.W.: Surgical treatment of cancer of the cervix recurrent after previous radiation therapy.

Surg. Gynaecol. Obstet. 186-190. August 1957.

BUCHSBAUM, H.J.: Para-aontic lymph node involvement in cervical carcinoma.

Am. J. Obstet. Gynaecol. 113:943-547, 1972.

BURGHAROT, E and PICKEL, H.: Local spread and lymph mode involvement in cervical cancer. Obstet. Gynaccol. $52: 138-145,1978$.

BURNS, B.C.,EVERETT, H.S., BRACK, C.B.: Value of urologic study in the management of carcinoma of the cervix.

Am. J. Obstet. Gynaecol. 80: (5), 997 - 1004, 1960.

CALAME, R.J.: Recurrent carcinoma of the cervix.

Am. J. Obstet. Gynaecol. 105: 3, 380-385, 1969.

DECKER, D.G. and SMITH, R.A.: Sequential radiation therapy and surgery for stage II and stage II cancer of the cervix.

A.m. J. Roentgenol, 102: (1), 152-160, 1968.

DOUBLEDAY, L.C. and BERNARDINO, M.E.: CT findings in the perirectal area following radiation therapy.

J. Comput Assist. Tomogr 4: 634-638, 1980.

VAN ENGELSHOVEN, J.M.A.: Echographic examination of the liver in order to evaluate an abnormal scintigram.

J. Belge Radiolog., 64: $25-29,1981$.

F.I.G.O.: Classification and staging of mallignant tumours in the female pelvis.

Acta Obstet. Gymecol. Sicand 50: 1 - 7, 1971.

FISHER, M.S.: Lumbar Spine Metastasis in Cervical Carcinoma: A Characteristic Pattern.

Radialogy 134: 631-634, 1980 .

FISHER, R.G., ACKER, S. and DAY, R.W.: Extension of cervical carcinoma to lumbar spine.

Obstetrics and gynecology, 45: I, $101-105,1975$.

FRIEDMAN, E.A. and TAYLOR, H.C. jr.: Comparative cancer cure statistics.

Am. J. Obstet. Gynecol, 93: 758-763, 1965.

GREEN, Th.H., MEIGS, J.V., ULFELDER, H., CURTIN, R.R.: Urologic complications of radical Wertheim hysterectomy: Incidence, ctiology, management and prevention.

Obstet. and Gynecol., 20: (3), 293-312, 1962.

GRIFFIN, Th.W., PARKER, R.G. and TAYLOR, W.T.: An cvaluation of procedures used in staging carcinoma of the cerwix.

Am. J. Roentgenol 127:825-827, 1976.

GUTHRIE, R.T., BUCHSBAUM, H.I., WHITE, A.J., LATOURETTE, H.B.: Para-aortic lymph node irradiation in carcinoma of the uterine cervix.

Cancer, 34: 166-168, 1974.

HAERTEL., M.: Zur Computertomographie gynäkologischer Karzinome.

Fortschr. Röntgenstr. 132: 652 - 657, 1980.

HENRIKSEN, E. The lymphatic spread of carcinoma of the cervix and of the body of the uterus.

A.m. J. Obstet. Gynaecol, 58: 5,924-942, 1949.

HEYMAN, J., KOTTMEIER, H.L., SEGERDAHL, C.O.: An investigation of the reliability of stage grouping in cancer of the uterine cervix.

Actat Obstet. Gynecol. Scand. 32: 65 - 79, 1953.

KILCHESKI, Th.S., ARGER, P.H., MULHERN, Ch.B., COLEMAN, B.G., KRESSEL, H.Y., and MIKUTA, J.I.: Role of computed tomography in the presurgical evaluation of carcinoma of the cervix.

J. Comput. Assist. Tomogr, , 5: 378-383, 1981 . 
KOLBENSTVEDT, A.: Lymphography in the diagnosis of metastases from carcinoma of the uterine cervix stages $I$ and II.

Acta Radialogica Diagnosis, 16:81 - 97, 1975 .

KOTTMEIER, H.L.: Complications following radiation therapy in carcinoma of the cervix and their treatment.

Am. J. Obstet. Gynaecol, 88: (7), 854-866, 1964.

LAGASSE, L.D., BALLON, S.C., BERMAN, M.L., WATRING, W.G.: Pretreatment Iymphangiography and operative evaluation in carcinoma of the cervix.

Am. J. Obstet. Gynaecol. 134: 219-224, 1979.

LANGER, M., LANGER, R., SCHUMACHER, K.A. and MAIER, W.: Darstellbarkeit und Diffe renzierungsmöglichkeit benigner und maligner gynäkologischer Tumoren in axialen Computertomogramm.

Geburtshilfe Frauenheilkd 41:551 - 555, 1981.

LEE, J.K.T., STANLEY, R.J., SAGEL, S.S. and MoGLENNAN, B.L.: Accuracy of CT in detecting intraabdominal and pelvic lymph node metastases from pelvic cancers.

Am. J. Roentgenol. 131: 675 - 679, 1978.

LIBSHITZ, H.I.: Diagnostic roentgenology of radiotherapy change.

The Williams \& Wilkins Company, Baltimore, 1979.

MUNNELL, E.W. and BONNEY, W.A.: Critical points of failure in the therapy of cancer of the cervix.

Am. J. Obstet. Gynaecol., 81: 3,521-535, 1961.

NAGELL VAN, J.R., RODDICK, J.W., LOWIN, D.M.: The staging of cervical cancer: Inevitable discrepancies between clinical staging and pathologic findings.

Am. J. Obstet. Gynaecol., 110:973-978, 1971.

NAGELL VAN, J.R., SPRAGUE, A.D. and RODDICK, J.W.: The effect of intravenous Pyelography and cystoscopy on the staging of cervical cancer.

Gynecol. Oncol. 3: 87-91, 1975.

NELSON, K.M., HEWETT, W.J. and CHUANG F. and J.T.: Neural manifestations of para-aortic node metastases in carcinoma of the cervix.

Obstet. and Gynecol. 40: I, 45-49, 1972.

NELSON, J.H., MACASAET, M.A., LU, Th., BOHORQUEZ, J.F., SMART, G.E., NICASTRI, A. D. WALTON, L.A.: The incidence and significance of para-aortic lymph node metastases in late invasive carcinoma of the cervix.

Am. J. Obstet. Gynaecol, 118: $749-756,1974$.

PARKER, R.G. and FRIEDMAN, R.F.: A critical awaluation of the roentgenologic examination of patients with carcinoma of the cervix.

Am. J. Roentgenol. 96: 100-107, 1966.

PAUNIER, J.P., DECLOS, L. and FLETCHER. G.H.: Causes, Time of death, and siltes of failure in squamous-cell carcinoma of the uterine cervix in intact uterus.

Radiology 88: $555-562,1967$.

PIVER, M.S. The value of pretherapy para-aortic lymphadenectomy for carcinoma of the cerwix uteri.

Surg. Gynecol Obstet, 145: 17-18, 1977.

PIVER, M.S. and BARLOW, J.J.: Para-artic lymphadenectomy, aortic node biopsy and aortic lymphangiography in staging patients with advanced cervical cancer.

Cancer, 32: $367-370,1973$.

PIVER, M.S. and BARLOW, J.J.: Para-aortic lymphadenectomy ins taging patients with advanced local cervical cancer.

Obstetrics and Gynecology, 43: $544-548,1974$. 
PIVER, M.S. and CHUNG, W.S. : Prognostic significance of servical lesion size and pelvic node metastases in cervical carcinoma.

Obstetrics and Gynecology, 46:507-510, 1975.

RUBIN, Ph, and PRABHASAWAT, D.: Characteristic bonte lesions in pastirradiated carcinoma of the cervix.

Radiology, 70: 703-717, 1961 .

SHINGLETON, H.M.,FOWLER, W.C. jr., PEPPER, F.D., PALUMBO, L.: Uretal Strictures following therapy for carcinoma of the cervix.

Cancer, 24: (1), $77-83,1969$.

SHINGLETON, H.M., FOWLER, W.C. and KOCH, G.G.: Pretreatment evaluation on cervical cancer.

Am. J, Obstet. Gynaccol., 110:385-389, 1971.

SZABÒ, B.C: Disseminatie onderzok bij carcinoma colli uteri, Thesis, 1981 Groningen.

TIMMER, P.R.: De behandeling van het cervixcarcinoom in het Academisch Ziekenhuis te Groningen van 1970 - 1979.

Thesis, 1982 Groningen.

WAGGONER, Ch.M and SPRATT, J.S.: Prognostic significance of radiographic ureteropathy before and after irradiation therapy for carcinoma of the cervix.

Am. J. Obstet. Gynecvol., 105: 1107-1200, 1969.

WALSH, J.W., AMENDOLA, M.A., HALL, D.J., TISNADO, J., GOPLERUD, D.R.: Recurrent catcinoma of the cervix: CT diagnosis.

AJR 136: 117-122, 1981.

WALSH, J.W., AMENDOL..A, M.A., KONERDING, K.F., TISNADO, J. and HAZRA, T. A.: Computed tomograplyy detection of pelvic and inguinal lymph-node metastases from primary and recurrent pelvic malignant disease.

Radiology $137: 156-166,1980$.

WALSH, J.W. and GOPLERUD, D.R.: Prospective Comparison between clinical and CT staging in primary cervical carcinoma.

AM. 3. Roentgenol. 137: 997 - 1003, 1981.

WELCH, I.S. "PRATT, J.H. and SYMMONDS, R.E.: The Wentheim hysterectomy for squamous cell carcinoma of the uterine cervix.

Am. J. Obstet. Gynaecol., 81: (5),978-987, 1961. 


\section{Chapter V}

\section{Endometrial cancer}

\subsection{Introduction}

Endometrial cancer is predominantly a disease of the menopausal and postmenopausal age groups, abnormal uterine bleeding being the most frequent symptom, and all patients so presenting require pelvic examination and fractional curettage to exclude malignancy (McGowan 1978). In the early stages of disease, uterine size and configuration may be normal and a normal pelvic examination does not exclude malignancy. Fractional curettage and endometrial histology are therefore essential diagnostic procedures. At a later stage of disease, there is a slow increase in uterine size, which may be difficult to differentiate from that caused by fibroids on pelvic examination alone. Later still, fixation of the uterus and induration of the parametria indicate extension beyond the uterus, and the rare occurrence of ascites would indicate distant metastases. Treatment and prognosis are governed by the stage of disease at the moment of diagnosis. Most patients are in stage I (table 5.1.) at presentation, implying a small sized lesion with or without myometrial infilltration but histologically, all degrees of differentiation may be found. The treatment of choice in stage $I$ is surgery with or without radiotherapy which yields a $90 \% 5$ year survival rate (Keller et al. 1974). Six - $15 \%$ of patients are in stage II, on the basis of cervical involvement, and require more aggressive therapy (radical abdominal hysterectomy and pelvic lymphadenectomy) with a resultant 5 years survival rate of only $36-55 \%$ (Antoniades et al., 1973, Homesley et al., 1977, Frick et al., 1973). Only 10\% present with stage III and $3 \%$ with stage IV disease, and have corresponding 5 year survival rates of $25-44 \%$ and $0-3 \%$ (Frick et al., 1973, Antoniades et al., 1976). Although treatment in such cases is selected on a more individual basis, the majority of stage III cases receives surgery and radiotherapy, while stage IV cases receive radiotherapy only.

\section{Table 5.1}

F.I.G.O. classification of carcinoma of the corpus uteri. (F.I.G.O. 1971).

Stage I
The carcinoma is confined to the corpus
The length of the uterine cavity is $8 \mathrm{~cm}$ or less.
The length of the uterine cavity is more than $8 \mathrm{~cm}$.
The sitage I cases should be sub-grouped with regard to the
histological type of the adenocarcinoma.
The carcinoma has involved the corpus and the cervix.
III The carcinoma has extended outside the uterus but not
IV The carcinoma has extended outside the true pelvis or has
obviously involved the mucosa of the bladder or rectum.




\subsection{Spread of endometrial cancer}

Endometrial cancer spreads in three ways :

1. Directly.

- A. into and through the myometrium to the peritoneum.

- B. along the endometrium to involve the cervix or Fallopian tubes.

$-C$. by dissemination of malignant cells in the peritoneal cavity.

2. By the lymphatic route.

- A. from the uterine fundus and cornu through the broad ligament to the aortic lymph nodes, and along the round ligament to the inguinal lymph nodes.

- B. from the lower segment and cervix to the iliac, hypogastric, obturator and sacral lymph nodes.

3. By the haematogenous route to distant organs (lung, bone, etc.).

The clinical assessment of direct spread is frequently hindered by obesity and manual estimation of uterine size is non-specific since enlargement is frequently caused by fibroids (Javert 1958). However, in contrast to uterine enlargement caused by fibroids, enlargement by carcinoma may produce lengthening of the uterine cavity as assessed by a sound (F.T.G.O., 1971). Metastases beyond the pelvis can rarely be diagnosed by clinical examination, even when supplemented by colposcopy, hysteroscopy, fractional curettage, chest X-ray, I.V.U. and skeletal X-rays, as specified in the F.I.G.O.-staging system.

Table 5.2. lists the true incidence of lymph node metastases in untreated patients with endometriall cancer as found by several authors at pelvic and para-aortic lymphadenectomy. The contrast between the low incidence in stage I and the much higher incidence in stage II (cervical infiltration) is clearly visible. There are, however, other factors influencing the incidence of lymph node metastases. Liu and Meigs (1955) found an incidence of 10 in 22 cases with myometrial involvement compared to only $\mathbb{1}$ in 25 cases where the tumour was limited to the endometrium. Creasman et al. (1976) demonstrated an increased incidence with uterine enlargement, myometrial invasion and poorer histological differentiation. All these factors must therefore be considered in the choice of therapy.

\section{Table 5.2}

The incidence of metastatic lymph nodes in patients with endometrial cancer as found at pelvic and para-sortic lymphadenectomy (several authors).

\begin{tabular}{|c|c|c|c|c|}
\hline \multirow[t]{2}{*}{ Author(s) } & \multicolumn{3}{|c|}{ clinical stage } & \\
\hline & \multicolumn{2}{|c|}{ I } & \multicolumn{2}{|c|}{ II } \\
\hline & pelvic & para & pelvic & para \\
\hline & lymph & aortic & lymph & aortic \\
\hline & nodes & lymph & nodes & lymph \\
\hline & nodes & & nodes & \\
\hline Liu and Mcigs 1955 & $4 / 33$ & - & $7 / 14$ & \\
\hline Morrowet al. 1973 & $39 / 369$ & - & $31 / 85$ & \\
\hline Creasman etal. 1976 & $16 / 140$ & $8 / 100$ & - & \\
\hline Total & $59 / 542$ & $8 / 100$ & $38 / 99$ & \\
\hline & $(10.9 \%)$ & $(8 \%)$ & $(38.4 \%)$ & \\
\hline
\end{tabular}


Adnexal metastases may also be missed clinically, as indicated by Gusberg's study (1078) of 251 patients, in which 25 of the 36 cases of adnexal metastases were only detectable microscopically. The true incidence of distant metastases at the time of diagnosis is unknown, but can be presumed to be very low. Yoonessi et al. (1979) found lung metastases in $16 \%$, liver metastases in $8 \%$ and bone metastases in $5 \%$ of 105 patients dying of endometrial cancer. Reddy et al. (1979) found recurrences with distant metastases in $2.8 \%$ of patients treated with surgery or combines surgery and radiotherapy for endometrial carcinoma stage I. D'Orsi et al. (1979) found lung metastlases initially or during the disease course in $3.6 \%$ of 669 patients with endometrial cancer.

In spite of the fact that most patients with endometrial cancer have stage I disease and the overall incidence of distant metastases is very low, many special radiological investigations are used in staging the disease, and these must therefore be discussed briefly.

\subsection{Radiological imaging techniques in staging endometrial cancer}

Although I.V.U., chest X-ray and skeletal X-rays can be used to stage endometrial cancer (F.I.G.O. 1971), the yield of tumour related abnomalities is very low. To our knowledge, there are no large studies on the incidence of I.V.U. abnormalities in patients with endometrial cancer, and although Klempener (1952) and Long and Montgomery (1950) quote rates of $40 \%$ and $32 \%$ respectively for hydronephrosis, these figures cannot be regarded as representative because their series were small and selected. It is likely that hydronephrosis is caused less frequently by endometrial than by cervical cancer because of the high incidence of limited disease in the former. Likewise, chest X-ray is necessary ats a base-line investigation, because, although the incidence of tumour related pulmonary abnormalities in endometrial cancer is very low, the incidence of pulmonary involvement is $35-37 \%$ in those cases where the disease is disseminated (D'Orsi et al. 1979). Many authors have adwocated the use of hysterography as an accurate diagnostic method for both the presence and extent of endometrial cancer (Dufresne et al. 1959, Hilfich et al. 1969, Wallace et al, 1974) and some have related size and location of the tumour, as demonstrated hysterographically, to the prognosis (Johnsson and Norman 1979). The technique, however, has gained little popularity, and has been almost totally abandoned. Angiography is used in an attempt to demonstrate tumour extension through myometrium to the pelvic wall and to differentiate endometrial carcinoma from other malignant and benign tumours of uterus or adnexa (Lang 1967, Lang 1980), but the results have been disappointing in general. As in cervical cancer, lymphography is often used to stage endometrial cancer, which itself may behave and spread like cervical cancer when the disease is in the lower segment or cervicall regions. Table 5.3 . correlates the incidence of lymphographic findings with clinical stage, and may be compared with table 5.2. Very little is known about the potential role of computed tomography in the diagnosis and staging of uterine corpus tumours. Heartel's (1980) series included 47 patients with endometrial cancer of whom 37 were scanned as a prinary staging procedure. He concluded, as did Breit and Rohde (1979), that there were no typical CT features for stage I and II endometrial cancer. Parametrial involvement was diagnosed by irregular uterine borders with soft tissue mass extensions. A hypodense region in the uterine corpus and uterine enlargement though not often visible, were considered to be non-specific signs which could also be caused by fibroids or haematomata. 
Table 5.3.

Incidence of abnormal lymphangiograms in patients with endometrial cancer related to clinical stage (several authors).

\begin{tabular}{lcccc}
\hline Awhor(s) & \multicolumn{4}{c}{ clinicalstage } \\
& $\mathrm{I}$ & II & III & IV \\
\hline Kademian et al. (1977) & $6 / 48$ & $3 / 25$ & $9 / 25$ & $6 / 10$ \\
Musumeciet al. (1980) & $12 / 134$ & $8 / 28$ & $8 / 14$ & $4 / 6$ \\
Total & $18 / 182$ & $11 / 53$ & $17 / 39$ & $10 / 16$ \\
& $(10 \%)$ & $(21 \%)$ & $(44 \%)$ & $(63 \%)$ \\
\hline
\end{tabular}

CT abnormalities indicative of lymph node metastases were found in nearly $50 \%$ of the patients. Hamlin et al. (198\%) prospectively compared CT findings before and after bolus contrast injection with macroscopic and microscopic pathological findings in 10 patients with early stage endometrial cancer. There was non-uniform contrast enhancement of the tumour in these cases but, being much less than in the adjacent myometrium, this resulted in a hypodense region on post contrast CT scans. This feature was only visible when the tumour had involved more than one third of the uterine wall, and in their opinion, CT may play a useful role in staging and in subsequent treatment planning. In three of these cases, the hypodense region had a hyperdense centre.

\subsection{Study of CT features in untreated patients with endometrial cancer}

\subsubsection{Introduction}

Computed tomography is often used in the diagnosis of disease of the female pelvis, and the CT features of a nomal uterus are described and discussed in chapter III. The CT features of a uterus with endometrial cancer are less well known, and the purpose of this study is to describe such features in untreated patients, and to compare them with surgical and pathological findings.

\subsubsection{Method and material}

Twenty-two consecutive patients aged $47-85$ years (average 64 years, all postmenopausal) with histologically proven endometrial cancer (19 adenocarcinoma of varying grade of differentiation and 3 adeno-acanthomas) had a CT scan of pelvis and abdomen as described in chapter II. In 14, the pelvis was scanned before and after intravenous bolus contrast in jection, in 6,15-30 minutes after a contrast injection at another level, while in 2, no intravenous contrast medium was used. All had a physical examination under anaesthesiat and fractional curettage 2 - 23 days before CT examination (average 10 days). The F.I.G.O.stages are listed in table 5.4 .

Twenty patients had a laparotomy within 27 days of CT scan (average 5.8 days), one being found to be inoperable and the remainder having total abdominal hysterectomy and bilateral salpingo-oophorectomy. Another patient had total abdominal hysterectomy and bilateral 
Table 5.4.

Relation between F.I.G.O. stages and surgical and pathological findings concerning the extent of disease in 22 patients with histologically proven endometrial cancer. (I patient was not operated and one patient proved to be inoperable during laparotomy).

\begin{tabular}{|c|c|c|c|c|c|c|c|c|c|}
\hline \multirow{3}{*}{$\begin{array}{l}\text { FIGO } \\
\text { srage }\end{array}$} & \multirow{3}{*}{$\begin{array}{l}\text { no. } \\
\text { parients }\end{array}$} & \multicolumn{8}{|c|}{ surgical and pathological findings: } \\
\hline & & \multicolumn{2}{|c|}{$\begin{array}{l}\text { myometrium } \\
\text { invasion }\end{array}$} & \multicolumn{2}{|c|}{$\begin{array}{l}\text { parametrium } \\
\text { involvement }\end{array}$} & \multicolumn{2}{|c|}{$\begin{array}{l}\text { lymph node } \\
\text { metastoses }\end{array}$} & \multicolumn{2}{|c|}{$\begin{array}{l}\text { ovarian } \\
\text { pathology }\end{array}$} \\
\hline & & $<50 \%$ & $>50 \%$ & yes & no & yes & no & yes & no \\
\hline IA & 8 & 5 & 3 & 0 & 8 & 0 & 8 & 2 & 6 \\
\hline $\mathbf{B}$ & 7 & 2 & 5 & 0 & 7 & 0 & 7 & 2 & 5 \\
\hline II & 2 & 1 & 1 & 0 & 2 & 0 & 2 & 0 & 2 \\
\hline III & 4 & 0 & 3 & 3 & 1 & 3 & 1 & 2 & 2 \\
\hline IV & 1 & - & - & - & - & - & - & - & $=$ \\
\hline Total & 22 & 8 & 12 & 3 & 18 & 3 & 18 & 6 & 15 \\
\hline
\end{tabular}

salpingo-oophorectomy 255 days after CT and one patient was not operated on account of malignant ascites.

All CT scans were reviewed with particular reference to uterine size, shape, and density before and after contrast injection, ovarian size, and parametrial soft tissue masses. Ovaries of more than three $\mathrm{cm}$ in diameter or containing cystic abnormalities were recorded as possible metastases, and irregular soft tissue mass extension from the uterus as parametrial involvement. Soft tissue masses of more than $1.5 \mathrm{~cm}$ in diameter in the region of the pelvic neurovascular bundle were recorded as enlarged lymph nodes. Non cystic focal liver lesions, suprarenal masses, peritoneall and omental soft tissue masses and skeletal lesions were recorded as possible metastases. All pathological reports were reviewed with particular reference to the location and size of the tumour, the extent of myometrial infiltration and the presence or absence of ovarian abnormalities. Surgical, pathological and CT findings were compared, and in 6 cases, the dimensions of the fresh operation specimens were compared with CT measurements.

\subsubsection{Results}

Surgical and pathological findings are listed in table 5.4. and $\mathrm{CT}$ findings in table 5.5. In 13 patients the uterus in CT cross-5ection was lobulated, in three circullar and in 6 oval and the average left-right diameter of the corpus was $6.1 \mathrm{~cm}(2.5-12 \mathrm{~cm})$ while that of the cervix was $4.9 \mathrm{~cm}(3.6-7.7)$. The dimensions of fresh operation specimens in 6 cases are compared with CT measurements in table 5.6.

In 17 cases $(77 \%)$ a central lucency was visible in the corpus, both before and after bolus contrast injection in three cases, and only after contrast injection in 9 cases. Of the remaining 5, three had no pre contrast scan and two had no post contrast scan to enable comparisons to be made. Table 5.5. expresses the lucency diameter as a ratio of the uterine diameter (L/D) 


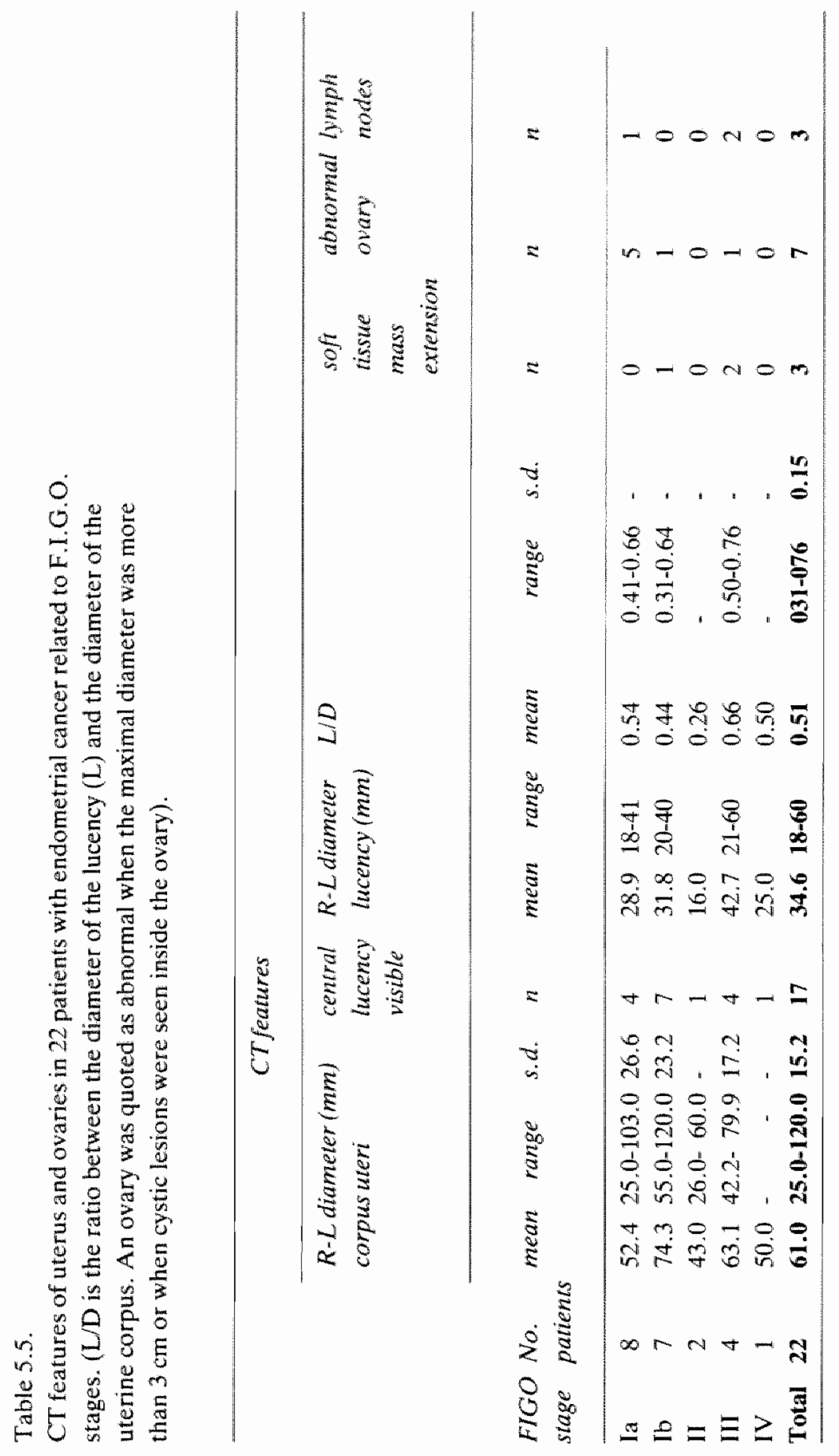


Table 5.6.

Comparison between the dimensions of corpus and cervix uteri in CT and the fresh surgical specimens, in 6 patients with endometrial cancer.

\begin{tabular}{|c|c|c|c|c|c|c|}
\hline \multirow[t]{2}{*}{ Patient } & \multicolumn{3}{|c|}{$\begin{array}{l}\text { Maximalcorpus } \\
R \text {-L diameter }\end{array}$} & \multicolumn{3}{|c|}{$\begin{array}{l}\text { Maximalcervix } \\
R \text {-L diameter }\end{array}$} \\
\hline & $C T$ & surgery & difference & $C T$ & surgery & difference \\
\hline 1 & $56.1 \mathrm{~mm}$ & $55 \mathrm{~mm}$ & $+20 \%$ & $64 \mathrm{~mm}$ & $26 \mathrm{~mm}$ & $+146 \%$ \\
\hline 2 & 64.7 & 60 & $+8 \%$ & 62.9 & 40 & $+72 \%$ \\
\hline 3 & 55.0 & 60 & $-8 \%$ & 49.0 & & \\
\hline 4 & 64.7 & 60 & $+8 \%$ & 50.0 & 45 & $+11 \%$ \\
\hline 5 & 57.0 & 55 & $+4 \%$ & 50.0 & 27 & $+85 \%$ \\
\hline 6 & 60.0 & 50 & $+20 \%$ & 51.0 & 35 & $+46 \%$ \\
\hline
\end{tabular}

and it can been seen that these lucencies were sometimes very large (fig. $5.1 \mathrm{~d}$ ). In the 12 cases with a pre and post contrast scan, slight contrast enhancement of the corpus centre could be demonstrated (from 32 - 81 Hounsfield Units pre contrast to 42 - 123 Hounsfield Units post contrast, the contrast enhancement being $7-82 \%$, average $44 \%$ ), but the enhancement of the rim was always much more intense.

In 8 patients, myometrial invasion was absent or less than $50 \%$ in extent. A central lucency was clearly visible on CT in all but three of these patients. In ten of the twelve cases with more than $50 \%$ myometrial invasion a large central lucency was visible, one of the exceptions being a case operated 255 days after CT scamning (patient delay). Of the 3 cases with invasion of the cervix, in one the large corpus lucency was also visible in cervical cuts, but of the other two, one had a completely normal CT scan and the other a small lucency visible in the uterine corpus.

The results of CT scanning in relation to parametrial involvement, lymph node pathology and ovarian pathology are listed in table 5.5 . It should be noted that pelvic lymphadenectomy was performed only for lymph node enlargement and not routinely.

Of the three cases of CT indicated lymph node enlargement, two were true-positives for metastatic disease and one was a false-positive being an enlarged node which was histologically normal. There was also one false-negative, being an enlarged pelvic node, palpably abnormal at operation and containing histologically proven metastatic deposits. CT indicated parametrial involvement in three cases, one being a false positive which proved histologically to be a fibroid causing local soft tissue mass extension. There was one false negative case in which there was local tumour extension at the fundus of the uterus. Of the 7 abnormal ovaries ( $18-50 \mathrm{~mm}$ diameter) (6 patients) on CT, six contained small cystic lesions, and the seventh was only slightly enlarged ( $31 \mathrm{~mm})$. All proved to be histologically abnormal, but only 4 were malignant, two containing a simple cyst and one a cystadenofibroma. In one patient with a malignant ovary correctly identified as pathological on CT, the contralateral ovary was not seen on CT, but proven histologically to be malignant. Two further patients had a malignant ovary not seen on CT. Six (28\%) of the 21 patients who were operated had at least one malignant ovary. The one patient with stage IV disease clinically had endometrial cancer and malignant ascites, and CT revealed omental masses 
and a renal mass lesion, and confirmed ascites. The patient was not operated and died 3 months later.

Punctate uterine calcification was seen in CT in 7 cases, six of whom had histologically proven fibroids, varying in size from $2-12 \mathrm{~cm}$ in diameter. The only additional CT evidence of fibroids was uterine enlargement in some cases. In 4 patients with no $C T$ evidence of fibroids at original or retrospective assessment, fibroids varying between 0.75 and $2.5 \mathrm{~cm}$ in diameter were nevertheless found histologically.

\subsubsection{Discussion}

Prognosis and therapy of endometrial cancer is determined by its spread within and beyond the uterus. The size of the uterus estimated by palpation is an unreliable prognostic sign because it is determined by many other factors such as fibroids, but the size of the uterine cavity as measured by sounding is part of F.I.G.O. classification. Ultrasound is insufficiently accurate in differentiating malignant from benign causes of uterine enlargement. Requard et al. (1981) found no diagnostic ultrasound criteria for endometrial cancer, but there were statistically significant differences in uterine shape and echo pattern between stage II - II disease and III - IV disease. Left-right diameter maesurement of the uterine corpus on CT compare well with surgical specimen maesurements (table 5.6.) but uterine length cannot be accurately measured on CT using only cross-sectional images (Chen et all. 1980). This study demonstrates statistically significant differences between left-right diameter measurements of the uterine corpus in 22 patients with endometrial cancer and those of the postmenopausal control group from chapter III $(0.001<P<0.01$, Student $t$ test $)$. Uterine calcifications suggestive of fibroids were visible in 4 of the 21 controls and 7 of the 22 endometrial cancer patients. In the patient group, however, fibroids were found histologically in 4 more patients, being completely missed on CT in three cases, the fourth case being a non-calcified fibroid clearly visible retrospectively on $\mathrm{CT}^{*}$ as a hyperdense intramural lesion deforming the uterine contour on a post contrast scan. Tada et al (1981) described the CT features of uterine myomata, based on operative correlation in 83 cases, as follows : a lobulations and/or protrusions of the outer contours of the uterus. b. soft tissue mass within the uterine cavity, which may be distorted or obliterated. c. calcification d. irregular low density areas within the soft tissue mass. Even using these criteria, the fibroids in the three cases in our patient group would still have been missed, probably because their diameters were only $1.5,2$ and $2.5 \mathrm{~cm}$ respectively.

Hamlin et al. (1981) related a central lucency in the uterine corpus on post contrast CT scan to the depth of myometrial invasion, and, although this phenomenon was seen in 17 $(77 \%)$ of the 22 patients of the present study, a central region of contrast enhancement in the lucent area, as also described by Hamlin et al. (198.) was never seen. The lucent area was frequently only visible on post contrast CT scans (fig. 5.1 and 5.2), and often inhomogeneous with some degree of contrast enhancement, indicating that the centre was not always entirely avascular. Many endometrial tumours are polypoid and exophytic, occupying much of the uterine cavity (Demopoulos, 1977) as found in cases of our material, while in other cases the uterine cavity contained only a small tumour and much necrotic tissue and blood clot, and CT differentiation of tumour from necrotic tissue was not possible. In one case of pyometra (not included in this study) a large central lucent area was visible in post contrast CT although pre contrast scan was normal and histopathological examination 

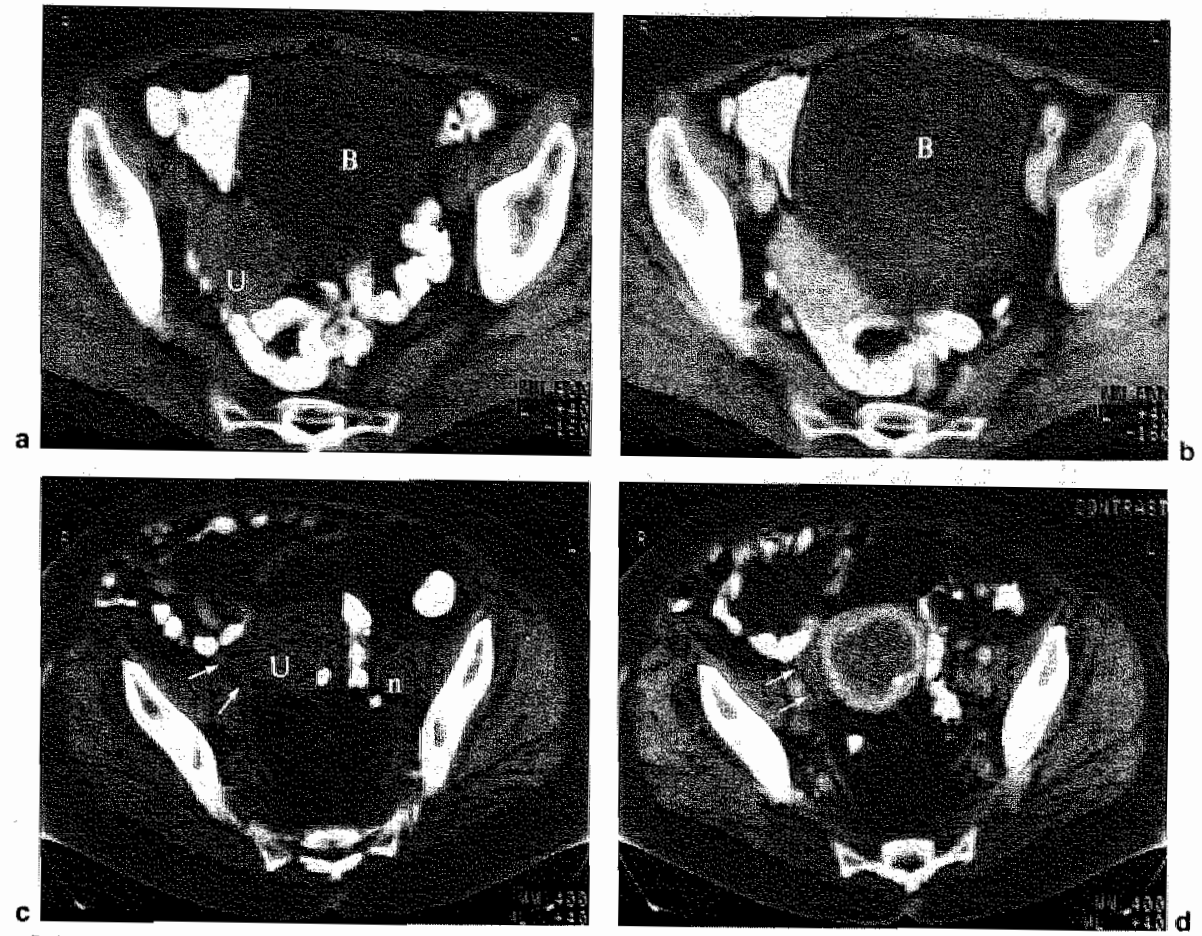

fig. 5.1 .

Two cases of adenocarcinoma of the endometriun., a and b. normal $C \mathrm{~T}$ scan before and after $i . v$. contrast; histology revealed a small carcinoma with less than $50 \%$ myometrial invasion. cand d. scans before and after $i . v$. contrast showing an uterus with calcification and a large lucency $(1 / D=0.65)$ in the post contrast scan, an enlarged external iliac lymph node (n) on the left and a soft tissue mass on the right side against the uterus presumably the tight ovary (arrows). Laparotomy demonstated inoperability due to parametrium involvement, positive pelvic lymph nodes, ascites and omental metastases ( $U=$ utcrus. $\mathrm{B}=$ bladder $)$.

revealed pyometra with no malignancy. Nevertheless, pyometra is nearly always associated with uterine malignancy, but a central lucency should not be regarded as specific for endometrial cancer, because it was also present in 4 of the 22 cases in the postmenopausal control group. The true ineidence of a hypodense zone in the uterine corpus in the control group is likely to be even higher, because only 10 of the 22 cases were scanned post contrast. However the left-right diameter of the lucent zone was much larger in the cancer group (18 $-60 \mathrm{~mm}$, average $34.6 \mathrm{~mm}$ ) than in the control group $(10-16 \mathrm{~mm}$, average $13.3 \mathrm{~mm})$, and there was a similar difference between the two groups when the lucency diameter is expressed as a ratio of the uterine diameter as a whole ( $L / D$, table 5.5). The difference is statistically significant ( $\mathrm{P}<0.001$ Student $t$ test).

Although, in general, the presence of a lucency in the uterine corpus, particularly on post contrast scans, does not in itself indicate pathology, if the diameter of the lucency is greater than $35 \%$ of the left-right uterine diameter, a gynaecological examination is indicated to exclude malignancy.

In the assessment of parametrial involvement, the false-positive and false-negative cases were caused respectively by misinterpreted fibroid and a missed fundal mass. Both these problems are common and almost unavoidable. The high number of true-negatives merely 

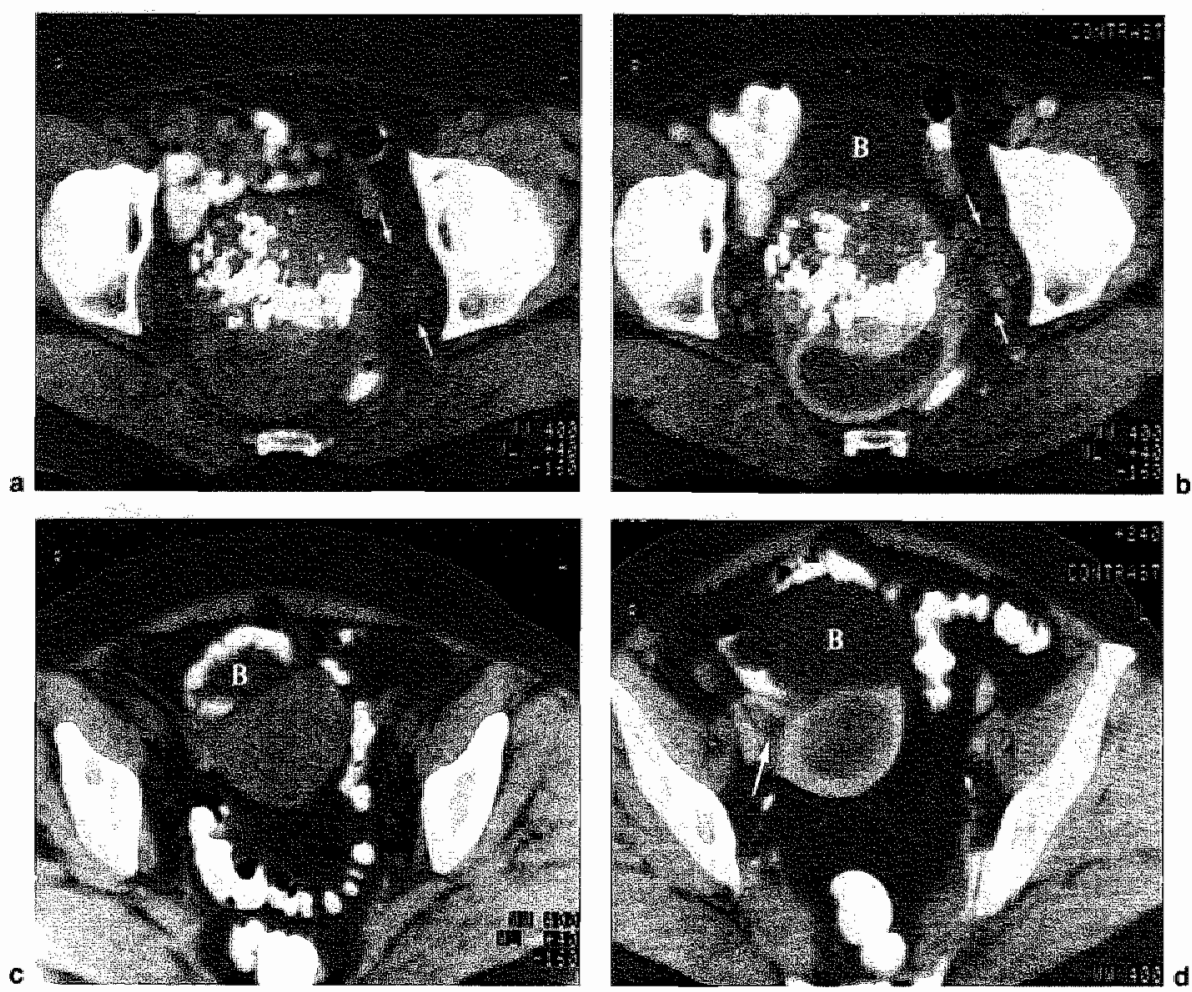

fig. 5.2 .

Two cases of adenocarcinoma of the endometrium. $\mathrm{Cr}$ sean before (a) and after b) i.v. contrast. $\mathrm{CT}$ demonstrates a large calcified pelvic mass ventral in the tterus, a large lucency (L.D $=0.76)$ dorsal in the uterus only visible on the post contrast scan and a soft tissue mass extension on the left (arrows) reaching the pelvic wall. Laparotomy revealed a large calcified fibroid, endometrial cancer with tumour invasion in the myometrium of more than $50 \%$ of its wall thickness and parametrial involvement on the left.

Cl scans before (c) and after (d) i.v. contrast. The scan after contrast teveals a large central lucency $(L / D=0,74)$ in the corpus and a small lucency in the right ovary (arrow), not wisible on the pre contrast scan. Pathologic examination demonstrated myometrial invasion of more than $50 \%$, tumour locations in the right ovary, metastatic lymph nodes ( not seen in $\mathrm{CT}$ ) and endocervical invasion $(\mathrm{B}=$ bladder).

reflects the high incidence of early stage cancers. Bolus contrast injection does not, in general, improve differentiation between fibroid and parametrial infiltration, because both may have similar enhancement characteristics. Furthermore, as discussed in chapter III the adnexa may appear singly or together in the same plane as the uterine fundus and continuous with it and they are therefore then indistinguishable from local tumor spread.

Ovarian pathology is frequently diagnosed on CT by the criteria of size and density. Histologically $28 \%$ of the patients had cancer in the ovaries which is a much higher incidence than mentioned by Gusberg (1978). Only 14\% of the ovaries in the postmenopausal control group were visible and all were solid. In the 22 paticnts in the cancer group, 10 ovaries $(23 \%)$ were identified, 4 solid and 6 cystic. All cystic lesions were histologically proven, 3 being malignant, emphasizing the seriousness of such a finding in postmenopausal patients with endometrial cancer. 


\subsection{CT in recurrent endometrial malignancy}

\subsubsection{Introduction}

The purpose of this study is to describe CT abnormalities in patients with recurrent endometrial malignancy and to compare these with surgical and/or clinical findings.

\subsection{Method and material}

Fourteen patients, previously treated for uterine corpus malignancy $(13$ endometrial cancer and one leiomyosarcoma) were suspected clinically of having recurrent disease, and therefore scanned between one and 180 months after original treatment. Four patients complained of back pain, one had urinary incontinence, one had recurrent urinary infection with a distally obstructed ureter on I.V.U., one had severe gastrointestinal symptoms with sigmoid narrowing on barium enema, two had ascites, one had a deep venous thrombosis, two were found to have pulmonary masses on routine chest X-ray for unrelated reasons, one had abnormal liver function tests on routine follow-up and in one paticnt the reasons for scanning were unknown. All CT scans were reviewed using the criteria in chapter IV and the results were compared with the findings of autopsy (4 patients), laparoscopy (1 patient) and further follow-up ( 9 patients), the 6 cases without recurrence being disease free after 6 months.

Table 5.7.

Comparison between CT and definite diagnosis in 14 patients with clinically suspected recurrent disease.

Surgicallinical diagnosis

norecurrence recurrence

CT diagnosis

Norecurrence $4 \quad 0$

$\begin{array}{lll}\text { Recurrence } & 2 & 8\end{array}$

Table 5.8 .

The incidence of $\mathrm{CT}$ abnormalities in 8 patients

(8CT scans) with proven recurrent endometrial cancer.

\begin{tabular}{ll}
\hline ascites & 2 patients \\
peritoneal/mesenteric metastases & 3 patients \\
liver capsule metastases & 2 patients \\
liver metastases & 4 patients \\
lymph node enlargement & 1 patient \\
pelvic mass lesion & 1 patient
\end{tabular}




\subsubsection{Results}

Table 5.7. compares the CT diagnosis with the clinical/surgical diagnosis in these 14 patients, and table 5.8 records the anatomical distribution of $\mathrm{CT}$ features.

Only 2 scans were completely normal. One scan demonstrated gallstones only and another scan confirmed ureteric obstruction alreadly demonstrated by I.V.LI., but no tumour. The remaining 10 scans suggested recurrent tumour, but two of these were false-positives when compared to clinical/aparoscopic findings. One was probably caused by poor bowel opacification because two presumed pelvic mass lesions wete not confirmed laparoscopically, and the patients had a disease free period of over 18 months. The other was scanned for a palpable pelvic mass, which was not confirmed on CT w but a pulmonary mass lesion was demonstrated in a lung base. The patient was, nevertheless, symptom free 12 months later. In the remaining \& patients, CT correctly demonstrated recurrent disease and all patients were dead within 6 months, in spite of chemotherapy in some cases.

\subsubsection{Discussion}

Table 5.7. indicates that in patients with suspected recurrent endometrial malignancy, $\mathrm{CT}$ is a reliable diagnostic method to confirm or exclude recurrence. The only false-positive abdominal scan was caused by poor bowel opacification. The anatomical distribution of recurrences given in table 5.8. indicates that CT scanning for recurrent disease should include the whole pelvis and upper abdomen.

\subsection{Conclusions}

1. A lucency in the uterine corpus with a diameter of $35 \%$ or more of the uterine diameter, as seen in $\mathrm{CT}$, should be regarded as an indication of uterine pathology and requests further gynaccological examination to exclude malignancy.

2. CT is a reliable diagnostic method to confurm or exclude endometrial cancer recurrence.

\section{References chapter $\mathrm{V}$}

ANTONIADES, 1., BRADY, L.W. and LEWIS, G.C.: The management of stage If carcinoma of the endometrium.

Cancer $38: 1838-18 \ldots, 1976$.

ANTONIADES, J., MORTEL, R., LEWEIS, G.C., FACOG, BRADY, L.W., FAUST, D.S., PRASSASVINICHAI, S., TORPIE, R.J. and ASBELL, S.O.: The management of carcinoma involving the eervix and body of the uterus.

Obstet. Gynecol. 42: 208-212, 1973.

BREIT, A. and ROHDE, U.: Computertomography in der Gynäcologie

Med. Klin. 74: 1881-1893, 1979.

CHEN, S.S., FACOG, RUMARI, S. and LEE, L.: Contribution of abdominal Computed tomography (CT) in the management of Gynecologic Cancer: Correlated study of CT image and Gross surgical pathology.

Gynceologic oncology 10: 162-172.1980. 
CREASMAN, W.T., BORONOW, R.C., MORROW, C.P., DISAIA, P.I. and BLESSING J.: Adenocarcinoma of the endometrium: Its metastatic lymph node potential.

Gynecol. Oncol 4: 239-243, 1976.

DEMOPOULOS, R.I.: Carsinoma of the endometrium, in: Pathology of the female genital tract. pp. 278 - 298 Eds: Blaustein A.

Springer Verlag New York, 1977.

D'ORSI, C.J., BRUCKMAN, J., MAUCH, P., SMITH, E.H.: Lung metastuses in cervical and endometrial carcinoma.

AJR 133: 719-722, 1979.

DUFRESNE, M.R., GERIN-LAJOIE, L, and MALTAIS, R.: Problems in hysterosalpingography. J. Am. Med. Assos. 170: 1169-1171, 1959.

F. I.G.O.: Classification and staging of malignant tumours in the female pelvis.

Acta Obstet. Gynecol. Scand. 50: $\mathbb{1}-7,1971$.

FRICK, H.C., MUNNEL, E.W., RICHART, R.M., BERGER, A.P. and LAWRY, M.F. Carcinoma of the endometrium.

Am. J, Obstet. Gynecol. 115:663 - 676, 1973.

GUSBERG, S.B.: Cancer of the endometrum: Diagnosis and Histogenesis.

in: Corscaden's Gynecologic Cancer pp 265 - 300 Eds.: Gusberg, S.B. an Frick II, H.C.

The Williams and Wilkins Company, Battimore, 1978.

HAERTEL, M.: Zur Computertomographie gynäcologischer Karzinome.

Fortschr. Röntgenstr. 132:652-657, 1980.

HAMLIN, D.J., BURGENER, F. A. and BEECHAM, J.B.: CT of intramural Endometrial carcinoma: Contrast enhancement is essential.

AJR 137: 551 - 554, 1981 .

HILFRICH, H.J., ALMENDRAL, A.C., FLASKAMP, D, und HOFMANN, P.: Untersuchungen über die diagnostische Bedeutung der Hysterographie beim Korpuskarzinom.

Geburtsh. Frauenheilk. 29:346-357, 1969.

HOMESLEY, H.D., BORONOW, R.C. and LEWIS, G.C. : Stage II endonetrial adenocarcinoma. Memorial Hospital for cancer, $1949-1965$.

Obstet. Gynecol. $49: 604-608,1977$.

JAVERT, C.T. : Prognosis of endonetrial cancer.

Obstet. Gynecol. $12: 556-570,1958$.

JOHNSSON, J.E. and NORMAN, O. : Relation between prognosis in early carcinoma of the uterine body and hysterographically assessed llocalization and size of tumour.

Gynecol. Oncol. 7:71 - 78, 1979.

KADEMIAN, M.T., BUCHLER, D.A. and WIRTANEN, G.W. : Bipedal lymphangiography in malignancies of the uterine corpus.

A.JR $129: 903-906,1977$.

KELLER, D., KEMPSON, R.L., LEVIGNE, G. and McLANNAN. : Management of the patient with early endometrial carcinoma.

Cancer $33: 1108-11 \ldots, 1974$.

KLEMPNER, E. : Gynecological lesions and ureterohydronephrosis.

Am. J. Obstet. Gynecol. 64: 1232-1241, 1952.

LANG, E.K.; Arteriography in Gynecology.

Rad. clin. N. Am. V: 133-149, 1967.

LANG, E.K. : Angiography ins the diagnosis and staging of pelvic neoplasms

Radiollogy $134: 353-358,1980$,

LIU, W. and MEIGS, J.V. : Radical hysterectomy and pelvic lymphadenectomy.

Am. J. Obstet. Gynecol. 69:1-32, 1955. 
LONG, J.P. and Montgomery, I.B. : The incidence of ureteral obstruction in benign and malignant gynecologic lesions.

Am. J. Obstet. Gynecol. $59: 552 \cdot 562,1950$.

McGOWAN, L.: Endometrial cancer.

in : Gynecologic oncology pp 238 - 257. Eds : McGowan, L. Appleton-Century-Crofts New York, 1978.

MORROW, C.P. "DI SAIA, P.I. and TOWNSEND, D.E. : Current management of endometrial cancer.

Obstet. Gynecol. $42: 399-405,1973$.

MUSUMECI, R. DE PALO, G., CONTI, U., KENDA, R., MANGIONI, C., BELLONI, C., MARZI, M., BANDIERAMONTE, G. : Are retroperitoneal lymph node metastases a major problem in endometrial adenocarcinoma?

Cancer $46: 1887-1892,1980$.

REDDY, S., LEE, M.S., HENDRICKSON, F. R. : Pattern of recurrences in endometrial carcinoma and their management.

Radiology $133: 737-740,1979$.

REQUARD, C.K., WICKS, J.D. and METTLER, F.A. Jr : Ultrasonography in the staging of endometrial carcinoma.

Radiology 140: 781 - 785, 1981 .

TADA, S. , TSUKIOKA, M. ISHIT, C., TANAKA, H. and MIZUNUMA, K. : Computed tomographic features of uterine myoma.

J. Comput. Assist. Tomogr. $5: 866-869,1981$.

WALLACE, S, BAO-SHAN JING and MEDELLIN, H. : Endometrial carcinoma : Radiologic assistance in diagnosis, staging, and management.

Gynecol. Oncology $2: 287-299,1974$.

YOONESSI, M. ANDERSON, D.G., MORLEY, G.W. : Endometrial carcinoma : causes of death and sites of treatment failure.

Cancer $43: 1944-1950,1979$. 


\section{Chapter VI}

\section{Gestational trophoblastic disease}

\subsection{Introduction}

Gestational trophoblastic disease (GTD) is a term describing the whole spectrum of tumours arising from the trophoblast of human pregnancy, varying from benign hydatiform mole to invasive mole and malignant choriocarcinoma. Although these tumours are relatively rare, they are of particular interest because they can be cured by chemotherapy in the majority of cases in spite of wide spread of disease at the moment of diagnosis and because of the fact that its diagnosis rests more upon a laboratory test - beta human chorionic gonadotrophin (beta HCG) - tham upon histopathological examination of tumour tissue.

Because of the spectrum of GTD, from benign to malignant, an accurate classification is important for prognosis and therapy, but since histological interpretation may be both difficult and confusion a clinical rather than a pathological classification is used (Goldstein 1982). This classification is based on clinical symptoms, careful monitoring of beta HCG levels and presence or absence of metastases, and divides patients with GTD into two groups: 1. patients with non-metastatic disease (no evidence of tumour spread outside the uterus) and 2. patients with metastatic disease : any spread beyond the uterus. The patients with metastatic disease are again divided into two groups of different prognosis dependent on the location of the metastases, the HCG production and the duration of the disease prior to chemotherapy. In the presence of brain or liver metastases the progniosis is worse than when the metastases are located only in the pelvis or lungs (Hammond et al. 1978). For this reason an accurate pre-treatment metastatic work-up is essential in all patients with presumptive evidence of persistent GTD either invasive mole or choriocarcinoma. This metastatic work-tup should include imaging procedures of brain, liver, lung and pelvis. Although for liver imaging radionuclide scans are often used, angiography should be the method of choice because metastatic choriocarcinoma is generally extremely vascular (Goldstein 1982). Pulmonary metastases can best be diagnosed with a chest $x$-ray and conventional lung tomograms and pelvic spread outside the uterus can be demonstrated with angiography and ultrasound (Levin et al. 1975). Angiography, however, is not only used as a method for visualizing the position and extent of trophoblastic tumours but also for differentiating benign hydatiform mole from malignant choriocarcinoma (Borell et al. 1966), and for monitoring treatment response (Brewis and Bagshawe 1968). In order to study the CT features of GTD and to establish the value of CT in visualizing the whole extent of the disease process, CT scans of one patient with a hydatiform mole and 4 patients with persistent GTD are reviewed and compared with the results of ultrasound and angiography if available. Moreover tumour volume measurements with CT and ultrasound are compared with the beta-HCG levels. 


\subsection{Method and material}

Eleven CT scans of five patients with gestational trophoblastic disease are reviewed and the CT features described.

One patient had a benign hydatiform mole and the results of CT and ultrasound were compared. Three patients had non-metastatic persistent GTD and the results of CT, ultrasound and angiography before, during or after chemotherapy were compared. The fifth patient had metastatic GTD (choriocarcinoma) because of lung metastases and had several CT scans during chemotherapy.

In 4 patients with persistent GTD, the tumour volume before, during or after chemotherapy was measured with CT and ultrasound, and the results were compared with the decreasing beta $\mathrm{HCG}$ levels.

\subsection{Results}

Fig. 6.1. shows the ultrasound and CT scans (before and after i.w. contrast) of the hydatiform mole. The hydatiform tissue is easily recognizable by its vesicular texture both with ultrasound and CT. These two examinations show the amnion sac with parts of the fetus, but with $\mathrm{CT}$ the uterine outline is more clearly demarcated and the surrounding structures are all visualized. After bolus contrast injection there is intense enhancement of the myometrium and of the mole.

In the 4 patients with persistent GTD all pre contrast CT scans demonstrated a large homogeneous uterus in which no separate structures could be identified (fig. 6.2,6.3). After i.v. bolus contrast injections, however, irregular lucencies became visible inside the uterus in which central or peripheral regions or dots of higher density. These lucencies were round or finger-shaped, irregularly bordered and sometimes very close to the outside of the normal contrasted myometrium, suggesting deep myonetrial invasion (fig. 6.4d).

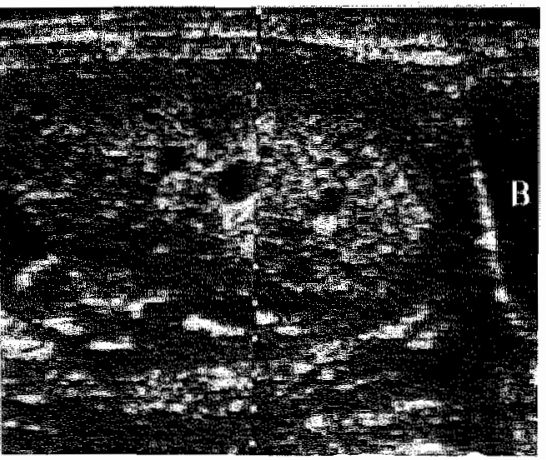

a

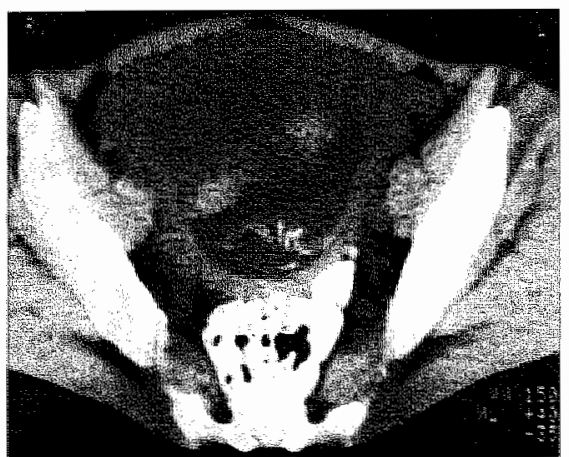

b

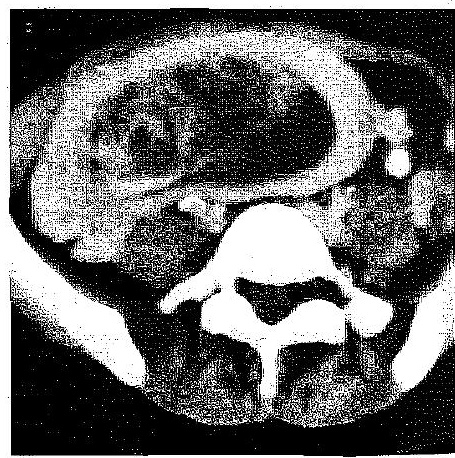

c

fig. 6. 1 .

Hydatiform mole with fetus wisualized with ultrasound (a) and pre-(b) and post (c) contrast CT scan. Note the vesicular texture in both imaging modalities and the homogeneous contrast uptake of the myometritum in $\mathrm{CT} .(\mathrm{B}=$ bladder $)$ 


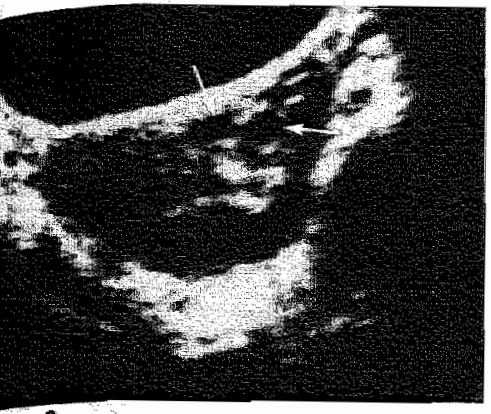

(a)

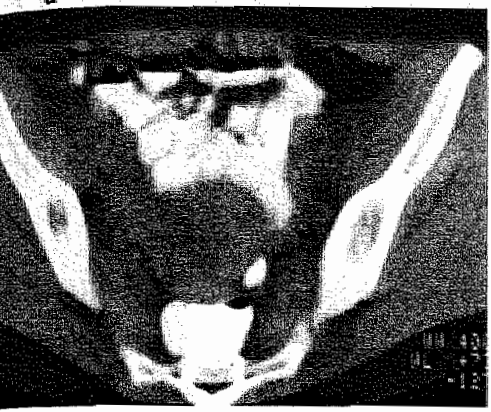

d

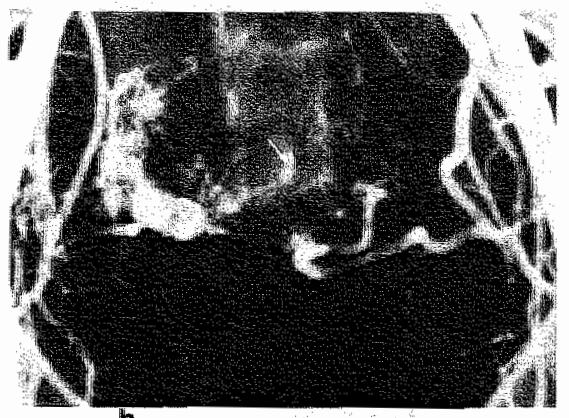

b

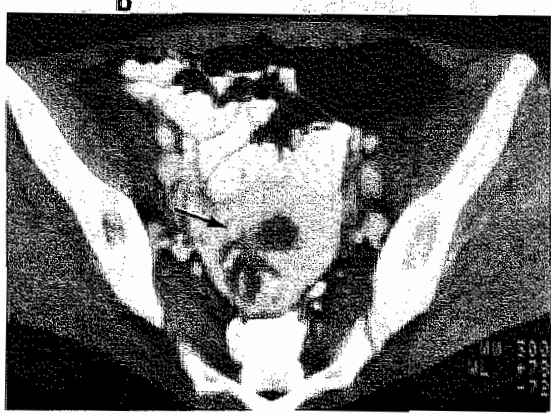

e

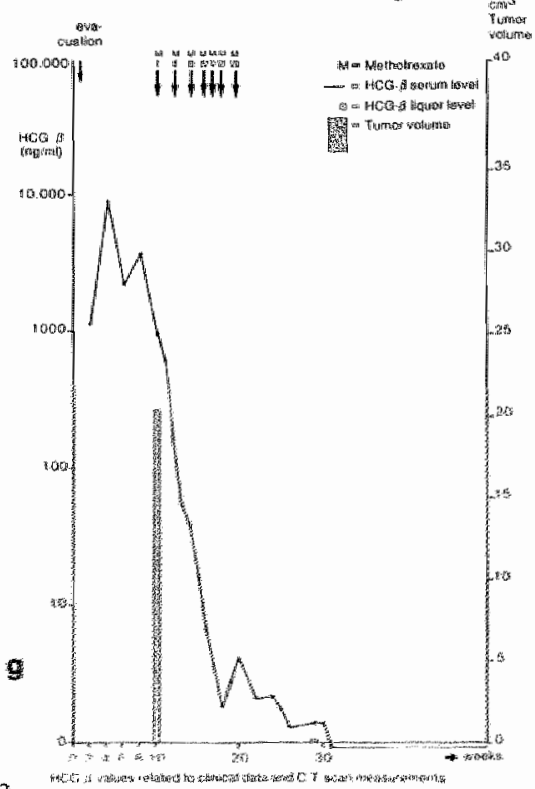

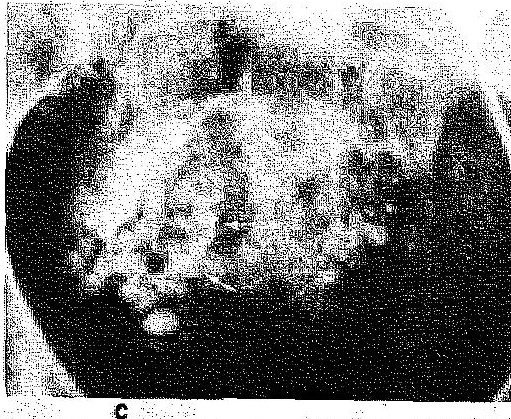

\&

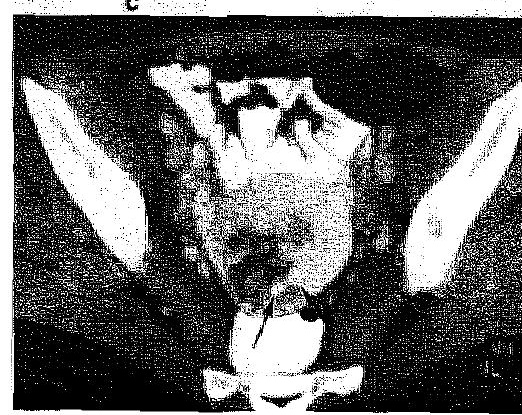

f

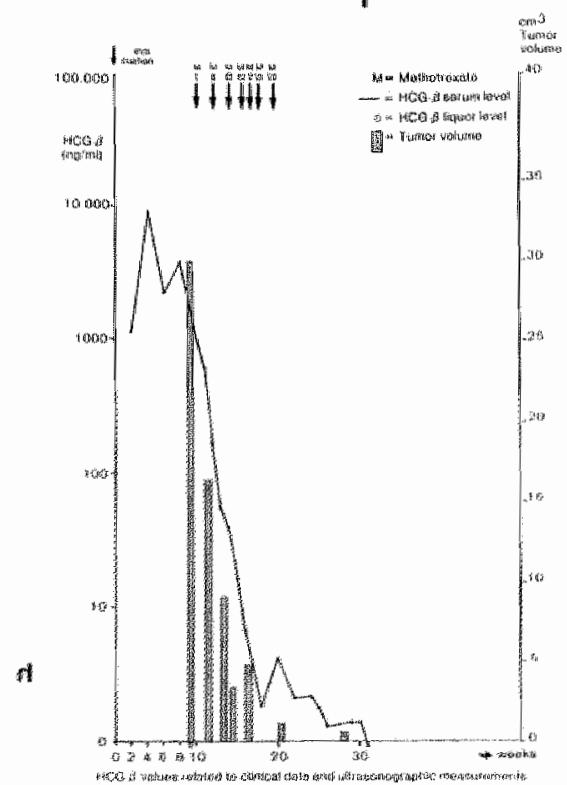

hig.

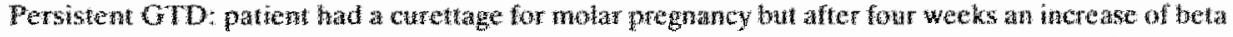

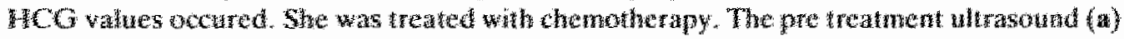

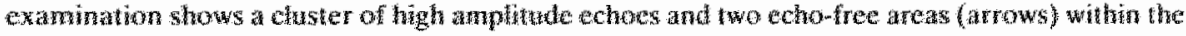

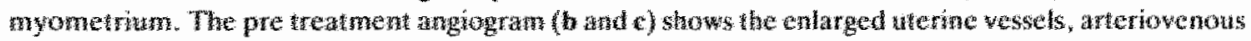

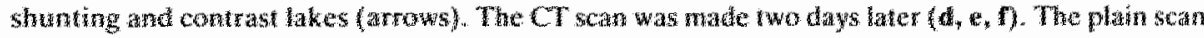

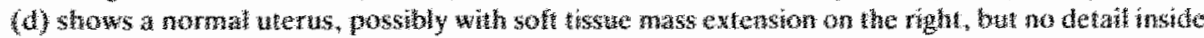

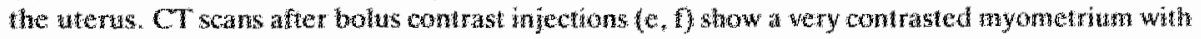

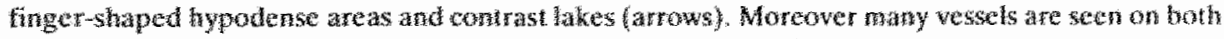

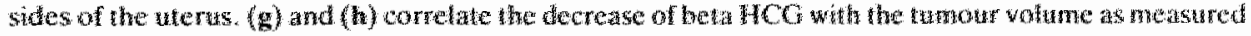

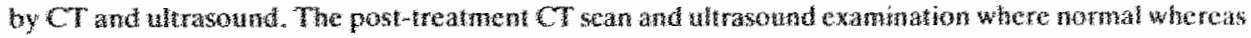

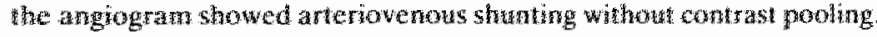




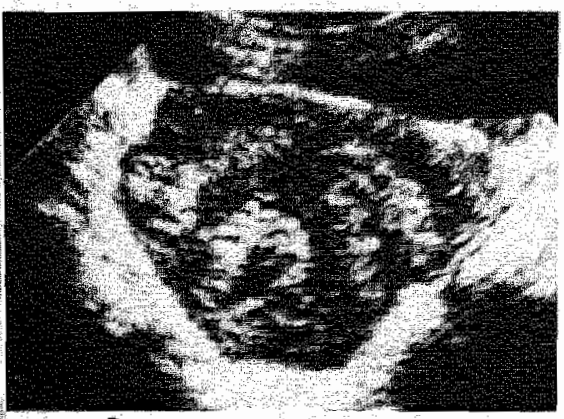

a

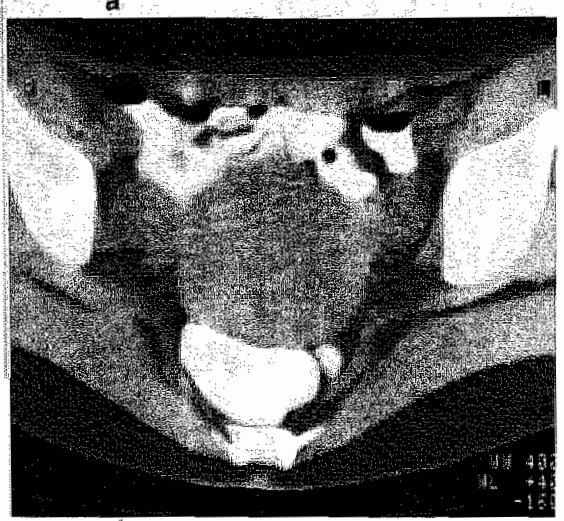

d
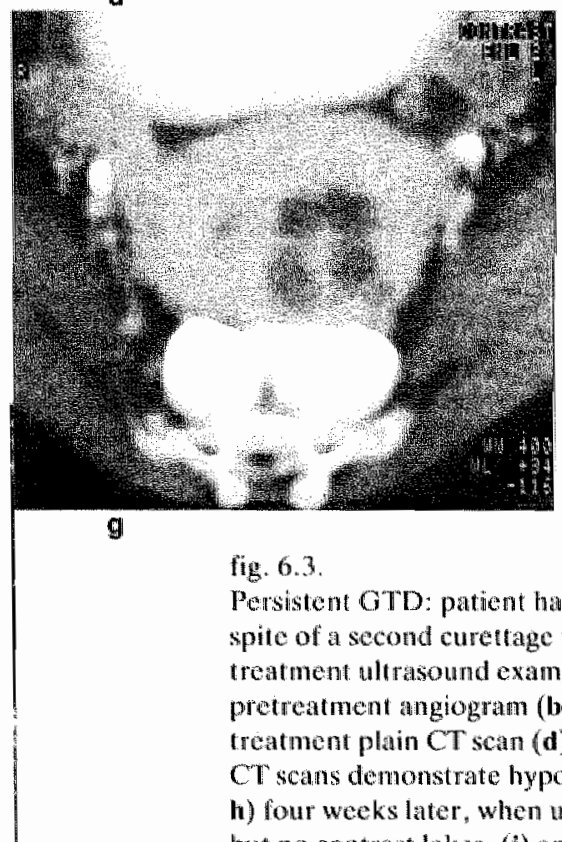

g

fig. 6.3

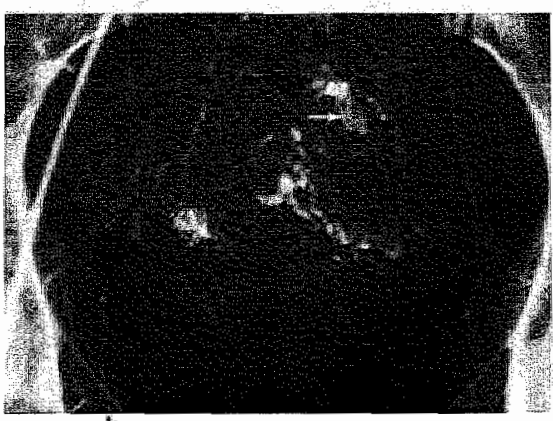

b.

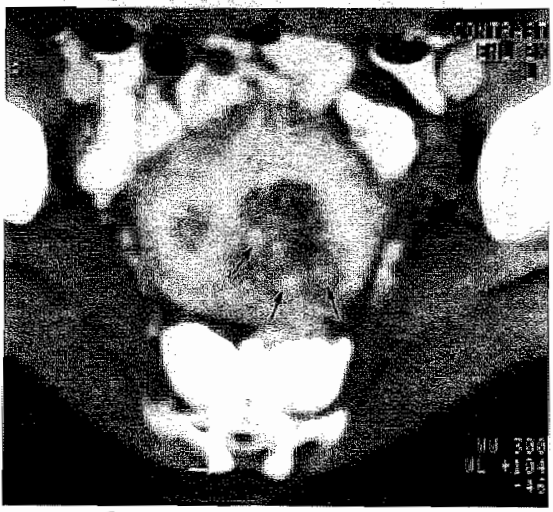

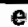

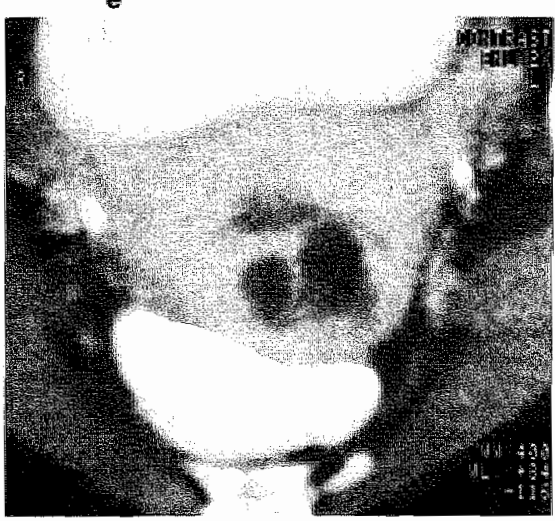

h

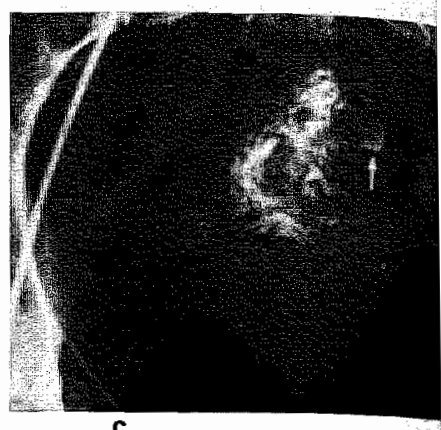

$\mathbf{c}$

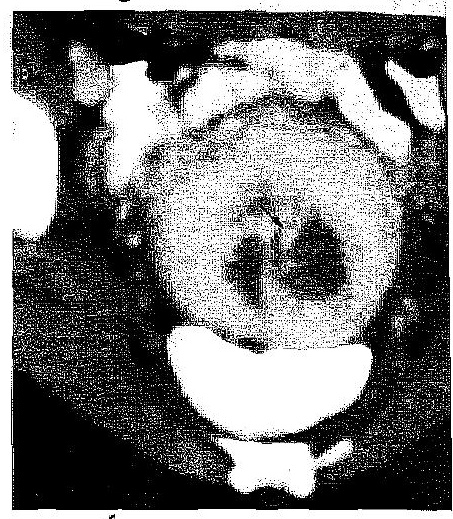

$f$

Persistent GTD: patient had a prostaglandin induction for molar pregnancy; blood lloss recurred in spite of a second curettage which yielded only decidual tissue. Beta HCG values increased. The pretreatment ultrasound examination (a) shows an irregular high amplitudo echo pattern. The pretreatment angiogram (b and $c$ ) shows contrast lakes (arrows) and arteriovenous shunting. The pretreatment plain CT scan (d) demonstrates and large uterus and was normal but the post bolus conirast $\mathrm{CT}$ scans demonstrate hypodense areas with contrast lakes (arrows) inside the uterus. CT scans ( $\mathrm{g}$ and h) four weeks later, when ultrassound and angiogram was normal, again demonstrate hypodense areas but no contrast lakes. (i) and (j) correlate the decrease of beta HCG with the tumour wolume as measured by $\mathrm{CT}$ and ultrasound. 

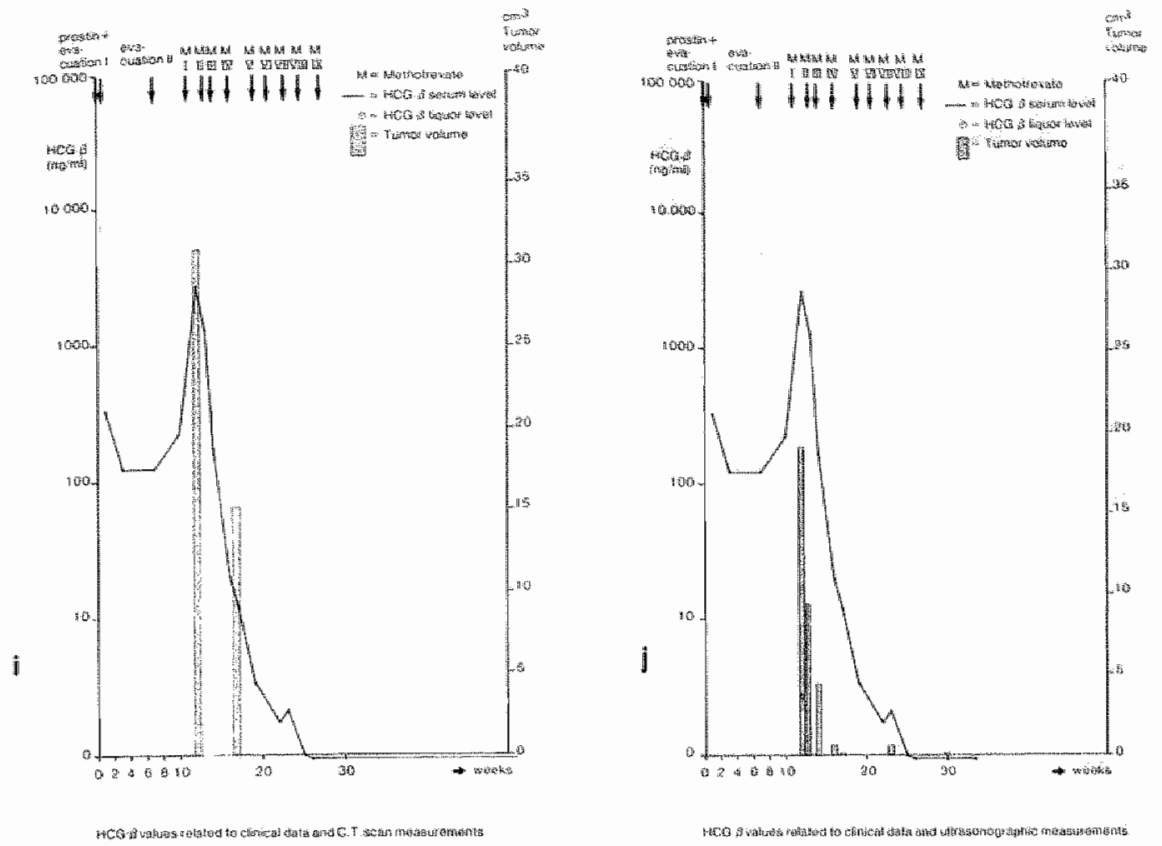

fige. 6.3

The 3 cases with non-metastatic GTD all had a sharply outlined uterus, normal ovaries except small cystic structures in one, and no CT evidence of tumour spread to spleen, liver, brain or pelvis. The CT abnormalities outside the uterus were dilated and highly contrasted vessels in the pelvis especially on the side of the tumour (fig. 6.2). Pre-treatment pelvic angiograms and ultrasound examinations were compared with $\mathrm{CT}$ and in all three cases, with good correlation for both size and location of the tumour. Arteriovenous shunting was much more clearly seen on angiogram while vascular lakes were more clearly visualized with contrast $\mathrm{CT}$. Tumour location within the uterus was better demonstrated by CT than by angiography or ultrasound.

The only case with metastatic GTD (lung metastases) also had CT evidence of tumour spread outside the uterus to pelvis and vagina while the myometrium scemed locally very deeply tumour invaded because only a small trim of contrasted myometrium remained (fig. 6.4). There was no CT evidence of liver or brain metastases. No angiogran was performed, but ultrasound examination showed an enlarged uterus with a very irregular speckled pattern, but no spread outside the uterus.

The 4 cases with persistent GTD had ultrasound examinations before and during chemotherapy and tumour volume was calculated from measurements of maximal diameter of all detectable lesions. When the ultrasound examination was normal the $\mathrm{CT}$ examination was repeated, and computor calculation of tumour volume was made by outlining the hypodense regions in each CT cut with a light-pen. Tumour volumes as measured by ultrasound and $\mathrm{CT}$, were compared with the beta-HCG level. Decrease in tumour volume was always accompanied by a decrease in beta-HCG levels (Fig. 6.2 and 6.3). When the uterus returned to normal on ultrasound, beta $\mathrm{HCG}$ was still slightly elevated and the post contrast CT scan showed a large hypodense centre in three patients and was normal in one. One patient with normal ultrasound and abnormal CT had a radical hysterectomy, and no active tumour could be demonstrated pathologically but the uterus was filled with necrotic tissue, undetected ultrasonographically (Fig. 6.4). 

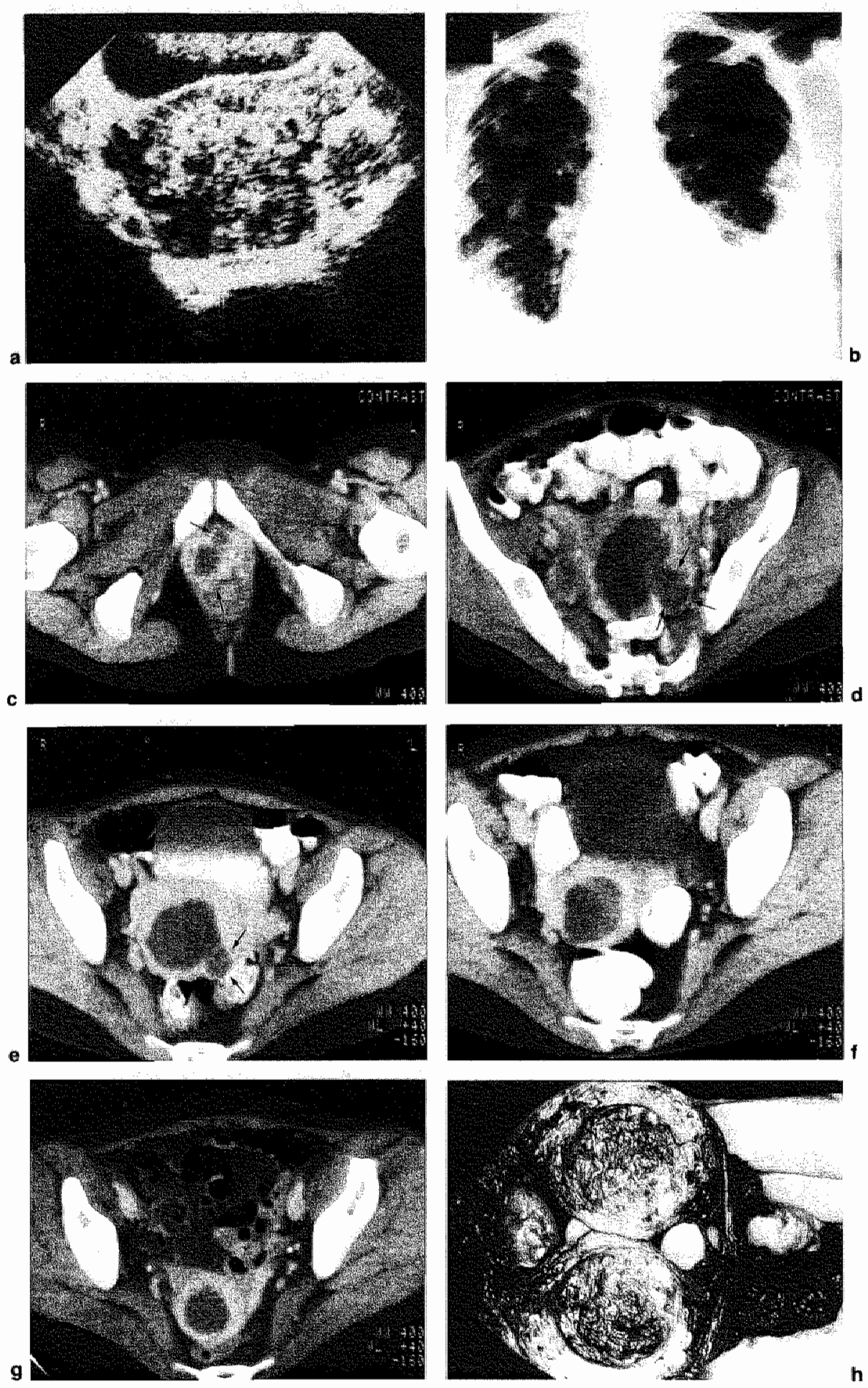

fig. 6.4 . 


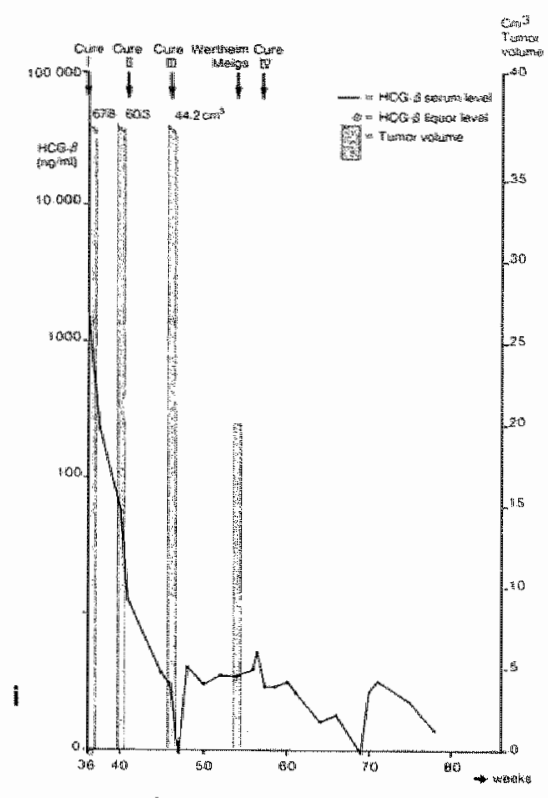

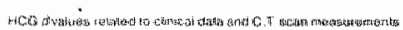

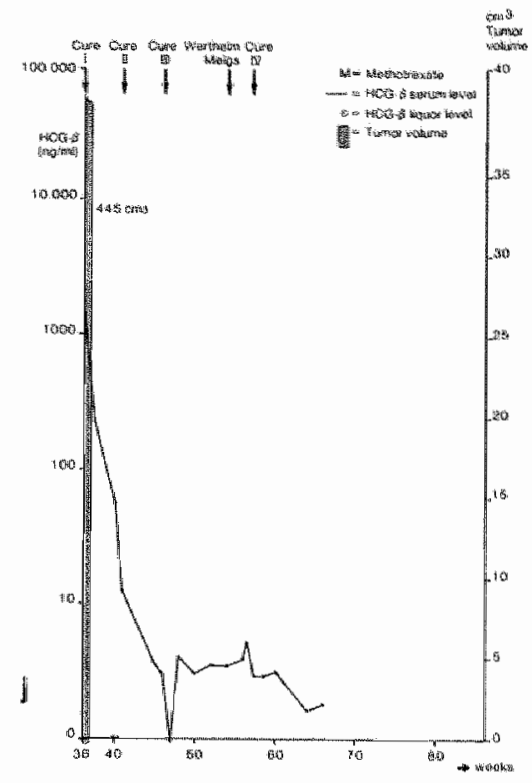

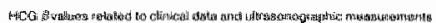

fig. 6.4.

Metastatic persistent GTD: A high risk case of choriocarcinoma which was referred to the gynatecology department from abroad. The exact initial treatment was unknown. (a) and (b) are respectively the pre-treatment pelvic ultrasound examination and chest $X$-ray and (c) and (d) the pre-treatment pelvic CT scans (after i.v. contrast injection). The hypodense mass in the vagina surrounded by a constrated rim is clearly visible (c, arrow) as is the large irregular lucency in the uterus (d) with extensive myometrial infiltration (arrows). (e), (f) and (g) are CT scans made respectively 4,10 and 17 weeks later, demonstrating the largest lucency diameter. At the time of $C T$ scan $g$, the ultrasound examination was normal and hysterectomy nine days later revealed only necrotic tissue central in the utterus and in the paracolpium but no viable tumour cells (h). (i) and (j) correlate the decrease of beta HCG with the tumour volume as measured by CT and ultrasound.

\subsection{Discussion}

About $15 \%$ of patients with a hydatiform mole go on to develop invasive mole. The degree of myometrial invasion ranging from a microscopic level to large single or multiple haemorrhagic lesions (Goldstein 1982). Fifty percent of cases of choriocarcinoma develop after passing a hydatiform mole, $25 \%$ after a normal pregnancy and $25 \%$ after a spontaneous or induced abortion (Levin et al. 1975). The level of beta HCO in the serum is directly related to the number of viable tumour cells and is therefore an excellent tumour marker that can be used for diagnosis and treatment, although it gives no information about the location of the tumour (in or outside uterus). For this reason many imaging procedures have been used with varying success.

Although there is no pathological proof, CT scans in these 4 cases of persistent GTD suggest that local myometrial invasion can clearly be demonstrated, provided the scans are made after (bolus) contrast injection. Plain CT scans show a normal uterus or non-specific enlargement and the use of $\mathrm{i} . \mathrm{V}$. contrast medium is essential to demonstrate any detail inside the uterus. In the benign hydatiform mole the contrasted myometrium was homogeneous and sharply outlined, whereas in invasive GTD irregular hypodense areas could be demonstrated, sometimes bordered by only a very small rim of normally contrasted myometrium. However this does not mean that all hypodense areas in the uterus represent 
viable tumour because, in one case (fig. 6.4), pathological examination of the hysterectomy specimen revealed only necrotic tissue. Comparison between pre and post treatment post contrast CT sans demonstrated differences which presumably result from the presence and absence of viable tumour. Pooling of contrast medium (contrast lakes) in or around the hypodense areas was visible in all four pre treatment $C T$ scans but not in the post treatment scans. In 3 of the 4 cases the post treatment post bolus contrast CT scans demonstrated only one or more sharply demarcated hypodense areas but no contrast pooling and in the fourth case the CT scan was entirely normal. This indicates the need for bolus contrast $C T$ scans, the abnormalities seen being comparable with the angiographic features as described by Borell et all. (1966). Arteriovenous shunting (filling of weins in the arterial phase in an afteriogram) can be better judged with angiography because of its AP view and because many sequential films can be made in the arterial phase (only one in CT). However if CT demonstrates very prominent veins on one side, arteriovenous shunting can be suspected. In angiography these prominent vessels may obscure the small irregular contrast collections or "contrast lakes" which are a typical tumour sign. The abnormal circulation decreases but may remain for some time after successful chemotherapy response and the presence of contrast lakes is essential for the diagnosis residual tumour (Brewis and Bagshawe, 1968). CT is without superposition, and because of its cross-sectional display these irregular contrast collections are easily seen and located in or outside the uterus. Bolus contrast scans are therefore essential.

Two out of 3 post treatment angiograms and ultrasound examinations were normal, but corresponding $\mathrm{CT}$ revealed some hypodense regions. The third post treatment angiogram demonstrated arteriovenous shunting but no contrast lakes, the ultrasound and CT examination being normal. The patient with metastatic GTD had no angiograms but post treatment ultrasonography was normal, while CT showed a large central hypodense area and operation revealed only necrotic tissue.

Decreasing tumour volume as measured by CT corresponds with decreasing beta HCG serum fevel's in all 4 patients, but absolute volume is over estimated because it also includes the necrotic tissue. The one patient with metastatic disease demonstrates clearly that metastatic lesions can also be visualized with CT. I.v. contrast is essential, however, since these vaginal and pelvic metastases were invisible on plain scan.

\subsection{Conclusion.}

A justifiable conclusion from these 5 patients is that $\mathrm{CT}$ is a valuable technique for demonstrating the spread of GTD in and outside the uterus, provided the scans are made after bolus contrast injections. 


\section{References chapter VI}

BORELL, U., FERNSTROM. I., MOBERGER, G., OHLSON, L. :The diagnosis of hydatiform mole, malignant bydatiform mole and choriocarcinoma with special reference to the diagnostie wathe of pelvic arteriography.

Charles C. Thomas, publisher, Springfield 111, 1966.

BREWIS, R.A., BAGSHAWE, K.D. : Pelwic arteriography in inwasive trophoblastic neoplasia. Br. J. Radiol. $41: 481-495,1968$.

GOLDSTEIN, D.P., BERKOWTTZ, R.S.: Gestational Trophoblastic Neoplasms in : Major problems in obstetrics and gynecology, volume 14, pp 1-4 Ed: Friedman, E.A., W.B. Saunders Company, 1982.

GOLDSTEIN, D.P., BERKOWITZ, R.S. : Gestational Trophoblastic Neoplasms in : Major problems in obstetrics and gynecology, volume 14. pp $98-121$ Ed: Friedman. E.A., W.B. Saunders Company. 1982.

HAMMOND, Ch.B., SCHMIDT, H.J., PARKER, R.T. : Gestational Trophoblastic Disease in: Gynecologic Oncology pp $359-381$ Ed : MoGowan. L. Appleton-Century-Crofts New York 1978.

LEVIN, D.C., STAIANO, S., SCHNEIDER, M., BECKER, J.A. : Complementary role of sonography and arteriography in management of uterine choriocarcinoma.

Am. J. Roentgenol. 125:462-468, 1975. 


\section{Chapter VII}

\section{Ovarian cancer}

\subsection{Introduction}

Ovarian cancer comprises only $25 \%$ of all female genital tract malignancies, but has a mortality rate that exceeds the combined rate for cervical and endometrial carcinoma. In the Netherlands the annual incidence of ovarian cancer is approximately 1000 as compared with an annual mortality of 870 (C.B.S. 1979).

The overall prognosis is poor, but depends on the extent of the disease at the time of diagnosis, the histological type and grade of tumour and the thoroughness of surgical removal of all tumour tissue (McGowan 1978). Symptoms are vague, non-specific or even absent in the early stages and physical findings are also minimal, so that the disease is usually extensive at the time of diagnosis. Parker et al. (1970) state that $59 \%$ of cases of ovarian cancer will have an initial finding of an abdominal or pelvic mass, $22 \%$ a diagnosis of an adnexal mass and $14 \%$ an initially wrong diagnosis of fibroids or other pelvic pathology. The differential diagnosis of a pelvic mass is very extensive, and pre-operative diagnosis of ovarian cancer is generally impossible. Cytology of ascitic fluid can be very helpful in confirming malignancy, but frequently gives no indication as to the site of the primary or the extent of the disease. Although X-ray, ultrasound and laparoscopy examinations are widely used, laparotomy remains essential for accurate diagnosis and staging of the disease. A further discussion of the potentials and limitations of imaging techniques follows a review of the spread of ovarian cancer.

\subsection{The spread of ovarian cancer}

Ovarian cancer spreads in three ways (Bergman, 1966, Feldman and Knapp, 1974, Julian et al., 1974, Parker et al., 1974,).

1. Directly both by invasion of neighbouring organs and by peritoneal dissemination and implantation into more distant serosal surfaces.

2. Through the lymphatic system.

a. To the pelvic and para-aortic retroperitoneal nodes and to the mesenteric nodes.

b. By diaphragmatic lymphatics from serosal seedlings to retrosternal and mediastinal nodes.

3. By the haematogeneous route to liver, brain, bone and other distant organs.

The most common type of spread is by peritoneal dissemination, $87 \%$ of the patients with ovarian carcinoma being found at autopsy to have peritoneal deposits (Bergman, 1966).

Rosenoff et al. (1975) studied the spread of ovarian cancer laparoscopically and found diaphragmatic seedlings in 30 of 49 cases overall, and in 7 of the 16 cases previously staged surgically as I or III. The right hemidiaphragm was involved in all but two of the 30 cases, whereas simultaneous involvement of the left hemidiaphragm occurred in only half of these cases. This finding may be explained by the studies of Meyers (1973) who demonstrated a continuous intraperitoneal fluid circulation by injecting radio-opaque contrast 
intraperitoneally and by following it fluoroscopically and radiographically. He found that the transverse mesocolon, small bowel mesentery, sigmoid mesocolon and peritoneal attachments of the ascending and descending colon served as watersheds and gravity caused pooling of peritoncal fluid in the most dependent peritoneal recesses. This correlated with the sites of predilection for intraperitoneal malignant seeding, which are:

1. The pouch of Douglas at the recto sigmoid level.

2. The right lower quadrant at the lower end of the small bowel mesentery.

3. The left lower quadrant along the superior border of the sigmoid mesocolon.

4. The right paracolic gutter lateral to the coecum and the ascending colon.

The left paracolic gutter is blocked by the phrenicocolic ligament, which may explain the larger number of deposits on the right, than on the left hemidiaphragms. Melaka and Rafla (1975) also confirm the early spread in the paracolic gutters, particularly on the right.

Blockage of the diaphragmatic lymphatics by diaphragmatic deposits may be a primary cause of the ascites so frequently seen in cases of ovarian cancer. (Feldman and Knapp, 1974).

Both direct and lymphattic spread occur early in the disease. Piver et al. (1978) studied the incidence of unsuspected metastases to the diaphragm, retroperitoneal lymph nodes, and omentum, as well as malignant cytologic peritoneal washings in women with presumed stage I or II ovarian cancer, and collated their results with those from similar series by other authors. The collated results are summarized in table 7.1. In autopsy studies of Julian et al. (1974) and Bergman (1966), lymph nodes were involved in $75 \%$ - $80 \%$ of cases indicating the thigh incidence of lymphatic involvement in the late stages of the disease.

\section{Table 7.1}

The incitence of unsuspected diaphragmatic, aortic lymph node and omental metastases and malignant cytologic washing in stage I and II ovarian cancer (several anthors)

\section{Lockion}

Daphragmatic methalstases

Aontic lymph nodes metastanes

Onental motastases

Positive cytology

Na of theidence Auhors
puritaris

70

$$
15.7 \%
$$

Rosenoflet all. (1975)

Spinelliet al. (1976)

Delgadoet al (1977)

Pivinet al (1978)

68

$10.3 \%$ Knapp and Friedman (1974)

Mustumeci et al. (1977)

Delgadoet al (1977)

Piveretall (1978)

$36 \quad 2.7 \%$

Knapp and Friedman (1974)

Delgado et al. (1977)

Piveretal. (1978)

87
$29.8 \%$

Mortonet al. (1960)

Creasman and Rutledge (1972)

Keotteleral. (1974)

Piveretal. (1978). 
The mesenteric nodes being as frequently involved as the para-iortic nodes (Julian at al. 1974). The haematogeneous route is a less common mode of extension but does occur, as demonstrated by isolated parenchymal organ metastases and bone marrow infitration with tumour. However the involvement of intra-abdoninal viscera (liver, spleen) is usually the result of visceral peritoneal spread with direct extension through the capsule into the contiguous parenchyma rather than individual metastases directly to the parenchyma of these organs and even pulmonary metastases are frequently caused by visceral pleural involvement with contiguous infiltration (Julian et al. 1974).

\subsection{F.I.G.O. classification of ovarian cancer}

The therapy and prognosis of owarian cancer patients is to a great extent dependient on the penetration of the ovarian capsule by the tumour and on the spread through the peritoncal cavity. Using clinical examination only it may be impossible to make practical stagegroupings and for this reason the F.I.G.O. recommended that the clinical staging of ovarian cancer should be based on findings at laparotomy as well as on clinical examination (F.I.G.O. 1971). The stage grouping for primary carcinoma of the ovary as accepted by the General Assembly of the F.I.G.O. in New York in 1970 is shown in table 7.2.

Table 7.2

Stage-grouping for primary carcinoma of the owary (F.I.G.O. 1971).

\begin{tabular}{|c|c|}
\hline Stage I & Growth limited to the ovaries. \\
\hline $\mathrm{Ia}$ & Growth limited to one ovary without ascites \\
\hline $\mathrm{lb}$ & Growth limited to both owaries without asci \\
\hline $\mathrm{Ic}$ & $\begin{array}{l}\text { Growth limited to one or botth ovaries, } \\
\text { with ascites and malignant cells in the fluid. }\end{array}$ \\
\hline Stage II & $\begin{array}{l}\text { Growth involving one or both ovaries } \\
\text { with pelvic extension. }\end{array}$ \\
\hline IIa & $\begin{array}{l}\text { Extension and/or metastases to the uterus } \\
\text { and/or tubes and/or other ovary. }\end{array}$ \\
\hline IIIb & Extension to other pet vic tissue. \\
\hline
\end{tabular}

Stage III

Growth inwolving one or both owaries with wide-spread intraperitoneal metastases.

Stage IV Growth involving onc or both ovaties with distant metastases.

Special category: Unexplored cases which are thought to be ovarian carcinoma. 


\subsection{Imaging techniques in the diagnosis and staging of ovarian cancer, review of literature}

\subsubsection{Plain radiography}

Plain X-rays of pelvis and abdomen can demonstrate a soft tissue mass with or without calcification. A benign ovarian cyst elevates the small intestine and, if sufficiently large, displaces bowel loops laterally. Many ovarian lesions, benign and malignant, tend to calcify. Calcification of psammoma bodies is sometimes seen in papillary neoplasms of the owary and is considered by some authors as a sign of slow growing malignancy (Papavasiliou, 1958; Moncada et al. 1974). Castro and Klein (1962) report such calcification in $12 \%$ of cystadenocarcinomas, and its characteristics hawe been emphasized by Lingley (1942). It is radiographically less dense than common calcification, due to its microscopic nature, and may appear as little more than a hazy shadow, in contrast to sharply defined irregular shadows of much greater density, which may also be seen in the same tumour and ure due to other forms of calcification. Furthermore, psammoma calcification may be spread throughout the pelvis and abdomen, and similar appearances in metastatic lesions in liver, lymph nodes, lung and breast may represent the same phenomenon (Nathason, 1950 , Royen and Ziter 1974, Moncada et al., 1974)

A quite different and very rare type of calcification is seen in mucinous cystic ovarian tumours (Stevens, 1971) and in pseudomyxoma peritonei. These are curvilinear opacities which may be seen in the periphery of the tumours (Noomann, 1965, Papavasiliou 1959 and Moncada 1974).

\subsubsection{Urography}

All large pelvic tumours can displace or obstruct the ureters. In the case of an ovarian tumour, the displacement is usually lateral but sometimes medial (Bryk, 1966). The literature incidence of ureteric obstruction varies from $58-69 \%$ in malignant ovarian conditions to $32-58 \%$ in benign ovarian masses (Long and Montgomery, 1950, Klempener 1952). Urography is primarily indicated to ascertain the course and number of the ureters pre-operatively.

\subsubsection{Barium studies}

Barium studies are indicated in the differential diagnosis of a palpable pelvic mass to differentiate primary colonic tumours from other pelvic masses, and to exclude or to determine the extent of bowel inwolvement. The radiological signs of such involvement are the subject of intense discussion in the literature (Asch et al. 1968, Bryk, 1967, Farmer and Hawk, 1964, Graham and Goldman, 1964, Khilnani et al, 1966, Marshak et al, 1.965. McCort, 1953, Meyers, 1976). Meyers (1976) differentiates between the radiological signs of direct invasion of the alimentary tract by immediately contiguous neoplasms and by intraperitoneal seedlings. The signs of direct contiguous invasion are fixation of the bowel wall with nodular irregularities or desmoplastic angulation of mucosal folds to an annular pattern, such abnormalities often stretching over a considerable length without the 
overhanging margins as seen in cases of primary colonic cancer. Characteristically the site of such infiltration by ovarian cancer is the lower border of the sigmoid colon. As described earlier, the locations of seedling tumours are determined by the ascitic fluid circulation described by Meyers (1973). Tn the pouch of Douglas the characteristic signs are "fixed parallel folds or nodular indentations of the anterior aspect of the rectosigmoid junction" (Meyers, 1976). Seedling deposits along the sigmoid mesocolon in the left lower quadrant produce changes characteristically localized to the upper border of the sigmoid colon, the associated desmoplastic reaction again causing distorsion of mucosal folds. The abnormalities caused by seedlings on the lower small bowel mesentery are non specific and cannot usually be distinguished radiologically from the changes produced by other mesenteric masses, primary lesions of the caecum or inflammatory reaction caused by appendicitis, regional enteritis, tuberculosis or amoebiasis.

\subsubsection{Lymphography}

The early occurrence of lymph node metastases in ovarian cancer has already been mentioned in paragraph 7.2, but little importance is generally attached to this, because at the time of diagnosis the treatment plan is generally directed by the extent of local and peritoneal spread (Wallance and Jing, 1974). Some authors, however, have used Jymphography in an attempt to stage the disease more accurately, and the incidences of lymph node metastases found by them are tabulated in table 7.3. With the exception of Mucemeci et al. (1980) who could find no area of predilection, all other workers found the majority of lymph node metastases in the para-aortic tegion.

Table 7.3.

The incidence of lymph node metastases found with lymphography (several authors).

\begin{tabular}{lccccc}
\hline Author(s) & Siagel & Stagell & Stagelll & Siage IV & Allcaxes \\
\hline Douglas et al. 1971 & - & - & - & - & $8 / 44(18 \%)$ \\
Parkeret al. 1974 & $3 / 13(22 \%)$ & $2 / 29(7 \%)$ & $9 / 22(41 \%)$ & $3 / 5(60 \%)$ & $17 / 69(25 \%)$ \\
Athey et al. 1975 & - & - & - & - & $33 / 72(46 \%)$ \\
Musumeci et al. 1980 & $6 / 70(8.6 \%)$ & $2 / 17(11.8 \%) 32 / 103(31.1 \%) 18 / 30(60 \%)$ & $58 / 220(26.4 \%)$
\end{tabular}

\subsubsection{Ultrasound}

Ultrasound is widely used in the differential diagnosis of space occupying lesions of the female pelvis. Lawson and Albarelli (1977) and Fleischer et al. (1978) claimed a diagnostic accuracy of $91 \%$ for ultrasonography in identifying the presence or absence of a mass as well as its location, size and consistency, and Fleischer et al. (1978) attempted a more detailed differential diagnosis. Deland et al. (1979) quoted a similar figure of $90 \%$. Kobayashi's (1976) figures give a positive diagnostic rate for benign ovarian cysts of $96,2 \%$ and for ovarian carcinoma of $77.6 \%$. The incidence of the different ultrasound characteristics 
of benign and malignant owarian tumours was described by Meire et al. (1978) who concluded that benign lesions are unilocular or multilocular with thin septa and no nodules, whereas malignant lesions are often multilocular with thin septa and nodules, or multilocular with thick septa with or without nodules.

Requard et al. (1981) compared the surgical and pathological findings in 32 patients with malignant ovarian tumours with the results of ultrasonography, and found a $97 \%$ accuracy in detecting pelvic tumours, of which $87.5 \%$ were correctly characterized as malignant. Ultrasonographic staging however was correct in only $48 \%$, ascites being missed in 5 patients but there were no fallse-positives. Additionally, ultrasound detected only 3 of the 15 cases of omental and peritoneal metastases and adenopathy was missed in 3 of the 4 patients with proven lymph node metastases. Paling and Shawker $(1981)$ reported the ultrasound appearance of ovarian cancers in 57 patients (stage IIB or higher). An extrapelvic tumour was detected by ultrasound in only 23 cases $(40 \%)$ including 8 patients with liwer metastases. In 10 cases a fixed mass or masses were seen within the peritoneal cavity, but it was impossible to localize these to omentum, mesentery or serosa. In only 5 of the 23 patients could tumour nodules, outlined by ascites fluid, be seen arising from an identifiable surface (liver, diaphragm or anterior abdominal wall).

\subsubsection{Computed tomography}

Literature about $\mathrm{CT}$ in diagnosing or staging ovarian cancer is scarce and the majority of the available studies is done with a second generation CT-scanner. Amendola et al. (1981) reported the results of $\mathrm{CT}$ scanning in 34 patients with Histologically proven ovarian malignancy and concluded, as Walsh et al. (1978) did, that CT could not supplant ultrasound in the primary evaluation of abdominal masses, but it may play a helpful role in the evaluation of treatment reponse in patients with ovarian malignancy. CT turned out to be superior to ultrasound in demonstrating tumour invasion of the bowel and pelvic ureters and retroperitoneal adenopathies but tumour implants smaller than $2 \mathrm{~cm}$ were not detected. Dumnick et al. (1979) could detect small peritoneal implants after intraperitoneal installation of water soluble contrast. Levitt et al. (1978) missed the omental and mesenteric metastases with $\mathrm{CT}$ in 9 of the 27 cases. The metastases were less than $1 \mathrm{~cm}$ in diameter, sometimes only microscopic or were adjacent to the primary tumour from which they could not be resolved by CT. Whitley et al. (1981) compared the CT results with the surgical findings in 22 patients. CT accuracy in detecting ascites and sensitivity in detecting peritoneal, omental or mesenteric involvement was $100 \%$, although specificity was much lower, namely $64 \%$, $67 \%$ and $88 \%$ respectively, the false-negatives being in the detection of small $(1 \mathrm{~cm})$ or microscopic tumour involvement on serosal surfaces. Detection of liver capsule involvement was also poor. They concluded that CT was a very helpful procedure in follow-up evaluation of patients with ovarian cancer and that may decrease the need for some second look laparotomies. 


\subsection{Computed tomography in ovarian cancer - a clinical study}

\subsubsection{Introduction}

The purpose of this study was to determine :

1. The accuracy of $\mathrm{CT}$ in diagnosing both the presence and the nature of pelvic mass lesions.

2. The accuracy of $\mathrm{CT}$ in staging ovarian cancer as compared to surgical staging procedures.

3. The diagnostic reliability of $\mathrm{CT}$ for treatment monitoring in patients with ovarian cancer.

\subsection{Outline of the study}

To fulfil the purpose stated, a retrospective study was made of all $\mathrm{CT}$ scans performed in the period 1-1-80 to 1-2-81 on patients with ovarian cancer. The results of CT were compared with detaled clinical and surgical records and were sufficiently encouraging to indicate a need for a prospective study on a much larger scale. Accordingly, with the cooperation of the gynaecology departments of the hospitals of Geleen, Heerlen, Maastricht, Rocrmond and Sittard, and the radiodiagnostic department of the de Wever hospital in Heerlen, an agreement was made to perform CT scans on the following patient groups :

1. All new patients with clinically suspected ovarian cancer would be CT scanned prior to first laparotony.

2. All patients with histologically proven ovarian cancer would have a CT scan :

a. before chemotherapy (some weeks after the first laparotomy)

b. during chemotherapy (on average half way through treatment)

c. after chemotherapy. (just prior to the "second look laparotomy).

3. All patients with suspected recurrence (even during chemotherapy) would have a CT scan.

All CT scans made for these indications in the period 1-2-81-1.4.82 in the de Wever hospital and in the period 1-2-81-7.9.82 in the St. Annadal hospital form the prospective study. Both the retrospective and prospective study involved a total of 139 patients on whom a total of $193 \mathrm{CT}$ scans were performed (106 patients had one CT scan, 18 paticnts two, 13 patients three, one patient four and one patient eight CT scans). Table 7.4. summarizes the distribution of all these CT scans into the different indication groups and differentiates between the retrospective (numbers between brackets) and prospective studies. For the purpose of this study, the chosen examination unit is the CT scan examimation, and as a result, 5 of the 18 patients of the retrospective study also form a part of the total of 126 patients in the prospective study, because they were submitted for further scanning during the prospective period.

All scans were performed on two identical CT scanners using a standardized procedure. but the patients reflected 5 different hospitals of origin.

In group 1 , the results of CT were compared with the definite diagnosis, as established clinically or surgically. In groups II and III the results of CT were compared with the clinical, surgical or autopsy assessments of the disease state, as appropriate. 


\subsubsection{CT in the diagnosis of ovarian cancer}

\subsubsection{Method and material}

Eighty-eight patients had a CT scan for clinically suspected ovarian tumour and all had undergone gynaecological examination (table 7.4. indication group 1, except the special cases, as explained in paragraph 7.5.4.1). In table 7.5. the reasons for suspecting ovarian tumour are tabulated against the eventual definite diagnosis. The $3 \mathrm{CT}$ scans performed for "other reasons" represent one patient with lower limb thrombosis and ascites, one with an abnormal I.V.U. and a past history of pseudomyxoma peritonei 10 years previously and one patient had a palpable pelvic mass and a past history of Hodgkin's disease thought clinically to have been cured. The "unknown" cases are included because the CT request form mentioned ovarian cancer as a possible diagnosis but the reason for suspicion was unclear. Table 7.6. lists the eventual definite diagnosis and records the confirmation method used. All laparotomies were performed within 30 days of the CT scan (average 9 days), except in one case (126 days). The laparoscopies were performed 12 and 16 days respectively after $C \mathrm{C}$ scan and the autopsy after 34 days. Of the 16 patients in whom the diagnosis was confirmed by follow-up, the three with non-ovarian malignant abdominal disease had a definite histological diagnosis and died of clinically wide spread disease within three months, and of the 13 patients with benign or no disease, 2 were alive and symptom-free 3 months later and the remainder 6 months later. All CT scans were performed using the standard procedure as described in chapter II and include the pelvis and upper abdomen except in 2 cases in which the pelvis was only scanned. In 36 cases the pelvis was scanned before and after bolus injection of urographic contrast medium.

Table 7.4

A.ll CT scans, forming the material of chapter VII, related to scan indication (indication groups) and surgical or clinical diagnosis (brackets indicate retrospective study).

Indication groups

\begin{tabular}{|c|c|c|c|c|c|c|}
\hline \multirow[b]{2}{*}{$\begin{array}{l}\text { Surgicallotiwical } \\
\text { diagnosis }\end{array}$} & \multicolumn{3}{|c|}{ I } & \multicolumn{2}{|l|}{ ll } & MI \\
\hline & & $\begin{array}{l}\text { ecial } \\
\text { ses }\end{array}$ & $\begin{array}{l}\text { bofore } \\
\text { chemo- } \\
\text { therapy }\end{array}$ & $\begin{array}{l}\text { during } \\
\text { chemo. } \\
\text { therapy }\end{array}$ & $\begin{array}{l}\text { afier } \\
\text { chemo- } \\
\text { herapy }\end{array}$ & $\begin{array}{l}\text { dinical suspicion } \\
\text { recurrend disease }\end{array}$ \\
\hline Ovarian cancer & $25+4)$ & 3 & 19 & 24 & $38+(8)$ & $11+(2)$ \\
\hline tumours & $24+(2)$ & - & - & * & - & . \\
\hline $\begin{array}{l}\text { Nogynaecological } \\
\text { pathology }\end{array}$ & $31+(2)$ & - & - & - & - & - \\
\hline Total & $80+(8)$ & 3 & 19 & 24 & $38+(8)$ & $11+(2)$ \\
\hline
\end{tabular}


All CT scans were assessed independently by two radiologists for the presence or absence of pelvic, omental or peritoneal-mesenteric masses, liver capsule or diaphragmatic masses, lymph node enlargement, liver metastases, ascites and possible tumour growth elsewhere. If one or both observers quoted one of these features as present, this was considered as a definite CT diagnosis. Mass lesions separate from the pelvic tumour, not clearly benign (e.g. liver or renal cyst) were considered to be metastases and quoted as satellite masses. Visible pelvic masses were then classified as round or lobulated, sharp or ill-defined, smaller or larger than $5 \mathrm{~cm}$. in diameter and subclassified as pure cystic, complex or solid. Cystic masses containing at least one solid structure of any size were defined as complex lesions. Furthermore, the presence of calcifications was noted,

CT results were compared with definite diagmosis and scan indication and the various CT features will be discussed.

\subsubsection{Results}

Tables 7.7 and 7.8 correlate CT scan abnormalities with initial indications and eventual definite diagnosis respectively. In 11 patients, the CT scan was normal. Two had diverticular disease and a palpable pelvic mass, with a definite clinical diagnosis of sigmoiditis, the remaining 9 having no abdominal disease. All were symptom free after 6 months. The one patient with satellite masses only had liver metastases already demonstrated ultrasonographically and histologically suggestive of ovarian adenocarcinoma, and CT confirmed these liver lesions and incidentally demonstrated a mass in the right breast, but was otherwise normal. Four patients had clinical ascites only, and $\mathrm{C} T$ simply confirmed this. Three were operated on within a week and the fourth died and was autopsied 34 days after the CT scan. Three had diffuse peritonitis carcinomatosa (adenocarcinoma) but no primary site was found, and in only one did the pathologist suggest ovary as the primary

\section{Table 7.5}

Reason for $\mathbb{C T}$ scanning correlated with definite dianosis in 88 conscentive pationts will suspected owarian tumour.

\begin{tabular}{|c|c|c|c|c|}
\hline \multirow[t]{2}{*}{ Indicathon CT scan } & $\begin{array}{l}\text { No. of } \\
\text { patents }\end{array}$ & & Definie diagnosis & \\
\hline & & $\begin{array}{l}\text { ovarian benign } \\
\text { concer gynateological } \\
\text { lumour }\end{array}$ & $\begin{array}{l}\text { mon-gynaccological } \\
\text { maligrinan abdominal } \\
\text { disease }\end{array}$ & 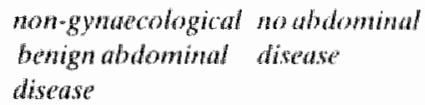 \\
\hline
\end{tabular}

\begin{tabular}{|c|c|c|c|c|c|c|}
\hline Palpable pelvic mass & 67 & 22 & 25 & 8 & 8 & 4 \\
\hline $\begin{array}{l}\text { Abnomal uhlt rasound } \\
\text { examination }\end{array}$ & 6 & 1 & - & 2 & 2 & l \\
\hline $\begin{array}{l}\text { Ascites of anknown } \\
\text { origin }\end{array}$ & 7 & 4 & - & 2 & 1 & 。 \\
\hline $\begin{array}{l}\text { Metastatic deposits of } \\
\text { unknown origin }\end{array}$ & 2 & $=$ & $=$ & 1 & - & 1 \\
\hline Dtherreason & 3 & 2 & 1 & - & - & . \\
\hline Unknown & 3 & - & . & - & - & 3 \\
\hline Total & 88 & 29 & 26 & 13 & 11 & 9 \\
\hline
\end{tabular}


Table 7.6

Definite diagnosis and method of confirmation in 88 consecutive patients with suspected ovarian tumour.

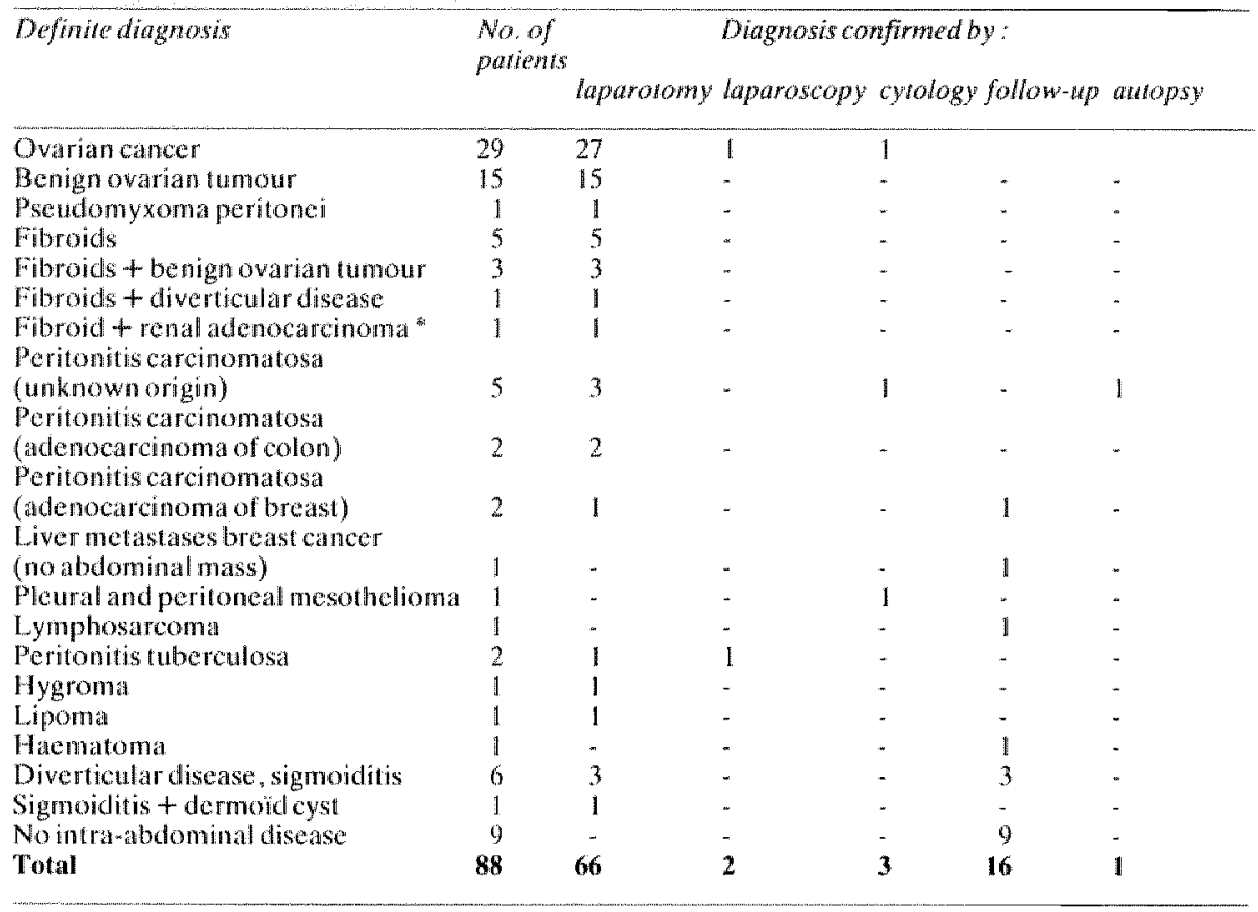

site. The fourth had tuberculous peritonitis. Of the 9 patients with satellite masses and ascites, one had laparoscopically proven tuberculous peritonitis with omental masses. A second had pseudomyxoma peritones with right ureteric obstruction on I.V.U., laparotomy revealing getatinous fluid in the peritoneal cavity, and cncapsulated in wo masses, one in the splenic region and the second obstructing the right ureter in the right lower quadrant. The corresponding CT findings were ascites and two low density regions, one within and one adjacent to the spleen, with curvilinear calcified borders suggestive of satellite masses. A third patient had laparoscopically demonstrated omental masses, histologically shown to be ovarian cancer, but the pelvis could not be visualized, and extreme obesity contraindicated laparotomy. The remaining 6 patients had histologically proven malignant abdominal discase. Two had peritonitis carcinomatosa at laparotony, but macroscopically normal ovaries (origins being colon and breast). Another died some days following CT scin without laparotomy or definite diagnosis, but with malignant ascites. Neither of the other three had a laparotomy, but one had breast cancer, possibly responsible for the collarged para-aortic nodes seen on CT, the of her had a pleuro-peritoneal mesothelioma and the last patient had cy tologically proven ovarian cancer but no laparotomy was done at that time. Of the four patients with a pelvic mass and ascites only, three had stage III malignant ovarian disease and the fourth a benign mucinous cystadenoma. The primary tumours in the two patients with a pelvic mass, ascites and satellite masses who had nonovarian abdominal malignancies, were cancer of the colon and lymphosarcoma. 
Table 7.7.

CT scan abnormalities in 88 patients w th clinically suspercted ovarian tumour related to indication for CTscan.

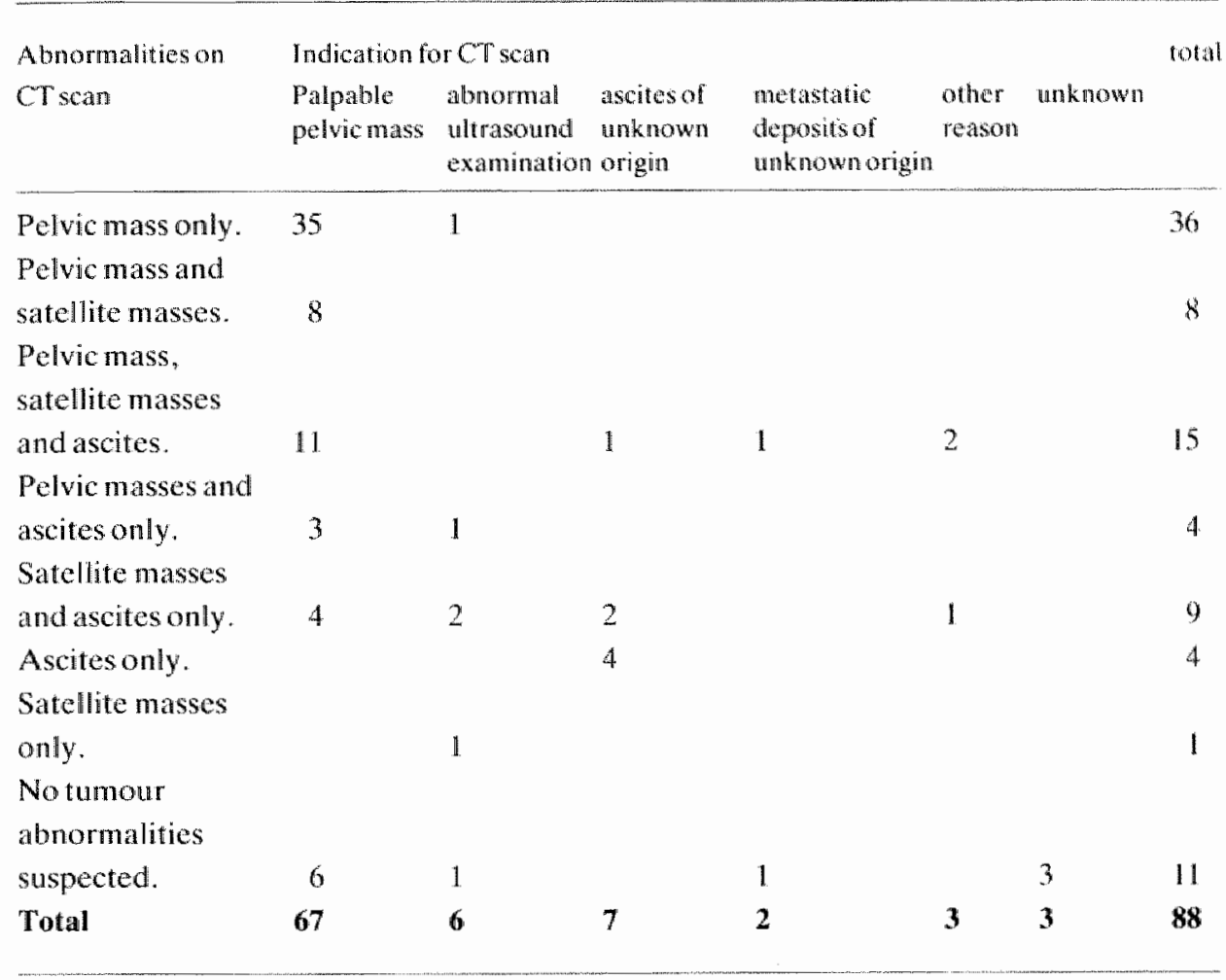

Three patients with a pelvic mass and satellite lesions only had benign disease, two being diverticular disease with surrounding inflammatory change cone combined with a bertign left ovarian dermoid cyst, fig. 7.10 ), and the third being a hygromal compressing the blatder together with a large ventral abdominal wall haematoma. A fourth had carcinoma of the sigmoid with Krukenberg ovarian metastases (fig. 7.7), the fifth had a large calcified fibroid and an incidentally found renal adenocarcinoma and the remainder had ovarian cancer.

Of the 36 solitary pelvic masses, only nine were malignant, seven being primary owartan cancer, and the eighth a primary colon tumour with ovarian metastases and the nirth a mucinous cystadenocarcinoma of the appendix (fig. 7.1f). The remaining 27 comprised 15 benign ovarian tumours, 5 uterine fibroids, 3 fibroids with a benign ovarian tumour, 1 abdominal haematoma, 2 diverticulitic masses and one a necrotic lipoma. Table 7.9 correlates the CT features of the mass with the definite diagnosis for the total of 63 ases of pelvic mass visible on $C T$.

In 36 cases (13 ovarian cancer, 5 fibroids, 10 benign ovarian tumours, 3 ot her abdominal malignancies and 5 benign abdominal diseasc), a pre and post i.\%. bolus contrast scan was made, to study the value of contrast enhancement. Contrast increased definition, particularly in the uterus, and sometimes dramatically, but revealed no new structures and 
Table 7.8

CT scan abnormalities in 88 patients with clinically suspected ovarian tumour related to definite diagnosis ("patient with calcified fibroid and renal adenocarcinoma).

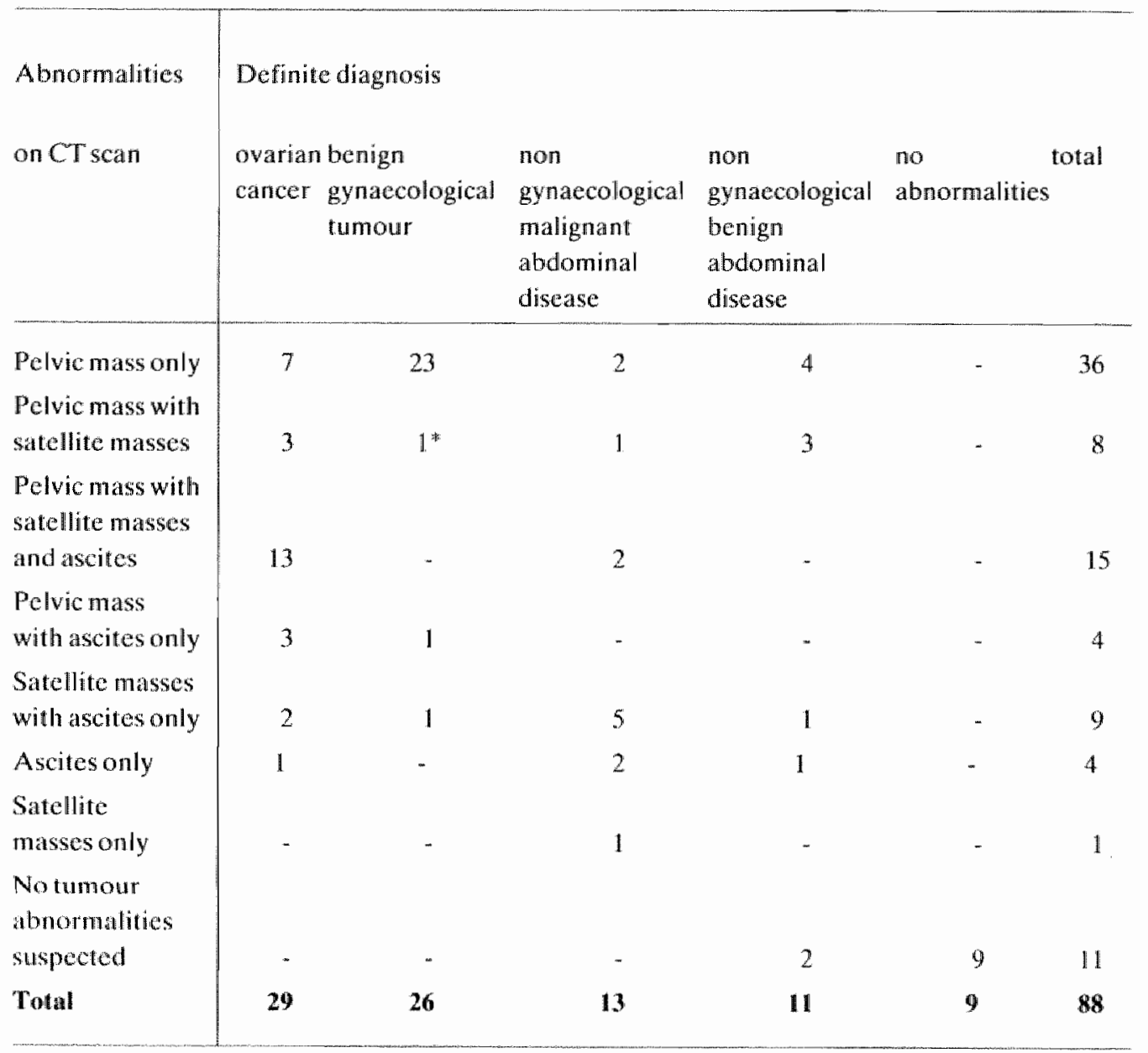

in no way altered the features tabulated in table 7.9. A remarkable feature of uterine fibroids was that areas of the tumour which were of high density compared to the surrounding tumour tissue prior to contrast enhancement remained unchanged by contrast injection, while the surrounding tumour tissue took up the contrast medium dramatically. This paradoxical contrast enhancement in uterine fibroids was unique in our material (fig. 7.8)

\subsubsection{Discussion}

It is generally accepted on the basis of diagnostic yield, non-invasiveness, low cost and paticnt acceptability, that ultrasonography is the examination of first choice in the detection and investigation of a pelvic mass lesion. The technique is, however, dependent on the skill of the examiner, and is difficult in obese patients. Further specific limitations include poor 
Table 7.9

The incidence of the various $\mathrm{CT}$ features in various pelvic mass lesions.

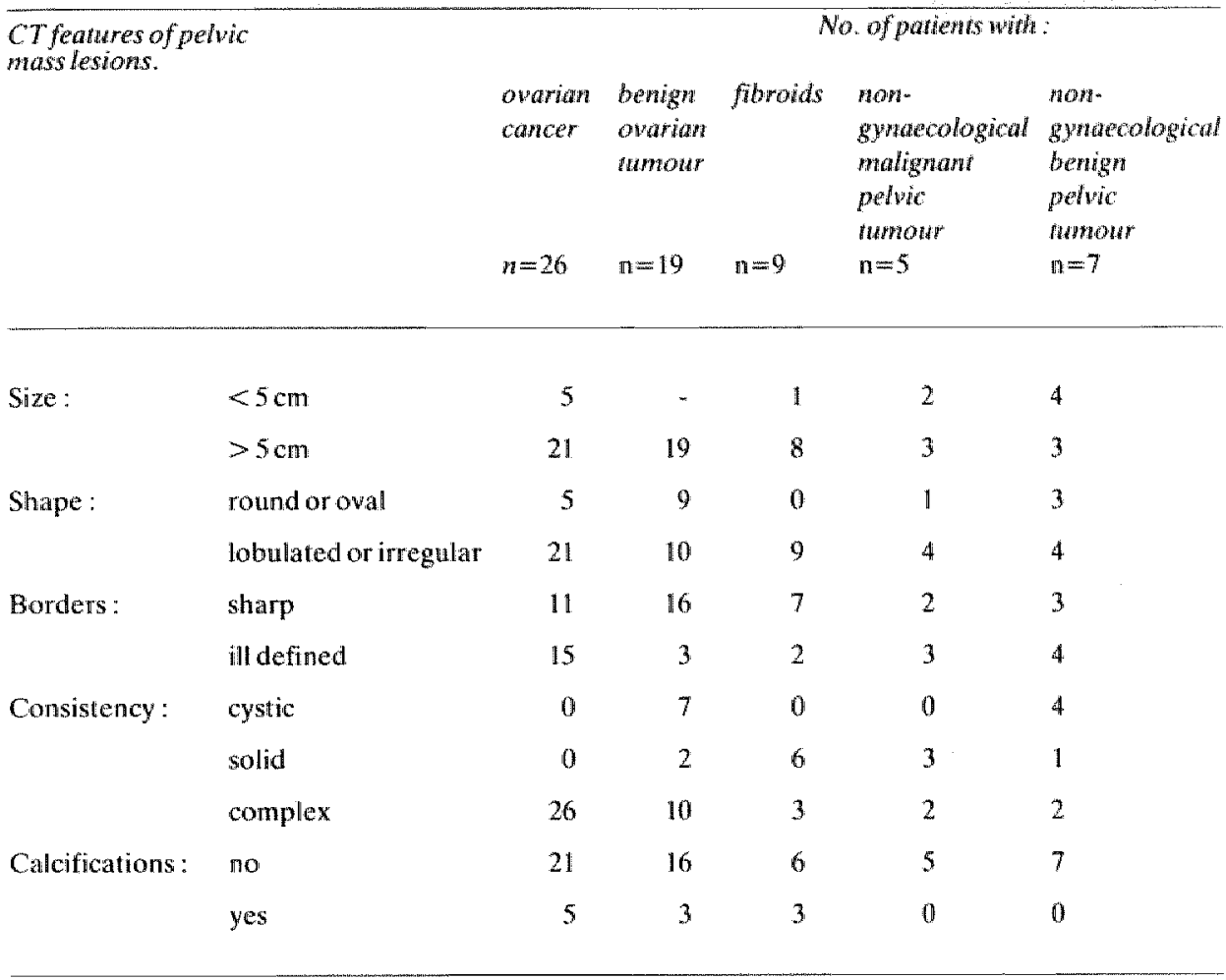

visualization of the pouch of Douglas in the presence of uterine calcification, and a tendency for bowel loops with adhesions to be misdiagnosed as pelvic tumours. CT, on the other hand, is independent of examiner technique, uninfluenced by fatty tissue or calcification. and bowel loops can be differentiated by the use of intra-luminal contrast. CT definition, however, depends on the presence of fat planes, and is therefore less effective in very lean patients.

Table 7.7 reveals the considerable variety of CT abnormalities seen in the 67 cases of palpabele pelwic mass. In 10 cases, CT did not confirm a pelvic mass, but in 4 of these, extra pelvic satellite lesions and ascites were seen and abdominal malignancy was subsequently confirmed (fig, 7.2a-c). In two further cases, sigmoid diverticula (fig. 7.1.a) were seen and operation was cancelled. The remaining four showed no CT abnormality, and all 6 were symptom free after 6 months follow-up.

Tables 7.7 and 7.8 show that there are no $\mathrm{CT}$ features pathognomonic for ovarian cancer. However, in our material, the complete absence of CT abnormalities would appear to exclude diagnosis of ovarian cancer in spite of abnormal clinical features. A visible pelvic mass only always indicated disease, but, although, this was mallignant in only nine cases, there was no more specific indication as to the definite diagnosis. The additional finding of satellite masses was strongly indicative of intra-abdominal malignant disease, especially when combined with ascites, but in four cases with satellite masses, the disease was in fact 

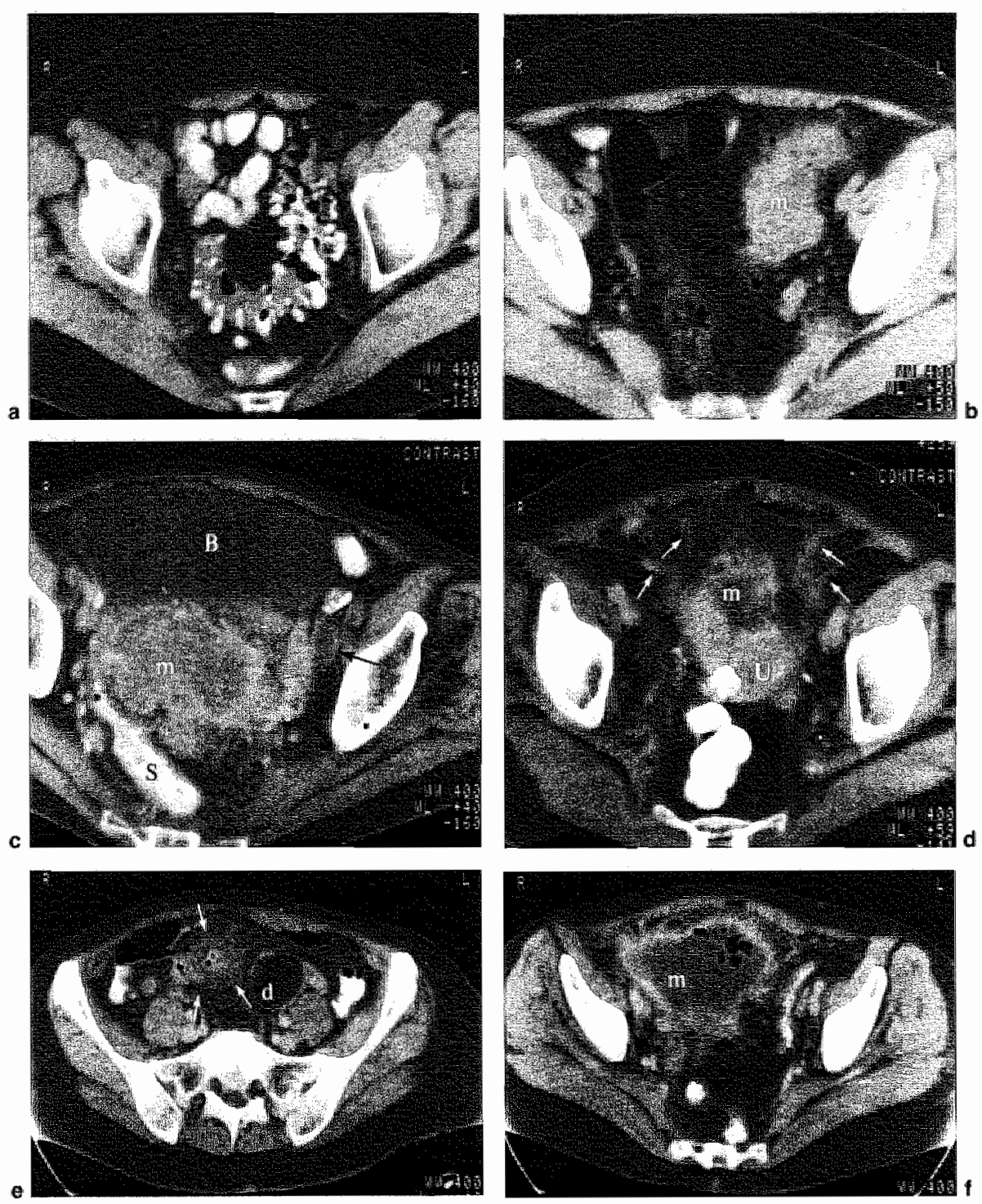

fig. 7.1.

Six cases with a palpable pelvic mass and gastrointestinal discase: a. no pelvie matss on CT but diverticulosis of the sigmoid; disease free follow-up of $6+$ months. b. solid mass ( $m$ ) in the region of the sigmoid; sigmoiditis with inflammation of surrotunding tissue. $c$. irregularly contrast enhanced pelvic mass ( $m$ ) displacing the sigmoid $(S)$ and a hypodense centre in the left iliac vein (arrow); intlanmatory proces and left iliac vein thrombosis probably caused by diverticulitis. d. irregular pelvic mass ( $m$ ) with a hypodense central region not separable from the uterus (U) and soft tissue strands to the periphery (arrows); sigmoiditis with infiltrating of the adjacent mesenteric fat.

e. irregular mass (only parily visible) with air densities (arrows) and a fatty tumour ( $-50 \mathrm{HU}$ ) on its left sicle (d); sigmoiditis with dermoid cyst in the left ovary. f. irregular mass (m) with a contrasted rim (after bolus contrast injection) and hypodense centre with air densities; mucinous cystadenocarcinoma of the appendix. 

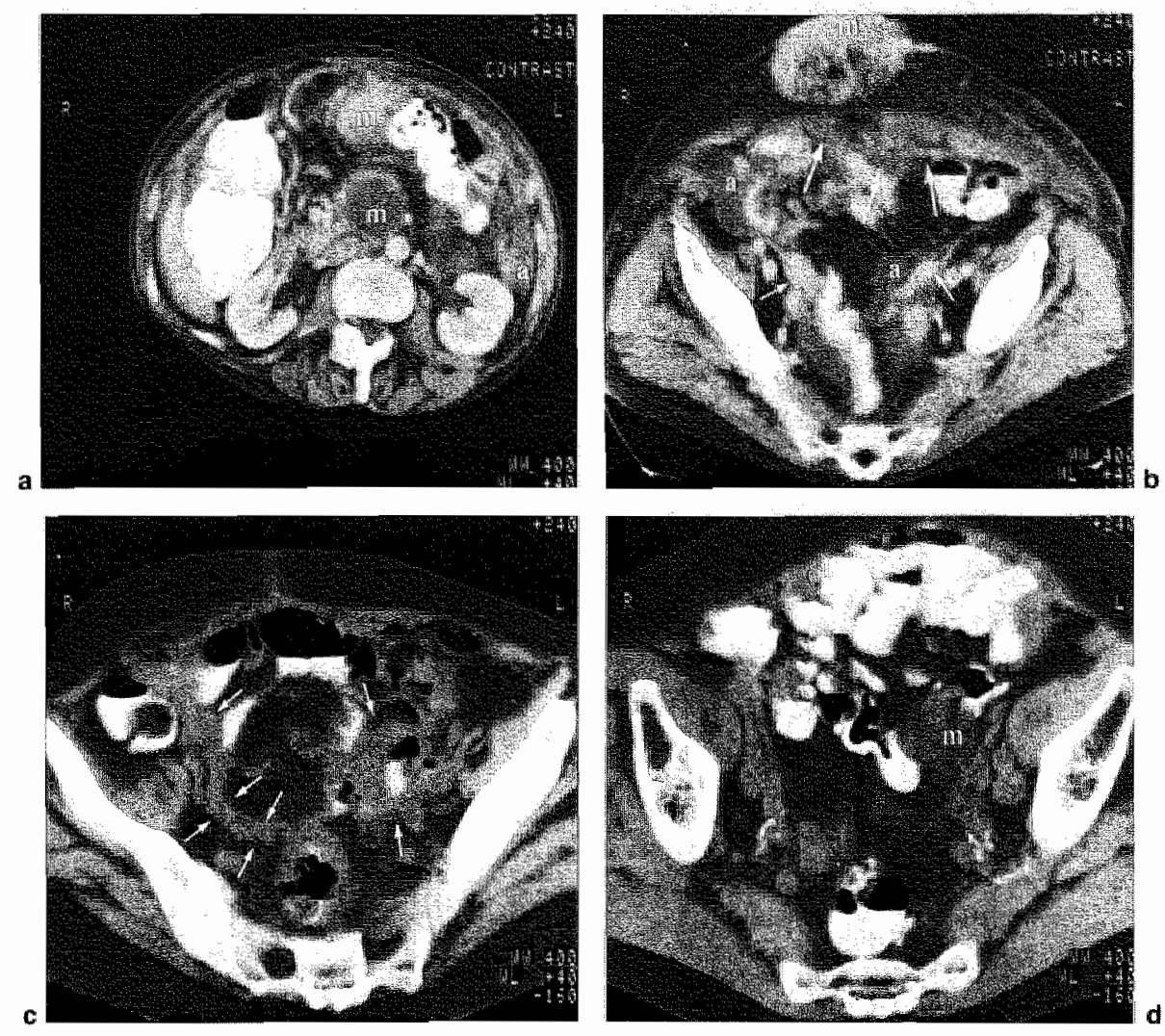

fig. 7.2.

Four cases with ascites and satellite masses on CT due to diffuse mesenteric and peritoneal involvement by metastatic breast cancer (a), lymphosarcoma (b), metastatic adenocarcinoma of the sigmoid (c) and metastatic adenocarcinoma of unknown origin (d). The ascites (a) in these cases is loculated atnd irregular strands of soft tissue density are visilyle between the bowel loops (small arrwos) just ats round cystic and solid masses $(\mathrm{m})$. The inner side of the ventral abdominal wall is ill defined and thicke ned with soft tissue masses (large arrows) presumably due to omental inwolwement. Note the subentaneous mass (m) in figure b.

benign (sigmoiditis fig. 7.1.d-c, hygroma and haematoma, tuberculous peritonitis fig. 7.3.c-d, and pseudomyxoma peritonei fig. 7.3.a-b).

Table 7.9 shows that in general, descriptive features of a pelvic mass on CT give no definite indication as to diagnosis, the exception in our material being that a truly cystic mass indicated only benign disease. This concurs with the findings of Meire et al. (1978) that cystic lesions on ultrasound indicate benign disease. Fig. 7.4, 7.5 and 7.6 show examples of benign and malignant ovarian tumours. Calcifications were visible in both benign and malignant ovarian tumours as punctate densities or as irregular hazy shadows of high density, the last representing psammoma body calcifications which might easily be mistaken for bowel or intravascular contrast medium. Density measurements gave no indication about the nature of the tumour, although in wo cases the fatty content could be predicted because of densities of -30 and $-50 \mathrm{HU}$, which proved to be respectively a ncerotic lipoma 
and a dermoid cyst (fig. 7.1.e). The rwo cases of secondary ovarian tumours (Krukenberg's tumour) could not be differentiated from other ovarian masses (fig. 7.7.).

The use of intravenous contrast enhancement may be essential to make an accurate diagnosis. An example is the wery irregular and paradoxical contrast uptake by uterine fibroids, seen in 3 of our cases. This can only be correctly judged by comparison with a precontrast scan, and is an important finding in the differentiation of fibroids from malignant ovarian tumours (fig. 7.8.). In describing the CT features of fibroids in 83 patients, Tada et al. (1981) recorded lobulation as the most frequent sign. In our experience, however, lobulation is a frequent feature of all pelvic masses. They mention the presence of low diensity areas in 19 cases, but the significance of this is not clear, because they do not mention exactly when they used intravenous contrast material. Although not mentioned by Tada et al., some of their pictures show areas of very high contrast uptake within the uterus which probably indicates richly vascularized fibroids. Karlsson and Persson (1980) performed angiography on 34 patients with fibroids and found a rich wascularity in 22
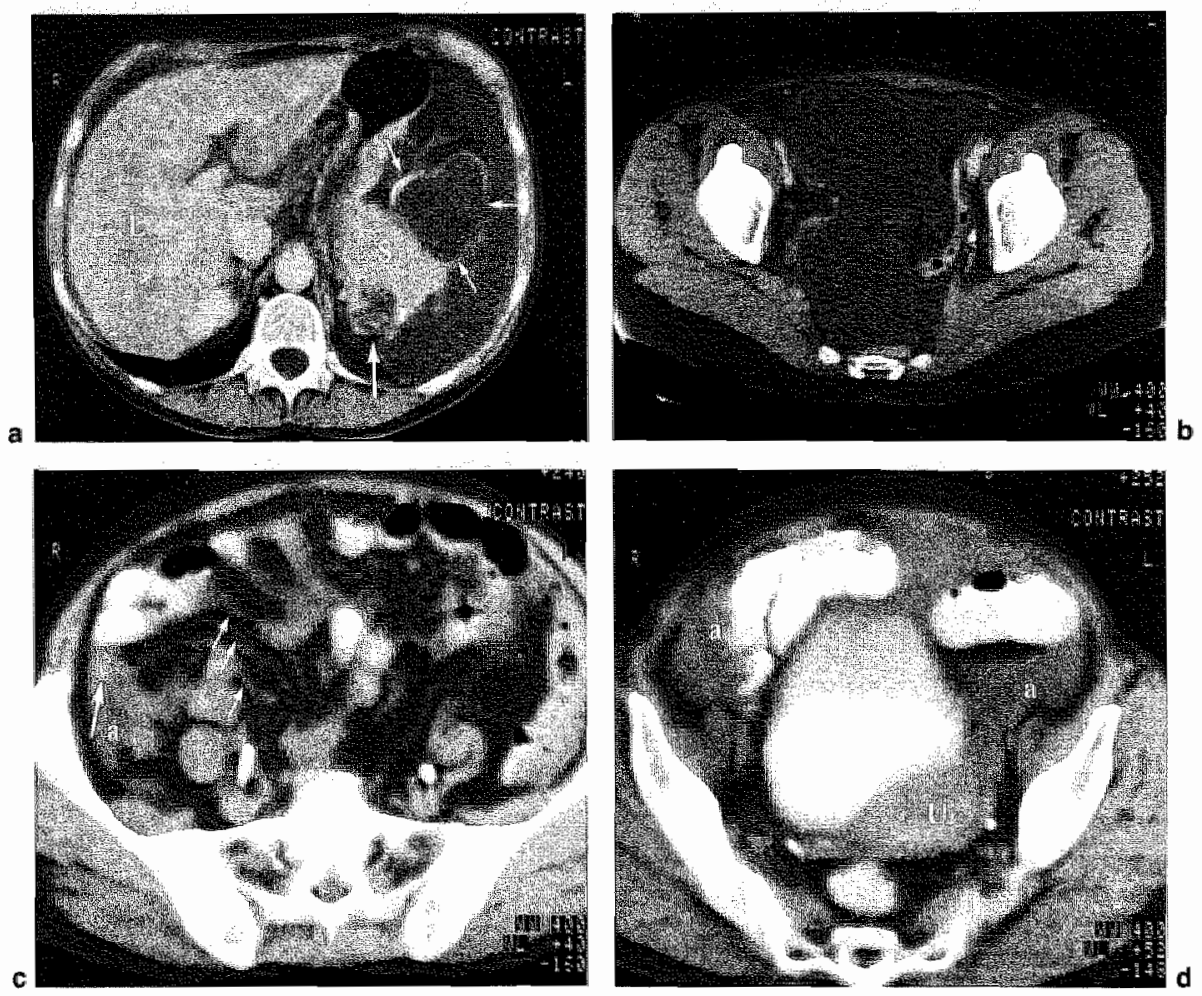

fig. 7.3.

Ascites and satellite masses on $\mathrm{CT}$ in benign abdominal disease. $\mathbf{a}$ and $\mathbf{b}_{\text {; }}$ pseudomyxoma peritonei with huge gelatineous masses in the peritoneal cavity, an infiltrating mass lesion in the spleen (large arrow) and a mass with calcified rim adjacent to the spleen (small arrows). The first mass was not found at operation, the spleen was not removed and the patient had a disease free period of $18^{4}$ months. $\mathbf{c}$ and $\mathbf{d}$ : Tuberculous peritonitis with loculated ascites (a) with soft tissue strands representng thickening of the mesenteric leaves (small arrows) and small masses (large arrow). $(U=$ uterus. $L=$ liver, $S=$ spleen 

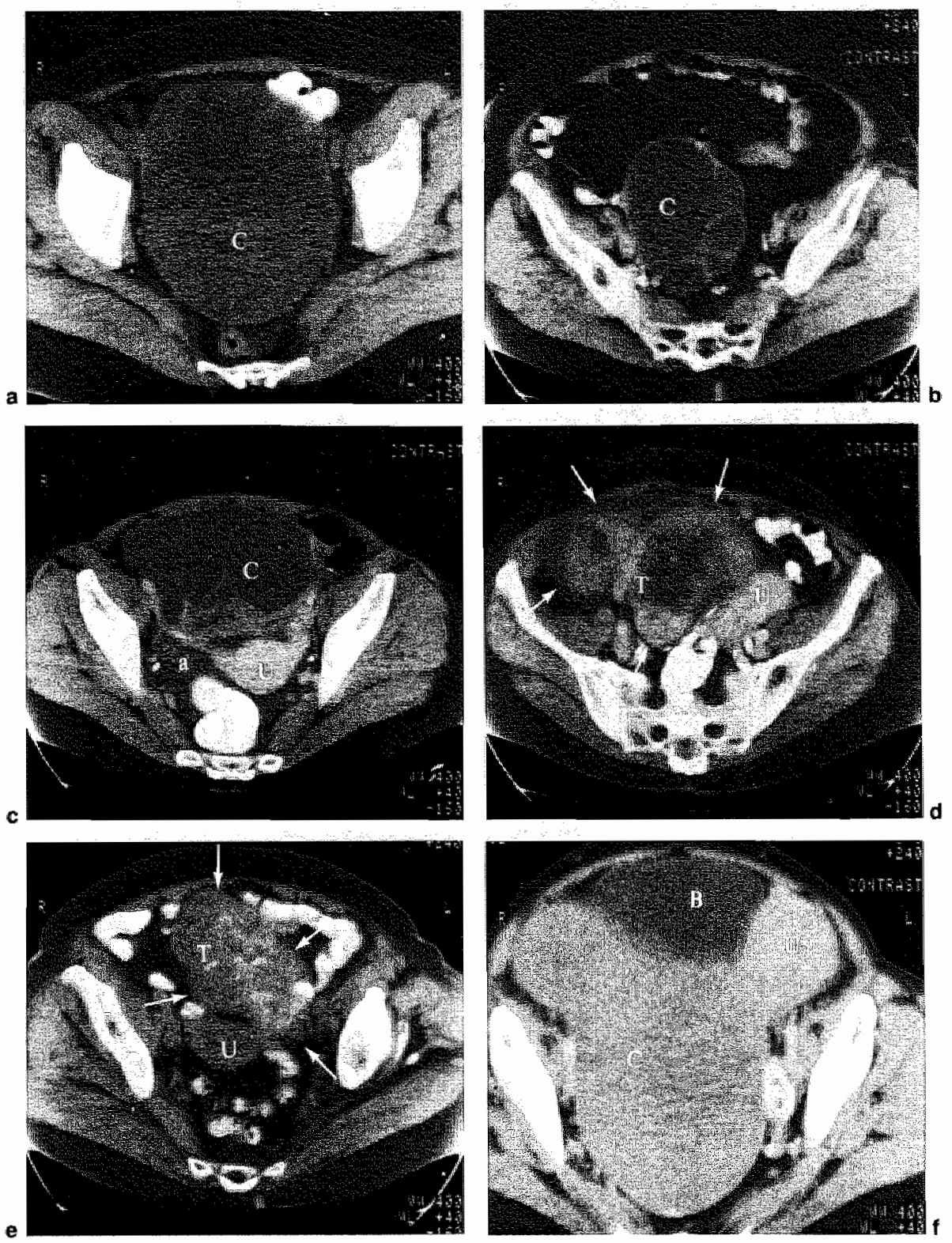

fig. 7.4.

Six cases of benign ovarian tumours showing the divers CT features. a. benign cyst. b. serous cystadenoma with thin septa. c. mucinous cystadenoma with thin septa, solid structures and asciles (a). d. irregular, ill defined complex mass ( $T$ ) being a thecoma. e. solid mass (T) with callifications ventral to the uterus being a thecoma. f. serous papillary cystadenoma (C). Note its solid but homogeneous structure compared to the contrast enhanced uterus. $(B=$ bladder, $U=$ uterus $)$ 
(56\%), but this tended to decrease with increasing fibroid size. Fibroids show a tendency to necrosis and calcification, and in our opinion, this can be seen in CT as islands of slightly increased or decreased density (often seen only with optimal window width and window level settings), whicl do not enhance with contrast, resulting in paradoxical contrast uptake seen on comparison of pre and post contrast films. In summary, the probable diagnostic CT features of uterine fibroids are the high contrast uptake of the normal uterus itself, and of fibroids in their early vascular stage, and paradoxical contrast uptake as they become necrotic and calcified. Histological examination in three of our cases showing paradoxical contrast uptake confirmed necrosis and calcification.

The value of using intravenous contrast in differentiating cystic pelvic masses is also emphasized by one case of a palpable pelvic mass in which botl CT and ultrasonography demonstrated two cystic pelvic masses , the larger of which was presumed to be an ovarian
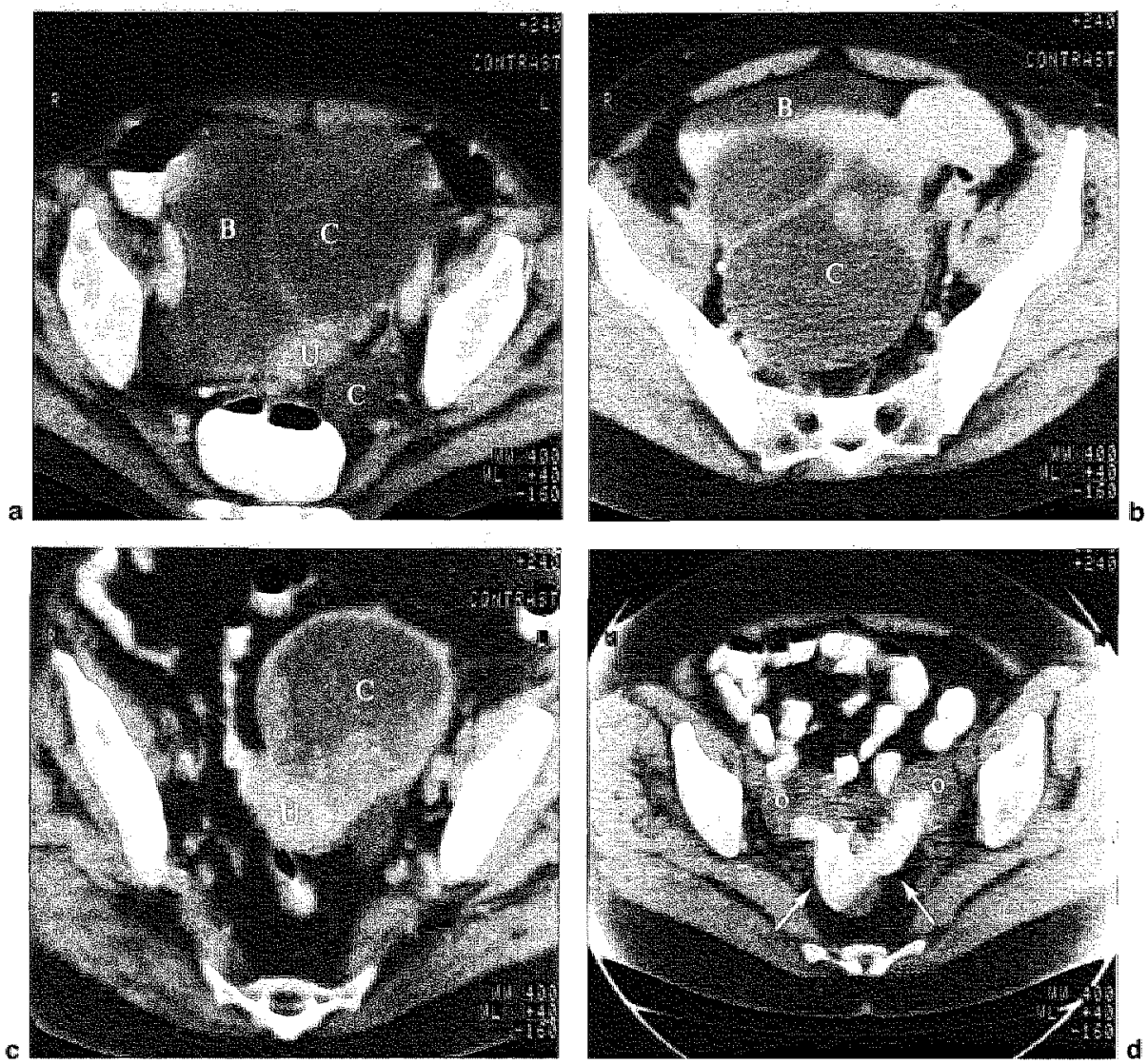

fig. 7.5 .

Four calses of owarian cancer: a. predominantly cystic fumours $(C)$ in both ovaries (small solid structures were visible at another level) one conpressing the bladder. b and e: predominantly cystic tumours with large solid structures. d. bilateral solid owaries connected by a tumour mass with psammoma callilications dorsal to the uterus (arrows). Note the difference between bowel contrast and the calcifications which were barely visible on the conventional $\mathrm{X}$-ray film. $(\mathrm{U}=$ uterus, $\mathrm{B}=$ bladder, $\mathrm{O}$ =ovaries) 
cyst. At operation, however, the smaller mass was found to be the ovarian cyst and the larger one a grossly distended bladder caused by a blocked catheter.
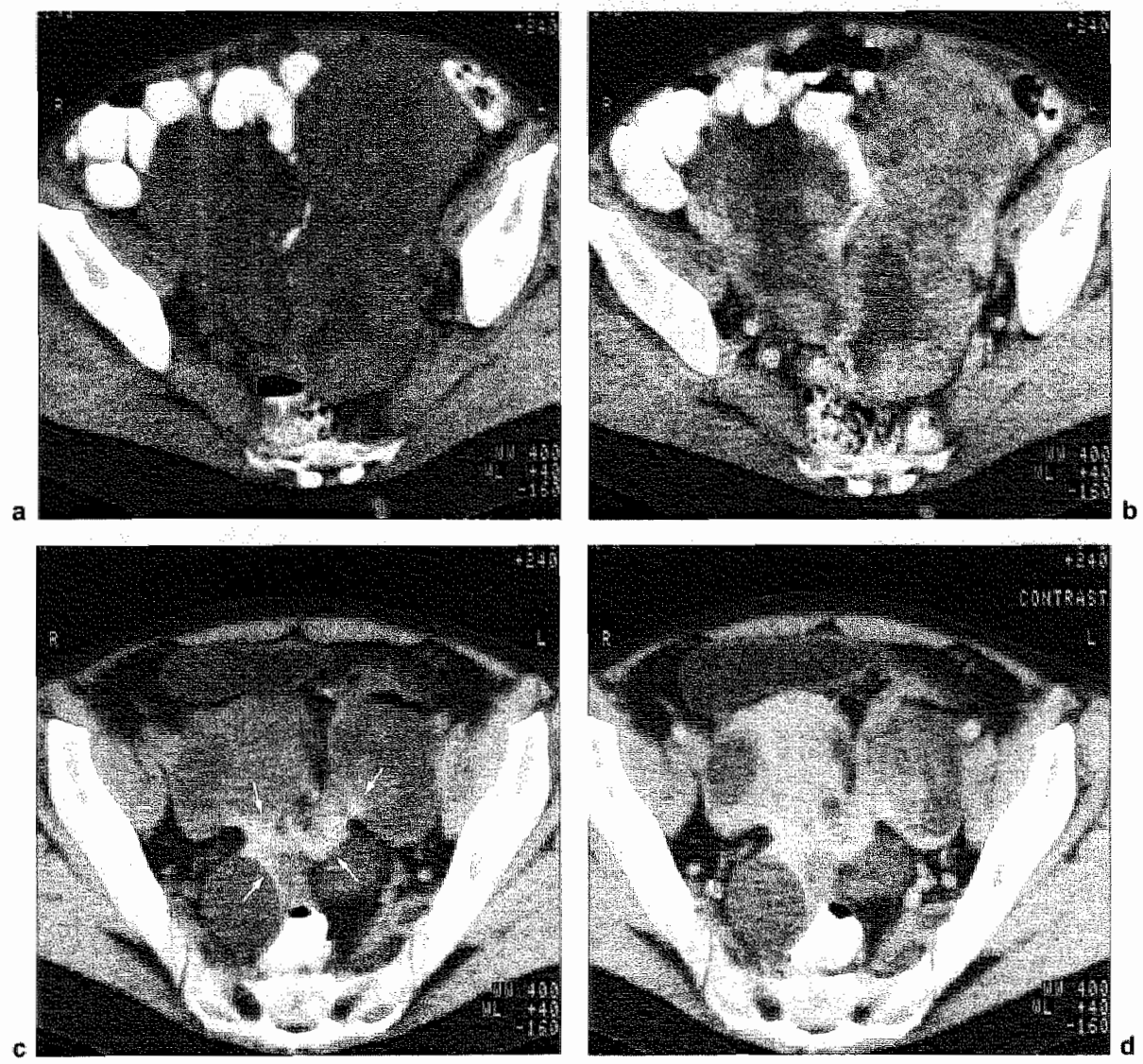

fig. 7.6.

Two cases of ovarian cancer; scans be fore (a and c) and after (b and d) bolus contrast injection. The calcifications are clearly visible in figure $c$ (arrows) but may be casily mistaken for contrast medium in the vascular phase in figure $d$.

\subsubsection{CT in staging ovarian cancer, a correlation study between $\mathrm{CT}$ and surgical findings}

\subsubsection{Method and material}

To assess the accuracy of CT in staging ovarian cancer, results are compared with those of operation or laparoscopy in 60 patients with histologically proven ovarian malignancy. Thirty-two patients were scanned before the primary staging laparotomy or laparoscopy (indication group I, table 7.4.), 26 before a second and two before a third look procedure (part of indication group IIc, table 7.4). In 18 cases (part of indication group IIc) no second look was done for several reasons. Because of a complete clinical remission (CCR) chemotherapy was stopped and the results of CT scanning were compared with a follow-up of at least 6 months. Table 7.10 relates the initial stage of dise ase with the type of dingnostic 
procedure.

The 32 patients submitted for initial staging laparotomy include 3 special cases (table 7.4.) in whom the histological diagnosis of ovarian cancer was made because of incidental operative findings (wo during appendectomy and one during sterilisation) prior to first CT scan.

This study is partly retrospective and partly prospective and the scans of the former are always between brackets. In the retrospective study all hospital records, especially operation reports, are reviewed in detail. Duriag the prospective study the gynaecologist was asked to record on a special form (appendix. III) the surgical findings, including size, if present, of pelvic, peritoneal, omental and diaphragmatic masses, the state of the liver and the presence or absence of enlarged lymph nodes, and finally a judgement as to the succes of debulking. This was classified as "maximal debulking", if a complete resection was possible or the maximal diameter of residual tumours was less than $2 \mathrm{~cm}$, "partial debul king" if the residual tumour was more than $2 \mathrm{~cm}$ diameter and "laparotomy" if the procedure was limited to biopsy only. The results of "second look" operations were classified as "complete surgical remission (CSR)" if no intra-abdominal malignancy was found by surgical, cytological and histological examination. If the operation revealed residual tumour, the size and location
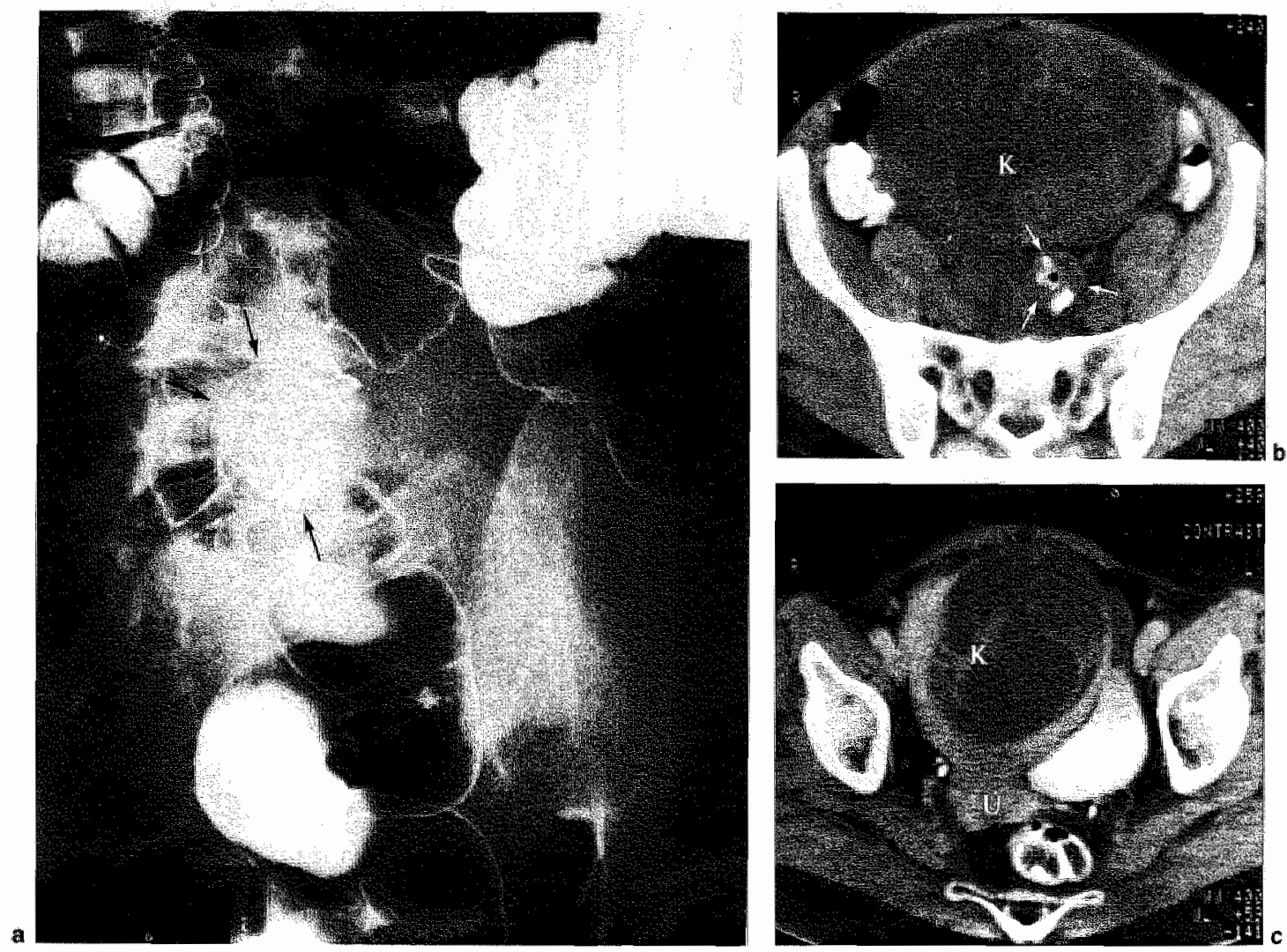

tig. 7.7.

Two cases of metastatic oxarian neoplasm (Krukenberg's tumours) with the colon as primary origin, a and a are of the same paticnt and the colon tumour is also visible on the CT scan (arrows). (U) = ulerus, $\mathrm{B}=$ biladdery 

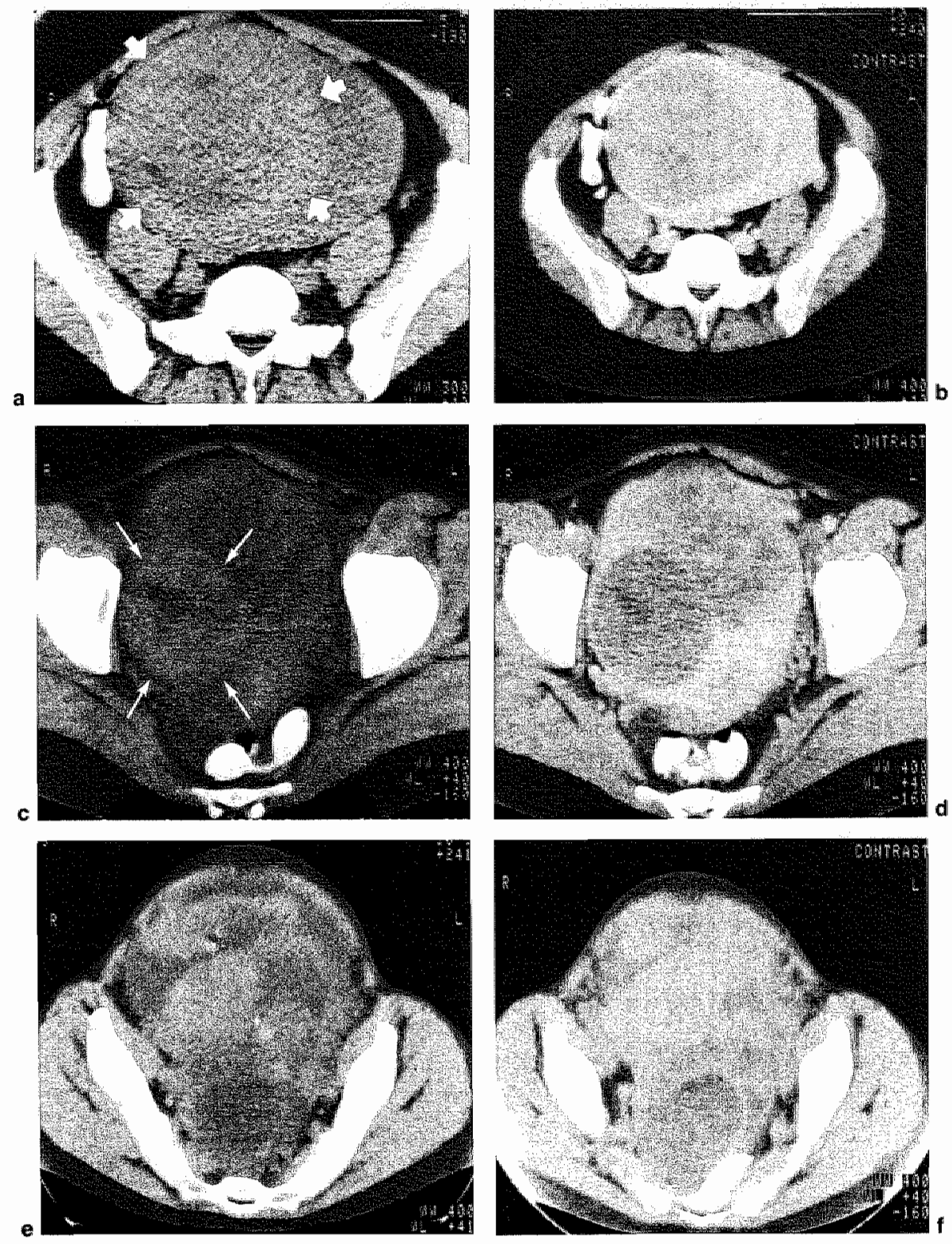

fig. 7.8 .

$C T$ features of large fibroids: CT scans before ( $a, c$ and $e$ ) and after $(b, d$ and $f)$ bolus contrast injection: $\mathbf{a}$ and $\mathbf{b}$ and $\mathbf{c}$ and $\mathbf{d}$ are fibroids, $\mathbf{e}$ and $\boldsymbol{r}$ is a malignant ovarian tumour. The areas of slightly increased density (arrows) in the fibroids do not enhance after bolus contrast injection, unlike the areas of higher density in the ovarian tumour. 
of the tumour were located.

In all cases, histological assessment was reviewed by one pathologist and the findings are listed in table 7.11.

All initial surgicall evaluation procedures were performed within 30 days of CT scan (average 7.ll days), with one exception of 126 days, and second and third look procedures were all performed within 90 days of CT scan (average 31.8 days) with one exception of 136 days. In 17 of the 32 initial evaluation cases a maximal debulking procedure was possibte, in 8 a partial debulking procedure, in 6 (including the laparoscopy case) a biopsy only, and in one patient (staged as: "special category") only ascitic fluid examination was done.

During 16 of the second (or third) look procedures residual disease was found and in 12 cases a complete remission. All second or third look procedures were performed within 20 months of the first laparotomy (average 10,1 months) with the exception of one patient who had a second look laparoscopy 10 years after the initial operation because of suspected recurrent disease. 20 Patients (22 CT scans) were treated with multiple drug therapy and 6 with single drug therapy. In 15 patients (17 CT scans) maximal debulking had been done at the first laparotomy, in 4 only partial debulking and in 7 debulking had been impossible. None had chemotherapy in the intervall between CT scan and second or third look procedures. Clinical assessment prior to each follow up scan was available in all but one case, and indicated complete clinical remission (CCR) in 20 cases (18 patients) partial clinical remission (PCR) in 5 and progressive clinical disease (PCD) in two cases.

All CT scans were performed using the standard procedure described in chapter II and include the pelvis and upper abdomen except in two cases in which only the pelvis was scanned. Intravenous contrast medium was given in some cases, as appropriate. All CT scans were reviewed independently by two radiologists as described in paragraph 7.5.3.1.

Tabla 7.10

Diagnostic procedures performed to evaluate the stage of disease in patients with ovarian cancer relatted to the initial stage of disease. The numbers between brackets are the CT scans of the retrospective study and the numbers marked (") are the speciat cases mertioned in table 7.4 .

\begin{tabular}{|c|c|c|c|c|c|c|c|}
\hline \multirow{2}{*}{ 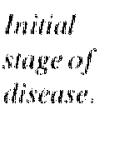 } & \multicolumn{2}{|c|}{ 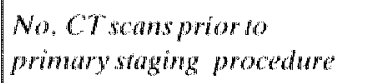 } & \multicolumn{2}{|c|}{$\begin{array}{l}\text { No. CT scans prior to } \\
\text { second took proced tare }\end{array}$} & \multicolumn{2}{|c|}{$\begin{array}{l}\text { No CT scoms prionto } \\
\text { hird look pro cedure }\end{array}$} & \multirow{2}{*}{$\begin{array}{l}\text { No. patients } \\
\text { whthont } \\
\text { second look } \\
\text { follow-top }\end{array}$} \\
\hline & lapanotomy & laparosopy & laparovomy & laparoscopy & laparotowy & Laparoscopy & \\
\hline Stage 1 & $3+2^{*}$ & - & 1 & 3 & . & - & 2 \\
\hline Stage ll & 4 & . & 2 & . & - & - & 6 \\
\hline Stage ITI & $13+1^{1}+(3)$ & 1 & $9+(3)$ & $1+(3)$ & 2 & - & $8+(1)$ \\
\hline Stage IV & $3+(1)$ & . & $3+(1)$ & . & . & - & 1 \\
\hline Spucial & & & & & & & \\
\hline category & - & $1($ cytology $)$ & - & - & - & . & . \\
\hline Total & $23+3^{3 k}+(4)$ & 2 & $15+(4)$ & $4+(3)$ & 2 & - & $17+(1)$ \\
\hline
\end{tabular}


Table 7.111

Histopathology of the ovarian cancer cases of chapter VII.

$\begin{array}{lr}\text { Serous cystadenocarcinoma } & 57 \\ \text { Municous cystadenocarcinoma } & 7 \\ \text { Endometroid carcinoma } & 7 \\ \text { Mixed mesodermal tumour } & 1 \\ \text { Granulosacel tumour } & 5 \\ \text { Teratoma } & 1 \\ \text { Choriocarcinoma } & 1 \\ \text { Clearcell tumour } & 1 \\ \text { Total } & 80\end{array}$

\subsubsection{Results}

Thirty-nine forms (appendix III) were correctly completed by the gynaccologist, and in the remaining 21 (including 11 from the retrospective study) the form was completed by consulting the formal operation report. It was subsequently realized that a question about ascites had been omitted in the printing of the questionaire form, and for this information, the formal operation reports had to be consulted in every case.

Table 7.12 compares the results of CT scanning with surgical findings in all 60 patients. The totals for the individual findings are incomplete, however, because only cases with definite positive or negative information recorded on the questionaire form or in the operation report were counted.

There were 4 false negative CT scans for ascites. One false negative finding for ascites was 43 days before operation, but CT also demonstrated satellite masses, subsequently proved at operation. In another case a hypodense region around the liver was present but interpreted as pleural fluid. There was pleural fluid but at operation 3 days later $600 \mathrm{ml}$ ascites was found. In 2 other cases a small amount of haemorthagic fluid was found in the peritoneal cavity.

The false-negative for liver metastases was only on the basis of operative palpation of the liver, no liver biopsy being performed. Although pre and post contrast $C T$ showed completely normal liver parenchyma, it did in fact demonstrate capsular irregularity on the lower border. There were two false-positives for liver metastases, the first patient having a $1.5 \mathrm{~cm}$ diameter central liver lesion on CT not confirmed at the second look operation 23 days later. However the patient died four months later with a clinical diagnosis of liver metastases, by which time subsequent CT scans showed multiple liver lesions. The second patient had an enormous suprarenal mass and an intrahepatic lesion, clearly visible on $\mathrm{CT}$ neither were confirmed at operation 13 days later, so the tumour was classified as stage III and a maximal debulking procedure was done. Nevertheless the patient died $41 / 2$ months later.

Satellite masses on the liver capsulle were visible in only 4 patients, one showing a $10 \mathrm{~cm}$ mass in the liver hilus and the second showing soft tissue densities on the dome of the liver (fig. 10a.). In the third patient the operation report (retrospective case) mentioned "large nodules on the dome of the liver" and in the last patient small irregularities on the liver surface in CT were interpreted by one observer as normal and by the other as abnormal 


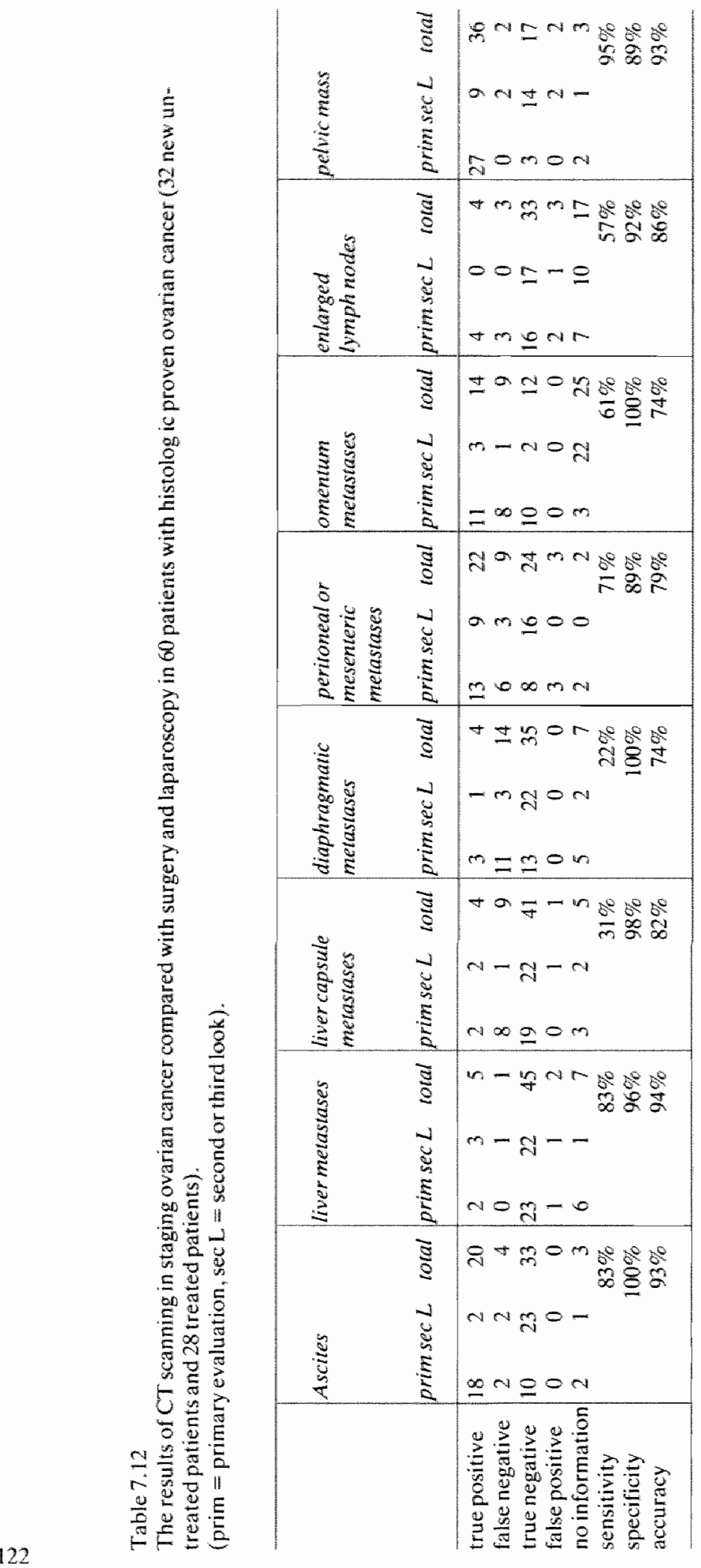


and the operation report mentioned small capsular irregularities. In the nine false-negative cases, surgery reported small nodules (less $\| \mathrm{cm}$ ) on the livercapsulte often described as "granular" or "miliary". In the one false-positive case an irregular outline of the liver in CT was quoted as satellite masses (fig. 7.10f.).

Diaphragmatic satellite masses visible on $\mathrm{CT}$ were little more than sone irregularities on the visceral aspect of the diaphragm, but operation demonstrated many large nodules 1 to $2 \mathrm{~cm}$ in diameter. Furthermore, there were 14 CT false-negatives.

CT was unable to demonstrate peritoneal and mesenteric satellite masses less than $3 \mathrm{~cm}$ in diameter, and the smallest omental mass visualized was $2 \mathrm{~cm}$ in diameter.

One of the 3 CT false-positive reports of enlarged lymph nodes was reported surgically as "doubtful interpretation, possibly some suspicious nodes".

The two false-negative pelvic mass cases had only pin-point lesions in the pouch of Douglas at operation, and one of the two false-positive findings was only in relation to laparoscopy.

Moreover for various reasons 18 patients with a complete clinical remission had no second look procedure. In 15 of these, the chemotherapy was stopped and in three continued.

Seventeen had a normal abdominal $\mathrm{CT}$ scan and the remaining one having a two centimeter pelvic mass on CT. Two had a recurrence and died 18 and 22 month after $C T$, both having a normal abdominal CT scan although 1 showed pleural fluid. All the other patients had a symptom free period of at least 6 months in 14 cases and 3 months in 2 cases, while in only one patient the therapy was continued (the patient with the small pelvic mass). In these 18 cases, there were therefore 15 true-negatives, 2 false-negatives and perhaps one falsepositive.

Table 7.13

Comparison between CT and surgical findings in 19 patients who had a CT scan after a staging or debulking laparotomy.

\section{CT findings}

\begin{tabular}{lll}
$\begin{array}{l}\text { Surgical } \\
\text { findings }\end{array}$ & $\begin{array}{l}\text { No residual } \\
\text { diseases more } \\
\text { than } 2 \mathrm{~cm} \text { in } \\
\text { diameter }\end{array}$ & $\begin{array}{l}\text { Residual } \\
\text { disease more } \\
\text { than } 2 \mathrm{~cm} \mathrm{in} \\
\text { diameter }\end{array}$ \\
\hline $\begin{array}{l}\text { No residual } \\
\text { disease more } \\
\text { than } 2 \mathrm{~cm} \text { in } \\
\text { diameter } \\
\text { residual } \\
\text { disease more } \\
\text { than } 2 \mathrm{~cm} \text { in } \\
\text { diameter }\end{array}$ & - & $3+4^{*}$ patients \\
\end{tabular}



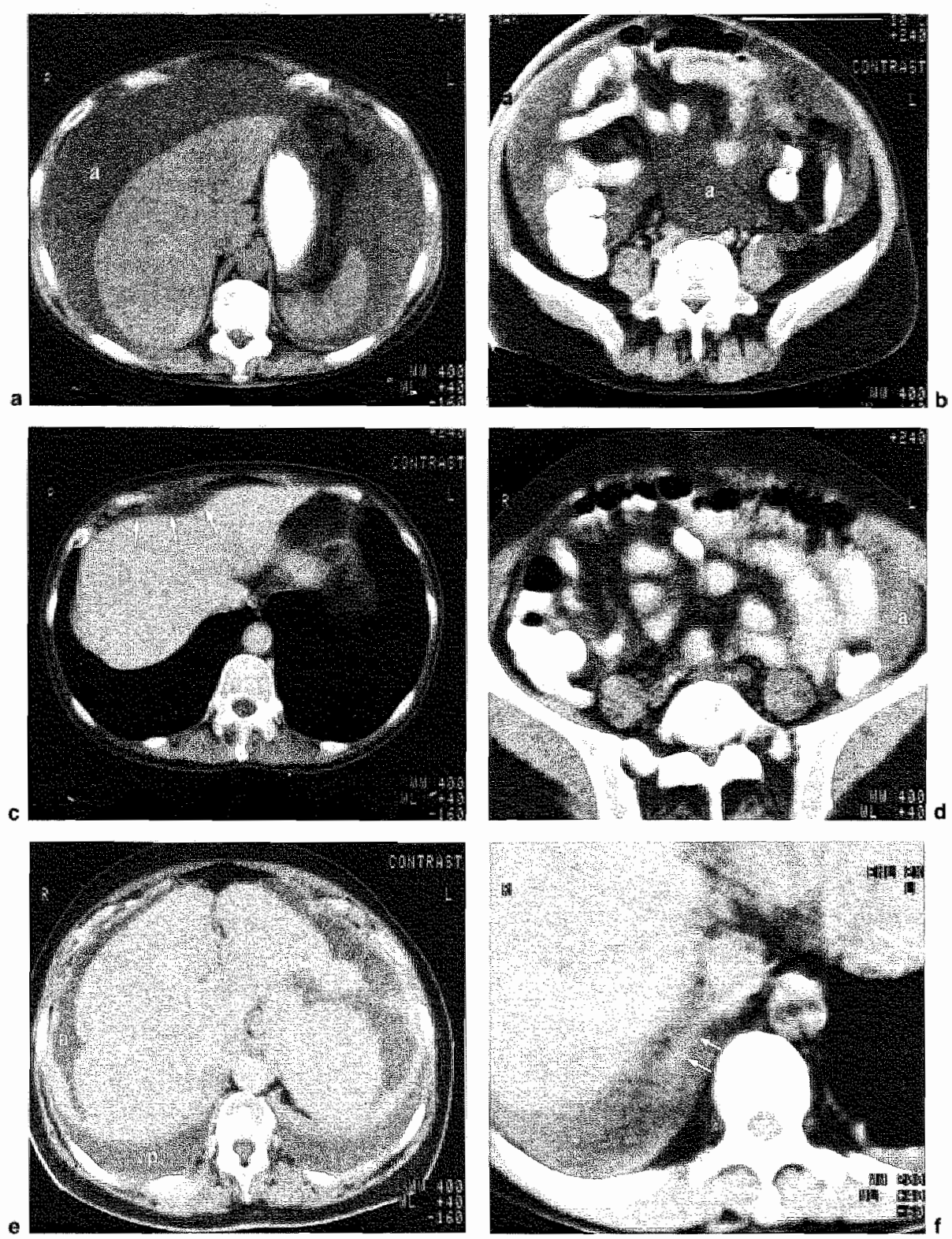

fig. 7.9.

Ascites and pleuralfluid. an and b: ovarian cancer with ascites (a) through the whoke peritoneal cavity. acound liver and spleed, in the paracolic gutters and between bowel toops. Note the ventral location of air containing bowel loops floating in the thid. In malignant ascites the fluid is loculated and the mesentery thickened and retracted (fig. d). c: A minimal amount of ascites may only be seen in the right hemidiaphragmatic region ventral to the liwer (arrows). Differentiation between pleural ( $p$ ) and peritoneal fluid by the interfice sign (fig. e) showing the interface to be stharp between liver and ascites, but hazy between diaphragm and pleural fluid, and by the displaced diaphragmatic crus (arrows, fig. f). 


\subsubsection{Discussion}

As already mentioned, intra-peritoneal spread of ovarian cancer is common and early (Bergman 1966, Rosenoff et al. 1975). The figures in our patient material do not differ significantly from those of others, in that, at staging laparotony, diaphragmatic metastases were present in $50 \%$, liver capsule metastases in $33 \%$ and peritoneal and omental metastases in at least $63 \%$. Sixty-eight percent were classified as stage III or IV, and in $53 \%$ maximal debulking was performed. Of the remainder, 7 patients had only a biopsy or cytology taken, all others having a partial debulking procedure. Wide-spread intra-abdominal disease with loops of bowel involved into a tumour mass may make considerable demands on the expertise of the gynaecologist or surgeon concerned, and even if technically possible, nay be contra-indicated by the general condition and age of the patient. Such factors also influence the extent to which the entire peritoneal cavity can be explored. Obtaining all necessary staging information may carry an unwarranted operative risk. Such decisions are a matter for the individual gynaecologist, of whom at least 10 are represented in our material. For this reason, the surgical information is confined to a note of the presence or absence of tumour in the different locations in all cases where this could be established. Particular aspects of the results as shown in table 7.12 will now be discussed.

\section{A. Ascites.}

A diagnostic accuracy for $\mathrm{CT}$ of $93 \%$ in the detection of ascites is worse than the results of Whitley et al (1981) and better than the results of ultrasonography (accuracy of $84 \%$ ) demonstrated by Requard et al. (1981). However, 4 false-negative findings need an explanation. In one case the ascites may have developed during the long period (43 days) between CT and operation and in 2 cases, the small quantity found at operation could barely be aspirated. Nevertheless in another patient $600 \mathrm{ml}$ ascites, not detected by CT, was found at operation three days later. This false-negative result was caused by the fact that all the fluid was located around the liver, and interpreted as pleural fluid, which was indeed also present in this patient. This interpretative error is already recognized and methods of avoiding it are clescribed in the literature (Dwyer 1978, Teplick et all 1982). Dwyer (1978) described the "displaced diaphragmatic crus sign" (fig. 7.9f.) caused by fluid accumulation in the pleural recess between crus and spine. Teplick et al. (1982) deseribed the so called "interface sign" (fig. 7.9e.), namely that the interface between liver and ascites always appears sharp while that between diaphragm and pleural fluid is always hazy and indistinct. Both signs were present in this patient (fig. 7.9f.).

In 20 patients CT demonstrated ascites very clearly. In all cases it was visible around the liver capsule particularly between liver and right hemidiaphragm ventrally (fig. 7.9c.). It was present in the right and left paracolic gutters in 15 and 16 cases respectively, but had spread to the left hemidiaphragm in only 14 cases. It was present in the pouch of Douglas in 14 cases and loculated in folds of the mesentery in 12 cases and in only 6 was it present throughout the whole abdomen. The typical appearance of malignant intraperitoneal fluid collection with all bowel loops retracted and grouped around the midline was never seen in this patient group but the ascites was often loculated between mesenteric folds due to adhesions caused by mesenteric cancer inwolvement (fig. $7.9 \mathrm{~d}$.). In supine position, in which all CT scans were made, the most dependent parts of the peritoneal cavity are the pelvis (especially the lateral pararectal recesses) and the posterior subhepatic space (Morison's pouch) which communicates freely with the right subphrenic space. Because of the negative pressure in the subdiaphragmatic region during inspiration as described by 

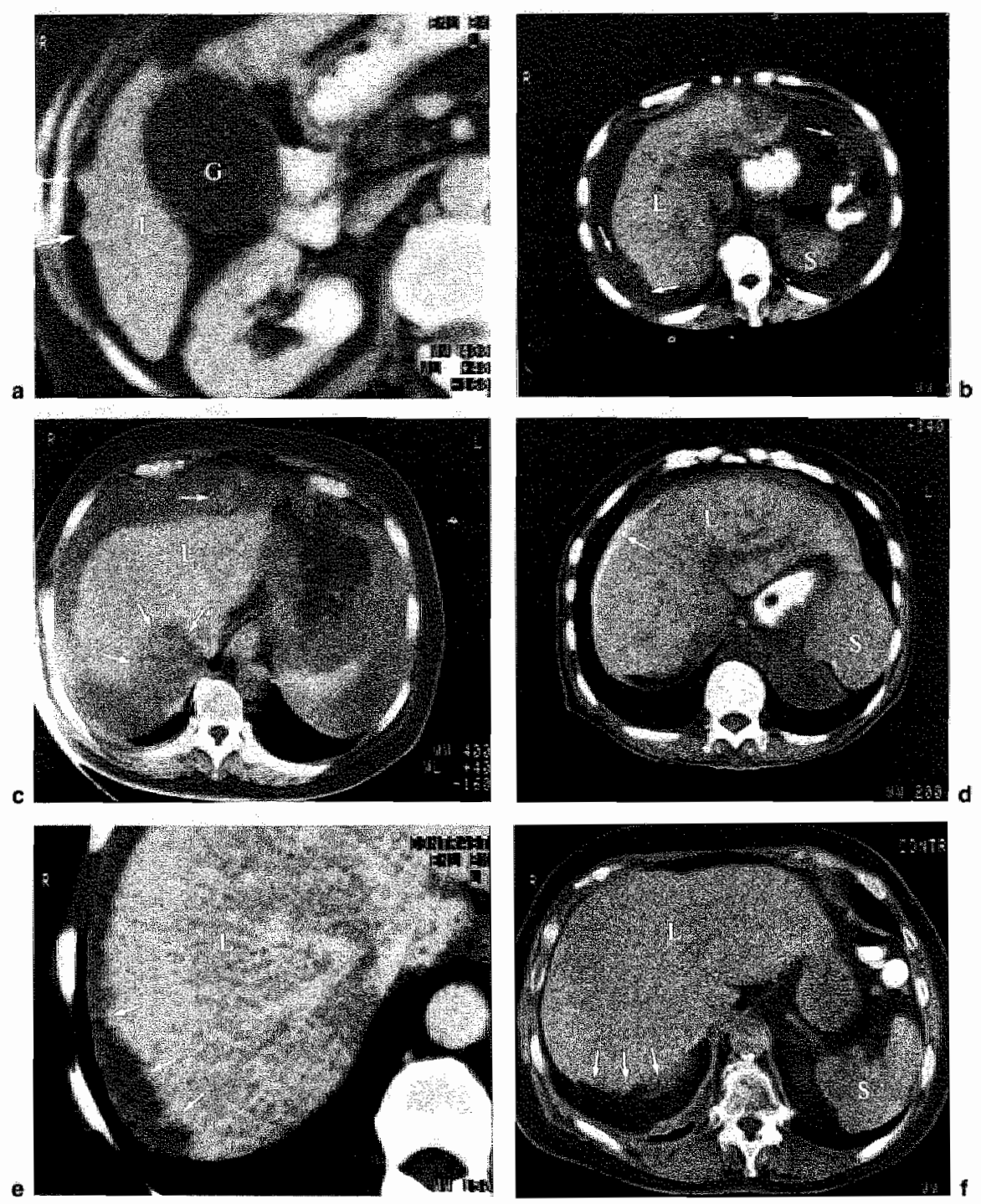

fig. 7. 10 .

Five cases of ovarian cancer with metastases on livercapsule and diaphragm. a: small nodules of soft tissue densities on the liver capsule (arrows), b: masses of soft tissue density (arrows) adjacent to the parietal peritoneum on the abdominal aspect of the diaphragm. $\mathrm{c}$ : ill defined mass between diaphragm and liver, cansing an irregular liver outline (arrow) and a soft density mass ventral to the liwer near the falciform ligament (arrow), d: Calcified rim around the liver (arrow) presumably caused by psammoma body calcifications (not histologically proven). e: Irregular lateral aspect of the liver (arrows) with strands of soft tissue density between liver and diaphragm outlined by ascites due by metastatic deposits. f: lrregular dorsal aspect of the liver (arrows) with no capsule metastases during surgery, probably caused by fibrotic changes after chemotherapy. $(\mathrm{L}=$ liver, $\mathrm{S}=$ spleen, $\mathrm{G}=$ gallbladder $)$ 
Overholt and Donchess (1935), this area will be first site of free fluid accumulation particularly on the right, because of the presence of the phrenicocolic ligament on the left. The presence of ascitic fluid ventrally is presumably due to displacement by the mass of the liver. Proto et al. (1976) demonstrated this ventral location of ascitic fluid ultrasonographically and stressed the importance of the specific gravity of the fluid with respect to other abdominal organs. Although the lack of ascites does not exclude malignancy, the presence of ascites is often associated with a malignant mass (Jones and Jones, 1981). If CT is to be used to detect ascites the right hemidiaphragmatic region nust be scanned.

\section{B. Pelvic mass lesion.}

Chapter 7.3.4. discuss the wide range of CT findings in patients with suspected ovarian cancer, a pelvic mass being a frequent finding. In established ovarian cancer, table 7.12 demonstrates an accuracy rate of $93 \%$ for the CT detection of pelvic mass and in the 32 cases scanned prior to primary evaluation of suspected ovarian cancer the accuracy was $100 \%$. The two false negative cases were small pin-point lesions at operation. The false positive findings were clear mass lesions on CT not found during surgery and laparoscopy and which may have represented non-opacified bowel on CT-scan. This stresses the need for optimal patient preparation for CT scans.

\section{Deposits on liver capsule and diaphragm.}

In detecting satellite masses on diaphragm and livercapsule, CT has a low accuracy and a very much lower sensitivity. The true positives consist of $1-10 \mathrm{~cm}$ masses on the livercapsule, and diaphragmatic masses between 1 and $2 \mathrm{~cm}$ in diameter. Nevertheless, masses of $1-2 \mathrm{~cm}$ in diameter were missed, even after a review of the films. Whitley et al. (1981) and Amendola et al. (1981) report similar findings. The most likely reason for the failure of CT to demonstrate these lesions is their small size and many are also missed at operation (table 7.1) (Bagley et all. 1973). Moreover the position of satellite masses between diaphragm and liver in a convex plane presents particular technical problems. Only part of this plane will be visualized in one CT-cut and when the plane is parallel to the scanplane, contrasting of a small lesion will be very poor due to partial volume averaging (fig. 2.5) especially in the absence of ascites. Ascites causes a better outline of liver surface and diaphragm resulting in a greater likelihood of detecting small masses, particularly on the lateral aspect of liver and diaphragm. Direct coronal CT cuts, as deseribed by van Waes and Zonneveld (1982) may improve the diagnostic accuracy of CT in diagnosing liver capsule or diaphragmatic metastases because with this technique the major part of the diaphragm and the liverdome are perpendicular to the scanplane. The use of consecutive slices with a narrow slice width may improve resolution and sensitivity, but will also result in higher radiation dose and examination time, which is hard to justify, since respiratory movement may exclude significant areas from examination.

When these metastases are large, it is often difficult to determine whether they are fixed to diaphragm or to liver capsule. Liver capsule metastases may compress or infiltrate the liver tissue sometimes causing irregularity of the liver contour in CT (fig. $7.10 \mathrm{c}$. and e.). However such an irregular outline only does not prove the presence of capsule metastases since in one case, showing this phenomenon, a laparotomy revealed no liver capsule lesions. This patient had already received chemotherapy and it may be possible that the metastases were destroyed leaving irregularity and fibrosis (fig. 7.10f). In 1 patient ( 2 CT scans), the liver 

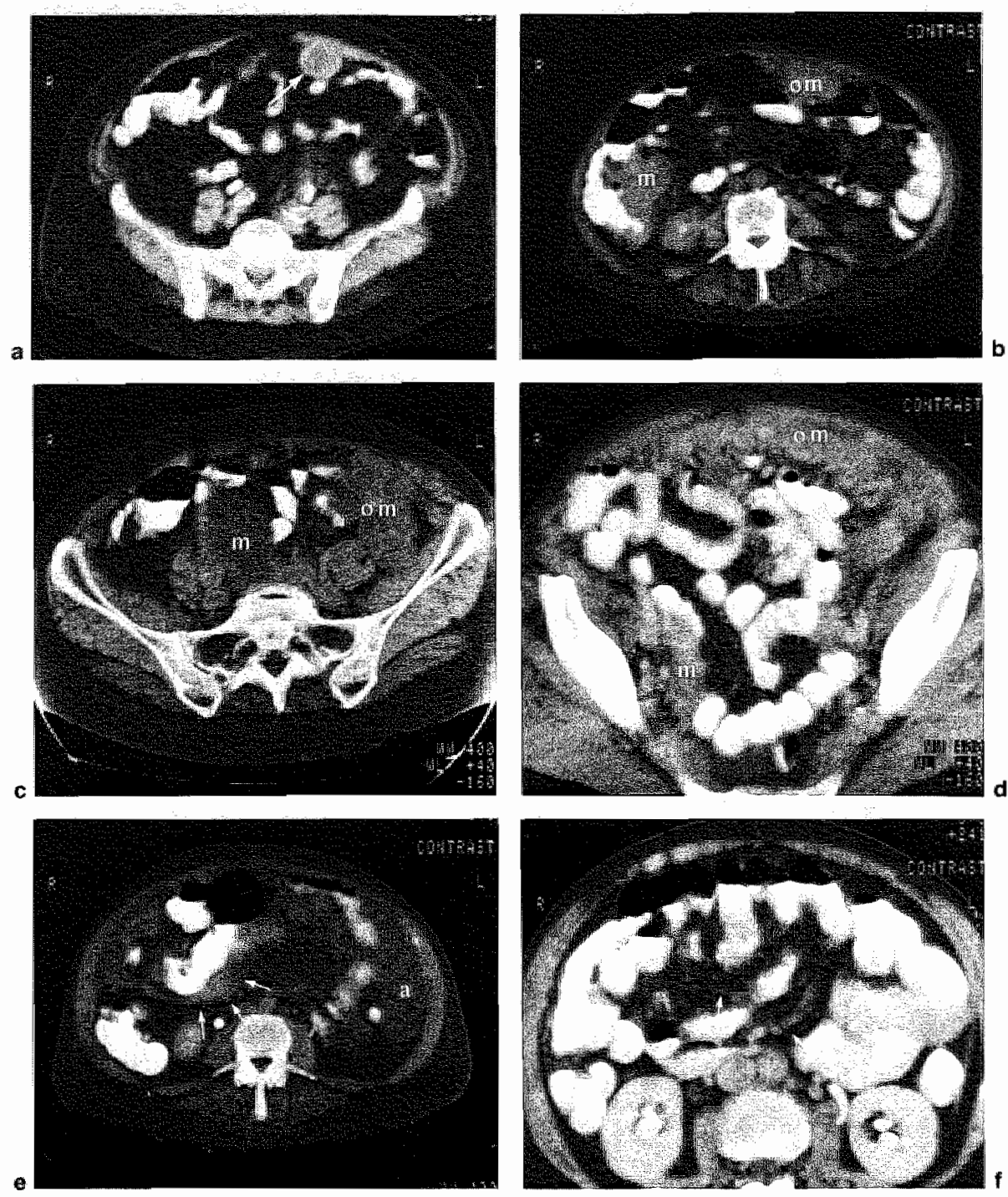

Iig. 7. 11 .

Six cases of pwarian cancer with metastases on omentum, bowel loops and mesentery. a: a round mass (arrow) on the inner aspect of the ventral abdominal wall (omental mass). b: soft tissue mass (om) on the inner aspect of the ventral abdominal wall (omental mass) and a mass lesion around the coecumn (m). c: soft tissue mass (om) between the ventral abdominal wall and the lieft iliacus muscle (omental mass, infiltrating the sigmoid) and the top of a pelvic mass (m). d: flat ill defined mass between bowel loops and ventral abdominal wall (om) being a tumour infiltrated omentum and more sharply demarcated masses $(\mathrm{m})$ along the parietal peritoneum. et sharply demarcated mass alongside the bowelloops (arrows). f: stellate pattern of diffuse mesenteric involvement. Compare this figure with the normal thin mesenteric lines (blood wessels). This pattern is seen in all diseases with peritoneal thickening : inflammation. haemorhage, radiation enteritis, malignant infiltration $(a=\operatorname{ascites})$. 
had a very thin calcified rim (fig. 7.10d) presumably caused by psammona body calcifications in capsule metastases. A more dense curvilinear calcification partly around an irregularly outlined spleen (fig. 7.3a) was seen in a patient with pseudomyxoma peritonei (not included in this paragraph).

\section{Peritoneal implants on bowel loops and mesentery.}

The diagnostic accuracy of CT for peritoneal implants between bowel loops and mesentery is also low, lesions less than $3 \mathrm{~cm}$ diameter being missed in 9 patients. Nevertheless, in 7 patients the size and location of peritoneal masses were exactly confirmed at operation. In one true positive case, CT demonstrated peritoneal nass on the caecum, but surgically this proved to be part of the large primary pelvic tumour, and there were many peritoneal implants of $1 \mathrm{~cm}$ diameter not seen on CT. These figures are not as good as those of Whitley et al. (1981) who had no fallse positive results in determining mesenteric involvement in 22 operatively controlled cases. In 22 patients CT correctly detected peritoneal implant between bowel loops and on the mesentery and in 6 of these (5 primary evaluation and one second look), no debulking was possible. Whitley et al. (1982) have described the CT features of mesenteric involvement and classified these in four different patterns : rounded masses, ill-defined masses, cake-like masses and stellate pattern. We have also seen these patterns and frequently two or three of these features were visible in the same slice. 111 defined irregular masses (fig. 7.11d.) or sharply demarcated flat masses (fig. 7.11e.) were the most obvious CT features, which were often combined with the so called stellate pattern (fig. 7.11f.). This stellate pattern may be caused by a diffuse mesenteric thickening due to metastatic seeding. The flat masses are metastatic seedings adjacent to the bowel loops or adenopathy in the same region (Whitley et al., 1982). They may cause interpretative problems because of their outline and density may simulate bowel loops or loculated ascites. Psammoma body calcifications may give all these metastatic deposits a high density and make them very difficult or impossible to differentiate from suboptimally opacified bowel loops (fig. 7.5d). If there is any doubt, the best way to differentiate tumour from bowel loop is to re-scan the same region, eventually after renewed bowel opacification. Of the three false-positives, one was caused by an enlarged follicular ovary with hydrosalpinx being interpreted as a peritoneal mass but in the other two cases the likely cause was poor contrast bowel opacification.

The false negative results were caused by miliary deposits on the visceral peritoneum, a condition non recognizable on CT unless the mesentery appears thickened.

\section{E. Omental masses.}

$\mathrm{CT}$ is no more accurate in demonstrating omental masses than in visualizing peritoneal implants (accuracy 75\%), with no false positives and nine false negatives. A normal omentum is fatty tissue and not visible on $\mathrm{CT}$. When a mass was present on the parietal aspect of the ventral abdominal wall this was quoted as an omental mass (fig. 7.11a-d.) but in fact this could also be a ventrally located mesenteric mass. There is no CT criterion to differentiate these both.

\section{F. Liver metastases.}

The incidence of liver lesions as detected surgically is low, and a CT accuracy rate of $94 \%$ in this study reflects the high number of true negatives. Although the accuracy of $\mathrm{CT}$ in 
diagnosing liver metastases is stressed by many authors (Bernardino et al, 1982), there is little knowledge about the accuracy of liver palpation at operation. Hogg and Pack (1955) compared laparotomy and autopsy findings concerning the presence of liver metastases in 100 patients and quoted an incorrect diagnosis of "freedom of liver metastases " at laparotomy of $5 \%$. Central liver lesions may neither deform the liver contour nor be palpable, and the liver may be wery difficult to visualize or palpate in the presence of multiple serosal implants and adhesions. Both false-positive patients died shortly after CT scan and operation, with clinical liver metastases, suggesting that CT is in fact more accurate than palpation.

In 23 patients who had pre and post contrast scans, four had demonstrable liver lesions (fig. 7.12), and another had a splenic lesion. In all these cases, lesions were visible on plain scan, but in one, contrast revealed a larger number of lesions.

The one false-negative case had irregularities on the liver capsule on CT, reported as capsular metastases, but thought at operation to be intrahepatic. As this would imply a higher clinical stage, an operative liver biopsy is necessary in view of the ambiguity. In one true-positive case, an additional large intrahepatic lesion on the dome of the liver was missed on $\mathrm{CT}$, and could otherwise have been false-negative. The likely reasons of partial volume averaging and respiratory movement have already been discussed. These problems are avoided in ultrasonography because of the continuous nature of the scamning technique which may be performed in several different planes.

A straight comparison of "presence or absence " of intra abdominal disease with the definite results of the second look procedures yields 4 CT false-negatives and no false-positives. In other words, CT abnormalities always indicated disease, though with some discrepancy as to the location, but a normal CT scan could not exclude disease.

\subsubsection{CT in treatment monitoring of patients with ovarian cancer.}

\subsubsection{Method and material.}

CT scans performed up to 2 months after initiall debulking procedure were assessed for the amount of residual tissue and compared with operation reports concerning the degree of debulking. CT estimations of tumour load in ovarian cancer patients, who were scanned repeatedly but not operated, while on chemotherapy, were studied and classified as "unchanged", "increasing" or "decreasing", according to whether the number of mass lesions was increased or decreased or the maximum cross-sectional area was changed by more than $25 \%$. The result of this classification was compared with clinical follow-up. Finally, scans performed for suspected cancer recurrence were compared with follow-up findings.

a. In 19 patients CT scan was performed within two months of staging laparotomy (average 24 days), in 14 before chemotherapy and in 5 after the first course of chemotherapy.

b. Nineteen patients with ovarian cancer had "routine follow-up" CT scans, but no laparotomy, while on chemotherapy. Fourteen had two scans and 5 had three. Scans were performed at 3 - 6 months intervals. Sixteen patients received multiple and three received single drug therapy. In 10 patients the first scan was made 3 to 6 weeks after the first staging laparotomy, but before starting chemothe rapy, and in 9 patients, two or 

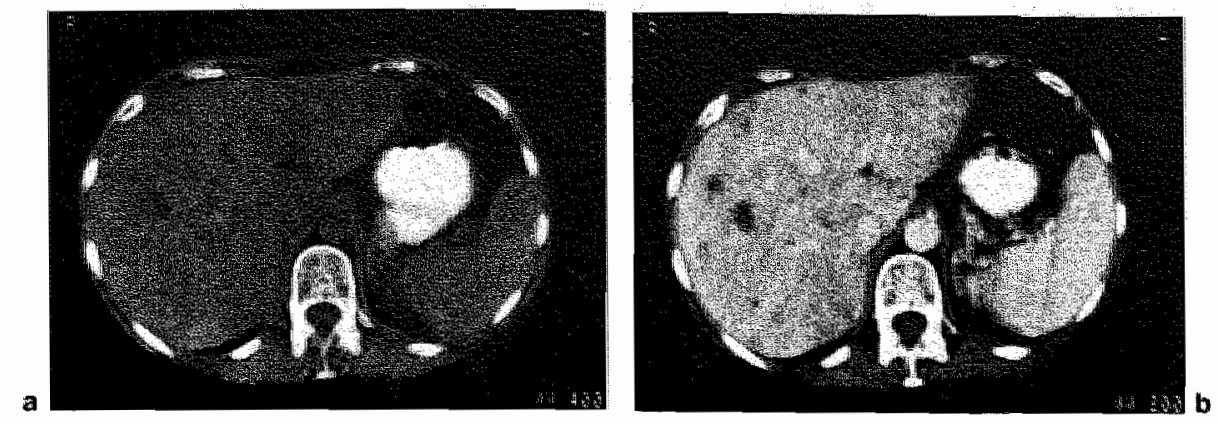

fig. 7.12.

Patient with many liver metastases from ovarian cancer: Cl: scan before (a) and after (b) bolus contrast injection.

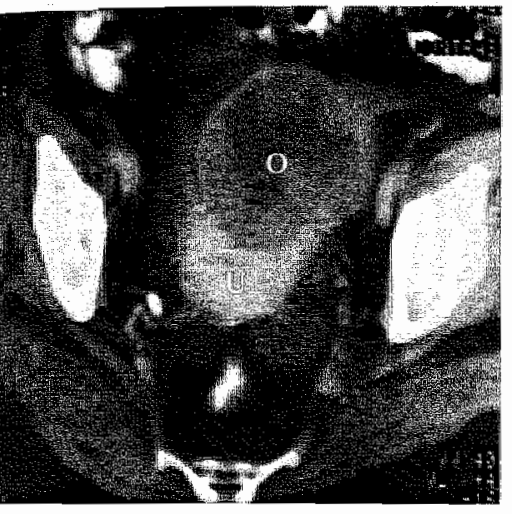

a

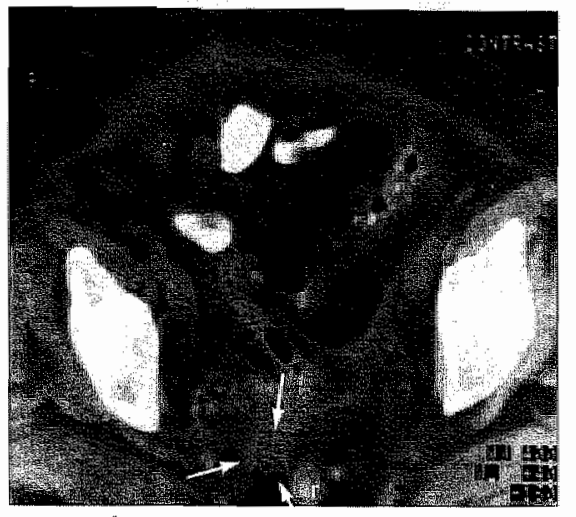

b

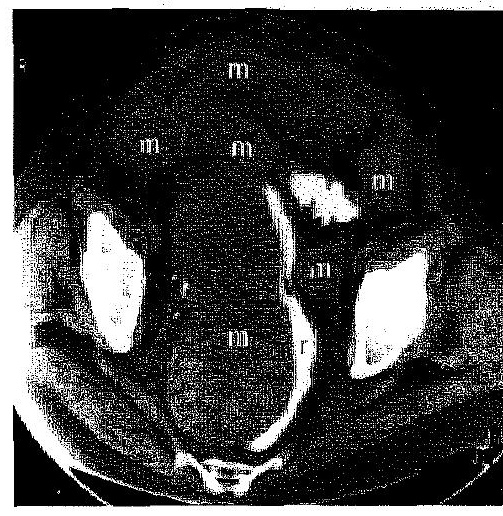

c

fig. 7.13 .

Owarian cancer (adenocarcinoma). (a) betore operation, (b) after maximal debulking, note the small residual mass (arrows). (c) six months later large recurrent mass (m) with multiple satellite masses

(m). $(U=$ uterus, $r=$ rectum, $o=$ primary ovarian tumour $)$

three months after starting chemotherapy. In 16 patients, the last CT scan was made six months after starting chemotherapy and ten of these had a second look procedure within 4 weeks of CT scanning. Thirteen patients had complete and 3 partial clinical remission. Of the 13 with complete clinical remission, 5 had no second look but chemotherapy was stopped and of the 6 with only partial clinical remission 4 had no second look procedure, and chemotherapy was therefore continued.

c. CT findings in 14 patients scanned for suspected recurrent disease were compared with clinical or autopsy findings

\subsubsection{Results.}

A. Table 7.13 compares the CT and operative findings in the 19 patients

Of interest are the 7 cases with residual disease on CT after a reportedly successful maximal debulking procedure. Of these 7 CT false-positives, 4 (marked *) were scanned $21-56$ 
days after operation by whicli time one course of chemotherapy had been given. One of these 4 died within 6 months with a severe recurrence and liver metastases predicted by CT and the other 3 had a complete clinical and CT remission after 6 months chemotherapy. Of the three other $\mathrm{CT}$ fallse-positives one had a recurrence 4 months later in exactly the same location as the primary CT abnormalities (fig. 7.13a-c) and died, one had a complete clinical remission after 6 month chemotherapy but the pelvic mass lesion prewiously seen on CT was confirmed at second look laparotomy (fig. 7.14a-d) and the last had complete clinical remission but not a CT remission and had no second look operation. The 4 patients with no surgical or CT residual disease maintained complete clinical remission (one confirmed by second look) for 9 months after completing treatment.

B. In 9 of the 19 patients scanned two or three times while on chemotherapy the scans remained unchanged. In 3 of these, all scans were normal, confirmed in 2 by second look laparotomy, and in one by over 8 months disease-free follow-up. In 6 the last CT scan was abnormal but unchanged compared with the previous scan, in spite of chemotherapy. Three of these 6 had complete clinical remission at the time of the last scan, but surgery showed residual tumour as predicted by CT (fig. 7.15). Two had a partial clinical remission of which one also had partial surgial remission as demonstrated at second look operation, and in the other chemotherapy was continued. One patient died two months after last scan with wide spread disease while on chemotherapy but this was not surgically confirmed.

In 2 of the 19 patients, increasing tumour load was visible on CT and both died within three months, with progressive disease.

In 7, decreasing tumour load was visible on CT and the last CT scan was normal in 4 (fig. 7.16) and showed residual disease in 3 (fig. 7.14), of which 1 had partial clinical remission and another complete clinical remission and both had residual abdominal disease at second look. The other 5 patients all had complete clinical remission, twice confirmed at second look and twice confirmed by a disease free period, without chemotherapy, of at least 12 months. One patient with residual disease on CT but a complete clinical remission, had chemotherapy stopped but follow-up was only 4 weeks.

In one of the 19 patients, the scan 6 weeks after staging and debulking operation showed widespread pelvic disease, but the scan after 6 months chemotherapy was nomal and the pattient was in a complete clinical remission. No second look procedure was done and chemotherapy was stopped, but a further scan 6 months later clearly demonstrated recurrent tumour.

C. Thirteen patients were scanned for clinically suspected recurrent disease, 6 while on chemotherapy and 7,2 - 12 months after chemothe rapy. In 8 cases, the CT suggested recurrent disease (fig. $7.13 . \mathrm{c}$ ), confirmed surgically in 2 and by follow up in 6 , and all died within 3 months of wide spread intra-abdominal disease. In the other 5, CT was normal. None of these were operated or received chemotherapy after CT, and all had a disease free follow-up of at least 6 months.

\subsubsection{Discussion}

It is generally accepted that patients with ovarian cancer (particularly staged III and IV) 

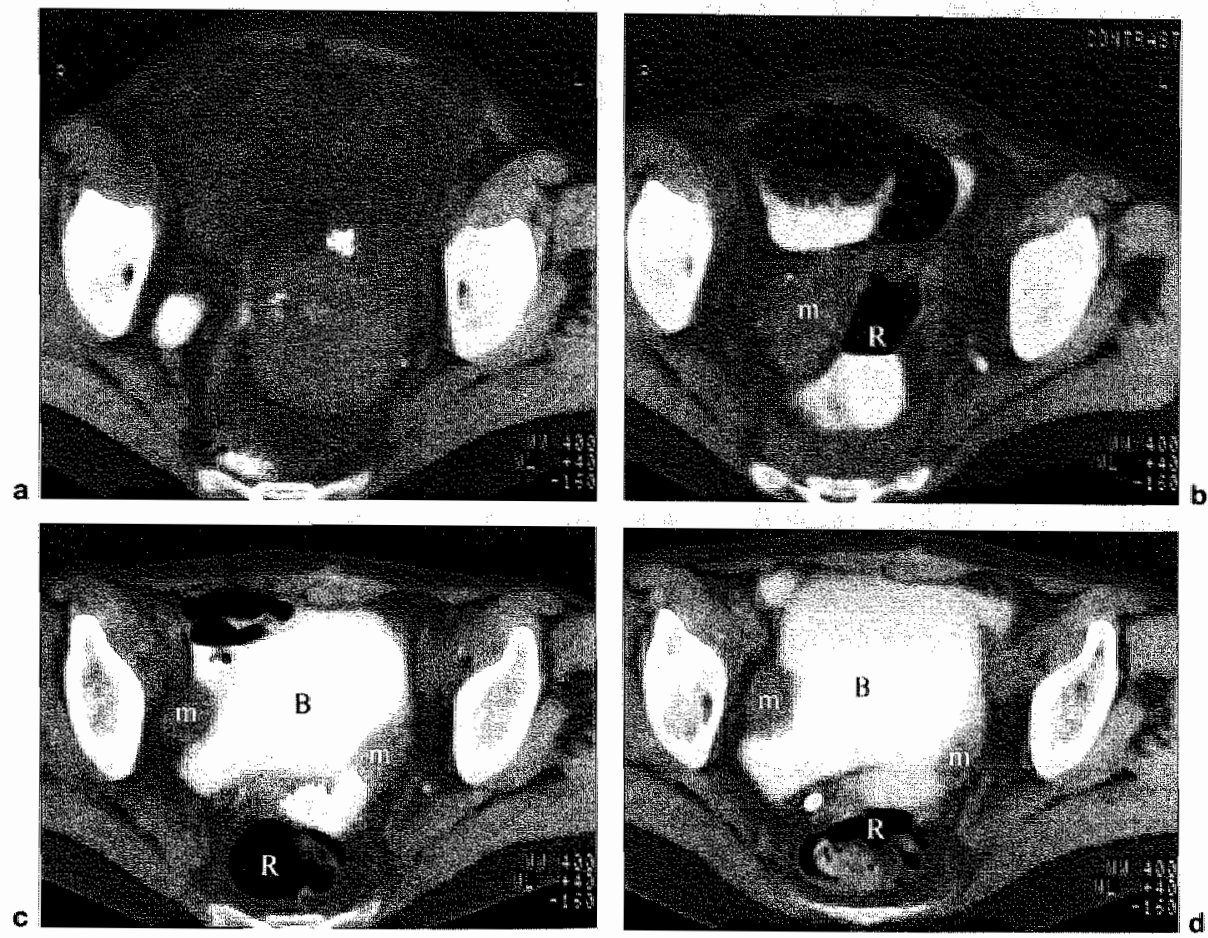

fig. 7.14.

Ovarian teratoma: (a) before operation, (b) two weeks after maximal debulking; note the residual mass (m), (c) after three months post chemotherapy the mass is decreased but has mot disappeared. (d) three months later on, after (changing) chemotherapy and before second look operation, the right mass is unchanged and the left is decreased in size. (both masses were found chring second look the same day). $(B=$ bladder, $R=$ rectum $)$
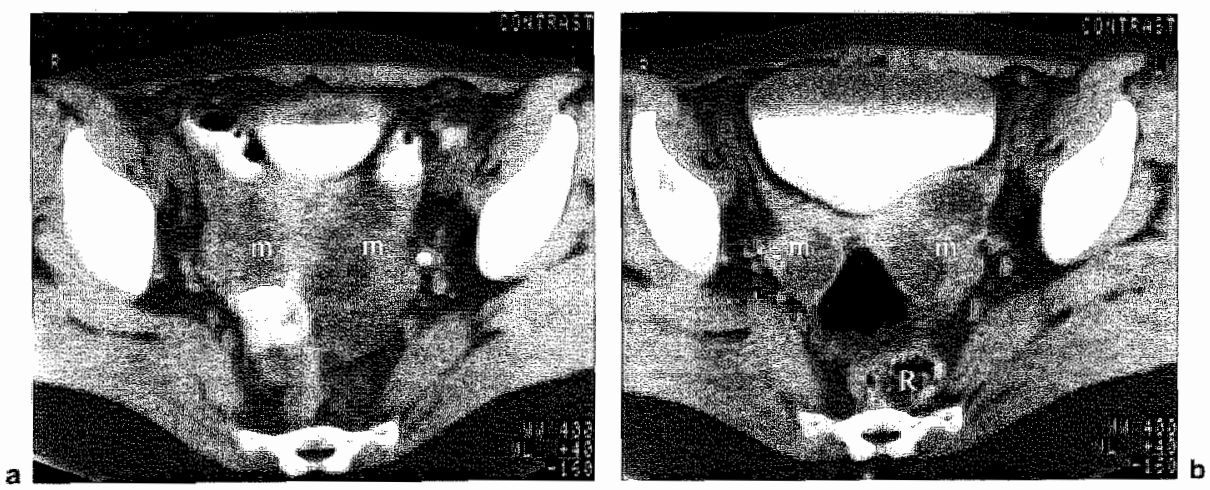

fig. 7.115 .

Serous cystadenocarcinoma ovarii ; (a) first CT scan after two chemotherapy courses. (b) CT scan four months later after 6 chemotherapy courses and in a complete clinical remission: CT demonstrates a smaller pelvic mass (confirmed by second look) but the maximal area was less than $25 \%$ changed. $(B=b l a d d e r, R=$ rectum,,$m=$ mass $)$ 
are candidates for chemotherapy, but its success and the final prognosis, is affected by the degree of surgical debulking (Neijt et al., 1980). If hysterectomy, bilateral salpingooophorectomy, omentectomy and removal of all visible and palpable metastases on peritoneum or bowel is possible, this, together with bowel resection if necessary, should be done. Such an operation taxes the skills of both gynaecologist and surgeon. However many patients already have wide spread disease, precluding maximal debulking, as was the case in 17 of the 32 untreated patients in this study, (paragraph 7.5.4.1.). In such cases a base-line CT study would be necessary to monitor the chemotherapeutic response.

Postoperative base-line CT was done in 19 patients, but 11 of these had maximal debulking. Notwithstanding CT showed pelvic mass lesions in 7 of these cases. In one patient this was an asymmetrical solid mass with calcifications (fig. 7.14) decreased in size by chemotherapy and proving at second look operation 6 months later to be residual tumour. Proof of the nature of the CT abnormalities was impossible in the other patients because all were treated and the lesions changed or disappeared. Some masses were very large, and the operation report mentioned no significant bleeding. Intra-abdominal blood collections are easily identified with $\mathrm{CT}$ but distinction from other mass lesions may be very difficult. The density of a fresh blood clot is $40-60 \mathrm{H}$.U., further increasing during the first week due to resorption of plasma, and thereafter decreasing in volume and density due to haemolysis and resorption over weeks or months (fig. 7.17). During this time, hypodense masses may be visible on CT, then often disappear completely. A baematoma may, however, organize, and become fibrotic or even calcify, and appear in CT as a solid or calcified mass llesion. (Von Klaus et al., 1981). Bolus contrast injections do not improve distinction from other mass lesions. In the initial phase, a hatematoma shows no contrast enhancement but in the organizing phase, irregular contrast enhancement, particularly peripherally, may be visible (Von Klaus et al. 1981: Baert et al. 1980). Any or all of these features may be seen in malignant ovarian tumour, making differentiation more or less impossible.

Also in the 7 cases of maximal debulking and residual disease on CT, 4 masses appeared solid, 2 cystic and 1 mixed on CT. Density was unrelated to time between CT and operation. The cystic masses were found 21 and 34 days postoperatively, the solid lesions $21-42$ days, and the mixed lesion 56 days postoperatively. Free blood will collect in the most dependent part of the pelvis, the pouch of Douglas, and around the rectum, respecting normal peritoneal borders. This is the likely explanation of symmetrical masses in the pouch of Douglas, draped around the rectum.

In a case of intraperitoneal bleeding of unknown origin, this sign of "respecting anatomical borders" was very clearly seen on CT 4 and 7 days after the accident (fig. 7.17 a). In 2 of the 7 cases, this phenomenon wats visible and both had complete clinical remission after chemotherapy. Nevertheless this phenomenon makes the interpretation of CT scans shortly after debulking procedure very difficult, and it would be better to make the "baseline" scan 2 - 3 months post operatively because the majority of haematomata will have then resorbed.

The drastic nature of chemotherapy and its considerable risks when prolonged make accurate assessment of tumour response essential (Reimer et al., 1977). Clinical parameters are unreliable, particularly in patients with non-palpable lesions and a second look laparotomy is therefore required. It is indicated (a) to discontinue therapy, (b) prior to resection of residual disease and $(c)$ to map out residual disease requiring a change of treatment (Phillips et al., 1979). A negative second look procedure allows the physician to 

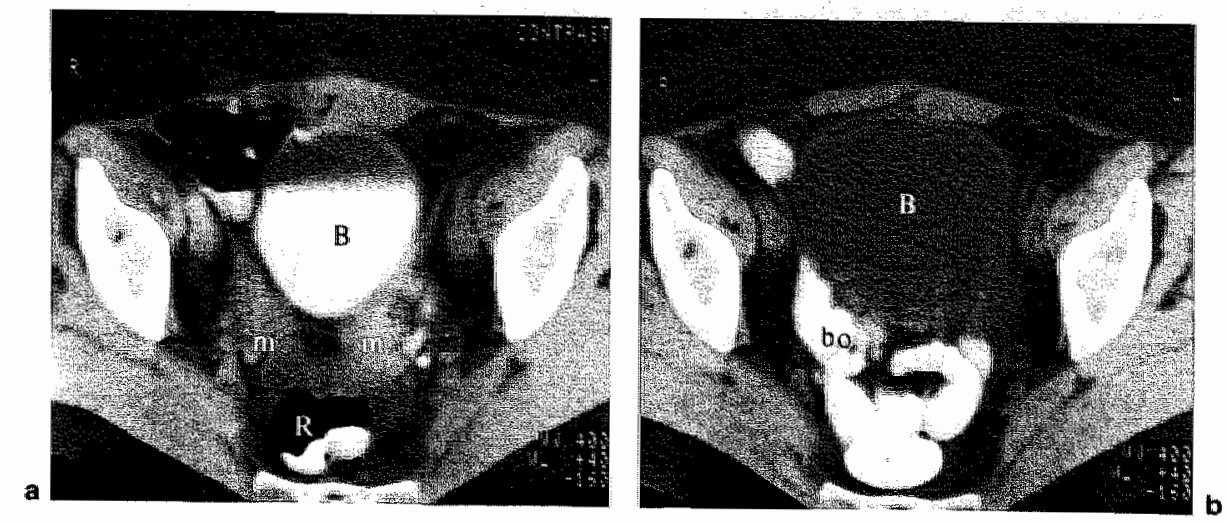

fig. 7.16.

Serous cystadenocarcinoma ovarii : (a) first CT scan one month and one course chemotherapy after maximal debulking demonstrated a residual pelvic mass. The second CT scan after 6 months (and 5 chemotherapy courses) was normal (b). Chemotherapy was stopped without a second look and patient refused further therapy. $(B=$ bladder, $b o=$ bowel, $m=$ mass)
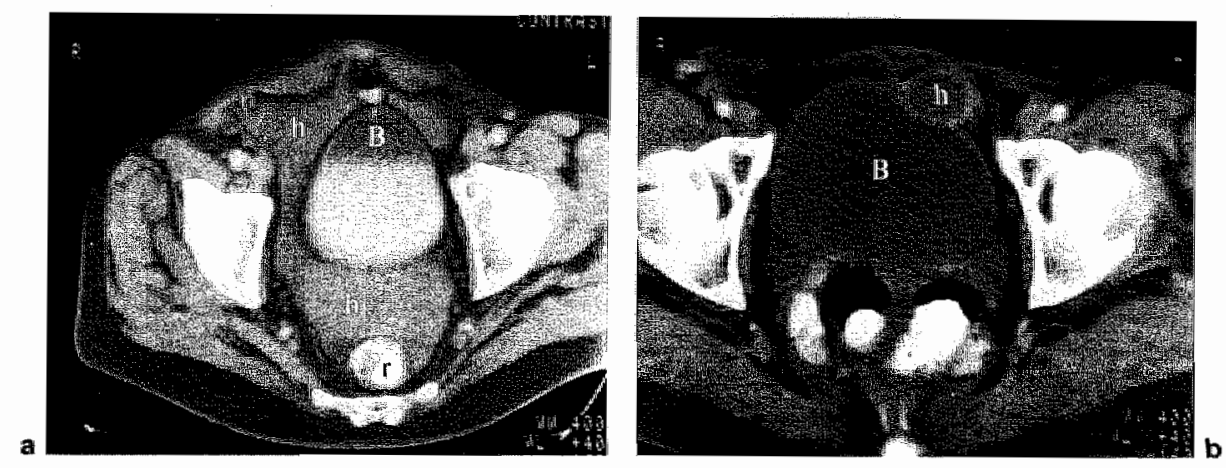

fig. 7.17.

Two cases of haematoma. a: acute intraperitoneal haematoma (h). Note the high density and its sharp demarcation with bladder (B) and rectum (r). b: four weeks old hatertatoma (h) ventral to the bladder (B). Note its low density and the contrast enhanced rim.

discontinue cytotoxic agents, but the problem is to decide when this should be done, being dependent on the amount of residual tumour after debulking, the histologic type and grade of the tumour and the cytotoxic agents used, and will vary from patient to patient.

Paragraph 7.5.4. demonstrates that a normal CT scan does not exclude residual disease, which would be very likely with an abnormal scan. Paragraph 7.5.5.2. B. demonstrates that it is possible to monitor tumour response with $\mathrm{CT}$. Stable disease on $\mathrm{CT}$ indicates that tumour is still present and a change of therapy or a laparotomy to remove the residual tumour may be indicated. Increasing tumour load on CT is a wery ominous sign making a change of therapy mandatory. Decreasing tumour load may allow the clinician to continue therapy and wait till a subsequent CT scan is normal before doing a second look procedure. 
A final word of caution is required. Three patients with non-gynaecological malignancies (2 histrocytomas and 1 non-Hodgkin lymphoma), not forming a part of this study, were treated with chemother apy and had $\mathrm{CT}$ evidence of residual tumour which proved histologically to be non malignant fibrotic mass. Similar cases are described in literature (Soo et al. 1981, Lewis et al. 1982). As this is just as likely to occur un ovarian cancer patients, persistent masses on CT over a long period, should not be an indication for prolongation or changé of treatment without histological confirmation of malignancy.

\subsection{Conclusion.}

1. CT is a very rellable diagnostic method in diagnosing and excluding pelvic mass lesions.

2. The inability of CT to demonstrate small peritoneal implants limits its role in staging ovarian cancer.

3. CT seems very helpful in monitoring tumour response to treatment in patients with ovarian cancer, and, although it cannot replace the second look operation, it can help to determine the optimal time for this procedure.

\section{References Chapter VII}

AMENDOLA, M.A., WALSH, J,W., AMENDOLA, B.E., TISNADO, J., HALL,D.J., GOPLERUD, D.R. : Computed tomography in the evaluation of carcinoma of the ovary.

J. Comput. Assist. Tomogr. 5: 179-186, 1981 .

ASCH, M.I., WIEDEL, P.D. and HABIF, D.V. : Gastrointestinal metastases from carcinoma of the breast : Autopsy study and 18 cases requiring operative intervention.

Arch. Surg. $96: 840-843,1968$.

ATHEY, P.A., WALLACE, S. JING, B.S., GALLAGER, H.S, SMITH, J.P. : Lymphography in watrian cancer.

Amer. I. Roentgenol.. 123:106*113,1975.

BAERT, A.L., WACKENHEIM, A and JEANMART, L. : Abdominal Computer Tomography, Atlas of Pathologieal Computer Tomography, volume 2.

Springer Verlag Berlin Heidelberg New York, 1980.

BAGLEY, C.M. ji., YOUNG, R.C., SCHEIN, P.S., CHABNER, B. A., DeVITA, V.T, : Owatian carcinoma metastatic to the diaphragm frequently undiagnosed at laparotomy. A preliminary report. Am. J. Obstet. Gynecol. 116: $397-400,1973$

BERGMAN, F. : Carcinoma of the ovary. A clinicopathological study of 86 autopsied cases with special reference to mode of spread.

Acta Obstet. Gynecol. Scand. 45:211-231, 1966.

BERNARDINO, M.E., THOMAS, J.L., BARNES, P.A. and LEWIS, E. : Diagnostic approaches to liver and spleen metastases.

Radiol. Clin. North Am. $20: 469$ - 485, 1982.

BRYK, D. : Roentgen evaluation of large uterine and ovarian masses.

Obstet, Gynecol., 28,630-632, 1966. 
BRYK, D. : Barium enema examination in the evaluation of large pelvic masses. Amer. J. Roentgenol., 101, 970-977, 1967.

CASTRO, J.R. and KLEIN, E.W. : The incidence and appearance of roentgenologically visible psammomatous calcifications of papillary cystadenocarcinoma of the ovaries.

Amer. J. Roentgenol., 88, $861-891$ (1962).

C.B.S. (Netherlands central bureau of statistics)

Kanker, morbiditeit en mortaliteit $1975 / 1976$,

staatsuitgeverij, the Hague, 1979.

CREASMAN, W.T. and RUTLEDGE, $F_{*}$ : The prognostic value of peritoneal cytology in gynecologic malignant disease.

Am. J. Obstet. Gynecol. $110: 773-781,1971$.

DELAND, M. FRIED, A., VAN NAGELL. J.R., DONALDSON, E.S. : UItrasonography in the diagnosis of tumours of the ovary.

Surg, Gynecol. Obstet. 148/346-348, 1979.

DELGADO, G., CHUN, B., CAGLAR, H. and BEPKO, F. : Paraaortic lymphadenectomy in gynecologic malignancies confined to the pelvis.

Obstet. Gynecol. $50: 418-423,1977$.

DOUGLAS, B., MACDONALD, J.S., BAKER, J. : Lymphography in carcinoma of the ovary.

Proc. R. Soc. Med. $64: 400-401,1971$.

DUNNICK, N.R., JONES, R.B., DOPPMAN, J.L., SPEYER, J., MYERS, C.E. : Intraperitoneal contrast infusion for assessment of intraperitoneal fluid dynamics.

Am. J. Roentgenol. 133:221 - 223, 1979.

DWYER, A. : The displaced crus : A sign for distinguishing between pleural fluid and ascites on computed tomography.

J. Comput. Assist Tomogr. 2 : $598-599,1978$.

FARMER, R.G, and HAWK, W.A. : Metastatic tumours of the small bowel.

Gastroenterology $47: 496-504,1964$.

FELDMAN, G.B. and KNAPP, R.C. : Lymphatic drainage of the peritoneal cavity and its significance in ovarian cancer.

Am. J, Obstet. Gynecol. 119:991-994, 1974.

FIGO (1971): Classification and staging of malignant tumours in the female pelvis.

Acta Obstet Gynecol. Scand $50: 1-7,1971$.

FLEISCHER, A.C., AVERETTE, J. jr. MILLIS, J.B. and JULIAN, C. : Differential diagnosis of pelvic masses by gray scale sonography.

Am. J. Roentgenol. 131: 469 - 476, 1978.

GRAHAM, W.P., III and GOLDMAN, A. : Gastrointestinal metastases from carcinoma of the breast.

Ann. Surg. 159: $477-480,1964$. 
HOGG, L. Jr. and PACK, G.T. : Diagnostic accuracy of hepatic metastases at laparotomy.

Arch. Surg. ?: $251-252,1955$.

JONES, H. and JONES, S. (eds) : Novak's Textbook of gynecoloy, pp $507-581$

Williams and Wikins, Baltimore, 1981.

JULIAN, C.G., GOSS, J., BLANCHARD, K. and WOODRUFF, J.D. : Biologic behaviour of primary ovarian malignancy.

Obstet. Gynecol. $44: 873-884,1974$.

KARLSSON, S. and PERSSON, P.H. : Angiography in uterine and adnexal tumours. Acta Rad. Diagn. $21: 11-20,1980$.

KEETTEL, W.C., PIXLEY, E.E. and BUCHSBAUM, H.J. : Experience with peritoneal cytology in the management of gynecologic malignancies.

Am. J. Obstet. Gynecol. 120:174 - 182, 1974.

KHILNANI, M.T., MARSHAK, R.H., ELIASOPH, J. and WOLF, B.S. : Roentgen features of metastases of the colon.

Am. J. Roentgenol. $96: 302-310,1966$.

VON KLAUS-HENNING-HUBENER : Computertomographie des Körperstammes. George Thieme Verlag Stuttgart. New York 1981.

KLEMPNER, E. : Gynaecologic lesions and ureterohydronephrosis.

Am. J. Obstet. Gynecol. $64: 1232$ - 1241, 1952.

KNAPP, R.C. and FRIEDMAN, E.A. : Aortic lymph node metastases in early ovarian cancer. Am. J. Obstet. Gymecol. 119:1013 - 1017, 1974.

KOBAYASHI, M. : Use of diagnostic ultrasound in trophoblastic neoplasms and ovarian tumors. Cancer 38: $441-452,1976$.

LAWSON, TH.L. and ALBARELLI, J.N. : Diagnosis of gynecologic pelvic masses by gray-scale ultrasonography: Analysis of specificity and accuracy.

Am. J. Roentgenol. $128: 1003-1006,1977$.

LEWIS, E., BERNARDINO, M.E., SALVADOR, P.G., CABANILLAS, F.F., BARNES, P.A. and THOMAN, J.L. : Post-therapy CT-detected mass in lymphoma patients : Is it visible tissue? J. Comput. Assist. Tomogr. 6:792-795, 1982.

LEVITT, R.G., SAGEL, S.S. and STANLEY, R.J. : Detection of neoplastic involvement of the mesentery and omentum by computed tomography.

Am. J. Roentgenol. 131: $835-838,1978$.

LINGLEY, J.R. : The significance of psammoma body calcification in the roentgen diagnosis of papillary turnours off the ovary.

Amer. J. Roentgenol. $47: 563-570,1942$.

LONG. J.P. and MONTGOMERY, J.B. : The incidence of ureteral obstruction in benign and malignant gynecologic lesions.

Am, J. Obstet. Gynecol. $59: 552$ - 562, 1950.

MARSHAK, R.H. KHILNANI, M.T, ELIASOPH, J, and WOLF, B. S. : Metastatic carcinoma of the small bowel.

Am. J. Roentgenol. $94: 385-394,1965$.

MeCORT, J.J. : Roentgenographic appearance of metastases to central lymph nodes of superior mesenteric artery in carcinoma of the right colon.

Radiology 60 : 641 - 646, 1953. 
McGOWAN, L. Owarian Cancer, in : Gynecologic oncology pp 283 - 33\| Ed : McGowan, L. AppletonCentury-Crofts., New York, 1978.

MEIRE, H.B., FARRANT, P. and GUHA, T. : Distinction of benign from malignant ovarian cysts by ultrasound.

Br. J. Obstet. Gynecol. 85:893-899, 1978.

MELAKA, F. and RAFLA, S. Variation of spread of owarian malignancy according to site of origin. Gynecol. Oncol. $3: 108-113,1975$.

MEYERS, M.A. : Distribution of the intra-abdominal malignant seeding : dependency on dynamics of flow of ascites fluid.

Am. J. Roent. Rad. Therapy 119: 198 - 206, 1973.

MEYERS, M.A. : Dynamic Radiology of the abdomen, Normal and Pathologic Anatomy, Springer Verlag, 1976.

MONCADA, R., COOPER, R.A., CARCES, M. BADRINATH, K. : Calcified metastases from malignant ovarian tumours.

Radiology, $113: 31 \cdot 35,1974$.

MORTON, D.G., MOORE, J.G. and CHANG, N. : The clinical value of peritoneal lavage for cytologic examination.

Am. J. Obstet. Gynecol. $81: 1115-1125,1961$.

MUSUMECI, R., DEPALO, G., KENDA, R., TESORO-TESS, J.D., DI RE FR,, PETRILLO, R., WILKE, Fr. : Retroperitoneal metastases from ovarian carcinoma : Reassessment of 365 patients studied with lymphography.

Am. J. Roentgenol. 134:449-452, 1980.

MUSUMECI, R. BANFI, A., BOLIS, G., CANDIANI, G.B., DE PALO, G., DI RE F. LUCIANI, L., LATTUADA, G.B; MANGIONI, C., MATTIOLI, G. and NATALE, N. : Lymphangiography in patients with ovarian epithelial cancer.

Cancer 40: $1444-1449,1977$.

NATHANSON, L. : Calcified metastatic deposits in the peritoneal cavity, liver and right lung field from papillary cystadenocarcinoma of the ovary.

Amer. J. Roentgenoll. $64: 467-469$, 1950.

NEIJT, J.P. , BARENTS, J.W., WENDRIK, C.P.J., VAN LINDERT, A.C.M., STRUYVENBERG, A., PINEDO, H.M. : Chemotherapie van het ovarium carcinoom stadium 111 en IV.

Ned. T. Geneesk. $124: 1601-1605,1980$.

NOONMAN, C.D. : Primary and secondary malignancy of the female reproductive system, Radiol. Clin. North Am. 375 - 387, 1965.

OVERHOLT, R.H. and DONCHESS, J.C. : Subfrenic abscess.

New England J. Med. $213: 294$ - 301, 1935.

PALING, M.R., SHAWKER, T.H. : Abdominal ultrasound in advanced ovarian carcinoma.

J. Clin. Uitrasound $9: 435-441,1981$.

PAPAVASILIOU, C.G. : Calcification in secondary tumors of the spleen, report of a case. Acta Radiol, $51: 278 \cdot 281,1959$.

PARKER, R.T., PARKER, C.H., WILBANKS, G.D. : Cancer of the ovary.

Am. J. Obstet. Gynecol. 108: 878, 1970.

PARKER, B.R., CASTELLINO. R.A., FUKS, Z.Y., BAGSHAW, M.A. The role of lymphography in patients with ovarian cancer.

Cancer $34: 100-105,1974$.

PHILIPS, B.P., BUCHSBAUM, H.J. LIFSHITZ, S. : Reexploration after treatment for ovarian cancer.

Gynecol. Oncol. 8: 339-345, 1979. 
PIVER, M.5., BARLOW, J.J., LELE, S.B. : Incidence of subclinical metastases in stage I and II Ovarian Carcinoma.

Obster and Gynecol. $52: 100-104,1978$.

PROTO, A.V., LANE, E.J. and MARANGOLA, J.P. A new concept of ascitic fluid distribution. Am. J. Roentgenol. $126: 974.980 .1976$.

REIMER, R.R.,HOOVER, R.,FRAUMENI, J.F. IT., YOUNG, R.C.: Acute leukemia after alkylating-agent the rapy of owarian cancer.

New England J. Med. 297, 177-181, 1977

REQUARD, C.K., METTLER, Fr.A., WICKS, J.D. : Preoperative sonography of malignant ovarian neoplasms.

Am. 1. Roentgenol. 137:79-82,1981.

ROSENOFF, S.H., DEVITA, V.T., HUBBARD, S., YOUNG, R.C. : Perittoneoscopy in the staging and follow-up of ovarian cancer.

Sem. Oncol $2: 223 \cdot 228,1975$.

ROYEN, P.M., ZITER, F.M.H. : Ovarium carcinoma metastatic to the breast.

Br. J. Radiol. $47: 356-357,1974$.

SOO, C.S., BERNARDINO, M.E. CHUANG, V.P. and ORDONEZ, N.: Pitfalls of CT findings in post-tlierapy testicular carcinoma.

1. Comput, Assist Tomogr. 5:39-41, 1981.

SPINELLI, P., LUINI, A., PIZZETT, P. et al, : Laparoscopy in staging and restaging of 95 patients with ovarian carcinoma.

Tumori $62: 493,1976$.

STEVENS, G.M. : The ovaries and adnexa. in : Allas of tumor radiology; the female reproductive tract pp 175-311. Ed : Hodes, P.J. Year book Medical Publishers Inc. Chicago, 1971 .

TADA, S., TSUKIOKA, M. ISHII, CH., TANAKA, H., MLUNUMA, K. : Computed tomographic features of uterine myoma.

J. Comput. Assist. Tomogr. $5: 866-869,1981$.

TEPLICK, J.G., TEPLICK, S.K., GOODMAN, L., HASKIN, M.E. : The interface sign : A COmputed tomographic sign for distinguishing pleural and intra-abdominal fluid.

Radiology 144:359-362, 1982

VAN WAES, P.F.G.M. ZONNEVELD, F.W. : Direct coronal body Computed Tomography.

1. Comput. Assist. Tomogr. 6:58-66, 1982.

WALLACE, S. JING, B.S.: Lymphography in tumours of the female genital system.

Radiol. Clin. North Am. 12:79-91, 1974.

WALSH, J.W. ROSENFIELD, A.T, JAFFE, C.C., SCHWARTZ, P.E., SIMEONE, J., DEMBNER, A.G., "TAYLOR, K J.W.: Prospective comparison of ultrasound and computed lomography in the evaluation of gynecologic pelvic masses.

Am. J. Roentgenol. 131:955-960, 1978.

WHITLEY, N. BRENNER, D. FRANCIS, A. KWON, T, VILLASANTA, U., AISNER,J, WTERNIK, P., WHITLEY, : Use of computed tomographic whole body scanner to stage and follow patients with advanced ovarian carcinoma.

Inwest Radiol. 16:479-486, 1981

WHITLEY, N.O., BOHLMAN, M.E., BAKER, L. P. : CT patterns of mesenteric disease.

J. Comput. Assist Tomogr, 6:490-496, 1982 . 


\section{Chapter VIII}

\section{Summary and conclusions}

Computed tomography (CT) has added a new dimension to the field of diagnostic imaging but its effective use depends on both radiologist and clinician understanding its limitations and potentials. Today, CT has a firm basis in the field of oncology in general and is already frequently used in diagnosing and staging gynaecological malignancies. This study has provided more information on this subject, from which certain useful conclusions about the practical application of $\mathrm{CT}$ in gynaecology can be drawn.

As a preliminary to any conclusion about CT in oncological pathology, some conclusions must be drawn from the anatomical study of chapter III. It is a fact that many CT features described in the literature in cases of gynaecological malignancies have been assumed to be abnormal without any adequate description of the corresponding $\mathrm{CT}$ features in healthy women. For this purpose a CT study of the female genital tract of 42 "gynaecologically normal" women was performed. The wide range of measured cervical and uterine size has a substantial overlap with the ranges suggested as pathological in literature and with measurements obtained in patients with cervical and endometrial cancer in this study, indicating that absolute measurements have little meaning. Surgical comparisons were not possible in the normal anatomy study, but the findings in chapter $V$ revealed a substantial discrepancy between the right-left diameter of the cervix as measured by CT and on surgical specimens, implying that the image regarded as cervix on CT may in fact contain a proportion of the surrounding structures (probably vaginal vault). Soft tissue strands from the cervix into the parametrium or irregular lateral cervical borders, regarded in literature as sign of tumour involvement, are in fact frequently seen in the normal subject.

An important observation from the study of contrast uptake by the normal uterus is, that the final enhancement is substantially higher in the uterine smooth muscle than in gluteal striated muscle, with a slow uptake and a subsequently long wash-out period, so that the myometrium is maximally enhanced 1 - 5 minutes after bolus contrast injection.

Both in normals and in patients with uterine malignancies, the uterus in plain (pre contrast) CT scans appears as a homogeneous featureless soft tissue mass, whereas after bolus contrast injection, very impressive abnormalities can be seen within the uterus in paticats with endometrial cancer and choriocarcinoma. In cervical cancer, the cervix in the pre contrast scan appears more or less homogeneoous whereas in the post contrast scan, an area of slightly lower density can be seen within the cervix presumably representing the tumour. 
In an attempt to test the reliability of $C T$ in detecting parametrial involvement in untreated patients with cervical cancer (chapter IV), the CT scan interpretations of two abservers were compared with the clinical findings in 48 patients and with surgery in 24 . Parametrial soft tiscue mass extension on CT shows a high degree of interobserver variability in its estimation and correlates poorly with both physical examination under anaesthesia and surgery, and is therefore an insufficiently reliable sign to influence treatment. With regard to lymph node involvement, the CT accuracy rate was only $75 \%$, possibly due to the presence of many small deposits in normal-sized nodes, but, whatever the reason, the accuracy rate is insufficient for diagnostic and therapeutic purposes. However, there was only one false-positive case and therefore enlarged nodes found with CT should be taken seriously enough to proceed to further investigations like percutaneous (CT guided) lymph node puncture.

In 3 of the cases of untreated cervical cancer the IVU was abnormal, resulting in a IIIb stage and in all threc cases CT demonstrated a soft tissue mass as cause of the ureter obstruction, but in only one of the 4 cases of presumed bladder wall invasion seen with cystoscopy, this was also visible on CT. The only case of sigmoid inwasion was not seen in CT. It can be concluded from this study that $\mathrm{CT}$ is unreliable in diagnosing parametrial invasion and cannot therefore assist in the therapeutically important differentiation between Ib and Ifb lesion. Although enlarged nodes can be seen with CT, metastastic nodes are frequently not enlarged and cannot therefore be identified with CT. CT was less accurate in diagnosing bladder wall and sigmoid invasion than cystoscopy and sigmoidoscopy respectively and cannot therefore replace these procedures. However CT was as accurate as I.V.U. in diagnosing ureteric obstruction, and could also demonstrate the cause of the obstruction. For these reasons, $C T$ is not indicated as a routine procedure in cervical cancer staging, particularly not in the early clinically stages. It may, nevertheless, be possible to make measurements of tumour bulk on CT, and this may have implications in the identification of high risk patients but abnormalities in CT must be confirmed either cytologically or histologically.

CT has a very important place in the diagnosis of recurrent cervical cancer but gives no information about the possibility of a solitary central recurrence, so cannot replace routine clinical follow-up procedures like physical examination, colposcopy and cytology. When a central recurrence is proven histologically, CT can be used to demonstrate the extent of disease and when $\mathrm{CT}^{3}$ is normal the patient is a candidate for curative surgery. However, when recurrence is suspected on clinical grounds, especially back pain, CT is the examination of first choice, but must include the whole pelvis and abdomen, because in 6 of the 14 cases with recurrent disease, all abnormalities would have been missed, had only the pelvis been scanned. CT is not indicated for routine follow-up, because it gives many false-positive findings, presumably caused by fibrosis, which in itself may produce progressive CT changes.

Although this study has revealed no specific CT signs for endometrial cancer (chapter V), the presence of a central hucency in the postmenopausal uterus with a diameter of at least $35 \%$ of the uterine diameter should be regarded as an indication of uterine pathology necessitating further gynaecological examination. The majority of such lucencies was only visible on post contrast scans. Small central lucencies were also visible in the normal control group but these were significantly smaller compared with those in the cancer patients. ( $p$. 0.001 . Student t test). There may be a relationship between these lucencies and the extent 
of disease, because 4 of the 5 cases without this lucency had stage la disease, 3 having little or no myometrial invasion. The fifth was operated 255 days after CT scanning. CT predicted 2 of the 3 cases of parametrial involvement but there was also one false-positive and one false-negative finding indicating that $\mathrm{CT}$ is no more accurate in this patient group than in cervical cancer.

Another conclusion which can be drawn from this study is that the presence of cystic ovarian lesions in postmenopausal patients with endometrial cancer should be taken seriously since there was a high incidence of concurrent ovarian malignancy.

This study was only done to describe CT features of endometrial cancer not to find arguments for the use of CT in staging the disease. As already mentioned, the diagnosis "endometrial cancer" is made by fractional curettage and histological examination, and as the majority of patients is in the early stage of disease and will be treated with surgery, there is no need for an accurate preoperative display of tumour extend in all these patients. CT scanning is therefore only indicated when the diagnosis is doubtful or when an additional mass is palpable which cannot be diagnosed with ultrasound.

However, CT scanning seems indicated in patients with symptoms suggestive of recurrent endometrial cancer and, as in recurrent cervical cancer, its diagnostic reliability is high.

In chapter VI the CT features of gestational trophoblastic disease (GTD) as seen in one patient with hydatiform mole and 4 with invasive molle or choriocarcinoma are described. Tumour invasion of the myometrium could be clearly demonstrated provided the CT scans were made after bolus contrast injection, and tumour spread outside the uterus could be seen in one patient. Comparison of bolus contrast CT scans before and after chemotherapy in four patients and with the surgical specimen in one suggests that, as in angiography, the CT diagnosis "viable trophoblastic tumour" can only be made by demonstrating contrast lakes. Hypodense areas in only post bolus contrast scans may be caused by necrotic tissue.

The ovarian cancer study (chapter VII) revealed no CT signs specific for ovarian malignancy. The only specific sign is that a smoothly bordered homogeneous cystic mass on CT is reliable evidence of the presence of a cyst. Complex and solid lesions, with or without calcifications may be benign or malignant and also the presence of ascites gives no definite indication of malignancy. Nevertheless, in a series of 88 consecutive patients with clinically suspected ovarian tumour, a normal CT scan excluded this diagnosis. Sixty-seven of these patients had a palpable pelvic mass and in 6 of them this mass could not be seen with CT and none of the 6 in fact had a pelvic mass lesion. However a visible pelvic mass in CT always indicated disease although frequently with no specific indication as to the diagnosis. A combination with ascites and especially satellite masses suggested malignancy although in 4 cases the disease was in fact benign.

The use of intravenous contrast medium is frequently essential, not only to identify bladder and ureters but also to make a more accurate or specific diagnosis possible, and the use of bowel contrast is mandatory to prevent false-positive diagnosis.

The correlation between $\mathrm{CT}$ and operative findings in 60 patients with proven ovarian cancer is not high enough to justify abandoning a purely diagnostic second look procedure, unless the CT is clearly abnormal, and there is no intention of carrying out further debulking. Although the diagnostic accuracy of $C T$ for ascites, liver metastases and pelvic mass lesions is acceptable, the high number of false-negatives makes it quite unacceptable for the detection of intraperitoneal spread. 
CT bad no important role in the primary evaluation and diagnosis of ovarian malignancies but looks very promising for treatment monitoring. The first CT scan should therefore be made 2 - 3 months after the (debulking) laparotomy to avoid false-positive interpretation due to the presence of unresolved haematomata but when the diagnosis is made by needle biopsy only, the scan can be made immediately. Subsequent sequential CT scanning should be carried out throughout the treatment period for as long as abnormalities remain visible and CT may make it possible to plan chemotherapy and the timing of second look operations on an individual base.

In general, computed tomography has no important role in the primary evaluation of gywacological malighancies but is very reliable in diagnosing recurren disease and is therefore the imaging examination of choice in patients with suspected or proven recurrences.

Furrhermore, CT is very promising in the evaluation of tumour response to therapy in patients with ovarian cancer but this requires further stady, using volume determination of Cr definable masses. 


\section{S A M E N V A T T I N G}

Computer tomografie (CT) speelt sinds de introductie ervan in 1972 een belangrijke rol in het onderzoek van de hersenen en wordt hiervoor sindsdien op grote schaal toegepast. De betekenis van CT voor het onderzoek van de rest van het lichaam was in het begin minder duidelijk, maar nu is zeker dat een der belangrijkste indicatiegebieden getegen is in de oncologie. Dit onderzoek beoogt meer informatie te verschaffen over de mogelijkheden van CT in de gynaecologische oncologie.

In een gedeeltelijk retrospectief, gedeeltelijk prospectief onderzoek worden do resultaten van 361 . CT scans bij in totaal 259 patienten die verdacht werden van of bekend waren met een maligne gynaecologische tumor vergeleken met de bevindingen bij operatie en/of klinisch onderzoek. Deze patienten waren afkomstig uit de regio zuid en midden-limburg en werden verwezen door de gynaecologen uit vijf verschillende ziekenhuizen mat de afdeling radiodiagnostiek van het de Wever Ziekenhuis in Heerlen of het St. Annadal Ziekenhuis in Maastricht woor het maken van een $\mathrm{CT}$ scan. Het klinisch onderzoek en de behandeling werd uitgevoerd door de verwijzend gynaecoloog.

Na de inleiding (hoofdstuk I) wordt in hoofdstuk II het basisprincipe van CT besproken. Vervolgens wordt kort ingegarn op de specificaties van de in deze studie gebruikte CT scanners (Philips Tomoscan 300), waarna de toegepaste scanprocedure en patientenvoorbereiding wordt beschreven.

In hoofdstuk III wordn de normale CT anatomie van het vrouwelijk kleine bekken beschreven. Deze beschrijving is gedeeltelijk gebaseerd op de literatuur. Door het ontbreken van informatie over de interpretatie van normale CT beelden van de genitalia interna zijn retrospectief de bekken CT scans van 42 patienten zonder afwijkingen ande genitalia interna beoordeeld. Uit deze studie blijkt dat de afmetingen van cervix en corpus uteri sterk varieren en dat de laterale begrenzing van de cervix meestal niet scherp is, doch rafelig met uitlopers in het parametrium. Dergelijke uitlopers zijn in de literatuur wel beschreven als teken van tumorinfiltratie. Bij 10 van deze patientem was het bovendien mogelijk de contrastopname in uterus, gluteusmusculatuur en bekkenvaten ma bolus contrast injectie te meten en in de tijd te vervolgen. Hieruit blijkt dat de uterus veel meer contrast opneemt dat de gluteus spier, en dat dit contrast slechts langzaam weer wordt afgegeven. De tijd van maximale contrastwersterking van de uterus ligt tussen de $1-5$ minuten na bolusinjectic.

Hoofdstuk IV begint met een literatuurstudie over de betekenis van conventionele röntgentechnieken en CT in het disseminatie onderzoek van onbehandelde patienten met een cervix carcinoom. Vervolgens worden in een gedeeltelijk retrospectief gedeeltelijk prospectief onderzock 56 patienten met een infiltratief cervix carcinoom met behulp van CT gestageerd. De CT scans zijn door twee radiologen onafhankelijk van elkatar beoordecld, gebruikmakend van in de literatuur beschreven kriteria voor pathologie, die op grond van de bevindingen uit hoofdstuk III iets gemodificeerd zijn. De CT stadia worden vergeleken met de klinische (F.I.G.O.) stadia (48 patienten) en met bevindingen bij operatic (24 patienten). De CT interpretatie van beide waarnemers betreffende parametrium infiltratie blijkt vaak te verschillen, hetgeen samen met de slechte correlatie met zowel de klinische 
als de chirurgische bevindingen antoont dat parametrium infiltratie computertomografisch niet betrouwbaar te diagnostiseren is. Ook de nauwkeurigheid van CT bij het opsporen wan lymfkliermetastasen is laag $(75 \%)$, hoewel in deze serie met slechts een vals-positieve bevinding. Bij 3 patienten toont het I. V.U. een distale ureterobstructie en bij alle 3 is de obstructic en de tumormassa als oorzaak van de obstructie computertomografisch zichtbaar. Bij slechts cen wan de 4 patienten met blaaswand infiltratie is dit computertomografisch zichtbaar, terwij $\|$ bovendien bij een van deze patienten sigmoid ingroei gemist is. De conclusie die uit deze studie kan worden getrokken is dat CT onbetrouwbaar is in het aantonen wan parametrium infiltratie bij het cervixcarcinoom. Het therapeutisch belangrijke onderscheid tussen stadium IB en IIB kan computertomografisch niet gemaakt worden. CT is even nawwkeurig alls het I.V.U. in de diagnostiek van ureterobstructic, maar minder nauwkeurig dan cystoscopie en sigmoidoscopie bij het aantonen van resp. blaaswand en sigmoidinfiltratie. Bovendien worden lymfklieren met metastasen vaak niet als zodanig herkend, aangezien ze niet vergroot zijn. Om deze redenen is CT niet geindiceerd in het routine disseminatic onderzoek van patienten met een cervix carcinoom, met name niet bij de klinische stadia I en II A. Misschien dat CT wel een rol kan spelen in de initiële screening van patienten met een cervix carcinoom stadium II B-IV en wel om de grootte en uitgebreidheid wan de tumor in beeld te brengen en zo high risk patienten te identificeren. Computertomografische afwijkingen moeten dan wel cytologisch of histologisch bevestigd worden.

Vervolgens worden de resultaten van CT beschreven bij 48 patienten ( $65 \mathrm{CT}$ scans), die behandeld waren voor een infiltratief cervixcarcinoom en al of niet verdacht werden van een recidief. Met maximaal twee vals negatieve bevindingen waarvan er achteraf een op een interpretatiefout blijkt te berusten, zijn alle recidieven (14) die niet beperkt blijven tot uterus of vagina duidelijk zichtbaar. Het groot aantal vals-positieve bevindingen, waarschijnlijk veroorzaakt door bestralingsfibrose, bevestigt nogmaals clat computertomografische afwijkingen histologisch of cytologisch bevestigd moeten worden. Bij 6 van de 14 patienten met een recidief zouden alle afwijkingen gemist zijn indien alleen het bekken gescand was. CT lijkt daarom vooral geïndiceerd bij patienten die op klinische gronden verdacht worden van een recidief maar dan moeten zowel bekken als bowenbuik gescand worden. Indien bij een histologisch bewezen centraal recidief (alleen in uterus of vagina) de CT scan normal is, dient curatieve chirurgie overwogen te worden. Hell groot atantal vals-positiove bevindingen beperkt echter de waarde van $\mathrm{CT}$ in het routine follow-up programma.

Hoofdstuk $\mathbf{V}$ geeft een korte inleiding over de betekenis van conventionele röntgentechnieken en $\mathrm{CT}$ in het disseminatie onderzoek van het endometriumcarcinoom. Vervolgens worden de CT beclden beschreven bij 22 patienten met een endometriumcarcinoom en vergeleken met de chirurgische en pathohistologische bevindingen in 21 patienten. Een opheldering in het corpus uteri, vaak alleen zichtbaar na intraveneuze contrast injectic blijkt een belangrijke indicator voor pathologie, maar is niet specifick voor het endometriumcarcinoom. Dergelijke ophelderingen worden ook gezien in de retrospectieve studie uit hoofdstuk III (normale anatomie), maar zijn dan wel veel kleiner. Hicruit wordt geconcludeerd dat een opheldering in het corpus uteri met een diameter van meer dan $35 \%$ van de totale uterus diameter een indicatie is voor pathologie en verder gynaecologisch onderzoek vereist. Mogelijk is er een relatie tussen de 
aanwezigheid van deze opheldering en de grootte van de wmor, aangezien 4 van de 5 patienten zonder deze opheldering slechts een kleine tumor hadden (stadium IA) en 3 patienten minimaal of geen myometrium infiltratie. Parametrium infiltratie lijkt bij deze patientengroep met CT niet nauwkeuriger aantoonbaar dan bij patienten met een cervix carcinoom. Vergrote of cysteus veranderde ovaria zijn een belangrijke bevinding aangezien dit in deze serie frequent gepaard gaat met maligniteit in deze ovaria.

Deze studie is uitgevoerd om de CT beelden van het endometriumcarcinoom te beschrijven en niet om argumenten te vinden om CT te gebruiken bij het stageren. De diagnose endometriumcarcinoom wordt meestal vroegtijdig gesteld d.m.v. gefractioneerde curettage en histologisch onderzoek en er is geen behoefte aan een pre-operatieve afbeelding van de tumor bij alle patienten. CT is daarom alleen geïndiceerd indien er twijfel bestaat aan de diagnose of indien bij klinisch onderzoek abnormale weerstanden in het kleine bekken worden vastgesteld.

$\mathrm{CT}$ is bovendien geïndiceerd bij patienten die verdacht worden van een recidief endometriumcarcinoom, aangezien dit recidief bij 8 van de 14 patienten kon worden aangetoond zonder vals-negatieve en met slechts twee vals-positieve bevindingen, waarvan er een veroorzaakt werd door een slechte patientenvoorbereiding.

In hoofdstuk VI worden de CT beelden beschreven bij een patiente met een mola hydatidosa en 4 patienten met een chorionepithelioom. Tumorinfiltratic in het myometrium was computertomografisch goed zichtbaar, maar alleen in CT scans die gemaakt waren na bolus contrast injectie. Ook tumorgroei buiten de uterus kon bij een patiente worden aangetoond. Een vergelijking tussen de scans woor en na chemotherapie suggereert dat, evenals bij arteriografie, de CT diagnose maligne trophoblast woekering alleen te stellen is door het aantonen van kleine contrastmeertjes (vascular-lakes) in de tumor.

Hoofdstuk VII geeft een beknopt literatuuroverzicht over de betekenis van de verschillende beeldvormende technieken bij het diagnostiseren en stageren van het ovariumcarcinoom. Vervolgens worden de resultaten van $C T$ beschreven bij 88 patienten die om verschillende redenen verdacht werden van een ovariumcarcinoom. Nagegaan is of bepaalde beelden specifiek zijn woor een benigne of maligne ovariee $\|$ proces. Dit blijkt niet het geval, hoewel een volledig glad begrensde homogene cysteuze tumor altijd een benigne cyste was.

Complexe en solide tumoren met of zonder calcificaties en zelfs met ascites, kunnen zowel op benigne als op maligne processen berusten. Indien cr ook nog tumoren elders in de buik worden gevonden is er meestal sprake van malignitcit, hoewel in deze serie ook dan nog bij 4 patienten het proces goedaardig was. Zeven en zestig patienten hadden een palpabele bekkentumor, doch deze tumor was bij 6 van hen computertomografisch niet zichtbaar en deze patienten bleken uiteindelijk ook geen tumor te hebben. Een normale CT scan sloot in deze serie de diagnose ovariumtumor uit.

Het toedienen van intraveneus contrast blijkt vak van belang om blatas en ureteren te markeren of om een meer specificke diagnose mogelijk te maken, terwijl oraal contrast noodzakelijk is om vals-positieve bevindingen te woorkomen.

Vervolgens zijn de chirurgische bevindingen bij 60 paticnten met een ovariumcarcinoom (30 primaire stageringslaparotomieën, 2 primaire stageringslaparoscopieën, 21

herstageringslaparotomieën en 7 herstageringslaparoscopieën) vergeleken met de resultaten 
van CT van bekken en bovenbuik. Uit deze studie blijkt dat de nauwkeurigheid van CT in het aantonen van ascites, levermetastasen en bekkentumoren hoog is, maar dat metastasen in het omentum, aan de diafragmakoepels en op het leverkapsel en het peritoneum valk nict zichtbaar zijn (veel vals-negatieve, maar weinig vals-positieve bevindingen). Hieruit word geconcludecrd dat CT van belang kan zijn voor het aantonen of uitsluiten van tumoren in het bekken, mat dat een meer specifieke diagnose met computertomografie vaak onmogelijk is. Bovendien speelt CT geen rol van betekenis bij de initiële stagering van het ovariumcarcinoom gezien de lage nauwkeurigheid van deze technick in het aantonen van intraperitoneale tumorverspreiding.

Bij 19 patienten met cen ovariumcarcinoom, van wie tijen de behandelling met chemotherapic meerdere CT scans gemaakt zijn, wordt gepoogd de response van de tumor op de ingestelde therapie te meten. Dit lijkt mogelijk en het tijdstip van herstageringslaparotomie ( $\mathrm{zg}$. second look operatie) zou mede met behulp van CT bepaald kunnen worden. Uit een vergelijking tussen de resultaten van de initiële stagerings- en debulkingsoperaties en kort na deze ingreep gemakkte CT scans (19 patienten) blijkt dat de eerste uitgangs CT scan niet onmiddelijk postoperatief, maar pas na 2-3 maanden gemaakt moet worden omdat een scan kort na een dergelijk grote ingreep vaak interpretaticproblemen oplevert, aangezien een haematoom niet met zekerheid van restant tumor is te onderscheiden. Vervolgens moet tijdens de behandelingperiode met cytostatica de CT scan om de 2-3 makanden herhaald worden. Bij een normale scan kan een herstageringslaparotomie overwogen worden, maar het is niet juist om vanwege een normale CT scan deze operatie achterwege te laten. Indien computertomografische afwijkingen zichtbaar blijven en eventuele debulking niet meer zinvol wordt geacht kan van deze ingreep worden afgezien. Wel moet getracht worden met behulp van cytologisch onderzoek eventuele CT afwijkingen te bevestigen. Het percutaan puncteren van verdachte gebieden kan op geleide van CT scan gebeuren.

Het is bovendien goed mogelijk met $\mathrm{CT}$ recidieven wan een ovariumcarcinoom aan te tonen of uit te sluiten, aangezien alle reciclieven (8) uit cen groep van 13 patienten die werdacht werden van een recidief computertomografisch herkend werden.

Geconchudeerd wordt dan CT geen belangrijke rol speett bij de primaire evaluatie en diagnostiek van maligne gynaecologische anmoren, doch dat deze techniek een wardevolle aanwinst is bij de diagnosviek van recidieven. Bovendien lijk CT een veelbelovend middel om bij parienten met een ovariumcarcinoom de response van de umor op de ingestelde therapie te meten en op deze manier de therapie te individualiseren. Verder onderzoek hierover is echter noodzakelijk. 
APPENDIX I

BEVINDINGEN GYNAECOLOGISCH ONDERZOEK BUJ PATTENTEN MET EEN INFILTRATIEF CERVIX CARCINOOM.

Naam

geb. datum

jaar en mnd diagnose

Gynaecoloog Dr.

Toucher d.d

Uterus normaal $\square$

vergroot

\section{Parametrium}

vrij

minder dan $1 / 2$ geinfilltreerd

meer dan $1 / 2$ geïnfiltreerd

(niet tot bekkenwand)

tot bekkenwand

\section{Lig. Sacro-uterinum}

normaal

minder dan voor de helff

geinfiltreerd

meer dan voor de helft

geinfiltreerd

\section{Adnexa}

niet palpabel

wel palpabel

nomat

vergroot

Dïgnose

Histologie

lindien meerdere gynaecologen toucherom. meerdore formulieren invulten.

\section{in narcose ja $\square$ neen $\square$}

anteflexie $\square$ mobiel ja $\square$ neen $\square$

strekstand

retroflexie $\square$

omschrijving

sondelengte

re. li.

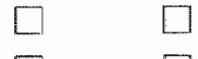

$\square$

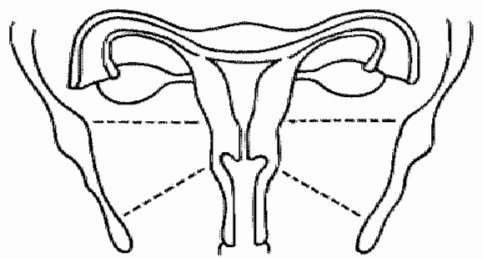

$\square \quad \square$

$$
\text { (1) }
$$
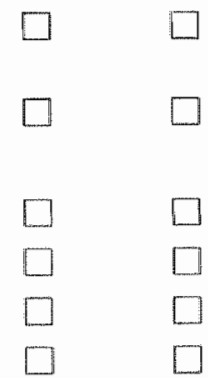

(

Speciale technieken

nivet
witgevord

\section{norm} mial

af wili- omsthrijuing

hend

\section{$X$-thorax}

$x \rightarrow c 0 l o n$

rectoscopis

1. $\mathrm{p}$.

cystoscopie

leverscintigralle

echografie

renografie

$\begin{array}{ll}\square & \square \\ \square & \square \\ \square & \square \\ \square & \square \\ \square & \square \\ \square & \square \\ \square & \square\end{array}$

Klinisch stadium

Therapia 


\section{APPENDIX II}

\section{OPERATIEVE BEVINDINGEN BIJ PATIËNTEN MET CER VIX CA I EN IIA}

haxm patient
geth. dat.
jaar en mond diagnose

Ciynaecoloog Dr.

OPERATIE d.d.

\section{Bevindingen:}

Jewer

klierstations

para-aortaal (alleen palp)

presacrabl

ilinca comm. re.

iliaca comm. li.

iliaca ext. re. (cran. x. Poupart)

iliaca ext. li. (cran. v. Poupart)

iliaca ext. re. (caud. v. Poupart)

iliaca ext. li. (caud v. Poupart)

hypogastrica re.

hypogastica li.

uterus

ra alnex

li. adnex

parametrium re.

parametrium li.

Overige bevindingen type operatie

\begin{tabular}{|c|c|}
\hline $\begin{array}{l}\text { niet } \\
\text { onderzocht }\end{array}$ & $\begin{array}{l}\text { nor } \\
\text { mad }\end{array}$ \\
\hline
\end{tabular}

$\begin{array}{ll}\square & \square \\ \square & \square \\ \square & \square \\ \square & \square \\ \square & \square \\ \square & \square \\ \square & \square \\ \square & \square \\ \square & \square \\ \square & \square \\ \square & \square \\ \square & \square \\ \square & \square \\ \square & \square \\ \square & \square \\ \square & \square \\ \square & \square\end{array}$

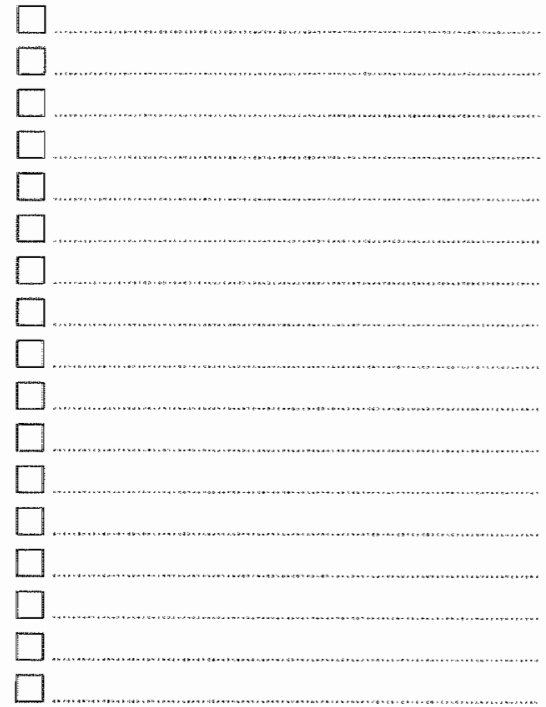

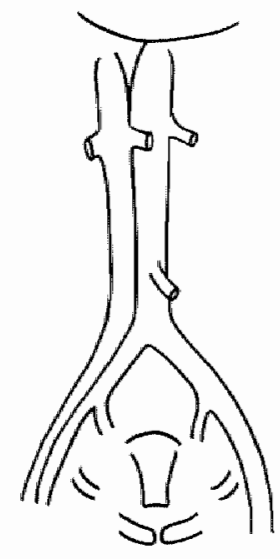




\section{APPENDIX III}

VERSLAG BEVINDINGEN DEBULKING OPERATIE OVARIUMCARCINOOM

Naam patient

geb. datum

jaar en mnd diagnose

gynaecoloog Dr.

A. Bowenbuik

diafragnakoepel re.

diafragmakoepelli.

lever

milt

mieren

omentum supra col.

omentum infra col.

B. Middenbuik

maag

jejunum

ileum

coecum

colon-assendens

colon-descendens

colon-transversum

C. Kleine bekken:

Uterus

re. adnex

li. adnex

peritoneum

cavum Douglasi

blaas

ureteren

sigmoid/rectum

D. KHieren:

para-aortaal

kleine bekken re.

kleine bekken li.

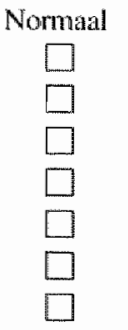

Omschrijving en grootte en aantal van de gevonden afwijkingen
Diagnose

Histologie

Chemotherapie gehad ja $\square$ neen welke

aantal kuren

klinische remissie ja $\square$ neen

\begin{tabular}{|c|c|c|}
\hline Optinale debulking nogelijk geneest dw $t$. residual disease $<2 \mathrm{~cm}$ & D & $\operatorname{Aac} a^{2} n$ \\
\hline Na debulking residual disease $>2 \mathrm{~cm}$ & & neatu \\
\hline Debuking onmogeljilk geweest & & neresty \\
\hline
\end{tabular}

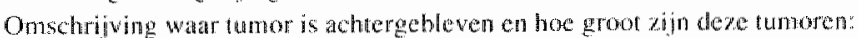




\section{APPENDIX IV}

The decision matrix (table 1 ) has been frequently used to evaluate diagnostic procedures. It relates the results of aliagnostic test with a binary outcome (normal, abnormal) to clinical or pathologicall findings, also with a binary outcome (disease, no disease).

Table 1.

A general decision matrix (McNeil and Adelstein, 1976).

\begin{tabular}{|c|c|c|c|}
\hline Test Results & $\begin{array}{c}\text { Disease } \\
\text { present } \\
(D+)\end{array}$ & $\begin{array}{c}\text { Disease } \\
\text { absent } \\
(\mathrm{D}-)\end{array}$ & Total \\
\hline Abnormal $(T+)$ & a & $\mathrm{c}$ & $a+c$ \\
\hline Normal $(\mathrm{T}-)$ & $b$ & d & $b+d$ \\
\hline Total & $a+b$ & $c+d$ & $a+b+c+d$ \\
\hline Sensitivity (TPR) & $=\frac{a}{a+b}$ & & \\
\hline Specificity (TNR) & $=\frac{d}{c+d}$ & & \\
\hline Accuracy & $=\frac{a+d}{a+b+c+d}$ & & \\
\hline
\end{tabular}

Four ratios, which can be derived from this table, are used in this thesis:

$\mathrm{TPR}=$ true-positive ratio ( $=$ sensitivity), is the proportion of positive tests in all patients with discasc, $a / a+b$.

$F P R=$ false-positive ratio is the proportion of positive tests in all patients without disease, $c / c+d$

TNR = true-negative ratio ( = specificity $)$, is the proportion of negative tests in all patients without disease, $d / c+d$.

FNR $=$ false-negative ratio is the proportion of negative tests in all patients with disease, $b / a+b$.

References:

McNeil, B.J. and Adelstein, S.J.

Determining the value of diagnostic and screening tests.

J. Nud. Med. : 17: 439-448 1976. 
I am greatly indebted to all the colleagues, technicians and secretaries who have been involved in realizing this thesis. In particular I am very gratefull to:

Prof.Dr. J. de Haan and Prof.Dr. J.H.J. Ruys for their constant support and stimulation which I needed to complete this study.

Prof.Dr. J. Drukker for his many critical advices especially concerning the chapter on anatomy.

Prof.Dr. J. Janssens for his critical reading and his thoughtful comments on the manuscript.

Drs. C.W.M. Versteege for the close cooperation during this study, not only in doing many CT examinations, using the standard protocol, but also for reviewing many of the CT" images.

All the gynaecologists and oncologists of the St. Barbara hospital in Gelleen, De Wever hospital in Heerlen, St. Annadal hospital in Mastricht, St. Laurentius hospital in Roernnond and the hospital "De Goddelijke Voorzienigheid" in Sittard, without their help this study would have been impossible.

Drs. D. Willebrand for reviewing the patho-histology of all pattients with ovarian cancer.

Dr. H. Sanches and Drs. Fr. Meijer for reviewing many CT-images.

Drs. H.A. Eerdmans of Philips Medical Systems for the advices and corrections concerning the technical and physical aspects of this study.

Dr. H. Hoogland for the cooperation during this study, especially concerning chapter VI.

Dr. A. Betts-Brown for studying the manuscript, offering much valuable criticism and his help in writing "Oxford-English".

Mrs. M. Dresen-Kriellaers for her assistance in translating the manuscript.

Mrs. A. Jenke-Krementa, Mrs. W. Prevoo-Gubbels and Mrs. M.C. Savelbergh for maniging the scanners and organizing the CT-departments in such a way that this study became possible.

Mrs. C. Gorissen, Mrs. M. Finders-Velraad and Mrs. Y. Bessems for their endless patience in typing the manuscript and many letters.

The members of the medical photography department of the St. Annadal hospital (Head:

C. Evers) for making many photographs over and over again.

Mr. A. Volovics of the DIV of the University of Limburg for the statistical advices.

Mr. C. Voskamp for his illustrations and help in the lay-out.

All the raiologists and registrars of the X-ray department of the St. Annadal hospital for their support and for doing part of my work when $I$ was writing this thesis. 



\section{Curriculum vitae}

J.M.A. van Engelshoven werd in 1945 in Maastricht geboren. In 1963, wa het cindexamen HBS-b (Hendric van Veldeke College, Maastricht) begon hij zijn studie in de geneeskunde aan de Katholieke Universiteit te Nijmegen. In 1969 haalde hij het doctoraal examen en in 1970 werd het arts-examen afgelegd. De militaire dienst werd vervuld in de afdeling voor Inwendige geneeskunde van het Militair Hospitaal "Dr. A. Mathijsen" (Hoofd: Dr. C.J. van Belle). Vervolgens werkte hij een jaar in de afdeling Inwendige Geneeskunde van het St. Elisabeth Ziekenhuis in Tilburg (Hoofd: Dr. V.A.M. Terwindt) en begon in 1974 zijn opleiding tot radiodiagnost in het Ziekenhuis St. Annadal te Maastricht (Opleider: Dr. G.J. van der Plaats). Na zijn inschrijving in het specialistenregister per 1 januari 1978. werkte hij nog drie maanden in de afdeling Radiodiagnostiek van het Northwich Park Hospital in Londen (Hoofd: Dr. L. Kreel) en een maand in de afdeling Radiognostiek van het St. Georg Krankenhaus in Hamburg (Hoofd: Dr. O. Pohlenz). Sindsdien is hij verbonden als radiodiagnost aan de Radiodiagnostick van het Ziekenhuis St. Annadal. 